Florida International University FIU Digital Commons

FIU Electronic Theses and Dissertations

University Graduate School

6-13-2017

\title{
Phenomenological and Molecular Basis of the Cnidarian Immune System
}

Tanya Brown

Florida International University, tbrow102@fiu.edu

DOI: $10.25148 /$ etd.FIDC001928

Follow this and additional works at: https://digitalcommons.fiu.edu/etd

Part of the Bacteriology Commons, Environmental Microbiology and Microbial Ecology Commons, Genetics Commons, Genomics Commons, Immunity Commons, Immunology of

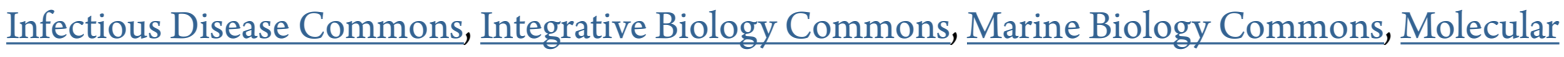
Genetics Commons, Pathogenic Microbiology Commons, and the Terrestrial and Aquatic Ecology Commons

\section{Recommended Citation}

Brown, Tanya, "Phenomenological and Molecular Basis of the Cnidarian Immune System" (2017). FIU Electronic Theses and Dissertations. 3468.

https://digitalcommons.fiu.edu/etd/3468

This work is brought to you for free and open access by the University Graduate School at FIU Digital Commons. It has been accepted for inclusion in FIU Electronic Theses and Dissertations by an authorized administrator of FIU Digital Commons. For more information, please contact dcc@fiu.edu. 


\section{FLORIDA INTERNATIONAL UNIVERSITY}

Miami, Florida

PHENOMENOLOGICAL AND MOLECULAR BASIS OF THE CNIDARIAN

IMMUNE SYSTEM

A dissertation submitted in partial fulfillment of the

requirements for the degree of

DOCTOR OF PHILOSOPHY

in

BIOLOGY

by

Tanya Brown

2017 
To: Dean Michael R. Heithaus

College of Arts, Sciences and Education

This dissertation, written by Tanya Brown, and entitled Phenomenological and Molecular Basis of the Cnidarian Immune System, having been approved in respect to style and intellectual content, is referred to you for judgment.

We have read this dissertation and recommend that it be approved.

Laurie Richardson

John Makemson

$\begin{array}{r}\text { Lidia Kos } \\ \hline \text { Kalai Mathee } \\ \hline \text { Mauricio Rodriguez-Lanetty, Major Professor }\end{array}$

Date of Defense: June 13, 2017

The dissertation of Tanya Brown is approved.

Dean Michael R. Heithaus

College of Arts, Sciences and Education

Andrés G. Gil

Vice President for Research and Economic Development and Dean of the University Graduate School

Florida International University, 2017 


\section{COPYRIGHT}

Chapters 2 and a portion of chapter 3 have been published in Plos One and Scientific

Reports respectively. Both journals allowed for the release of publications to authors of the paper for educational use at the home institution, Florida International University.

\section{Chapter 2:}

Brown, T., D. Bourne, and M. Rodriguez-Lanetty. 2013. Transcriptional Activation of c3 and hsp70 as Part of the Immune Response of Acropora millepora to Bacterial Challenges. Plos One 8.

\section{Chapter 3:}

Brown, T. and M. Rodriguez-Lanetty. 2015. Defending against pathogens immunological priming and its molecular basis in a sea anemone, cnidarian. Scientific Reports 5. 


\section{ACKNOWLEDGMENTS}

I would like to thank the current and former members of the Rodriguez-Lanetty Lab for their encouragement and support during my time here. The sense of community and support made this work possible and enjoyable. I would also like to thank my advisor, Dr. Mauricio Rodriguez-Lanetty for taking a chance on me and for his guidance and support. Thank you for believing in me when I didn't. Through his support I was able to learn and grow a lot! My committee members: Dr. Laurie Richardson, Dr. John Makemson, Dr. Kalai Mathee, and Dr. Lidia Kos have been instrumental in the completion of this dissertation. Their helpful comments have greatly improved this work. I would like to also thank my former committee member, Dr. Don Ennis for his help and support during the majority of my $\mathrm{PhD}$ work. I would like to thank Florida International University for a teaching assistantship and the dissertation year fellowship as support for my $\mathrm{PhD}$. Furthermore, I would like to thank my master's thesis advisor, Dr. Dan Brazeau for taking a chance on me and introducing me to the exciting world of coral molecular biology and to inspire me to further graduate studies. Drs. Howard Lasker, Mary Alice Coffroth, Richard Alexander, and Kathy Browne have all been instrumental in fostering my love for marine biology. Finally, I would like to gratefully acknowledge PLoS ONE for allowing me to reprint a publication which originally appeared in volume 8 , issue 7 as Chapter 2 of this dissertation as well as Nature Publishing Group for allowing the reprint of a publication which originally appeared in Scientific Reports in Volume 5 in the December issue as part of Chapter 3 of this dissertation. 


\section{DEDICATION}

I dedicate this dissertation to my dad, Albirt, E. Brown, who encouraged me to pursue this degree but was never able to see me finish, and to my mother and sister, for their unconditional love, support, and understanding during this process. 


\section{ABSTRACT OF THE DISSERTATION \\ PHENOMENOLOGICAL AND MOLECULAR BASIS OF THE CNIDARIAN IMMUNE SYSTEM}

by

Tanya Brown

Florida International University, 2017

Miami, Florida

Professor Mauricio Rodriguez-Lanetty Major Professor

Coral reefs are one of the most diverse ecosystems on the planet due partially to the habitat structure provided by corals. Corals are long lived organisms that can live for hundreds of years and as a result growth of many species is very slow. As a result of this, recovery of corals from disease outbreaks is very slow and difficult and therefore the ecosystem is deteriorating rapidly. Due to this increase in disease and its detrimental effect on coral reefs, it has become imperative to study how corals respond to disease outbreaks. The response of the coral to pathogens is believed to be controlled by the innate immune system. However, the immune pathways and components of these pathways used by cnidarians to combat pathogens are still rudimentary. This work showed that $\mathrm{C} 3$ and heat shock protein 70 are components of the coral immune system that positively respond to disease occurrence. As disease out breaks become more frequent, the question has arisen as to whether cnidarians have homologs to of the adaptive immune system that allow them to respond more rapidly to subsequent 
encounters with the same bacterium. In the cnidarian model system Exaiptasia pallida, immune priming occurs up to one month after the initial sub lethal exposure to the pathogen. This transient form of priming could be the result of host energy allocation in place of establishing long term immune priming which could be too energetically costly. Cnidarians may only activate priming during summer months, when ocean temperatures and bacterial load are high. Specificity of immune priming in E. pallida requires further investigation with more bacterial pathogens. In this dissertation, one bacterial strain shows specificity while the other does not. Furthermore, the priming response involves many pathways which include pathogen recognition, inflammation, and activation of NF$\kappa \mathrm{B}$. The discovery of immune priming in a sea anemone shows that this phenomenon evolved earlier in the tree of life than previously thought. Additionally, identification of priming in E. pallida is suggestive of its presence in corals which would allow for potential vaccinations of vulnerable corals. 


\section{TABLE OF CONTENTS}

CHAPTER $\quad$ PAGE

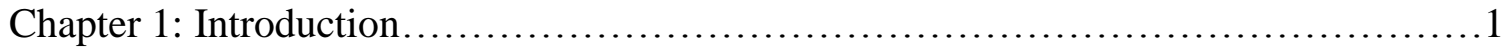

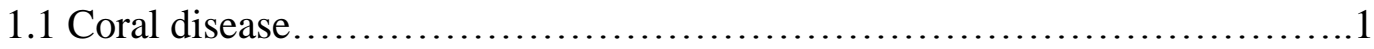

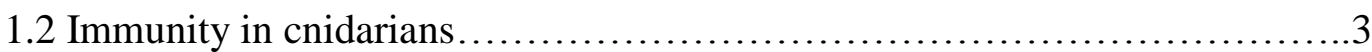

1.2.1 Transmembrane PRRs..................................... 5

1.2.2 Humoral response.........................................

1.2.3 Cell mediated immunity....................................9

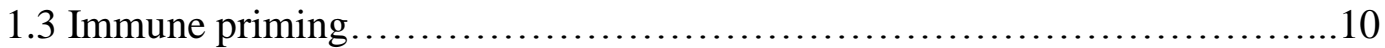

1.4 Dissertation objectives, hypothesis, and organization......................11

1.5 References........................................................... 13

Chapter 2: Transcriptional activation of $c 3$ and $h s p 70$ as part of the immune response

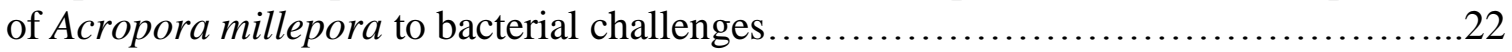

2.1 Abstract.........................................................22

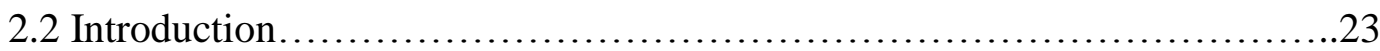

2.3 Materials and Methods................................................. 26

2.3.1 Coral collection and acclimation..............................26

2.3.2 Bacterial strains and culture preparations.....................27

2.3.3 Experimental design of bacterial challenge experiments...........27

2.3.4 PSII quantum yields $\left(\mathrm{F}_{\mathrm{v}} / \mathrm{F}_{\mathrm{m}}\right)$ of coral samples..................29

2.3.5 RNA isolation, cDNA preparation, and gene expression assays by quantitative PCR ..............................................29

2.3.6 RNA profiling of coral associated bacterial communities using denaturing gradient gel electrophoresis............................ 30

2.3.7 Statistical analysis ........................................... 31

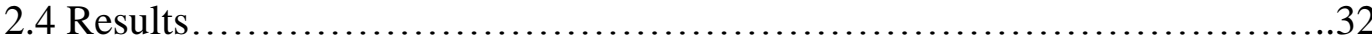

2.4.1 Response of Acropora millepora corals to bacterial challenge......32

2.4.2 Coral associated bacterial shifts during challenge experiments......34

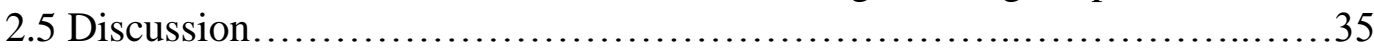

2.6 Conclusions......................................................... 40

2.7 References........................................................ 48

Chapter 3: Defending against pathogens - immunological priming and its molecular basis in a sea anemone, a basal metazoan cnidarian..............................55

3.1 Abstract......................................................... 55

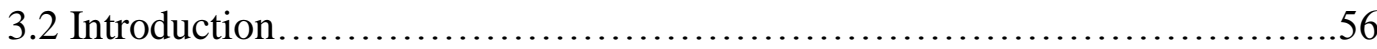

3.3 Materials and Methods..............................................59

3.3.1 Exaiptasia pallida anemone husbandry.......................59

3.3.2 Pathogenic bacteria species and culture preparation...............60

3.3.3 Determination of bacterial concentrations for infection trials......60

3.3.4 Temperature dependent pathogen virulence.....................61

3.3.5 Determination of sub - lethal pathogen exposure..................62

3.3.6 Priming experiments on Exaiptasia pallida anemones.............62

3.3.7 Specificity of immune priming in Exaiptasia pallida anemones.....63 
3.3.8 Quantitative PCR assay for determining Vibrio coralliilyticus load on the anemones................................................64

3.3.9 Statistical analysis of survivorship data and pathogen load on inoculated anemones....................................................66

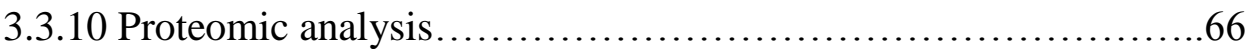

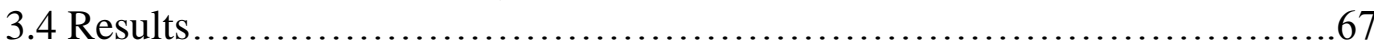

3.4.1 Host response to bacterial pathogen improves upon related pathogen encounter..............................................67

3.4.2 Priming trial with $V$. coralliilyticus ...........................68

3.4.3 Priming trials with $S$. marcescens.............................70

3.4.4 Priming specificity ............................................ 70

3.4.5 Proteomic analysis to dissect the molecular changes associated with the immune $V$. coralliilyticus associated priming response............72

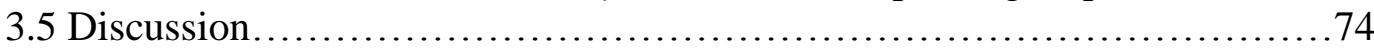

3.5.1 Proteomic analysis of immune priming in E. pallida ................78

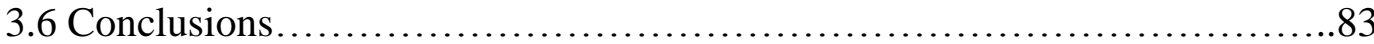

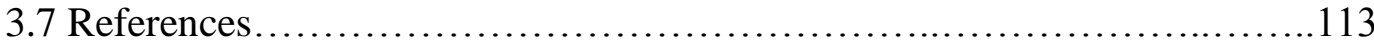

Chapter 4: Transcriptomics of immune priming in the sea anemone Exaiptasia

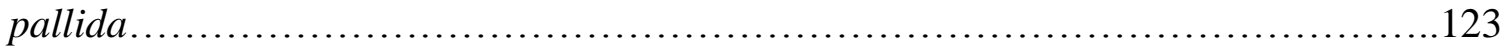

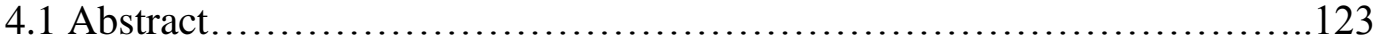

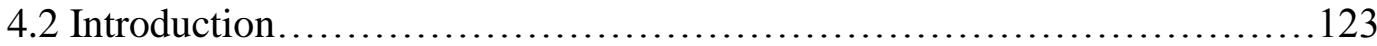

4.3 Materials and Methods............................................... 127

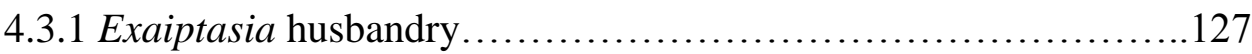

4.3.2 Experimental design and sample collection.....................127

4.3.3 Pathogen culture method.......................................128

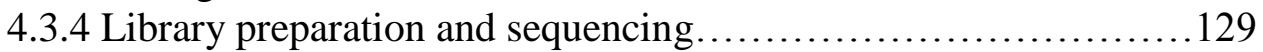

4.4 Results and Discussion..................................................130

4.4.1 Overall trends in gene expression in primed host..................130

4.4.2 Overrepresented gene ontology terms amongst differentially expressed genes.................................................. 131

4.4.3 Enrichment of phosphoric diester hydrolase activity ...............131

4.4.4 Enrichment of GTPase and Rho guanyl-nucleotide exchange

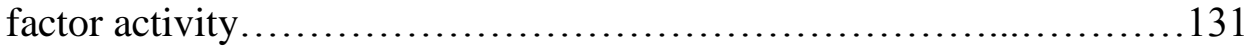

4.4.5 Molecular mechanisms of immune priming .......................132

4.4.5.1 Signaling ............................................

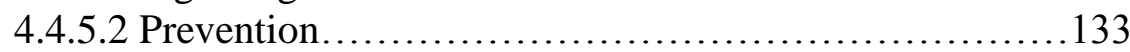

4.4.5.3 Protection...............................................134

4.4.6 A potential role of epigenetics in priming.......................136

4.4.7 Differentially expressed transcript with ortholog involved in adaptive immunity .................................................. 137

4.4.8 Incongruence and congruence with proteomic evidence of immune priming.................................................. 138

4.4.9 Transcriptome of infection in naïve host to first encounter of

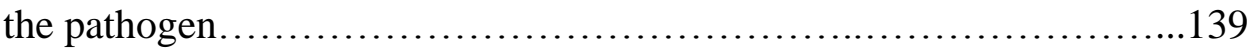

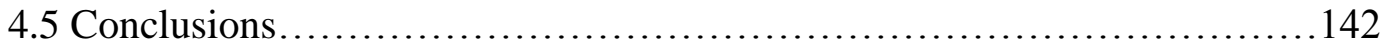


4.6 References........................................................ 168

Chapter 5: Final conclusions and synthesis.................................... 180

5.1 Conclusions.......................................................... 180

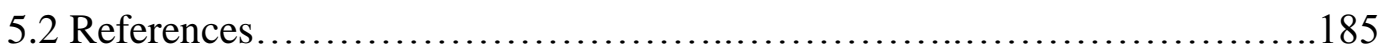

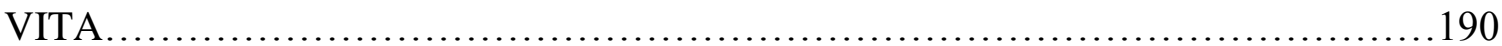




\section{LIST OF TABLES}

CHAPTER-TABLE

PAGE

2-1. Forward and reverse primers used to amplify the following genes of interest (GOI), including internal control genes (ICG), in Q-RT-PCR assays

3-1. Identification of 32 proteins subjected to Mass Spectrometry analysis

3-2. Blast2GO gene ontology terms provided for the 30 proteins analyzed by Mass Spectrometry........................................................... 112

4-1. Transcripts associated with enriched GO terms found in this study..............148

4-2. Genes differentially expressed in primed E. pallida prior to and after the secondary challenge.

4-3. Differentially expressed transcripts from a comparison of zero hour naïve vs. zero hour primed treatments

4-4. Differentially expressed transcripts from a comparison of four hour naïve vs.

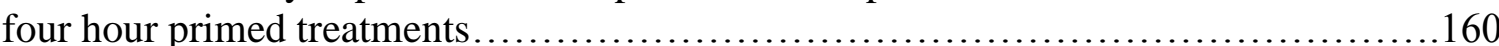

4-5. Differentially expressed transcripts from a comparison of four hour naive vs. four hour unchallenged treatments. 


\section{LIST OF FIGURES}

CHAPTER-FIGURE

PAGE

2-1. Photographs of Acropora millepora coral nubbins from the first experiment at 48 hours after bacterial inoculation

2-2. Photographs of $V$. coralliilyticus inoculated nubbins from the second set of experiments at concentrations: $10^{4} \mathrm{CFU} / \mathrm{ml}, 10^{5} \mathrm{CFU} / \mathrm{ml}, 10^{6} \mathrm{CFU} / \mathrm{ml}$, and control, after 48 hours.

2-3. Dark adapted PSII quantum yield $\left(\mathrm{F}_{\mathrm{v}} / \mathrm{F}_{\mathrm{m}}\right)$ of Symbiodinium associated with coral nubbins after 48 hours from the bacterial inoculation during the second set of experiments.

2-4. Relative transcriptional expression of the three genes of interest from $A$. millepora at 6 and 24 hours after inoculation with either $V$. coralliilyticus or Alteromonas sp. A-B: c3; C-D: hsp70; E-F: c-type lectin........................44

2-5. Correspondence analysis (CA) of bacterial 16S rDNA DGGE banding patterns. ..45

2-6. DGGE of bacterial communities from Alteromonas sp. (A) innoculated, $V$.

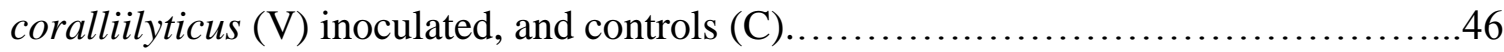

3-1. The sea anemone, Exaiptasia pallida, utilized in the immunological studies as a Cnidarian model system. .85

3-2. Percent survival of Exaiptasia pallida to the exposure of the bacterial pathogen

Vibrio coralliilyticus over ten days. .86

3-3. Percent survival of Exaiptasia pallida to the exposure of the bacterial pathogen Serratia marcescens over ten days

3-4. Percent survival of Exaiptasia pallida anemones varying the exposure time to $V$. coralliilyticus at a dose of $10^{8} \mathrm{CFU} \mathrm{ml}^{-1}$ : ten days, three days, and control..............88

3-5. Kaplan-Meier survival plots for Exaiptasia pallida during 10-day lethal challenge to the pathogen Vibrio coralliilyticus following two weeks, four weeks and six weeks recovery period post priming with a sub-lethal exposure. 
3-6. Relative Abundance of Vibrio coralliilyticus load in infected Exaiptasia pallida anemones estimated through specific quantitative PCR amplification of the pathogen 16S rDNA.

3-7. Kaplan-Meier survival plots for Exaiptasia pallida during 10-day lethal challenge to the pathogen Serratia marcescens following two weeks and four weeks recovery periods post priming with a sub-lethal exposure.

3-8. Kaplan-Meier bacterial specificity survival plots for Exaiptasia pallida during 10-day lethal challenge after a sub-lethal exposure to the pathogen Vibrio coralliilyticus following: two weeks and four weeks recovery period.

3-9. Kaplan-Meier bacterial specificity survival plots for Exaiptasia pallida during 10-day lethal challenge after a sub-lethal exposure to the pathogen Serratia marcescens following: two weeks and four weeks recovery period

3-10. Histogram of the differentially expressed proteins as a function of fold change from Exaiptasia pallida anemones four weeks post priming in comparison to naïve anemones never exposed to the pathogen.

3-11. CyDye switch, two dimensional fluorescence difference gel electrophoresis (2D-DIGE) analysis of proteomes from naïve $(\mathrm{N}=3)$ and pathogen-primed $(\mathrm{N}=3)$ Exaiptasia pallida sea anemones.

3-12. Representation of biological processes Gene Ontology (GO) terms for the 32 Exaiptasia pallida characterized proteins

3-13. Proposed model of Heat Shock Proteins (HSP), Cathesin and Glutamate Receptor (iGluR) roles in cnidarian molecular defense priming.

4-1. Volcano plots indicating differentially expressed transcripts for: zero hour naïve vs zero hour primed, four hour naïve challenged vs four hour primed, four hour unchallenged vs four hour naïve challenged

4-2. Venn diagram indicating transcripts that are shared by the treatments which are identified by transcript number from the genome (AIPGENE number) and annotation from Blast2GO.

4-3. Working model of immune priming in E. pallida.

4-4. Counts of differentially expressed genes between pairwise comparisons of all treatments (FDR-corrected p-value $<0.05 ; 2$-fold minimum fold change). 


\section{Chapter 1: Introduction}

Coral reefs are among the most diverse ecosystems in the world with corals forming the framework of this ecosystem. Coral reefs provide many benefits as an ecosystem [1]. Corals provide structural habitat for many organisms that inhabit coral reefs by providing refuge for many fish as well as invertebrates. Additionally, they provide an important buffering zone by dampening waves before they reach onshore regions and therefore provide protection during hurricanes. Natural products produced by various species of corals are providing compounds that are being used by the pharmaceutical industry to combat diseases and inflammation [2]. Coral reefs are also very important for tourism, accounting for $\$ 375$ billion dollars annually in total value for goods and services worldwide, which includes fisheries. Additionally, NOAA suggests that coral reefs in southeast Florida have a value of $\$ 8.5$ billion dollars (NOAA fisheries: http://floridakeys.noaa.gov/corals/economy.html).

\subsection{Coral disease}

Coral reef ecosystems are declining rapidly due to global climate change and disease outbreaks. In fact, disease outbreaks have become so dramatic that they have altered the seascape and the community structure of the reef. In the Caribbean, coral reefs in general were declining at a rate of 5.5-9.2\% per year in 2003 [3]. In the Indo-Pacific, the decline is slightly less at $2 \%$ per year [4]. These numbers have been rapidly increasing since the previous surveys and are projected to continue to increase as human impacts on coral reefs increase [5]. Not only have the number of incidences of disease increased but also the number of known coral diseases has also increased. To date there are 35 reported 
coral diseases [6] while in 1965 there were two known diseases [7]. These diseases impact over 80 coral species. However, of these only five have a known pathogen or consortium of bacteria that have fulfilled Koch's postulates [7-20]. Two of these bacteria are Vibrio coralliilyticus $[8,9,15]$ and Serratia marcescens [13]. V. coralliilyticus is a coral pathogen that was originally isolated from the coral Pocillopora damicornis where it causes tissue damage. It is a gram-negative rod shaped bacteria that has a sheathed flagella. Evolutionarily, its closest relatives are V. tubiashii, V. nereis, and V. shilonii [8]. Additionally, the bacterium consists of geographically distinct strains that exhibit genetic variation [21]. V. coralliilyticus also shows temperature dependent virulence, causing tissue damage at temperatures above $27^{\circ} \mathrm{C}$ [9] where it attacks Symbiodinium cells [8]. The exact mechanism by which $V$. coralliilyticus regulates its pathogenicity is still unknown and may be strain specific, but there are several potential virulence factors that are up-regulated in the bacterium at elevated temperatures: motility, host degradation, quorum sensing, antibiotic resistance, hemolysis, cytotoxicity and bioluminescence [22]. The genome of $V$. coralliilyticus consists of two chromosomes, which is consistent with other Vibrio sps [22-24]. The larger chromosome arm, C1, contains genes associated with viability and growth, while the smaller arm, C2, has genes that are used for adaptation to environmental change [22,25]. Additionally, there are two pathogenicity islands associated with this bacterium. Both are found on the $\mathrm{C} 1$ chromosome. The first pathogenicity island (CP-1) is shown to be upregulated at temperatures above $27^{\circ} \mathrm{C}$ and thus is considered to contribute to the pathogenicity of the bacterium [22].

S. marcescens strain PDL 100 is the strain of bacteria that causes white pox disease in the coral Acropora palmata. It is a gram-negative motile rod [13]. This bacterium also causes 
disease in a wide range of plants, invertebrates, vertebrates, and humans [26]. In corals, the disease causes rapid tissue loss that is greatest during elevated temperatures [13]. White pox forms white patches all along the coral colony and is very contagious, moving rapidly along a reef [13]. The method of infection for $S$. marcescens may be that it outcompetes other bacteria in the coral mucus of A. palmata and becomes pathogenic [27]. Virulence of $S$. marcescens has been shown to be driven by pilli adherence to host epithelial surfaces, hydrophobicity (allowing for adhesion to more surfaces), lipopolysaccharides, and various extracellular compounds (example: an enzyme that degrades chitin). Additionally, virulence is likely regulated by the bacterium's ability to swarm where quorum sensing (QS) plays an essential role [28], since during early growth on coral mucus, the bacterium behaves enzymaticaly most similarly to commensal bacteria in the mucus. However, after overnight culturing of the PDL 100 isolate, the enzymatic activity changed to be more similar to the pathogenic human form of the bacterium [27]. The chemotactic ability of S. marcescens to coral mucus is increased at $30^{\circ} \mathrm{C}$ in comparison to $20^{\circ} \mathrm{C}$.

\subsection{Immunity in cnidarians}

Due to the rapid decline in coral cover and increase in the number of known pathogens, it has become critical to study how corals defend against disease in order to guide management plans for the coral reef ecosystem. However, the understanding of the coral immune system is still rudimentary. Advances in molecular and cellular biology have allowed for some understanding of the innate immune system in cnidarians [5,29-38]. Unfortunately, functional studies on the putative immune genes and pathways are lacking. In order to gain a better understanding of the cnidarian immune system, 
functional studies are needed. Genome - wide studies on several cnidarians have shown that not all members use the same pathways to defend against pathogens [32]. Components of toll-like receptor (TLR), interferon (INF), and complement pathways are present in Nematostella, Acropora, Hydra, and Exaiptasia, but the members present differ between species [32,36]. For example, all four organisms contain the complement pathway component $\mathrm{C} 3$ but apexins are only found in Acropora and Hydra [32,35].

A generalized model of innate immunity is arising as a result of these studies which indicate that the cnidarian immune system functions in the same manner as in other organisms. The innate immune system consists of two branches: the first is the sensing arm, and the second is the effector arm [5]. The sensing arm is the component that recognizes the immune threat that activates the effector arm. The effector arm then activates the humoral and/or cellular response such as inflammation or cytotoxic responses, and phagocytosis, which will neutralize the threat [5]. The subsequent immune response occurs in two phases. The first phase is activated immediately after the pathogen has breached the anatomical barriers of the host. At this time, antimicrobial enzymes such as lysozyme digest the bacterial cell wall by breaking the peptidoglycan bonds while antimicrobial peptides like defensins directly lyse it. Additionally during this phase, epithelial cells secrete antimicrobial peptides into the mucosal surface fluids.

During the second phase of the immune response, cells further sense the presence of the pathogen by using pattern recognition receptors (PRR) that bind to highly conserved cell wall structures on foreign entities, microbe-associated molecular patterns (MAMP). Examples of MAMPs include flagellin, lipopolysaccharide (LPS), lipoteichoic acid, and peptidoglycan [39]. Six distinct families of microbe detection receptors have been 
identified in cnidarians. Three of these are transmembrane receptors or sensors: Toll like receptors (TLRs), lectins, and integrins. The final three are members of families of intracellular receptors: nucleotide-binding and oligomerizing domain (NOD)-like receptors (NLRs) and the complement like system [5]. The immune response of cnidarians is composed of three components: transmembrane, humoral, and cellular. These will be discussed below.

\subsubsection{Transmembrane PRRs}

The transmembrane PRRs have been studied in corals. TLR structure has been well studied in invertebrates $[32,40-44]$. They have an outer leucine rich repeat domain (LRR) which is responsible for pattern recognition and a cytoplasmic component that is called the Toll/interleukin - 1 receptor (TIR) which mediates signal transduction. A complete TLR (containing both the LRR and TIR components) has been identified in Acropora digitifera [32]. Additionally, the cytoplasmic TIR component alone has been identified in: A. palmata, A. millepora, Orbicella faveolata [32,43], and the sea anemone Exaiptasia pallida [42]. Several components of pathways associated with the TLRs have been identified in the A. digitifera genome: the myeloid differentiation primary adaptor protein (MyD88) which activates downstream signaling pathways, homologs of the transcription factor NF-kB which leads to cell death, and the mitogen-activated protein kinases (MAPK) which are involved in thermal stress amongst other roles [32,43].

Lectins are a second family of transmembrane receptor proteins that are found ubiquitously throughout the animal kingdom. They are important in cell recognition of bacteria and viruses. The receptors contain carbohydrate recognition domains which 
allows for calcium dependent binding to carbohydrate components of foreign entities. Lectins have been identified in several corals [45-47]. The lectin, Millectin has been identified and described in A. millepora which contains a peptide recognition site and a carbohydrate - binding site. It is upregulated in response to LPS but has also been shown to recognize non-self structures by binding and agglutinating the pathogens Vibrio harveyi and V. coralliilyticus [45]. A second lectin a Techylectin has been identified in the scleractinian species Oculina [47]. The coral Techylectin is similar in structure to Techylectin isolated from the Japanese horseshoe crab which has broad spectrum antimicrobial activities. It is therefore presumed that the Oculina sp. Techylectin also has these activities but functional studies are needed [5].

Microbes that elude immune surface receptors can be sensed at an intracellular level using MAMPs which are known as nucleotide oligomerization domain (NOD)-like receptors (NLRs). Triggering of NLRs causes the activation of numerous proinflammatory pathways. Analysis of the A. digitifera genome reveled a diverse array of NLRs which contain a death-effector domain (DED), death domain (DD), and caspase recruitment domain (CARD) which are all involved in apoptosis $[5,48]$.

The complement system is a major effector mechanism of the innate immune system. In higher vertebrates, the complement system proceeds by three mechanisms: 1) antibody antigen binding (classical pathway), 2) mannose-binding lectin (MBL), and 3) spontaneous binding of complement (alternative pathway) [39]. All of these pathways lead to the activation of $\mathrm{C} 3$ which is cleaved to $\mathrm{C} 3 \mathrm{a}$ and $\mathrm{C} 3 \mathrm{~b}$. After cleavage, $\mathrm{C} 3 \mathrm{a}$ diffuses to cause an inflammatory response while $\mathrm{C} 3 \mathrm{~b}$ remains attached to the microbe surface and serves as an opsinin. This opsinin binds to complement receptors to initiate 
phagocytosis and activates the events that lead to the formation of the membrane attack complex (MAC) which ultimately leads to cell lysis $[49,50]$. Since corals lack an adaptive immune system, activation of the complement system should occur by MBL or spontaneously [51]. Putative complement genes have been identified in cnidarians. They have been identified in three coral species: Swiftia exserta [52], Gorgonia ventalina [29], and A. millepora [32]. Additionally, functional studies have identified the over expression of $\mathrm{C} 3$ in these corals during pathogenic challenge linking it to the immune response $[53,54]$. Genomic sequencing has also revealed the presence of other components of the complement system in corals: Factor B, mannose - binding lectin serine protease (MASP), MBLs, and ficolins [52,54-61]. The cnidarian model system, E. pallida also has components of the complement system. Functional studies have shown that a Factor B gene (serine protease that in vertebrates aids in the formation of $\mathrm{C} 3$ via the alternative pathway)(Ap_Bf-1) and a MASP gene (AP_MASP) are up regulated in challenges with S. marcescens but that a second Factor B gene (AP_Bf-2b) is down regulated during pathogen challenge [35].

\subsubsection{Humoral response}

The humoral response of corals is characterized by the synthetic release of chemical compounds upon their activation. These chemicals include melanin, antimicrobial peptides (AMP), and secondary metabolites. The main function of the compounds is to kill the invading microbe by: opsonization and agglutination. This permeabilizes the cell membrane of the invading cell causing lysis, and disruption of metabolism [62]. These compounds are constitutively present in corals and are stored in granules within epithelial cells or contained in free living cells. If they are contained in the free living cells, the 
compounds can be recruited to the affected areas [63]. These compounds can also be synthesized and released in situ in response to mechanical stress, injuries, or pathogen detection [64-66].

Melanization is a humoral response that has been well studied in corals. It involves the synthesis and deposition of melanin around foreign entities or wounds [34,63,67-70]. Within the melanin synthesis cascade, the enzyme phenoloxidase (PO) is an essential component needed to synthesize melanin. In corals, A. millepora, and Porites sp., activation of PO has been shown to occur in response to diphenols (DOPA), which are catalyzed as a result of enzymatic oxidation after PO is activated [63]. Two melanin synthesis pathways have been identified in corals: tyrosinase-type and laccase-type. Additionally multiple POs (catecholase, cresolase, and laccase) have been identified in several coral families: Pocilloporidae, Acroporidae, Merulinidae, Mussidae, Fungiidae, Faviidae, and Poriferidae. The synthesis of melanin has also been shown in response to wound healing, pathogenic response, and sustained elevated water temperatures. $[63,69,71]$. Additionally base line PO levels have been assessed as well as size and abundance of melanin containing granular amebocytes for several coral species [72]. It appears that these baseline values correspond to disease and bleaching susceptibility and immunocompetence. Corals with lower baseline values are more susceptible while those with higher baseline values are more resistant to disease and bleaching [34].

Antimicrobial peptides (AMPs) have antimicrobial properties but also show immunomodulatory activity such as apoptosis and regulation of gene transcription. However, little is known about AMPs in corals. Damicornin which was isolated from Pocillopora damicornis is the only AMP isolated from a coral [73]. This AMP inhibits 
gram negative bacteria and is continuously produced in granular cells from the epithelium from where it is released during LPS challenge [73]. Peroxidase enzymes have also been linked to immunity in organisms and have been linked to phagocytosis [74] and the synthesis of melanin [68]. Peroxidase activity has also been linked to the stress response and immune constituent of corals. Peroxidase production was induced in Gorgonia ventalina in response to fungal pathogen exposure [68]. Other natural products that contain antimicrobial properties have also been studied in gorgonian and scleractinian corals. Gorgonians are known to be rich in secondary metabolites with antimicrobial properties. For example, nine polycyclized diterpenes were isolated from Briareum polyanthes. All of these showed antimicrobial properties against the human pathogens: Plasmodium falciparum and Mycobacterium tuberculosis [75]. Additionally some lipid metabolites extracted from $G$. ventalina show inhibitory activity against the known coral fungal pathogen Aspergillus sydowii [76-78]. Scleractinian corals Montipora capitata, Porites lobata, and Pocillopora meandrina showed some antimicrobial activity against $S$. marcescens, V. coralliilyticus, and $V$. shiloi. The antibacterial activity of extracts varied among the species and as a function of coral health [79].

\subsubsection{Cell mediated immunity}

Phagocytosis is a fundamental innate immune response and has been found to occur in some coral species using amebocytes $[5,80]$. The role of amebocytes in corals is variable and has been studied mostly in gorgonians where they are linked to wound healing and protection from infection. In Swiftia exserta amebocytes gather during wound healing as in an inflammatory response to clean the wound [81] but in Plexaurella fusifera they line the edge of the wound and differentiate to form new epithelial cells [82]. In G. ventalina 
greater numbers of granular amebocytes are present in tissue infected with $A$. sydowii than uninfected tissue $[69,71]$. Amebocytes have also been found in scleractinian corals in response to immunological challenge but due to their thinner mesoglea in comparison to gorgonians the amebocytes are smaller and fewer in number $[80,83]$. Porites sp. showed granular amebocytes in abnormally pigmented tissue [63]. Additionally $P$. cylindrica showed the release of melanin from angular amebocytes and amebocyte differentiation from epithelial tissue during wound healing [34]. Unfortunately, other scleractinian coral species have shown less infiltration of amebocytes or they are not visible during stress. These corals include: Montastrea cavernosa under sediment stress, in pigmented tissue of Acropora millepora [63], and wound healing in Montipora capitata [83].

\subsection{Immune priming}

Since corals and invertebrates possess only an innate immune system it is accepted that they do not possess any form of immunological memory whereby the organism responds more rapidly to secondary encounters with a pathogen. However, despite the lack of the adaptive immune system, immunological priming has been documented in several invertebrates [84-89]. Immune priming is of interest in cnidarians because they are long lived organisms. During their long life they presumably encounter the same bacteria many times. Additionally, evidence of potential immune priming exists in cnidarians.

Two coral species that had previously been susceptible to disease caused by a bacterium are no longer susceptible. One example is depicted in the coral, Oculina patagoncia which had been susceptible to bacterial induced bleaching by $V$. shiloi. However, studies conducted at a later date no longer caused signs of disease in this species despite the 
bacterium's continued adhesion to the coral surface [90]. The second example is seen in the coral Acropora palmata which had been susceptible to S. marcescens strain PDL100 but currently this pathogen no longer causes disease in this species [91]. There are several hypotheses for why this change in disease susceptibility could occur. The first is that resistant phenotypes of the coral species could have been selected for. The second is that the bacterium may have mutated and can no longer cause an infection. The final reason is that the coral may have become immunologically primed to the bacterium. This means that the coral remembered a previously encountered bacterium and responded more rapidly to it in subsequent encounters. One of the questions raised by this dissertation will be to explore the possibility of immune priming in cnidarians.

\subsection{Dissertation objectives, hypothesis, and organization}

The purpose of this dissertation was to identify mechanisms used by cnidarians to defend against biotic stressors. First I investigated if known immune gene homologs involved in the complement and heat stress pathways in higher vertebrates are also involved in the innate immune response of basal metazoans in response to biotic stressors. Secondly, my dissertation explored the evolutionary roots of immunological priming by investigating whether this phenomenon is found in basal metazoans. The final data chapter explored the molecular mechanisms underpinning immunological priming in early diverged organisms. 
Chapter two addressed the following question and hypotheses:

- Are gene homologs previously associated with the complement system and heat stress of evolutionarily more complex organisms also involved in the immune response of basal metazoans in response to biotic stressors?

- $\mathrm{H}_{\mathrm{O}-2 \mathrm{~A}}$ : If cnidarians use an immune system as a defense mechanism against biotic stressors then it should be activated when these stressors are introduced into the environment.

- $\mathrm{H}_{\mathrm{O}-2 \mathrm{~B}}$ : If c3-like, c-type lectin, and heat shock protein $70($ hsp70) are functionally conserved throughout the tree of life, then their expression will change when challenged with biotic stressors in basil metazoans.

Chapter three addressed the following questions:

- Is immune priming conserved throughout the tree of life? Do basal metazoans have the ability to remember a previously encountered biotic stressor and have a heightened and quicker immune response to subsequent encounters with the biotic stressor?

$\circ \mathrm{H}_{\mathrm{O}-3-\mathrm{A}}$ : If immune priming is a phenomenon found throughout the tree of life, it will be found in basal metazoans in response to repeated encounters with biotic stressors.

$\circ \mathrm{H}_{\mathrm{O}-3-\mathrm{B}}$ : If immune priming has been conserved throughout the tree of life, the response to biotic stressors will be specific.

○ $\mathrm{H}_{\mathrm{O}-3-\mathrm{C}}$ : If immune priming is conserved in basal metazoans, a proteomic signature will be present during the response. 
The fourth chapter addressed the following question:

- What are the genes and pathways involved in immune priming in a basal metazoan?

- $\mathrm{H}_{\mathrm{O}-4-\mathrm{A}}$ : If immune priming occurs in cnidarians, a molecular signature will be associated with it.

Chapter five provides a general discussion and synthesizes the findings from all chapters and re-addressees all the hypotheses.

\subsection{References}

1. Moberg F, Folke C (1999) Ecological goods and services of coral reef ecosystems. Ecological Economics 29: 215-233.

2. Senthilkumar K, Kim S-K (2013) Marine invertebrate natural products for antiinflammatory and chronic diseases. Evidence-Based Complementary and Alternative Medicine 2013.

3. Buddemeier RW, Ware JR (2003) Coral reef decline in the Caribbean. Science 302: 391-393.

4. Bruno JF, Selig ER, Casey KS, Page CA, Willis BL, et al. (2007) Thermal stress and coral cover as drivers of coral disease outbreaks. Plos Biology 5: 1220-1227.

5. Toledo-Hernández C, Ruiz-Diaz C (2014) The immune responses of the coral. Invertebr Surviv J 11: 319-328.

6. Kline DI, Vollmer SV (2011) White Band Disease (type I) of endangered Caribbean acroporid corals is caused by pathogenic bacteria. Scientific Reports 1 .

7. Sutherland KP, Porter JW, Torres C (2004) Disease and immunity in Caribbean and Indo-Pacific zooxanthellate corals. Marine Ecology Progress Series 266: 273-302.

8. Ben-Haim Y, Thompson FL, Thompson CC, Cnockaert MC, Hoste B, et al. (2003) Vibrio coralliilyticus sp nov., a temperature-dependent pathogen of the coral Pocillopora damicornis. International Journal of Systematic and Evolutionary Microbiology 53: 309-315. 
9. Ben-Haim Y, Zicherman-Keren M, Rosenberg E (2003) Temperature-regulated bleaching and lysis of the coral Pocillopora damicornis by the novel pathogen Vibrio coralliilyticus. Applied and Environmental Microbiology 69: 4236-4242.

10. Denner EBM, Smith GW, Busse HJ, Schumann P, Narzt T, et al. (2003) Aurantimonas coralicida gen. nov., sp nov., the causative agent of white plague type II on Caribbean scleractinian corals. International Journal of Systematic and Evolutionary Microbiology 53: 1115-1122.

11. Kushmaro A, Loya Y, Fine M, Rosenberg E (1996) Bacterial infection and coral bleaching. Nature 380: 396-396.

12. Kushmaro A, Rosenberg E, Fine M, Loya Y (1997) Bleaching of the coral Oculina patagonica by Vibrio AK-1. Marine Ecology-Progress Series 147: 159-165.

13. Patterson KL, Porter JW, Ritchie KE, Polson SW, Mueller E, et al. (2002) The etiology of white pox, a lethal disease of the Caribbean elkhorn coral, Acropora palmata. Proceedings of the National Academy of Sciences of the United States of America 99: 8725-8730.

14. Richardson LL, Goldberg WM, Carlton RG, Halas JC (1998) Coral disease outbreak in the Florida Keys: Plague Type II. Revista De Biologia Tropical 46: 187-198.

15. Ben-Haim Y, Rosenberg E (2002) A novel Vibrio sp. pathogen of the coral Pocillopora damicornis. Marine Biology 141: 47-55.

16. Geiser DM, Taylor JW, Ritchie KB, Smith GW (1998) Cause of sea fan death in the West Indies. Nature 394: 137-138.

17. Kushmaro A, Banin E, Loya Y, Stackebrandt E, Rosenberg E (2001) Vibrio shiloi sp. nov., the causative agent of bleaching of the coral Oculina patagonica. International Journal of Systematic and Evolutionary Microbiology 51: 13831388 .

18. Kushmaro A, Rosenberg E, Fine M, Haim YB, Loya Y (1998) Effect of temperature on bleaching of the coral Oculina patagonica by Vibrio AK-1. Marine Ecology Progress Series 171: 131-137.

19. Rosenberg E, Ben-Haim Y, Toren A, Banin E, Kushmaro A, et al. (1999) Effect of temperature on bacterial bleaching of corals. Microbial ecology and infectious disease ASM Press, Washington, DC: 242-254.

20. Smith GW, Ives LD, Nagelkerken IA, Ritchie KB (1996) Caribbean sea-fan mortalities. Nature: 487. 
21. Pollock FJ, Wilson B, Johnson WR, Morris PJ, Willis BL, et al. (2010) Phylogeny of the coral pathogen Vibrio coralliilyticus. Environmental Microbiology Reports 2: $172-178$.

22. Kimes NE, Grim CJ, Johnson WR, Hasan NA, Tall BD, et al. (2012) Temperature regulation of virulence factors in the pathogen Vibrio coralliilyticus. The ISME Journal 6: 835-846.

23. Chun J, Grim CJ, Hasan NA, Lee JH, Choi SY, et al. (2009) Comparative genomics reveals mechanism for short-term and long-term clonal transitions in pandemic Vibrio cholerae. Proceedings of the National Academy of Sciences 106: 1544215447.

24. Okada K, Iida T, Kita-Tsukamoto K, Honda T (2005) Vibrios commonly possess two chromosomes. Journal of Bacteriology 187: 752-757.

25. Makino K, Oshima K, Kurokawa K, Yokoyama K, Uda T, et al. (2003) Genome sequence of Vibrio parahaemolyticus: a pathogenic mechanism distinct from that of V. cholerae. The Lancet 361: 743-749.

26. Grimont F, Grimont PA (2006) The genus Serratia. The prokaryotes: Springer. pp. 219-244.

27. Krediet CJ, Ritchie KB, Teplitski M (2009) Catabolite regulation of enzymatic activities in a white pox pathogen and commensal bacteria during growth on mucus polymers from the coral Acropora palmata. Diseases of Aquatic Organisms 87: 57-66.

28. Alagely A, Krediet CJ, Ritchie KB, Teplitski M (2011) Signaling-mediated cross-talk modulates swarming and biofilm formation in a coral pathogen Serratia marcescens. The ISME Journal 5: 1609-1620.

29. Burge CA, Mouchka ME, Harvell CD, Roberts S (2013) Immune response of the Caribbean sea fan, Gorgonia ventalina, exposed to an Aplanochytrium parasite as revealed by transcriptorne sequencing. Frontiers in Physiology 4.

30. Libro S, Kaluziak ST, Vollmer SV (2013) RNA-seq profiles of immune related genes in the staghorn coral Acropora cervicornis infected with white band disease. Plos One 8.

31. Libro S, Vollmer SV (2016) Genetic signature of resistance to White Band Disease in the Caribbean staghorn coral Acropora cervicornis. Plos One 11.

32. Miller DJ, Hemmrich G, Ball EE, Hayward DC, Khalturin K, et al. (2007) The innate immune repertoire in Cnidaria - ancestral complexity and stochastic gene loss. Genome Biology 8. 
33. Palmer CV, Graham E, Baird AH (2012) Immunity through early development of coral larvae. Developmental and Comparative Immunology 38: 395-399.

34. Palmer CV, Traylor-Knowles N, Willis BL, Bythell JC (2011) Corals use similar immune cells and wound-healing processes as those of higher organisms. Plos One 6.

35. Poole AZ, Kitchen SA, Weis VM (2016) The role of complement in cnidariandinoflagellate symbiosis and immune challenge in the sea anemone Aiptasia pallida. Frontiers in Microbiology 7.

36. Sunagawa S, Wilson EC, Thaler M, Smith ML, Caruso C, et al. (2009) Generation and analysis of transcriptomic resources for a model system on the rise: the sea anemone Aiptasia pallida and its dinoflagellate endosymbiont. BMC Genomics 10.

37. Vidal-Dupiol J, Dheilly NM, Rondon R, Grunau C, Cosseau C, et al. (2014) Thermal stress triggers broad Pocillopora damicornis transcriptomic remodeling, while Vibrio coralliilyticus infection induces a more targeted immuno-suppression response. Plos One 9.

38. Vidal-Dupiol J, Ladriere O, Destoumieux-Garzon D, Sautiere PE, Meistertzheim AL, et al. (2011) Innate immune responses of a scleractinian coral to vibriosis. Journal of Biological Chemistry.

39. Murphy K (2012) Janeway's immunobiology 8th edition. New York, New York: Garland Science, Taylor \& Francis Group.

40. Medzhitov R (2000) Toll-like receptors in innate and adaptive immunity. Molecular Biology of the Cell 11: 282A-282A.

41. Zheng L, Zhang L, Lin H, McIntosh MT, Malacrida AR (2005) Toll-like receptors in invertebrate innate immunity. ISJ 2: 105-113.

42. Lehnert EM, Burriesci MS, Pringle JR (2012) Developing the anemone Aiptasia as a tractable model for cnidarian-dinoflagellate symbiosis: the transcriptome of aposymbiotic A. pallida. BMC Genomics 13: 271.

43. Schwarz JA, Brokstein PB, Voolstra C, Terry AY, Miller DJ, et al. (2008) Coral life history and symbiosis: functional genomic resources for two reef building Caribbean corals, Acropora palmata and Montastraea faveolata. BMC Genomics 9: 97. 
44. Yang C, Zhang J, Li F, Ma H, Zhang Q, et al. (2008) A Toll receptor from Chinese shrimp Fenneropenaeus chinensis is responsive to Vibrio anguillarum infection. Fish \& Shellfish Immunology 24: 564-574.

45. Kvennefors ECE, Leggat W, Hoegh-Guldberg O, Degnan BM, Barnes AC (2008) An ancient and variable mannose-binding lectin from the coral Acropora millepora binds both pathogens and symbionts. Developmental and Comparative Immunology 32: 1582-1592.

46. Wood-Charlson EM, Weis VM (2009) The diversity of C-type lectins in the genorne of a basal metazoan, Nematostella vectensis. Developmental and Comparative Immunology 33: 881-889.

47. Hayes ML, Eytan RI, Hellberg ME (2010) High amino acid diversity and positive selection at a putative coral immunity gene (tachylectin-2). BMC Evolutionary Biology 10.

48. Hamada M, Shoguchi E, Shinzato C, Kawashima T, Miller DJ, et al. (2012) The complex NOD-like receptor repertoire of the coral Acropora digitifera includes novel domain combinations. Molecular Biology and Evolution: mss213.

49. Gros P, Milder FJ, Janssen BJ (2008) Complement driven by conformational changes. Nature Reviews Immunology 8: 48-58.

50. Mayilyan K, Kang Y, Dodds A, Sim R (2008) The complement system in innate immunity. Innate immunity of plants, animals, and humans: Springer. pp. 219236.

51. Cerenius L, Soderhall. K (2004) The prophenoloxidase-activation system in invertebrates. Immunological Reviews 198: 116-126.

52. Dishaw LJ, Smith SL, Bigger CH (2005) Characterization of a C3-like cDNA in a coral: phylogenetic implications. Immunogenetics 57: 535-548.

53. Brown T, Bourne D, Rodriguez-Lanetty M (2013) Transcriptional activation of $c 3$ and $h s p 70$ as part of the immune response of Acropora millepora to bacterial challenges. Plos One 8.

54. Kvennefors ECE, Leggat W, Kerr CC, Ainsworth TD, Hoegh-Guldberg O, et al. (2010) Analysis of evolutionarily conserved innate immune components in coral links immunity and symbiosis. Developmental and Comparative Immunology 34: 1219-1229. 
55. Kimura A, Sakaguchi E, Nonaka M (2009) Multi-component complement system of Cnidaria: $\mathrm{C} 3, \mathrm{Bf}$, and MASP genes expressed in the endodermal tissues of a sea anemone, Nematostella vectensis. Immunobiology 214: 165-178.

56. Baumgarten S, Simakov O, Esherick LY, Liew YJ, Lehnert EM, et al. (2015) The genome of Aiptasia, a sea anemone model for coral symbiosis. Proceedings of the National Academy of Sciences of the United States of America 112: 1189311898.

57. Ocampo ID, Zarate-Potes A, Pizarro V, Rojas CA, Vera NE, et al. (2015) The immunotranscriptome of the Caribbean reef-building coral Pseudodiploria strigosa. Immunogenetics 67: 515-530.

58. Shinzato C, Shoguchi E, Kawashima T, Hamada M, Hisata K, et al. (2011) Using the Acropora digitifera genome to understand coral responses to environmental change. Nature 476: 320-U382.

59. Fujito NT, Sugimoto S, Nonaka M (2010) Evolution of thioester-containing proteins revealed by cloning and characterization of their genes from a cnidarian sea anemone, Haliplanella lineate. Developmental \& Comparative Immunology 34: $775-784$

60. Ganot P, Moya A, Magnone V, Allemand D, Furla P, et al. (2011) Adaptations to endosymbiosis in a cnidarian-dinoflagellate association: differential gene expression and specific gene duplications. PLoS Genetics 7.

61. Hambleton EA (2013) Symbiosis specificity and innate immunity in Aiptasia, a model system for cnidarian-dinoflagellate symbiosis: Stanford University.

62. Ellis R, Parry H, Spicer J, Hutchinson T, Pipe R, et al. (2011) Immunological function in marine invertebrates: responses to environmental perturbation. Fish \& Shellfish Immunology 30: 1209-1222.

63. Palmer CV, Mydlarz LD, Willis BL (2008) Evidence of an inflammatory-like response in non-normally pigmented tissues of two scleractinian corals. Proceedings of the Royal Society B-Biological Sciences 275: 2687-2693.

64. Geffen Y, Ron EZ, Rosenberg E (2009) Regulation of release of antibacterials from stressed scleractinian corals. FEMS Microbiology Letters 295: 103-109.

65. Destoumieux D, Muñoz M, Cosseau C, Rodriguez J, Bulet P, et al. (2000) Penaeidins, antimicrobial peptides with chitin-binding activity, are produced and stored in shrimp granulocytes and released after microbial challenge. Journal of Cell Science 113: 461-469. 
66. Ganz T (2003) The role of antimicrobial peptides in innate immunity. Integrative and Comparative Biology 43: 300-304.

67. Mydlarz LD, Couch CS, Weil E, Smith G, Harvell CD (2009) Immune defenses of healthy, bleached and diseased Montastraea faveolata during a natural bleaching event. Diseases of Aquatic Organisms 87: 67-78.

68. Mydlarz LD, Harvell CD (2007) Peroxidase activity and inducibility in the sea fan coral exposed to a fungal pathogen. Comparative Biochemistry and Physiology A-Molecular \& Integrative Physiology 146: 54-62.

69. Mydlarz LD, Holthouse SF, Peters EC, Harvell CD (2008) Cellular responses in sea fan corals: granular amoebocytes react to pathogen and climate stressors. Plos One 3.

70. Mydlarz LD, McGinty ES, Harvell CD (2009) What are the physiological and immunological responses of coral to climate warming and disease? Journal of Experimental Biology 213: 934-945.

71. Petes L, Harvell C, Peters E, Webb M, Mullen K (2003) Pathogens compromise reproduction and induce melanization in Caribbean sea fans. Marine Ecology Progress Series 264: 167-171.

72. Palmer CV, Bythell JC, Willis BL (2010) Levels of immunity parameters underpin bleaching and disease susceptibility of reef corals. FASEB Journal 24: 1935-1946.

73. Vidal-Dupiol J, Ladriere O, Meistertzheim AL, Foure L, Adjeroud M, et al. (2011) Physiological responses of the scleractinian coral Pocillopora damicornis to bacterial stress from Vibrio coralliilyticus. Journal of Experimental Biology 214: 1533-1545.

74. Rodríguez A, Esteban M, Meseguer J (2003) Phagocytosis and peroxidase release by seabream (Sparus aurata L.) leucocytes in response to yeast cells. The Anatomical Record Part A: Discoveries in Molecular, Cellular, and Evolutionary Biology 272: 415-423.

75. Ospina CA, Rodríguez AD (2006) Bioactive compounds from the gorgonian Briareum polyanthes. Correction of the structures of four asbestinane-type diterpenes. Journal of Natural Products 69: 1721-1727.

76. Dube D, Kim K, Alker AP, Harvell CD (2002) Size structure and geographic variation in chemical resistance of sea fan corals Gorgonia ventalina to a fungal pathogen. Marine Ecology-Progress Series 231: 139-150. 
77. Alker AP, Smith GW, Kim K (2001) Characterization of Aspergillus sydowii (Thom et Church), a fungal pathogen of Caribbean sea fan corals. Hydrobiologia 460: 105-111.

78. Kim K, Harvell C, Kim P, Smith G, Merkel S (2000) Fungal disease resistance of Caribbean sea fan corals (Gorgonia spp.). Marine Biology 136: 259-267.

79. Gochfeld DJ, Aeby GS (2008) Antibacterial chemical defenses in Hawaiian corals provide possible protection from disease. Marine Ecology-Progress Series 362: 119-128.

80. Mullen Kerri M PEC, Harvelle C Drew. (2004) Coral Resistance to Disease.

81. Olano CT, Bigger CH (2000) Phagocytic activities of the gorgonian coral Swiftia exserta. Journal of Invertebrate Pathology 76: 176-184.

82. Meszaros A, Bigger C (1999) Qualitative and quantitative study of wound healing processes in the coelenterate, Plexaurella fusifera: spatial, temporal, and environmental (light attenuation) influences. Journal of Invertebrate Pathology 73: $321-331$.

83. Work TM, Aeby GS (2010) Wound repair in Montipora capitata. Journal of Invertebrate Pathology 105: 116-119.

84. Johnson KN, van Hulten MCW, Barnes AC (2008) "Vaccination" of shrimp against viral pathogens: phenomenology and underlying mechanisms. Vaccine 26: 48854892.

85. Kurtz J (2004) Memory in the innate and adaptive immune systems. Microbes and Infection 6: 1410-1417.

86. Kurtz J, Franz K (2003) Evidence for memory in invertebrate immunity. Nature 425: 37-38.

87. Little TJ, O'Connor B, Colegrave N, Watt K, Read AF (2003) Maternal transfer of strain-specific immunity in an invertebrate. Current Biology 13: 489-492.

88. Roth O, Sadd BM, Schmid-Hempel P, Kurtz J (2009) Strain-specific priming of resistance in the red flour beetle, Tribolium castaneum. Proceedings of the Royal Society B-Biological Sciences 276: 145-151.

89. Sadd BM, Schmid-Hempel P (2006) Insect immunity shows specificity in protection upon secondary pathogen exposure. Current Biology 16: 1206-1210. 
90. Israely T, Banin E, Rosenberg E (2001) Growth, differentiation and death of Vibrio shiloi in coral tissue as a function of seawater temperature. Aquatic Microbial Ecology 24: 1-8.

91. Sutherland KP, Porter JW, Turner JW, Thomas BJ, Looney EE, et al. (2010) Human sewage identified as likely source of white pox disease of the threatened Caribbean elkhorn coral, Acropora palmata. Environmental Microbiology 12: 1122-1131. 


\section{Chapter 2: Transcriptional activation of $c 3$ and $h s p 70$ as part of the immune response of Acropora millepora to bacterial challenges.}

\subsection{Abstract}

The impact of disease outbreaks on coral physiology represents an increasing concern for the fitness and resilience of reef ecosystems. Predicting the tolerance of corals to disease relies on an understanding of the coral immune response to pathogenic interactions. This study explored the transcriptional response of two putative immune genes (c3 and c-type lectin) and one stress response gene (hsp 70 ) in the reef building coral, Acropora millepora challenged for 48 hours with bacterial strains, Vibrio coralliilyticus and Alteromonas sp. at concentrations of $10^{6}$ cells $\mathrm{ml}^{-1}$. Coral fragments challenged with $V$. coralliilyticus appeared healthy while fragments challenged with Alteromonas sp. showed signs of tissue lesions after $48 \mathrm{hr}$. Coral-associated bacterial community profiles assessed using denaturing gradient gel electrophoresis changed after challenge by both bacterial strains with the Alteromonas sp. treatment demonstrating the greatest community shift. Transcriptional profiles of $c 3$ and $h s p 70$ increased at 24 hours and correlated with disease signs in the Alteromonas sp. treatment. The expression of $h s p 70$ also showed a significant increase in $V$. coralliilyticus inoculated corals at $24 \mathrm{~h}$ suggesting that even in the absence of disease signs, the microbial inoculum activated a stress response in the coral. $C$-type lectin did not show a response to any of the bacterial treatments. Increase in gene expression of $c 3$ and $h s p 70$ in corals showing signs of disease indicates their potential involvement in immune and stress response to microbial challenges. 


\subsection{Introduction}

Coral reefs worldwide are in decline due to natural and anthropogenic stressors both at the local and global scales [1-4]. An emerging factor contributing to their decline is the outbreak of destructive diseases caused by bacteria, viruses, protozoa, or fungi that are observable in the field as lesions or bands of tissue loss [2,5-7]. However, the causes of many coral diseases still remains unknown $[2,8,9]$ due to a number of factors including inconsistent disease descriptions [10], complex host/agent interactions, challenging experimental systems, and the potential that many pathogens may not be cultured in the laboratory [2,11]. Microorganisms may be normal components of the reef ecosystem, though altered environmental conditions may shift benign organisms to pathogenic roles via the expression of virulence factors [8]. The best studied example is the Vibrio shiloi infection of the Mediterranean coral Oculina patagonica where bacterial virulence is enhanced by increased seawater temperatures, resulting in coral bleaching $[9,12,13]$. Increases in seawater temperatures might also compromise the immune system in corals and therefore affect their ability to fight infections, particularly those corals that have undergone bleaching due to thermal stress [14-16]. It remains unknown whether environmental stress (e.g. increased water temperatures or eutrophication) taxes the coral host metabolically, thus increasing its disease susceptibility. A better understanding of the actual mechanisms employed by corals to fight and resist disease-causing agents and how host defense mechanisms are compromised by environmental factors is required to tease apart these complex interactions.

Though the current understanding of cnidarian and coral immunity is rudimentary [17], a number of studies have provided insight into how cnidarians protect themselves from 
infection $[18,19]$. The combination of cellular and humoral factors utilized to respond to microbial challenges has been shown to vary from one organism to another. For corals, it has been documented that mucociliary activity [20,21], skeletal biomineralization [22], antimicrobial activity [23-25], and melanization and phenoloxidase activity [16,26] appear to play important roles in the defense against microbial infectious agents.

Furthermore some cnidarian genes homologous to innate immune genes from higher metazoans have been identified [27-33]. However, the functional involvement of these putative immune genes in cnidarian immunity has not yet been experimentally verified [17]. To avoid falling into the "homology trap" where gene homology is based on the wrong notion of concordance [17,34], it is now imperative to start characterizing and confirming the functional role of putative immune homolog genes identified in the context of coral immune response. Of particular interest in this study are two putative coral immune genes: $c 3$ and mannose-binding c-type lectin, which have been shown to be involved in the immune repertoire of other biological model systems. Additionally a heat stress response gene, $h s p 70$, was assessed due to the general importance of stress core genes in the response of organisms to a large number of biological and abiotic stressors [35].

The complement system is an important element of the complement cascade that has been well documented in higher metazoans and is involved in opsonization of pathogens, chemotaxis and activation of leukocytes, and direct killing of pathogens [36-38]. In some invertebrates such as in the horseshoe crab, Carcinoscorpius rotundicausaa, an opsonization role has been described for a homolog of complement C3-like protein [39]. In cnidarians, several $c 3$ homolog genes have been identified from transcriptome 
sequencing projects including the octocoral Swiftia [29], the scleractinian Acropora millepora [27], the sea anemones Nematostella vectensis [40], and Aiptasia pallida [32]. Despite this, the function and involvement of C3-like proteins in cnidarian immunity, remains untested.

Another important component of the immune repertoire in both vertebrate and invertebrate organisms are carbohydrate-based recognition receptors such as C-type lectins [36,41]. C-type lectins bind to glycans and thus play a role in biological processes such as cell-cell adhesion, pathogen recognition, bacterial cell wall recognition, and phagocytosis [36,41]. Identified lectin homologs in cnidarians contain extensive sequence variation, which may indicate the potential to bind bacterial pathogens [33]. For example, in the anemone Nematostella vectensis, 92 putative $c$-type lectin genes have been described [33]. However, the connection of many of these c-type lectin proteins with respect to the immune functional response of corals to microbial agents has not been established.

Heat shock protein expression increases after exposure to abiotic stressors including heat or cold challenges and biotic challenges during infection and disease development $[42,43]$. The involvement of these proteins in the immune system has also been widely reported in higher metazoans showing a connection to the activation of the innate complement system [44]. For instance, human HSP70 activates the Toll/IL-1 receptor signaling pathway during a highly inflammatory response [42,43]. Moreover, accumulation of Hsp70 following sub-lethal thermal treatments in the invertebrate Artemia franciscana appears to provide protection against subsequent pathogen challenges $[43,45]$. The involvement of coral $h s p 70$ has been clearly shown in the 
response to thermal challenges $[31,46,47]$; however its implication in coral immunity is still unknown.

This study investigated the transcriptional changes of the three genes of interest $c 3$, mannose-binding c-type lectin, and hsp70 from the widely distributed Indo-Pacific coral Acropora millepora. Challenges were conducted using the identified coral bacterial pathogen, Vibrio coralliilyticus and a potential pathogen, Alteromonas sp. The actual functional involvement of these putative immune genes in corals during the defense response to infectious agents has not been experimentally verified and it is imperative to characterize and confirm these functional roles in the context of coral immune response [17].

\subsection{Material and Methods}

\subsubsection{Coral collection and acclimation}

Two adult $A$. millepora coral colonies were collected from reefs around Orpheus Island $\left(18^{\circ} 37^{\prime} 06^{\prime \prime} \mathrm{S} 146^{\circ} 29^{\prime} 37^{\prime \prime} \mathrm{E}\right)$ in the inner central section of the Great Barrier Reef. Coral nubbins $4-5 \mathrm{~cm}$ in length were fragmented from the adult coral colonies and acclimatized for five weeks in outdoor 5000-L aquaria under natural light conditions at the Australian Institute of Marine Sciences (Townsville, Australia). Coral nubbins were then placed in experimental aquarium tanks and allowed to recover from the mechanical manipulation for eight days prior to experimental treatments. 


\subsubsection{Bacterial strains and culture preparation}

Two bacterial strains were used in this study: V. coralliilyticus strain LMG 23696, previously identified as a coral pathogen isolated from Nelly Bay Magnetic Island, Australia [48], and an Alteromonas species isolated from A. millepora corals also sampled from Magnetic Island. $V$. coralliilyticus has been implicated as one of the causes of white syndrome disease in Acropora corals [11,48] while Alteromonas spp. have been correlated with disease and also a normal resident of the mucus layer [49-53] and skeleton $[53,54]$. The $16 \mathrm{~S}$ rRNA gene sequences for each strain are deposited in the GenBank database under the following accession numbers, EU372917 and GU903232 respectively.

Bacterial strains were recovered from glycerol stocks and inoculated into the general heterotrophic bacterial medium, Marine Broth-2216 (Difco, USA) and grown to end logarithmic phase at $27^{\circ} \mathrm{C}$ with shaking (150rpm). Cultures were centrifuged at 5,000g for 10 minutes, washed and resuspended in phosphate buffered saline (PBS). This process was repeated three times to remove residual culture media. The cells were prepared to a

final concentration of $1 \times 10^{9}$ cells $\mathrm{ml}^{-1}$ in PBS. Bacterial cell density was determined by counting colony-forming units (CFU; described by Sussman et al [48]) and by constructing a cell density calibration curve of absorbance (595nm) vs. CFU.

\subsubsection{Experimental design of bacterial challenge experiments}

Three acclimated coral nubbins were placed in each of nine replicated 5-L aquarium tanks. Coral nubbins from colony 1 were placed in three tanks and challenged with $V$. coralliilyticus. Nubbins from colony 2 were placed in three other tanks and challenged 
with Alteromonas sp. Finally three tanks were allocated for control corals, each containing 6 nubbins (three from each colony). Two separate experiments were conducted under this experimental design, with the treatment group compared to the control nubbins originating from the same colony. Each 5-L aquarium was inoculated with the relevant bacterial strain to a final cell concentration of $1 \times 10^{6} \mathrm{cell} \mathrm{ml}^{-1}$ in each tank. Bacteria were not added to control tanks, though a similar volume of PBS was added since it was used to wash the bacteria before inoculation in the treatments. The aquaria were operated as a closed system: seawater was not replaced for the duration of the 48-hour experiment to avoid potential cross-contamination and release of bacteria. However, aeration was maintained in the tanks to provide water movement. Temperature loggers were deployed in the tanks to assess the temperature fluctuation during the entire course of the 48-hour experiment. Visual observations of the coral nubbins were conducted every hour for the first 12 hours and then every six hours until the end of the experiment.

Nubbins were collected 6 and 24 hours after the bacterial inoculation. Nubbins could not be collected at 48 hours after bacterial inoculation since the Alteromonas sp. inoculated nubbins had very little viable tissue associated with them. At each sampling time, one coral nubbin from each replicate tank was collected and immediately snap frozen in liquid nitrogen, and stored at $-80^{\circ} \mathrm{C}$ until sample processing.

A second bacterial challenge experiment was repeated which corroborated the visual results of the effect of bacterial inoculation on coral nubbins. All nubbins from this repeat experiment were fragmented from a single colony and not acclimatized to the light conditions in the outdoor aquarium facility prior to the experiment. All other aspects of 
the experiment were identical to the first though samples were not collected for subsequent molecular analysis.

\subsubsection{PSII quantum yields $\left(\mathbf{F}_{\mathrm{v}} / \mathbf{F}_{\mathrm{m}}\right)$ of coral samples}

The photosynthetic efficiency (PSII quatum yield) of the associated symbiotic dinoflagellates (Symbiodinium) from all coral nubbins (treatments and control) were assessed using a Maxi imaging-pulse-amplitude-modulation (iPAM) fluorometer (Walz, Germany) 48 hours after bacterial inoculation. Coral nubbins were placed in darkness for $20 \mathrm{~min}$ and then exposed to a saturation light pulse (Gain $=1-2$, Intensity $=1-2$, Saturation Pulse =7) using the iPAM. The dark adapted PS II quantum yields were calculated by using the formula: $F_{v} / F_{m}=\left(F_{m}-F_{0}\right) / F_{m}$, where $F_{m}=$ maximal fluorescent yield, and $\mathrm{F}_{0}=$ Dark fluorescent yield .

\subsubsection{RNA isolation, cDNA preparation, and gene expression assays by quantitative PCR}

Frozen coral nubbins were pulverized into powder using a French press under ultrafreezing conditions $\left(\sim-120^{\circ} \mathrm{C}\right)$. Total RNA was extracted from approximately $200 \mu \mathrm{g}$ of frozen pulverized coral tissue samples using the RNeasy Plant Mini Kit (Qiagen, Valencia, CA) according to the manufacturer's protocol. Concentrations of total RNA were determined using the NanoDrop ND 1000 UV-Vis Spectrophotometer (NanoDrop Technologies Inc, Wilmington DE). Integrity of the samples was checked on MOPS denaturing RNA gels (Embi Tec, San Diego, CA). Total RNA (250ng) was reverse transcribed to cDNA using the QuantiTect reverse transcription kit (Qiagen, Valencia, CA) according to the manufacturer's protocol. 
Quantitative real time PCR (qPCR) was performed on the three genes of interest, $c 3, c$ type Lectin, and $h s p 70$ using a Rotor Gene Q1 cycler (Qiagen, Valencia, CA). Several other putative coral immune genes such as TLR4-like, TLR-23-like, and several isoforms of C-type lectins were also initially explored but no adequate PCR oligonucleotide were developed. One microliter from each of the reverse transcription reactions was used along with the Rotor Gene SYBR Green PCR master mix (Qiagen, Valencia, CA) to carry out the qPCR according to the manufacturer's protocol. The primers used to amplify each gene are shown in Table 2-1. Primer concentrations were optimized for each of the primer pairs, resulting in the use of $1 \mu \mathrm{M}$ for $c 3$ and $h s p 70$, and $0.5 \mu \mathrm{M}$ for $c$-type lectin. Additionally, two internal control genes (ICGs), actin [55,56,57] and ribosomal protein 12 (rpl12) [56,58], were run simultaneously for normalization of data using a concentration of $1 \mu \mathrm{M}$ for both the forward and reverse primers. Reactions for each gene of interest and ICGs were performed in triplicate. The comparative delta Ct method was used to correct for PCR efficiency and determine relative quantities of the transcript.

\subsubsection{RNA profiling of coral associated bacterial communities using denaturing gradient gel electrophoresis}

Total RNA was extracted from coral nubbins collected at 24-hours post bacterial challenge using methods described previously. RNA samples (100ng) were reverse transcribed using the QuantiTect reverse transcription kit (Qiagen) with $1 \mu \mathrm{M}$ of the modified bacterial specific primer 907R (CCTACGGGDGGCWGCAG) [59]. After

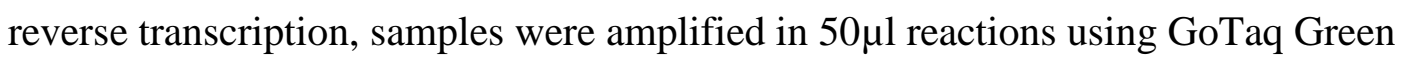
Master Mix (Promega, Madison, Wisconsin, USA) with $2.5 \mathrm{mM} \mathrm{MgCl}_{2}, 0.25 \mu \mathrm{M}$ 907R, and $0.75 \mu \mathrm{M} 341 \mathrm{~F}-\underline{\text { Clamp }}$ 
WGCAG) [59]. The PCR program was as follows: 5 minute initial denaturation at $95^{\circ} \mathrm{C}$, followed by 35 cycles of $95^{\circ} \mathrm{C}$ for 30 seconds, $51^{\circ} \mathrm{C}$ for 60 seconds, and $72^{\circ} \mathrm{C}$ for 60 seconds, and a final extension for 7 minutes. The PCR products were run on DGGE using a 6\% acrylimide denaturing gradient gel (30-65\% gradient) for 14 hours at 97 volts at a constant temperature of $60^{\circ} \mathrm{C}$.

Bands of interest were excised from the gel and incubated at room temperature for 24 hours in $30 \mu 1$ nuclease-free water followed by recovery of the DNA by ethanol precipitation. Samples were resuspended in $30 \mu 1$ nuclease-free water and $1 \mu 1$ of the sample was used in a $25 \mu \mathrm{L}$ PCR reaction using GoTaq Green Master Mix (Promega, Madison, Wisconsin, USA), $0.25 \mu \mathrm{M}$ of both $341 \mathrm{~F}$ and $907 \mathrm{R}$ that did not contain a GC clamp. The PCR cycle was as follows: 5 minute initial denaturation at $95^{\circ} \mathrm{C}$, followed by 35 cycles of $95^{\circ} \mathrm{C}$ for 30 seconds, $51^{\circ} \mathrm{C}$ for 60 seconds, and $72^{\circ} \mathrm{C}$ for 60 seconds, and a 7 minute final extension. PCR products were directly sequenced by the DNA Analysis Facility at Yale University (New Haven, Connecticut, USA) using the 907R primer. Recovered sequence identity was assessed using a BLAST comparison in GenBank and a check for chimeras was carried out using Greengenes Bellepheron database [60].

\subsubsection{Statistical analysis}

Data that were not homoscedastic were transformed prior to downstream analysis. Statistical analyses of the gene expression data were performed on each of the genes of interest using the relative copy numbers normalized to the geometric mean of the two internal control genes following the approach by Vandesompele et al [61] and Rodriguez- 
Lanetty et al. [56]. Significant differences in gene expression among treatments (bacterial treatments vs. control) and across time (6 and 24h) were tested with a two-way ANOVA (SAS, Cary, NC). Comparisons were only executed within bacterial treatments (i.e. within the Alteromonas treatment and separately within the $V$. coralliilyticus treatment) since separate colonies were used in each treatment.

DGGE gel images were digitized using Gel2K [62] in order to create a presence/absence matrix. This data was analyzed with a correspondence analysis and was performed using the Vegan package for the R environment $[63,64]$.

\subsection{Results}

\subsubsection{Response of Acropora millepora corals to bacterial challenge}

No bleaching or visible lesions were observed on A. millepora nubbins challenged with V. coralliilyticus $\left(1 \times 10^{6}\right.$ bacteria $\mathrm{ml}^{-1}$; Figure $\left.2-1 \mathrm{~A}\right)$ or the control treatments throughout a 48-hour bacterial challenge experiment. In contrast, coral nubbins challenged with Alteromonas sp. $\left(1 \times 10^{6}\right.$ bacteria $\left.\mathrm{ml}^{-1}\right)$, displayed signs of bleaching and lesions in the coenosarc tissue (tissue between polyps) after 24 hours. By 48 hours, most of the coenosarc and polyp tissue was degraded in all replicate coral nubbins in this treatment (Figure 2-1B). A repeated experiment resulted in the same results with all coral nubbins challenged with the Alteromonas sp. showing tissue necrosis (Figure 2-1C), while $V$. coralliilyticus challenged and control nubbins displayed no signs of lesions (Figure 2-2). However, coral nubbins challenged with lower concentrations of Alteromonas sp. (1 x

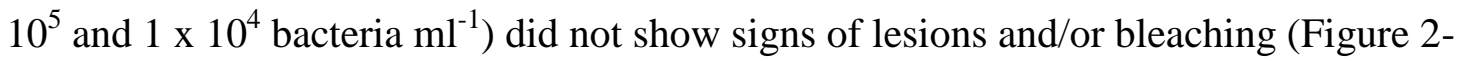
1D-E). 
Photosynthetic efficiency (PSII quantum yield; $F_{\sqrt{ }} / F_{m}$ ) of symbiotic dinoflagellates (Symbiodinium) was significantly reduced (one-way ANOVA, p<0.01; Figure 2-3) following challenge by Alteromonas sp., confirming a bacterial effect on the photophysiology of the symbiotic dinoflagellates associated with the coral nubbins. In contrast, nubbins challenged with $V$. coralliilyticus did not show a significant difference in photosynthetic efficiency, indicating that Symbiodinium in these coral nubbins were not compromised.

No changes of $c 3$ gene expression was detected (two-way ANOVA, $\mathrm{p}=0.146$; Figure 24A) for coral nubbins challenged with $V$. coralliilyticus. However, an increase of $h s p 70$ gene expression was detected at $24 \mathrm{~h}$ in the challenged corals compared to the controls (ANOVA $\mathrm{p}=0.0149$; Figure 2-4C). The gene expression of the $c$-type lectin in the $V$. coralliilyticus experiment did not show a response to the bacterial challenge (2 way ANOVA $p=0.9449$ ) but did decrease significantly between 6 and 24 hours for the controls (ANOVA, $\mathrm{p}=0.0068$; Figure 2-4E). For coral nubbins challenged with Alteromonas sp., which showed signs of tissue lesion and disease, a significant increase of gene expression of $c 3$ was detected from 6 hours to 24 hours (two-way ANOVA, $\mathrm{p}=0.002$, Tukey, $\mathrm{p}<0.0001$; Figure 2-4B). In addition, the increased $c 3$ gene expression at 24 hours in this Alteromonas sp. bacterial challenge was significantly higher than controls (Tukey, $\mathrm{p}<0.0001$; Figure 2-3B) at the same time point. Similar to the $c 3$ gene expression, the transcriptional profile of $h s p 70$ in Alteromonas sp. challenged nubbins was significantly higher at 24 hours than controls (ANOVA, $p=0.0159$; Figure 2-4D). Additionally, no significant changes were observed in the gene expression profile of control coral nubbins at 6 and 24 hours for $h s p 70$ (ANOVA, $\mathrm{p}=0.3744$ ). The 
transcriptional response of the c-type lectin was not affected by the bacterial challenge ( 2 way ANOVA $\mathrm{p}=0.1532$ ) when compared to the controls but did show a nonsignificant decreasing trend in expression from 6 to 24 hours (Figure 2-4F).

\subsubsection{Coral associated bacterial shifts during challenge experiments}

Profiling of bacterial communities associated with coral nubbins using denaturing gradient gel electrophoresis (DGGE) combined with multivariate correspondence analysis of a presence/absence matrix for all observed bands, documented shifts in the bacterial community for Alteromonas sp. challenged corals (Figure 2-5; Figure 2-6). The bacterial assemblages associated with the Alteromonas treatment clustered separately from all controls, differentiated mainly by the CA1 axis of the correspondence analysis, which explained $26.9 \%$ of the variation (Figure 2-5). V. coralliilyticus treatments also clustered separately from its control by the CA2 axis which accounted for $20.8 \%$ of the variation. Interestingly, the bacterial community profile associated with the $V$. coralliilyticus treated nubbins was similar to the community profiles of control nubbins for the Alteromonas sp. treatment (Figure 2-5). All bands that were able to be excised and sequenced from the DGGE are deposited in Genbank (accession numbers KC313998 KC314010). The retrieved sequences from both treatments were affiliated within the Gammaproteobacteria and profiles were consistent across all the samples, indicative of a stable microbial community. Sequences affiliated to the genus Endozoicomonas (BLAST identity: $96 \%$ sequence identity over $527 \mathrm{bp}$ ) were identified as one of the dominant members of both microbial communities. None of the dominant bands in the DGGE represented any species of Vibrio or Alteromonas sp, corroborating the lack of infection by $V$. coralliilyticus in the experiment. An unclassified sequence to the level of genus but 
also related to the order of Oceanospirillales (accession number: AB680857) was

retrieved from only corals challenged with $V$. coralliilyticus.

\subsection{Discussion}

This study compared the visual tissue disease development and the transcriptional response of several putative immune genes from A. millepora to challenge from two bacterial strains $V$. coralliilyticus, and an Alteromonas sp in two separate experiments. Transcriptional increases of $c 3$ and $h s p 70$ in the Alteromonas sp. challenged corals suggest the involvement of these genes in the immunological/defense response of the coral, A. millepora to microbial challenge. Corals challenged with $V$. coralliilyticus did not show visible signs of disease, however, an increase in $h s p 70$ suggests bacterial inoculation activates a coral host stress response and implicates heat shock proteins as a critical component in the early responses of corals to potential infectious agents. The response likely occurs prior to a strong host immune reaction and before visible signs of disease is apparent.

C3 - like protein has previously been postulated to play a role in the innate immune system in cnidarians $[27,29]$. However, this hypothesis has remained untested due to a lack of functional data. Findings from this study support the previous hypothesis since the expression of $c 3$ in A. millepora increased in response to Alteromonas sp. bacterial challenge. The increase in expression coincided with visual signs of disease in the coral nubbins at 24. To our knowledge, this is the first study to show transcriptional activation of a cnidarian $\mathrm{C} 3$-like protein gene in response to a live microbial challenge. A previous study in which lipopolysaccharide (LPS) was injected into A. millepora failed to show a 
significant response of $c 3$ to the treatment [65]. However, their experimental outcome could have been due to LPS only being one component involved in bacterial mediated virulence. This is corroborated in a study in Drosophila which showed that peptidoglycan - free LPS caused a seven-fold weaker response than a living Gram - negative bacterium [66]. This highlights the importance of using a live pathogen when screening for components involved in the immune response. The transcriptional upregulation of $c 3$ in response to microbial challenges reported here, coupled with previous molecular characterization showing similarity in functionally critical domain structures and amino acid residues of cnidarian C3-like protein homologs to those in higher metazoans $[27,29,40]$ are consistent with a key role of C3-like protein in the immune response of corals. Additionally, it has previously been demonstrated that the transcriptional expression of $c 3$ is localized in the gastrodermal cells [27], the cells lining the gastrovascular cavity that interact with a vast number of microbes [67]. Further studies are now required to determine whether C3-like protein has a role in opsonization and pathogen recognition. Unlike the corals challenged with Alteromonas sp, $V$. coralliilyticus inoculated coral nubbins were visibly healthy after 48 hours, with no changes in $c 3$ expression and photosynthetic yield of Symbiodinium being observed. This suggests that corals were less compromised physiologically by the bacterial challenge with $V$. coralliilyticus and that the inoculation may not have activated a strong immune response.

Another novel finding from our study is the transcriptional upregulation of $h s p 70$ detected in both the Alteromonas sp. and $V$. coralliilyticus treatments. The expression of heat shock proteins in general, including Hsp70, have been shown to increase with heat 
stress in corals [31,68-79]. Our findings suggest that changes in $h s p 70$ transcripts also occur in corals in response to microbial challenges, in the absence of thermal stress. Several studies conducted on the brine shrimp Artemia have already shown that heatinduced accumulation of Hsp70 appears to protect Artemia sp. from pathogenic infection by $V$. campbellii $[43,80]$. Recently, Baruah et al (2011) presented evidence that Hsp70 enhances resistance to pathogens by priming and enhancing the expression of the prophenoloxidase system. Prohaszka and Fust (2004) proposed that extracellular heat shock proteins may represent the ancestral danger signal of cell death or lysis-activating innate immunity [81]. In support of this hypothesis, human HSP70 has been implicated in the antibody-independent activation of the complement immune system, ultimately interacting with C3 [42]. Thus, in the Alteromonas sp. challenged nubbins, the increased expression of $h s p 70$ could be a downstream result of pathogen recognition and subsequent involvement in the immune activation of a $\mathrm{C} 3$ - like protein in corals, though this hypothesis requires further experimental investigation. A different scenario was observed in V.coralliilyticus with a significant increase of $h s p 70$ transcripts, even when there was no visible sign of disease, but lack of expression of $c 3$. In this case an increase of Hsp70 proteins following host/pathogen recognition was potentially sufficient to protect the coral, possibly by activating other constitutive components of the coral effector immune systems, such as the pro-phenoloxidase cascade. These findings highlight the potential importance of heat shock proteins, in particular Hsp70, as a core stressor protein useful in assessing coral health status.

Unlike the clear transcriptional response of $c 3$ and $h s p 70$ to bacterial challenges, the $c$ type lectin gene examined in this study did not show a differential change at the 
transcriptional level to bacterial treatments. C-type lectins are proteins well known to act as pattern recognition receptors enhancing pathogen removal through phagocytosis in invertebrates [41] and/or activation of the complement system cascade following pathogen recognition in higher metazoans [37]. Moreover, c-type lectins found in cnidarian genomes have been shown to have a highly variable substrate-binding region, suggesting that this domain may recognize a large range of pathogens [30]. The lack of a significant transcriptional response of c-type lectin to the bacterial challenges conducted in our study could be attributed to the timing of sampling. It is possible that we could have missed an early up-regulation of this gene within the first six hours after bacterial inoculation. Consistent with this rationale is the fact that Kvennefors et al (2010) documented a significant increase in expression of millectin after only 45 minutes post injection with LPS. After this initial peak, expression of the gene decreased gradually over the following twelve hours [65]. This could also explain the fact that we detected a decreasing trend, though not statistically significant, in the expression of c-type lectin from 6 to 24 hours in the bacterial treatments. Further studies are required to confirm whether or not the c-type lectin explored here plays a role in coral immunity.

A. millepora nubbins exposed to $V$. coralliilyticus did not exhibit detectable signs of lesions throughout the 48-hour experimental period. Pathogen infection trials are highly problematic due to complex host/pathogen interactions, which are very difficult to control in aquarium-based environments. One contributing factor is that $V$. coralliilyticus has not yet been conclusively identified as a pathogen of A. millepora and host specificity is important in coral infections. However, some experimental infections on coral juveniles suggest that $V$. corallilyticus can replicate the development of white syndrome disease in 
A. millepora [82]. V. coralliilyticus virulence has also been demonstrated to be water temperature dependent with virulence being activated at $27-29^{\circ} \mathrm{C}[12,13]$. A study investigating $V$. coralliilyticus infection of Pocillopora damicornis demonstrated no lesions for treatments at $25^{\circ} \mathrm{C}$ [83], temperatures similar to those used in the bacterial challenges of this study. Despite the fact that no disease developed during the $V$. corallilyticus treatment, this study focused on exploring the gene expression response of coral to the bacterial challenge itself. Alteromonas sp. challenged nubbins did show pronounced lesions within 24 hours of treatment. In corals, Alteromonas sp. has been correlated to disease but it is also a normal resident of the mucus layer [49-53] and skeleton $[53,54]$. The bacterium has also been isolated from the water column surrounding coral colonies indicating that there may be a specific interaction of the bacterium with the coral $[49,52]$. The effect of the bacterium infectivity on coral nubbins was density dependent with further challenge experiments showing that an inoculation of $10^{6} \mathrm{CFU} / \mathrm{ml}$ caused disease signs whereas dilutions of $10^{5}$ and $10^{4}$ did not. This effect has been documented in the larvae of the oyster, Crassostrea gigas where a decreased Alteromonas sp. inocula causes a delayed effect in infectivity progression [84].

Correspondence analysis of bacterial profiles generated from DGGE analysis demonstrated that the Alteromonas sp. challenged corals caused a major shift in the coral associated bacterial community away from a stable community observed in control nubbins. This shift was likely the result of necrosing tissue allowing colonization of many other opportunistic bacteria, potentially enhancing a stronger immune response by the coral. Previous studies have shown similar shifts in the microbial communities during disease and bleaching events [85]. The V. coralliilyticus challenged corals also 
demonstrated a shift in the bacterial community from its experimental control, though the resultant community profile was similar to the control group of the Alteromonas sp. treatment. This result further supports the notion that the bacterial community shift was unlikely to have a detrimental effect on coral fitness.

\subsection{Conclusions}

Our findings verify, at the transcriptional level, the functional involvement of C3-like protein and $\mathrm{Hsp} 70$ in the immune response of A. millepora to bacterial challenges. Interestingly, this is the first study that reports the involvement of a heat shock protein in the coral immune response. Further studies investigating whether these genes have a similar role in other coral species are required along with the characterization and confirmation of the functional role of these and other putative immune homolog genes identified in the context of coral immune response. The derived information is of fundamental importance as functional immune genes may be used as bioindicators to assess coral health status. 
$\mathbf{A}$

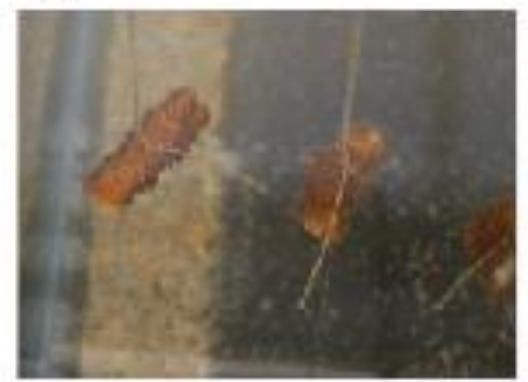

C

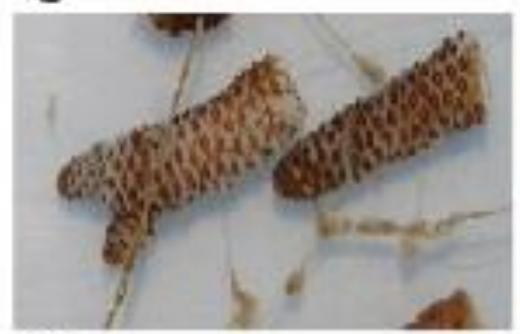

E

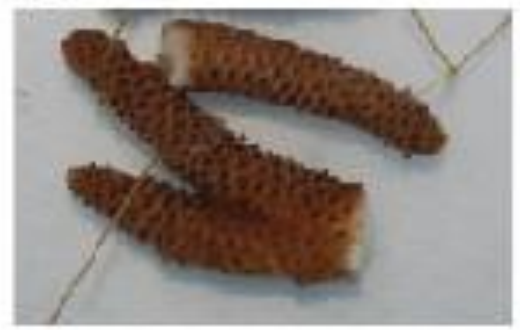

B

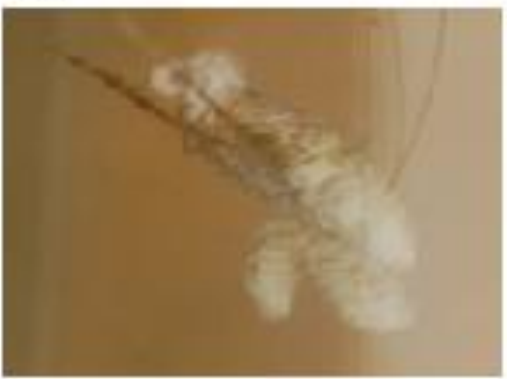

D

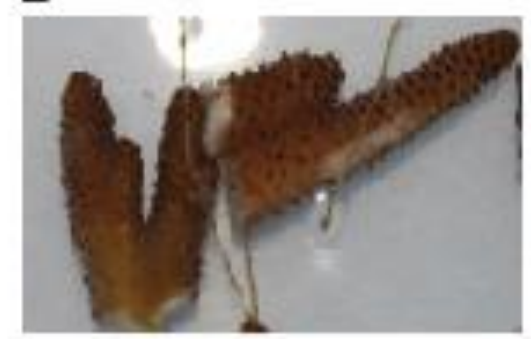

Figure 2-1. Photographs of Acropora millepora coral nubbins from the first experiment at 48 hours after bacterial inoculation. A. corals challenged with V. coralliilyticus; B. corals challenged with Alteromona sp. Photographs of coral nubbins from the second experiment at 48 hours after inoculation with Alteromonas sp. at different concentrations. C: $10^{6} \mathrm{CFU} / \mathrm{ml}$; D: $10^{5} \mathrm{CFU} / \mathrm{ml}$; E: $10^{4} \mathrm{CFU} / \mathrm{ml}$. 

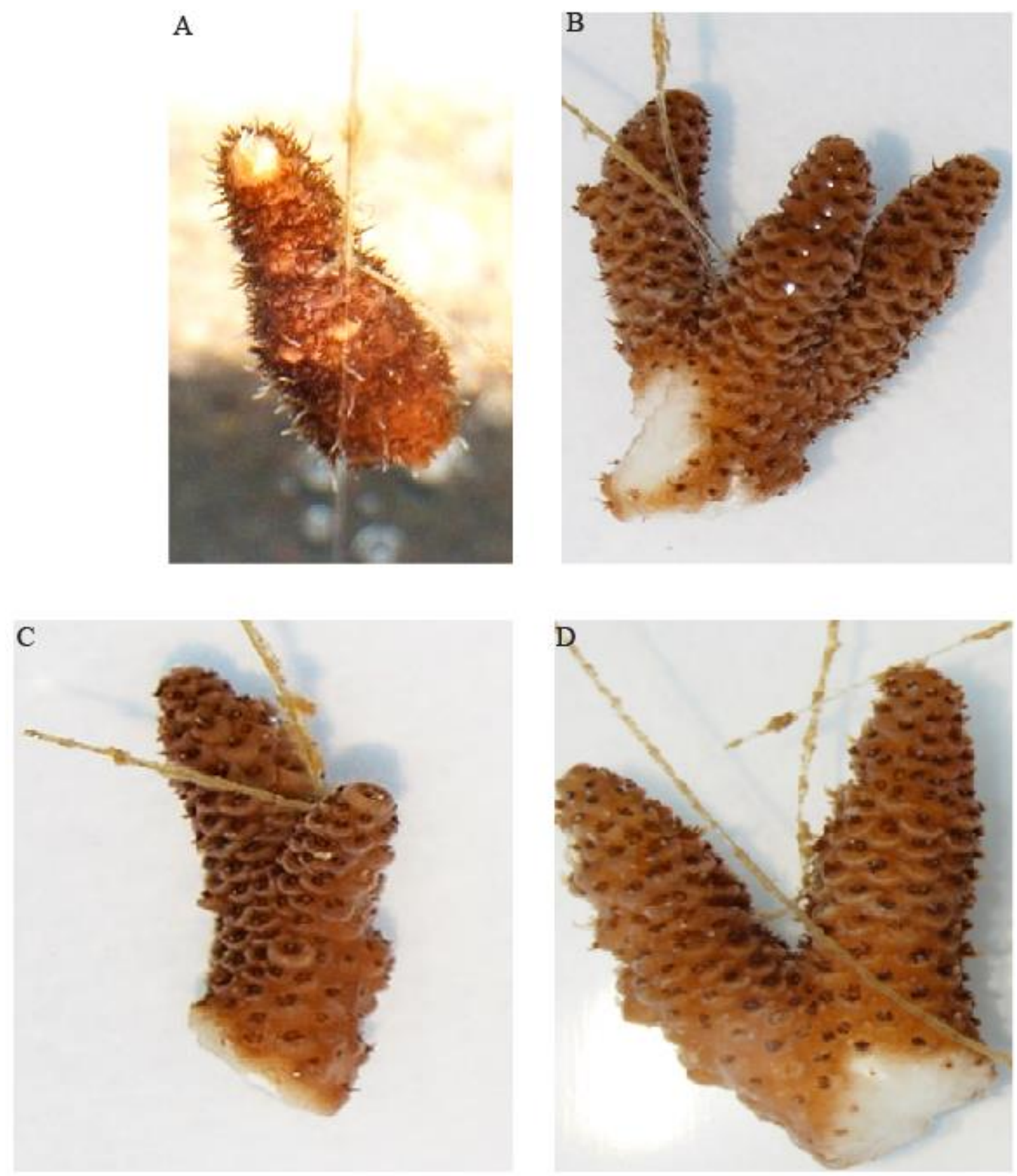

Figure 2-2. A-C: Photographs of V. coralliilyticus inoculated nubbins from the second set of experiments at concentrations: $10^{4} \mathrm{CFU} / \mathrm{ml}(\mathrm{A}), 10^{5} \mathrm{CFU} / \mathrm{ml}(\mathrm{B}), 10^{6} \mathrm{CFU} / \mathrm{ml}(\mathrm{C})$, and control (D), after 48 hours. 


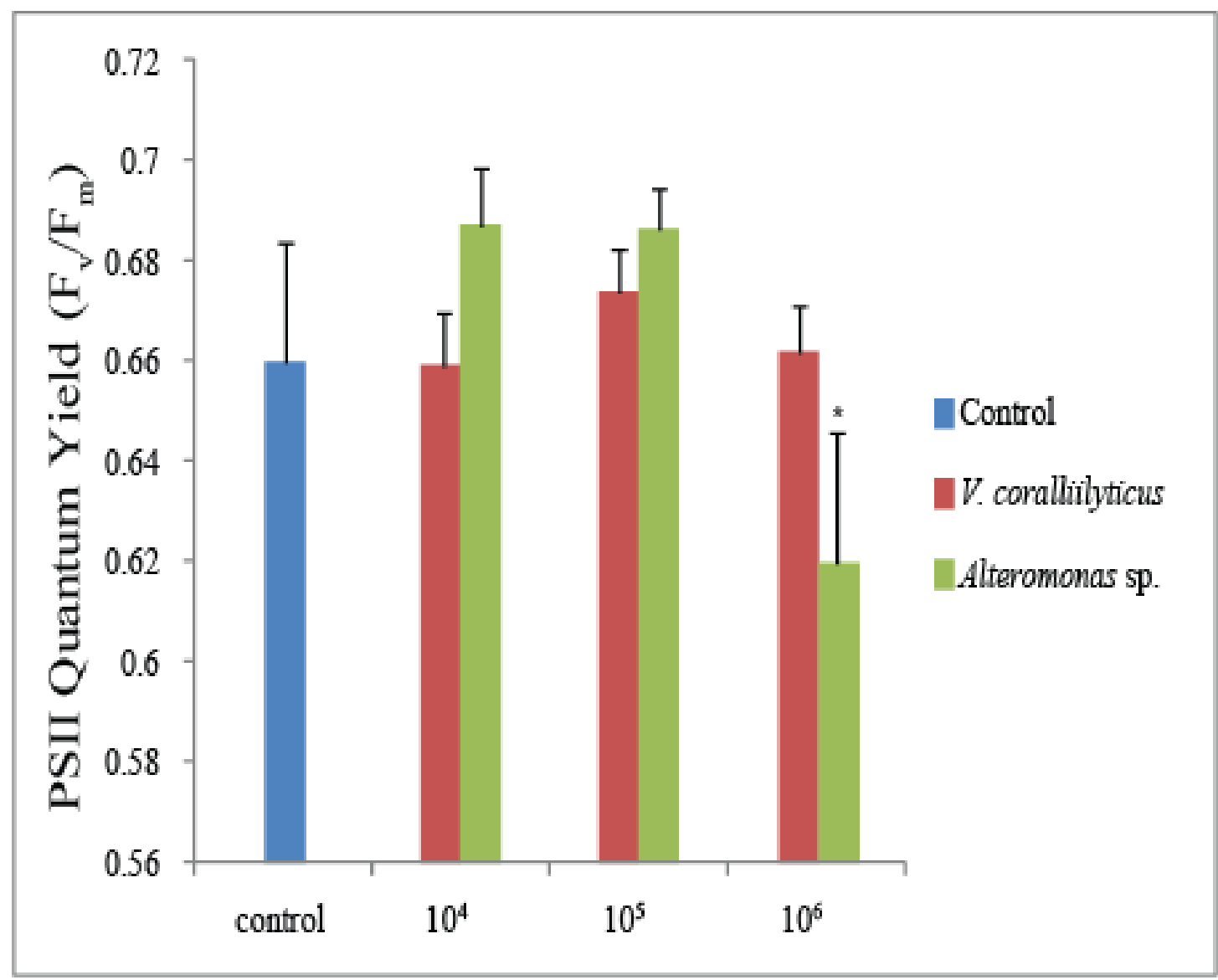

Figure 2-3. Dark adapted PSII quantum yield $\left(\mathrm{F}_{\mathrm{v}} / \mathrm{F}_{\mathrm{m}}\right)$ of Symbiodinium associated with coral nubbins after 48 hours from the bacterial inoculation during the second set of experiments. Error bars indicate standard deviation of the mean. $\left(^{*}\right)$ indicates significance $(\mathrm{p}<0.05)$ between treatment and control. 
Vibrio coralliilyticus
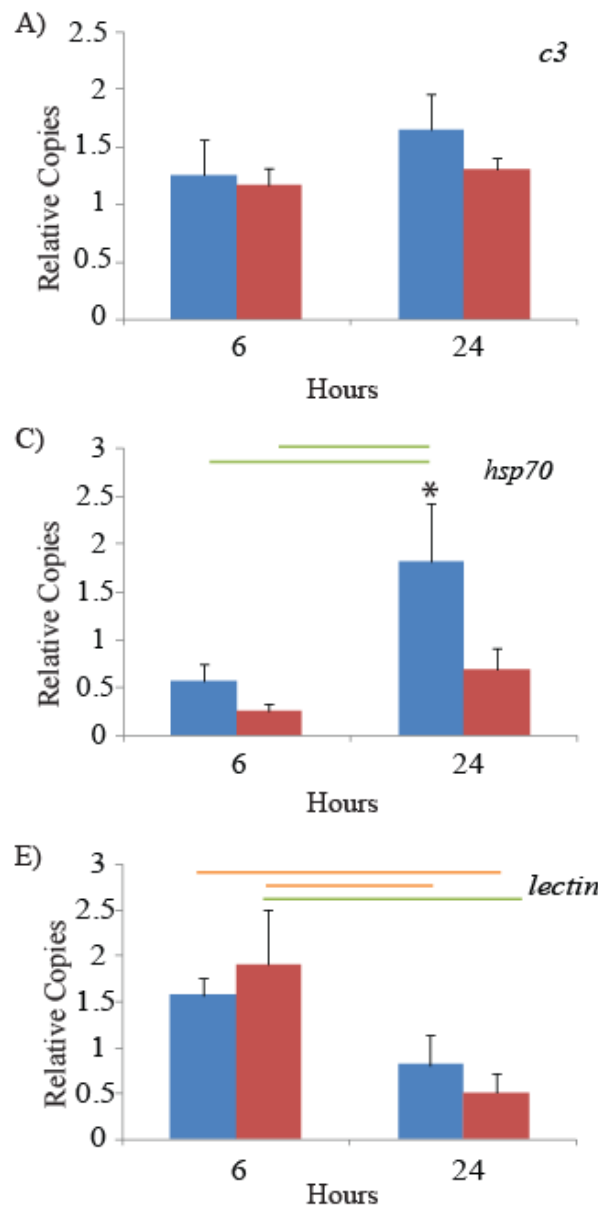

n Challenged

- Control
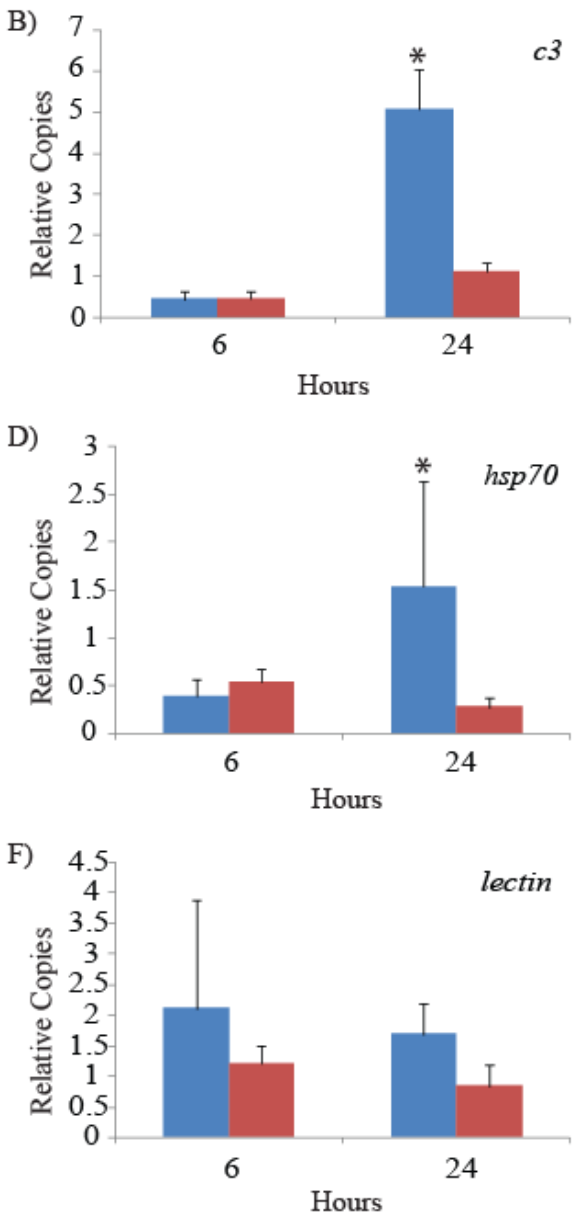

Figure 2-4. Relative transcriptional expression of the three genes of interest from $A$. millepora at 6 and 24 hours after inoculation with either $V$. coralliilyticus or Alteromonas sp. A-B: c3; C-D: hsp70; E-F: c-type lectin. The Q-RT-PCR data for these genes was normalized using internal control genes (ICGs) indicated in Table 1. Error bars indicate standard deviation of the mean. $(*)$ indicates significance between treatment and control at the indicated hour. Green bars indicate significance at $\mathrm{p}<0.01$ and orange bar indicates $\mathrm{p}<0.05$. 


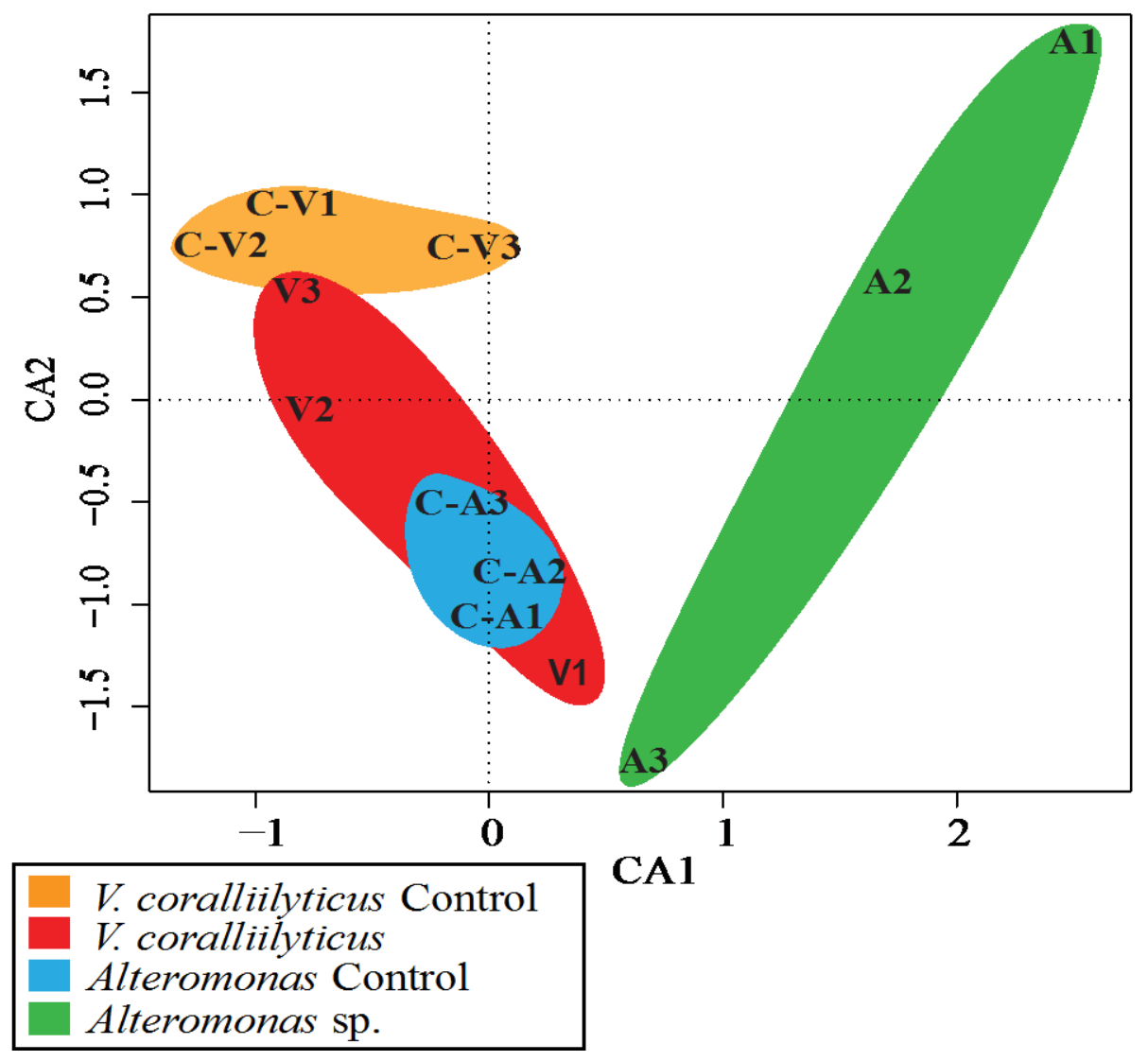

Figure 2-5. Correspondence analysis (CA) of bacterial 16S rDNA DGGE banding patterns. CA1 accounts for $26.9 \%$ of the variation; CA2 accounts for $20.8 \%$ of the variation. $\mathrm{C}-\mathrm{V}$, control - colony 1 (orange), $\mathrm{C}-\mathrm{A}$, control colony 2 (blue); V, Vibrio treatment (red); A, Alteromonas sp. treatment (green). 


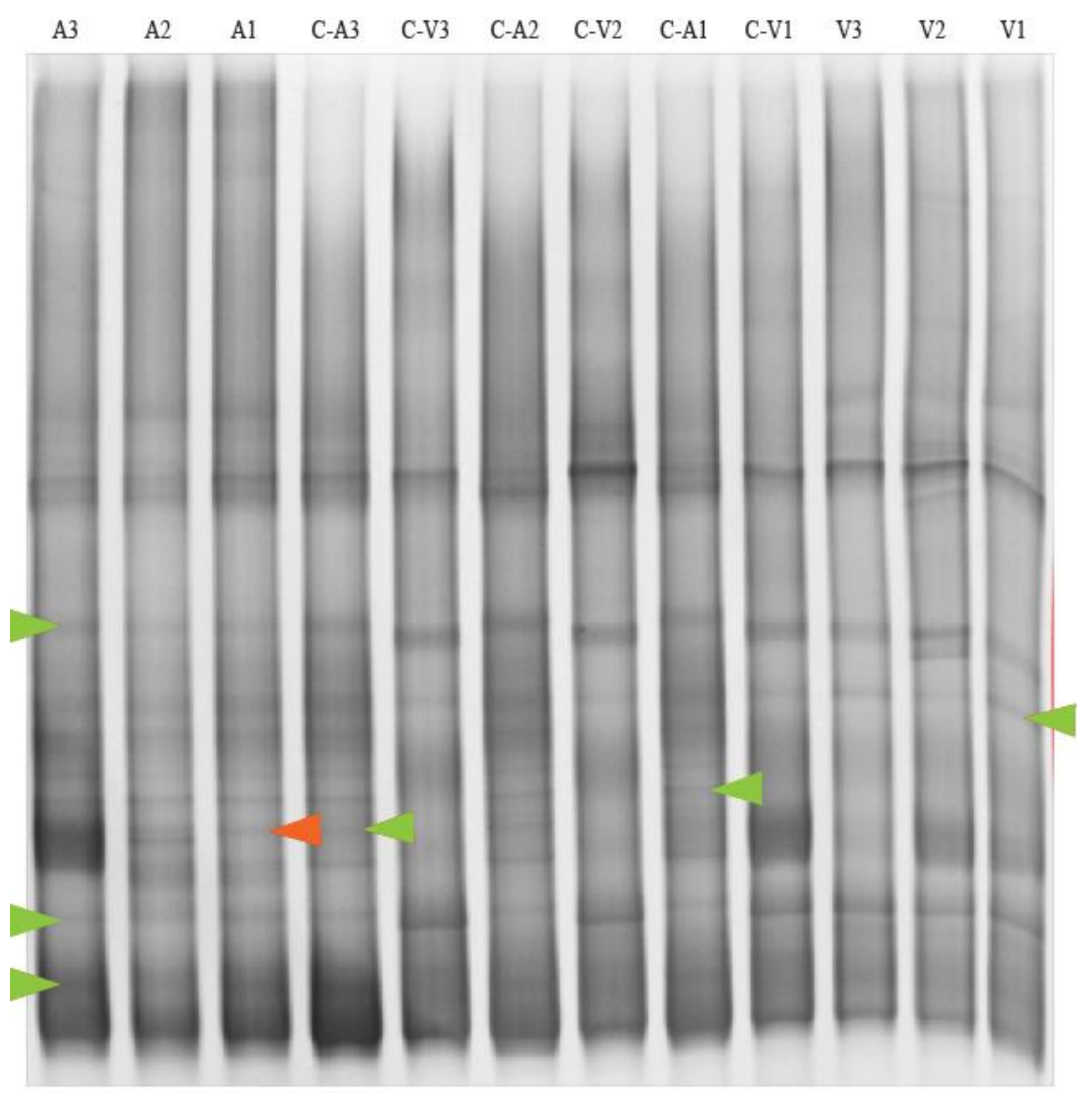

Figure 2-6. DGGE of bacterial communities from Alteromonas sp. (A) innoculated, $V$. coralliilyticus (V) inoculated, and controls (C). Green arrows indicate bands most closely related to Endozoicomonas sp. and orange arrows to Oceanospirillum beijerinckii. 


\begin{tabular}{ccl}
\hline Gene & $\begin{array}{c}\text { PCR } \\
\text { Product }\end{array}$ & \multicolumn{1}{c}{ Primer Sequence (5' to 3') } \\
\hline c3-like & $96 \mathrm{bp}$ & $\begin{array}{l}\text { For: GTGAAGGTGGAACCAGAGGA } \\
\text { Rev: GAACCGGAAGTGATTGTCGT }\end{array}$ \\
& & For: CAGGTCTGGATCGGACTCAT \\
c-type lectin & $230 \mathrm{bp}$ & Rev: CATGTCCAGTGGTTGTACGC \\
& & For: GAGCCCTCAGTAACCAGCAC \\
hsp70 & $128 \mathrm{bp}$ & Rev: CATTGTGGAGCGGAAAAGTT \\
& & For: CAAGGCAACACAAGACTGGA \\
rpl12 & $150 \mathrm{bp}$ & Rev: CTTGCGATCTTGGTGGTT \\
& & For: CTCTTCCCCATGCCATCTTA \\
actin & $113 \mathrm{bp}$ & Rev: TTGATGTCTCGCACGATCTC \\
& &
\end{tabular}

Table 2-1. Forward and reverse primers used to amplify the following genes of interest (GOI), including internal control genes (ICG), in Q-RT-PCR assays. 


\subsection{References}

1. Hughes TP, Baird AH, Bellwood DR, Card M, Connolly SR, et al. (2003) Climate change, human impacts, and the resilience of coral reefs. Science 301: 929-933.

2. Harvell CD, Kim K, Burkholder JM, Colwell RR, Epstein PR, et al. (1999) Review: Marine ecology - emerging marine diseases - climate links and anthropogenic factors. Science 285: 1505-1510.

3. Pandolfi JM, Connolly SR, Marshall DJ, Cohen AL (2011) Projecting coral reef futures under global warming and ocean acidification. Science 333: 418-422.

4. Hoegh-Guldberg O (1999) Climate change, coral bleaching and the future of the world's coral reefs. Marine and Freshwater Research 50: 839-866.

5. Richardson LL (1998) Coral diseases: what is really known? Trends in Ecology \& Evolution 13: 438-443.

6. Mydlarz LD, McGinty ES, Harvell CD (2009) What are the physiological and immunological responses of coral to climate warming and disease? Journal of Experimental Biology 213: 934-945.

7. Antonius A (1982) The 'band' diseases in coral reefs. Proceedings of the International Coral Reef Symposium: 7-14.

8. Harvell D, Aronson R, Baron N, Connell J, Dobson A, et al. (2004) The rising tide of ocean diseases: unsolved problems and research priorities. Frontiers in Ecology and the Environment 2: 375-382.

9. Rosenberg E, Koren O, Reshef L, Efrony R, Zilber-Rosenberg I (2007) The role of microorganisms in coral health, disease and evolution. Nature Reviews Microbiology 5: 355-362.

10. Work TM, Aeby GS (2006) Systematically describing gross lesions in corals. Diseases of Aquatic Organisms 70: 155-160.

11. Bourne DG, Garren M, Work TM, Rosenberg E, Smith GW, et al. (2009) Microbial disease and the coral holobiont. Trends in Microbiology 17: 554-562.

12. Ben-Haim Y, Thompson FL, Thompson CC, Cnockaert MC, Hoste B, et al. (2003) Vibrio coralliilyticus sp nov., a temperature-dependent pathogen of the coral Pocillopora damicornis. International Journal of Systematic and Evolutionary Microbiology 53: 309-315. 
13. Ben-Haim Y, Zicherman-Keren M, Rosenberg E (2003) Temperature-regulated bleaching and lysis of the coral Pocillopora damicornis by the novel pathogen Vibrio coralliilyticus. Applied and Environmental Microbiology 69: 4236-4242.

14. Harvell D, Kim K, Quirolo C, Weir J, Smith G (2001) Coral bleaching and disease: contributors to 1998 mass mortality in Briareum asbestinum (Octocorallia, Gorgonacea). Hydrobiologia 460: 97-104.

15. Mydlarz LD, Couch CS, Weil E, Smith G, Harvell CD (2009) Immune defenses of healthy, bleached and diseased Montastraea faveolata during a natural bleaching event. Diseases of Aquatic Organisms 87: 67-78.

16. Palmer CV, Mydlarz LD, Willis BL (2008) Evidence of an inflammatory-like response in non-normally pigmented tissues of two scleractinian corals. Proceedings of the Royal Society B-Biological Sciences 275: 2687-2693.

17. Rinkevich B (2011) The 'immunology trap' of anthozoans. Visions and Perspectives.

18. Mullen Kerri M PEC, Harvelle C Drew. (2004) Coral Resistance to Disease.

19. Mydlarz LD, Jones LE, Harvell CD (2006) Innate immunity environmental drivers and disease ecology of marine and freshwater invertebrates. Annual Review of Ecology Evolution and Systematics. pp. 251-288.

20. Bigger CH, Jokiel PL, Hildemann WH, Johnston IS (1982) Characterization of alloimmune memory in a sponge. Journal of Immunology 129: 1570-1572.

21. Paul JH, Deflaun MF, Jeffrey WH (1986) Elevated levels of microbial activity in the coral surface microlayer. Marine Ecology-Progress Series 33: 29-40.

22. Le Campion-Alsumard T, Golubic S, Hutchings P (1995) Microbial endoliths in skeletons of live and dead corals - Porites lobata (Moora, French - Polynesia). Marine Ecology-Progress Series 117: 149-157.

23. Geffen Y, Rosenberg E (2005) Stress-induced rapid release of antibacterials by scleractinian corals. Marine Biology 146: 931-935.

24. Kim K, Page CA, Harvell CD (2009) The role of environment and microorganisms in diseases of corals: overview of DAO Special 5 Introduction. Diseases of Aquatic Organisms 87: 1-3.

25. Koh EGL (1997) Do scleractinian corals engage in chemical warfare against microbes? Journal of Chemical Ecology 23: 379-398. 
26. Mydlarz LD, McGinty ES, Harvell CD (2010) What are the physiological and immunological responses of coral to climate warming and disease? Journal of Experimental Biology 213: 934-945.

27. Miller DJ, Hemmrich G, Ball EE, Hayward DC, Khalturin K, et al. (2007) The innate immune repertoire in Cnidaria - ancestral complexity and stochastic gene loss. Genome Biology 8.

28. Bosch TCG, Augustin R, Anton-Erxleben F, Fraune S, Hemmrich G, et al. (2009) Uncovering the evolutionary history of innate immunity: The simple metazoan Hydra uses epithelial cells for host defence. Developmental and Comparative Immunology 33: 559-569.

29. Dishaw LJ, Smith SL, Bigger CH (2005) Characterization of a C3-like cDNA in a coral: phylogenetic implications. Immunogenetics 57: 535-548.

30. Kvennefors ECE, Leggat W, Hoegh-Guldberg O, Degnan BM, Barnes AC (2008) An ancient and variable mannose-binding lectin from the coral Acropora millepora binds both pathogens and symbionts. Developmental and Comparative Immunology 32: 1582-1592.

31. Rodriguez-Lanetty M, Harii S, Hoegh-Guldberg O (2009) Early molecular responses of coral larvae to hyperthermal stress. Molecular Ecology 18: 5101-5114.

32. Sunagawa S, Wilson EC, Thaler M, Smith ML, Caruso C, et al. (2009) Generation and analysis of transcriptomic resources for a model system on the rise: the sea anemone Aiptasia pallida and its dinoflagellate endosymbiont. BMC Genomics 10.

33. Wood-Charlson EM, Weis VM (2009) The diversity of C-type lectins in the genorne of a basal metazoan, Nematostella vectensis. Developmental and Comparative Immunology 33: 881-889.

34. Klein J (1997) Homology between immune responses in vertebrates and invertebrates: does it exist? Scand J Immunology 46: 558-564.

35. Lopez-Maury L, Marguerat S, Bahler J (2008) Tuning gene expression to changing environments: from rapid responses to evolutionary adaptation. Nature Reviews Genetics 9: 583-593.

36. Carroll MC (1998) The role of complement and complement receptors in induction and regulation of immunity. Annual Review of Immunology 16: 545-568.

37. Carroll MC, Prodeus AP (1998) Linkages of innate and adaptive immunity. Current Opinion in Immunology 10: 36-40. 
38. Dempsey PW, Allison MED, Akkaraju S, Goodnow CC, Fearon DT (1996) C3d of complement as a molecular adjuvant: bridging innate and acquired immunity. Science 271: 348-350.

39. Zhu Y, Thangamani S, Ho B, Ding JL (2005) The ancient origin of the complement system. EMBO Journal 24: 382-394.

40. Kimura A, Sakaguchi E, Nonaka M (2009) Multi-component complement system of Cnidaria: $\mathrm{C} 3, \mathrm{Bf}$, and MASP genes expressed in the endodermal tissues of a sea anemone, Nematostella vectensis. Immunobiology 214: 165-178.

41. Fujita T (2002) Evolution of the lectin-complement pathway and its role in innate immunity. Nature Reviews Immunology 2: 346-353.

42. Prohaszka Z, Singh M, Nagy K, Kiss E, Lakos G, et al. (2002) Heat shock protein 70 is a potent activator of the human complement system. Cell Stress \& Chaperones 7: $17-22$.

43. Sung YY, Pineda C, MacRae TH, Sorgeloos P, Bossier P (2008) Exposure of gnotobiotic Artemia franciscana larvae to abiotic stress promotes heat shock protein 70 synthesis and enhances resistance to pathogenic Vibrio campbellii. Cell Stress \& Chaperones 13: 59-66.

44. Srivastava P (2002) Roles of heat-shock proteins in innate and adaptive immunity. Nature Reviews Immunology 2: 185-194.

45. Baruah K, Ranjan J, Sorgeloos P, Bossier P (2010) Efficacy of heterologous and homologous heat shock protein 70s as protective agents to Artemia franciscana challenged with Vibrio campbellii. Fish \& Shellfish Immunology 29: 733-739.

46. Gates RD, Edmunds PJ (1999) The physiological mechanisms of acclimatization in tropical reef corals. American Zoologist 39: 30-43.

47. Brown BE, Downs CA, Dunne RP, Gibb SW (2002) Exploring the basis of thermotolerance in the reef coral Goniastrea aspera. Marine Ecology-Progress Series 242: 119-129.

48. Sussman M, Mieog JC, Doyle J, Victor S, Willis BL, et al. (2009) Vibrio zincmetalloprotease causes photoinactivation of coral endosymbionts and coral tissue lesions. Plos One 4.

49. Ibrahaim ASS (2008) Diversity of coral Eunicea fusca associated bacteria using culture dependent techniques. Research Journal of Microbiology 3: 614-621.

50. Ritchie KB (2006) Regulation of microbial populations by coral surface mucus and mucus-associated bacteria. Marine Ecology-Progress Series 322: 1-14. 
51. Allers E, Niesner C, Wild C, Pernthaler J (2008) Microbes enriched in seawater after addition of coral mucus. Applied and Environmental Microbiology 74: 32743278 .

52. Kooperman N, Ben-Dov E, Kramarsky-Winter E, Barak Z, Kushmaro A (2007) Coral mucus-associated bacterial communities from natural and aquarium environments. FEMS Microbiology Letters 276: 106-113.

53. Raina J-B, Tapiolas D, Willis BL, Bourne DG (2009) Coral-associated bacteria and their role in the biogeochemical cycling of sulfur. Applied and Environmental Microbiology 75: 3492-3501.

54. Littman RA, Willis BL, Bourne DG (2009) Bacterial communities of juvenile corals infected with different Symbiodinium (dinoflagellate) clades. Marine EcologyProgress Series 389: 45-59.

55. Altincicek B, Vilcinskas A (2006) Metamorphosis and collagen-IV-fragments stimulate innate immune response in the greater wax moth, Galleria mellonella. Developmental and Comparative Immunology 30: 1108-1118.

56. Rodriguez-Lanetty M, Phillips WS, Dove S, Hoegh-Guldberg O, Weis VM (2008) Analytical approach for selecting normalizing genes from a cDNA microarray platform to be used in q-RT-PCR assays: a cnidarian case study. Journal of Biochemical and Biophysical Methods 70: 985-991.

57. Wang KJ, Ren HL, Xu DD, Cai L, Yang M (2008) Identification of the up-regulated expression genes in hemocytes of variously colored abalone (Haliotis diversicolor Reeve, 1846) challenged with bacteria. Developmental and Comparative Immunology 32: 1326-1347.

58. Baugh LR, Kurhanewicz N, Sternberg PW (2011) Sensitive and precise quantification of insulin-like mRNA expression in Caenorhabditis elegans. Plos One 6.

59. Bellantuono AJ, Hoegh-Guldberg O, Rodriguez-Lanetty M (2012) Resistance to thermal stress in corals without changes in symbiont composition. Proceedings of the Royal Society B-Biological Sciences 279: 1100-1107.

60. DeSantis TZ, Hugenholtz P, Larsen N, Rojas M, Brodie EL, et al. (2006) Greengenes, a chimera-checked 16S rRNA gene database and workbench compatible with ARB. Applied and Environmental Microbiology 72: 5069-5072.

61. Vandesompele J, De Preter K, Pattyn F, Poppe B, Van Roy N, et al. (2002) Accurate normalization of real-time quantitative RT-PCR data by geometric averaging of multiple internal control genes. Genome Biology 3. 
62. Norland S (2004) Gel 2K 1.2.6 ed. Bergin, Norway: University of Berlin.

63. Oksanen SF, Blanchet FG, Kindt R, Legendre P, O'Hara RB, et al. (2011) VEGAN: community ecology package. $\mathrm{R}$ package. 1.17-8 ed.

64. Core RD (2011) R: a language and environment for statistical computing. Vienna, Austria: R Foundation for Statistical Computing.

65. Kvennefors ECE, Leggat W, Kerr CC, Ainsworth TD, Hoegh-Guldberg O, et al. (2010) Analysis of evolutionarily conserved innate immune components in coral links immunity and symbiosis. Developmental and Comparative Immunology 34: 1219-1229.

66. Werner T, Borge-Renberg K, Mellroth P, Steiner H, Hultmark D (2003) Functional diversity of the Drosophila PGRP-LC gene cluster in the response to lipopolysaccharide and peptidoglycan. Journal of Biological Chemistry 278: 26319-26322.

67. Dunn SR (2009) Immunorecognition and immunoreceptors in the cnidaria. ISJ 6: 714.

68. Downs CA, Mueller E, Phillips S, Fauth JE, Woodley CM (2000) A molecular biomarker system for assessing the health of coral (Montastraea faveolata) during heat stress. Marine Biotechnology 2: 533-544.

69. Feder ME (1999) Organismal, ecological, and evolutionary aspects of heat-shock proteins and the stress response: established conclusions and unresolved issues. American Zoologist 39: 857-864.

70. Black NA, Voellmy R, Szmant AM (1995) Heat-shock protein induction in Montastraea faveolata and Aiptasia pallida exposed to elevated-temperatures. Biological Bulletin 188: 234-240.

71. Choresh O, Azem A, Loya Y (2007) Over-expression of highly conserved mitochondrial 70-kDa heat-shock protein in the sea anemone Anemonia viridis. Journal of Thermal Biology 32: 367-373.

72. Choresh O, Ron E, Loya Y (2001) The 60-kDa heat shock protein (HSP60) of the sea anemone Anemonia viridis: a potential early warning system for environmental changes. Marine Biotechnology 3: 501-508.

73. Downs CA, Fauth JE, Robinson CE, Curry R, Lanzendorf B, et al. (2005) Cellular diagnostics and coral health: declining coral health in the Florida Keys. Marine Pollution Bulletin 51: 558-569. 
74. Fang LS, Huang SP, Lin KL (1997) High temperature induces the synthesis of heatshock proteins and the elevation of intracellular calcium in the coral Acropora grandis. Coral Reefs 16: 127-131.

75. Hashimoto K, Shibuno T, Murayama-Kayano E, Tanaka H, Kayano T (2004) Isolation and characterization of stress-responsive genes from the scleractinian coral Pocillopora damicornis. Coral Reefs 23: 485-491.

76. Hayes RL, King CM (1995) Induction of 70-kD heat shock protein in scleractinian corals by elevated temperature: significance for coral bleaching. Molecular Marine Biology and Biotechnology 4: 36-42.

77. Sharp VA, Brown BE, Miller D (1997) Heat shock protein (hsp 70) expression in the tropical reef coral Goniopora djiboutiensis. Journal of Thermal Biology 22: 1119.

78. Sharp VA, Miller D, Bythell JC, Brown BE (1994) Expression of low-molecularweight hsp-70 related polypeptides from the symbiotic sea anemone anemoniaVirdis forskall in response to heat-shock. Journal of Experimental Marine Biology and Ecology 179: 179-193.

79. Tom M, Douek J, Yankelevich I, Bosch TCG, Rinkevich B (1999) Molecular characterization of the first heat shock protein 70 from a reef coral. Biochemical and Biophysical Research Communications 262: 103-108.

80. Baruah K, Ranjan J, Sorgeloos P, MacRae TH, Bossier P (2011) Priming the prophenoloxidase system of Artemia franciscana by heat shock proteins protects against Vibrio campbellii challenge. Fish \& Shellfish Immunology 31: 134-141.

81. Prohaszka Z, Fust G (2004) Autoimmunity against heat shock proteins: complex regulation by genomic and environmental factors. Tissue Antigens 64: 334-334.

82. Sussman M, Willis BL, Victor S, Bourne DG (2008) Coral pathogens identified for white syndrome (WS) epizootics in the Indo-Pacific. Plos One 3.

83. Vidal-Dupiol J, Ladriere O, Meistertzheim AL, Foure L, Adjeroud M, et al. (2011) Physiological responses of the scleractinian coral Pocillopora damicornis to bacterial stress from Vibrio coralliilyticus. Journal of Experimental Biology 214: 1533-1545.

84. Garland CD, Nash GV, Sumner CE, McMeekin TA (1983) Bacterial pathogen of oyster larvae (Crassostrea gigas) in a Tasmanian hachery. Australian Journal of Marine and Freshwater Research 34: 483-487.

85. Bourne D, Iida Y, Uthicke S, Smith-Keune C (2008) Changes in coral-associated microbial communities during a bleaching event. ISME Journal 2: 350-363. 


\section{Chapter 3: Defending against pathogens - immunological priming and its molecular basis in a sea anemone, a basal metazoan cnidarian}

\subsection{Abstract}

Cnidarians, in general, are long-lived organisms and hence may repeatedly encounter common pathogens during their lifespans. It remains unknown whether these early diverging animals possess some type of immunological reaction that strengthens the defense response upon repeated infections, such as that described in more evolutionary derived organisms. Here we show results that sea anemones that had previously encountered a pathogen under sub-lethal conditions had a higher survivorship during a subsequently lethal challenge than naïve anemones that encountered the pathogen for the first time using two different known coral pathogens. Anemones subjected to the lethal challenge two and four weeks after the sub-lethal exposure using Vibrio coralliilyticus presented seven- and five-fold increases in survival, respectively, compared to the naïve anemones. However, anemones challenged six weeks after the sub-lethal exposure showed no increase in survivorship. Serratia marcescens challenged anemones subjected to a lethal exposure four weeks after the sub-lethal exposure showed increased survivorship with 25 percent surviving the secondary exposure. We argue that this shortlasting priming of the defense response could be ecologically relevant if pathogen encounters are restricted to short seasons characterized by high stress. Further studies are needed to determine if priming is pathogen specific as V. coralliilyticus appears to provide specificity wile $S$. marcescens does not. The ability to confer specificity may be 
dependent on how common the pathogen is in the environment. Furthermore, we discovered significant changes in proteomic profiles between naïve sea anemones and those primed after pathogen exposure suggesting a clear molecular signature associated with immunological priming in cnidarians. Our findings reveal that immunological priming may have evolved much earlier in the tree of life than previously thought.

\subsection{Introduction}

The ability of the immune system to respond more rapidly and effectively to a pathogen that has been encountered previously is a trait well characterized in vertebrates and mechanistically explained by the functional uniqueness of the adaptive immune system [1]. In contrast, it has long been assumed that invertebrates have an immune response that differs considerably from the acquired immune response found in vertebrates. Invertebrates possess only an innate immune system, which is characterized by invariable pattern recognition receptors (PRRs) that target more general and less specific pathogensassociated molecular patterns (PAMPs). The current consensus is that invertebrates lack the components of the adaptive immune system, such as those well characterized in vertebrates including highly variable major histocompatibility complex (MHC) receptors, immunoglobulins, and B and T cells that undergo clonal expansion and long term cell survival following antigen induced activation [1-4]. These elements of the adaptive immune system underlie the mechanism of the immunological memory phenomenon demonstrated in vertebrates. However, increasing evidence over the past years suggests that invertebrate immunity is much more complex than was generally believed. Immunological priming, the stimulation of the immune system with long-lasting effects that accelerate subsequent exposures to infectious pathogens, has been documented for a 
few groups of invertebrates, such as insects and crustaceans [5-10]. The first studies to demonstrate that initial pathogen exposure confers lasting specific protection were for the crustacean copepod Macrocyclops albidus [6] and for the social insect Bombus terrestris [9]. Nevertheless, evidence of immunological priming in many other invertebrates remains absent, particularly for early diverging animals.

A hallmark trait of immune memory in vertebrates is the fact that it is pathogen specific. In other words, the improved secondary response is to a particular pathogen not a group of bacteria or viruses. Pathogen specific immune priming has been found in several invertebrates: fruit fly Drosophila melanogaster [11], the woodlice Porcellio scaber [12] and mosquito Anopheles gambiae [13]. The specific immune priming appears to be driven by phagocytes in insects. In D. melanogaster, the pathogen specific immune priming is found in response to only certain bacteria such as Streptococcus pneumonia and Beauveria bassiana [11]. In P. scaber hemocytes showed an increased ability to phagocytize a previously encountered bacterial strain than a new bacterial strain [12]. In A. gambiae infection with Plasmodium resulted in quantitative and qualitative granulocyte differentiation of hemocytes that persisted for the lifespan of the mosquito [13].

Cnidarians, including corals and sea anemones, are evolutionarily early-diverged metazoans and of great interest since some of these invertebrates can live for hundreds of years, suggesting they are potentially exposed to the same pathogens on many occasions during their lifespans. This has led to the mystery of how these long-lived organisms have done so well with only an innate immune system as the protective mechanism against infectious agents. As of yet, it is unknown if the defense response of these 
organisms strengthens upon repeated infections. Pioneering studies on coral skin grafts conducted in the late 1970s demonstrated that corals were able to reject skin grafts from genetically distinct donors more rapidly the second time the grafts were applied, suggesting for the existence of a memory property of non-self recognition [14-16]. Selfand allogeneic recognition has also been described in sea anemones [17] and soft corals [18]. While this phenomenon is not directly comparable with a defense against a pathogen, it might indicate that these basal metazoans have the capacity to remember foreign biological interactions. Additionally, understanding this aspect of immunology in corals and other cnidarians is imperative in light of the global concern of increasing epizootic disease outbreaks currently affecting the health of corals [19-22] and the persistence of these fragile coral reef ecosystems [23-26].

In the present study, we investigated whether priming is existent in cnidarians in response to pathogenic infections and if this response is pathogen specific. There are three hypotheses that will be tested in this chapter. The first is that immune priming is a phenomenon found throughout the tree of life and that as a result it will be found in basal metazoans in response to repeated encounters with biotic stressors. The second is that if immune priming is conserved throughout the tree of life, the response to biotic stressors will be specific. The final hypothesis is that if immune priming is conserved in basal metazoans, a proteomic signature will be associated with the response. 


\subsection{Materials and Methods}

\subsubsection{Exaiptasia pallida anemone husbandry}

Anemones used in these experiments were from the clonal CC7 population of Exaiptasia pallida (formerly Aiptasia pallida) (Figure 3-1) (John Pringle Lab, Stanford University) and were maintained in filtered artificial seawater at approximately $27^{\circ} \mathrm{C}$. Populations were kept on a day:night cycle of $12 \mathrm{~h}$ light: $12 \mathrm{~h}$ dark with 30 to $60 \mu$ mole photons $\mathrm{m}^{-2} \mathrm{~s}^{-1}$ of light and fed freshly hatched brine shrimp nauplii twice a week. E. pallida used in this study were all approximately $3 \mathrm{~mm}$ in diameter and $10 \mathrm{~mm}$ high. E. pallida was chosen as the study organism for this study since they are easily reared and grown in the laboratory and these anemones closely resemble coral species in their associations with the same symbiotic dinoflagellate genus, Symbiodinium, and many of the same bacterial species $[27,28]$. These characteristics make the sea anemone an adequate system for asking biological questions of relevance for coral reef systems. The clonal CC7 line of sea anemones was used for these experiments and has been reared in the laboratory for more than six years. Using the clonal line of anemones was advantageous as it removed any potential physiological and disease resistance variability that could be associated with unknown genetic differences among individual anemones found in a natural population. Moreover, the clonal anemones harbor the same symbiotic dinoflagellate type of Symbiodinium A4 (sensu: cp23S rRNA genotyping; [29]), indicating that the photophysiology of these clonal anemones is likely the same. Since experimental anemones were reared under the same environmental conditions for the last six years, the nutritional and physiological status of all anemones were presumed to be the same. 


\subsubsection{Pathogenic bacteria species and culture preparation}

Vibrio coralliilyticus strain BAA 450 (ATCC) and Serratia marcescens PDL100 BAA 632 (ATCC) were used for the infection experiment. $V$. coralliilyticus is a major coral pathogen known to cause coral bleaching [30] and white syndrome in Acropora corals [31]. It has also been shown to cause disease and mortality in E. pallida [32]. The anemone responds to $V$. coralliilyticus with darkening of the tissues and retraction of tentacles, followed by complete disintegration of polyp tissues $[32,33]$. The disease progression pattern is consistent with the behavior of necrotizing pathogens [32]. $S$. marcescens PDL100 is a bacterial strain that causes white pox disease in Acropora palmata [34] and has also been shown to cause mortality in E. pallida [35,36]. $S$. marcescens can degrade E. pallida in three to five days [36].

To recover the bacteria from the glycerol stocks, the frozen cultures were streaked out and grown overnight on Marine Agar (Difco, USA) at $30^{\circ} \mathrm{C}$. The following day a single colony was picked with an inoculating loop and grown to logarithmic phase at $30^{\circ} \mathrm{C}$ in Marine Broth-2216 (Difco, USA) while shaking at $100 \mathrm{rpm}$. Cultures were centrifuged at $10,000 \mathrm{~g}$ for five minutes, washed and re-suspended in sterile seawater. Bacterial cells were prepared to the designated final concentration based on a growth curve of $V$. coralliilyticus and S. marcescens generated with optical density readings at $600 \mathrm{~nm}$ plotted against known bacterial culture concentration (CFU).

\subsubsection{Determination of bacterial concentrations for infection trials}

In order to determine an infective dose of the coral pathogens V. coralliilyticus and $S$. marcescens, ten-day infection trials were conducted on E. pallida anemones. Single 
anemones, acclimated to the experimental temperature $\left(30^{\circ} \mathrm{C}\right)$, were placed into single wells of a twelve-well culture dish containing filtered artificial seawater. During these trials, anemones (six per concentration) were challenged with three concentrations of the bacterium: $10^{6}, 10^{7}$, or $10^{8} \mathrm{CFU} \mathrm{ml}{ }^{-1}$ at $30^{\circ} \mathrm{C}$. A temperature of $30^{\circ} \mathrm{C}$ was used since coral pathogenic bacteria have been shown to become pathogenic at temperatures exceeding $28^{\circ} \mathrm{C}[30,37]$. The inoculation of bacteria was conducted using the balneation technique [38]. Anemones were monitored daily over ten days to assess behavioral changes and mortality events.

\subsubsection{Temperature dependent pathogen virulence}

To test if $V$. coralliilyticus and $S$. marcescens showed similar temperature-dependent infectivity in E. pallida as they do in corals, infection trials were conducted at $25^{\circ} \mathrm{C}$ and $30^{\circ} \mathrm{C}$ for ten days. This experiment also allowed for the determination of the effect of experimental temperature on anemone survivorship. The bacterial concentration used for this experiment was $10^{8} \mathrm{CFU} \mathrm{ml}{ }^{-1}$ for both bacterial strains as this inoculum dose showed the most consistent infectivity pattern on anemones (Figure 3-2 and 3-3). Four treatments were conducted for each bacterium $\left(+\mathrm{Bacteria}\right.$ at $25^{\circ} \mathrm{C},+$ Bacteria at $30^{\circ} \mathrm{C}$, - Bacteria at $25^{\circ} \mathrm{C}$, and - Bacteria at $30^{\circ} \mathrm{C}$ ). Each treatment contained a total of six anemones. The anemones were allocated in single wells of twelve-well tissue culture plates. The inoculation of bacteria on the + Bacteria treated anemones were conducted using the balneation technique [38]. Anemones were monitored daily over ten days to assess behavioral changes and mortality events. 


\subsubsection{Determination of sub-lethal pathogen exposure}

The sub-lethal exposure was not defined based on bacterial dose but based on the duration of exposure to the pathogen. From the infections experiments described above, the survivorship curves showed consistently that no anemone died during the first three days of pathogen exposure at a dose of $10^{8} \mathrm{CFU} \mathrm{ml}^{-1}$ when $V$. coralliilyticus was used as the pathogen (Figure 3-2) and two days for S. marcescens (Figure 3-3). Based on these results, an additional experiment was conducted aiming to confirm if the above described sub-lethal exposures at $10^{8} \mathrm{CFU} \mathrm{ml}^{-1}$ could be considered a sub-lethal treatment. For this, anemones were exposed to either bacterial pathogen for the predetermined exposure time (three days for $V$. coralliilyticus and two days for $S$. marcescens), and placed in pathogen-free filtered seawater. The inoculations were carried out using the balneation technique [38]. The survivorship of these anemones was compared to a second group of anemones that remained under the bacterial exposure for a total of 10 days. Along with these two treatments, a control group of anemones were maintained in pathogen-free seawater. The results from this experiment were fundamental to define the sub-lethal challenge used in subsequent priming experiments described below.

\subsubsection{Priming experiments on Exaiptasia pallida anemones}

All experiments in this section were conducted at $30^{\circ} \mathrm{C}$ and at a final concentration of $10^{8}$

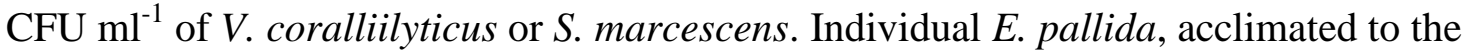
experimental temperature $\left(30^{\circ} \mathrm{C}\right)$ were placed into a single well of a twelve-well tissue culture plate containing filtered artificial seawater. Studies were conducted in three phases: sub-lethal exposure, recovery period, and lethal exposure. During the sub-lethal 
exposure, as indicated in the previous section, anemones (referred to as primed anemones) were challenged for three days with $V$. coralliilyticus (Figure 3-2) or two days with S. marcescens. The sub-lethal exposures were followed by recovery periods, which varied as two, four, or six weeks. In this phase, anemones were removed from the sublethal exposure wells, transferred to pathogen-free seawater and left to recover during the designated recovery times. The final phase of the experiment consisted of the lethal exposure. From the previous experiment, it was determined that exposure to pathogen concentration of $10^{8} \mathrm{CFU} \mathrm{ml}{ }^{-1}$ between 4 and 10 days was considered a lethal challenge for $V$. coralliilyticus (Figure 3-2) and between 3 and 10 days for S. marcescens (Figure 33). During this phase the primed anemones were challenged again with the same bacterium. Additionally, a second treatment (defined as non-primed E. pallida) was composed of naïve anemones that were not subjected to sub-lethal exposure but challenged with the same bacterium in the last phase of the experiment. The control anemones were kept at $30^{\circ} \mathrm{C}$ for the entire experiment but were never challenged with the bacterium.

\subsubsection{Specificity of immune priming in Exaiptasia pallida anemones}

Specificity of immune priming in E. pallida was assessed. All experiments in this section were conducted at $30^{\circ} \mathrm{C}$ and at a final concentration of $10^{8} \mathrm{CFU} \mathrm{ml}^{-1}$ of $V$. coralliilyticus or S. marcescens. E. pallida were acclimated to the experimental temperature of $30^{\circ} \mathrm{C}$ and placed into a single well of a twelve-well tissue culture plate containing filtered artificial seawater. As in the previous section, the experiments were conducted in three phases: sub-lethal exposure, recovery period, and lethal exposure. During the sub-lethal exposure, primed anemones were challenged with $V$. coralliilyticus or $S$. marcescens for three or 
two days respectively. The sub-lethal exposures were followed by recovery periods, which varied as two or four weeks. In this phase, anemones were removed from the sublethal exposure wells, transferred to pathogen-free seawater and left to recover. The final phase of the experiment consisted of the lethal exposure and contained five treatments. Primed anemones were randomly divided into two groups. The first group of primed anemones was challenged with the same bacterium they were challenged with during the sub-lethal phase of the experiment at a pathogen concentration of $10^{8} \mathrm{CFU} \mathrm{ml}{ }^{-1}$. The second group was challenged with the second bacterium not used in the priming experiment at pathogen concentration of $10^{8} \mathrm{CFU} \mathrm{ml}^{-1}$. For example if $V$. coralliilyticus was the bacterium used for the challenge experiments during the sub-lethal exposure, half of those anemones would be challenged with $V$. coralliilyticus and the other half with $S$. marcescens. Additionally, two more treatments were tested: non-primed and control anemones. Non-primed E. pallida were composed of naive anemones that were not subjected to sub-lethal exposure. Half were challenged with $V$. coralliilyticus while the other half were challenged with $S$. marcescens. The control anemones were kept at $30^{\circ} \mathrm{C}$ for the entire experiment but were never challenged with the bacterium.

\subsubsection{Quantitative PCR assay for determining Vibrio coralliilyticus load on the}

\section{anemones}

To determine the clearance dynamics of the $V$. coralliilyticus pathogen by the exposed anemones after the sub-lethal exposure time and during the lethal challenge, a quantitative real time PCR (qPCR) assay specific to test for pathogen presence was conducted. An S. marcescens qPCR assay could not be conducted due to primer specificity problems. Anemone samples were collected immediately after finishing the 
sub-lethal exposure, and two and four days afterwards. During the lethal challenge (secondary exposure), anemones were collected at the following time points: one, three, seven and ten days after the start of the lethal exposure. For all the sampling times, three anemones were collected from each of the three treatments (primed, non-primed and controls). Total DNA was extracted from the collected anemones using the DNeasy Plant Mini Kit (Qiagen, Valencia, CA). DNA concentrations were estimated using the NanoDrop 2000c (Nano-Drop Technology, Wilmington, DE). V. coralliilyticus specific primers designed by Polson 2008 were used for the qPCR: 96F (5'GTTRTCTGAACCTTCGGGGAACG-3') and 1019R (5'-

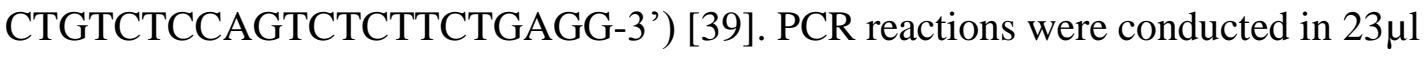
reactions with $12.5 \mu 1$ of SYBR green master mix (BioRad, Hercules, CA) and $0.2 \mu \mathrm{M}$ of each primer. The PCR conditions were as follows: $95^{\circ} \mathrm{C}$ at $5 \mathrm{~min}$ followed by 40 cycles of $95^{\circ} \mathrm{C}$ at $30 \mathrm{sec}, 67^{\circ} \mathrm{C}$ at $30 \mathrm{sec}$, and $72^{\circ} \mathrm{C}$ at $60 \mathrm{sec}$. Dissociation curves were analyzed to confirm single product amplification at the end of qPCR runs. Samples were run in triplicate and mean values were used for calculations. Pathogen load on the infected anemones was expressed as relative proportion to amount of bacteria used at the initial inoculation $\left(10^{8} \mathrm{CFU} \mathrm{ml}{ }^{-1}\right)$. For the calculations, we used the following equation; $2_{\mathrm{i}}^{(\mathrm{Ct}-\mathrm{Ct}}$ ${ }_{a}^{\text {a }}$; where $\mathrm{Ct}_{\mathrm{i}}$ represented the mean amplification cycle value for the DNA extracted from the initial inoculum $\left(10^{8} \mathrm{CFU} \mathrm{ml}{ }^{-1}\right)$, and $\mathrm{Ct}_{\mathrm{a}}$ represented the mean amplification cycle value for the DNA extracted from the infected anemone. A relative proportion of 1 means the pathogen load on an infected anemone corresponds to the same amount of pathogen found in concentration of $10^{8} \mathrm{CFU} \mathrm{ml}^{-1}$. 


\subsubsection{Statistical analysis of survivorship data and pathogen load on inoculated}

anemones

For the priming experiments, Kaplan Meier estimators and survival plots were constructed for each of the three different recovery periods using the statistical software SPSS 21 (IBM). Post hoc comparisons using the Mantel - Cox test were further conducted to determine significant differences among the survival curves for each of the treatments. Analysis of variance (ANOVA) was performed in conjunction with a Tukey's posthoc test to assess significance difference in the bacterial load on the anemones during different times after the sub-lethal challenge and during the lethal challenge.

\subsubsection{Proteomic analysis}

In order to determine the molecular changes underpinning immunological memory in $E$. pallida anemones, a proteomic analysis was conducted by Applied Biomics (Hayward, CA) according to the company's standard protocol. V. coralliilyticus was used as the bacterial pathogen for this experiment due to its efficacy as a pathogen. Additionally, this pathogen was used since qPCR assays were able to confirm complete clearance of the pathogen during the recovery period between the sub-lethal and lethal infections. This was not feasible for $S$. marcescens since primer specificity was not attained for the assay. In this analysis, the proteomic profiles of anemones primed with the pathogen during a sub-lethal exposure were compared to naïve anemones never exposed to the pathogen four weeks after the experimental anemones were subjected to the sub-lethal exposure. Fifteen anemones were collected from each of two treatments. These fifteen anemones were pooled in three groups of five anemones each and snap frozen in liquid nitrogen. 
The pooling of anemones was necessary since it allowed enough tissue material for extraction of proteins to run the proteomic analyses. Samples were sent to Applied to Biomics (Hayward, CA) for two-dimensional differential in-gel electrophoresis (2D DIGE) profiling and separation. The 2D DIGE gels were scanned using a Typhoon image scanner (GE Healthcare). The images were analyzed using Image Quant software (GEHealthcare), and then subjected to in-gel analysis and cross-gel analysis using DeCyder software version 6.5 (GE-Healthcare). Protein differential expression ratio changes were obtained by in-gel DeCyder software analysis. Of the spots that were differentially expressed, 32 were subjected to isolation using an Ettan Spot Picker (GE Healthcare) followed by MALDI-TOF (MS) using a 5800 mass spectrometer (AB Sciex).

Proteins were identified by submitting the peptide mass and fragmentation spectra to GPS Explorer version 3.5 using the MASCOT search engine (Matrix Science) where the National Center for Biotechnology Information non-redundant (NCBInr) database and $E$. pallida genome (Pringle Lab, Sanford University) were explored. Significant candidates had either protein score C.I.\% or Ion C.I.\% greater than 95.

\subsection{Results}

\subsubsection{Host response to bacterial pathogen improves upon repeated pathogen}

\section{encounter}

To assess the response of E. pallida anemones to repetitive encounters with the infectious agent, we first determined a sub-lethal exposure of the bacterial pathogens $V$. coralliilyticus and S. marcescens that would allow priming of the host without causing mortality. It was determined that a concentration of $1 \times 10^{8} \mathrm{CFU} \mathrm{ml}^{-1}$ of either bacterial 
agent causes stress and mortality in E. pallida anemones after four days of exposure for V. coralliilyticus (Figure 3-2) and three days for S. marcescens (Figure 3-3). Within a ten-day bacterial exposure using $V$. coralliilyticus, mortality ranged from 60 to $90 \%$ in the anemones (Figure 3-2A) while S. marcescens challenge showed 100 to $70 \%$ mortality during the same time period (Figure 3-3A). However, if anemones were removed from the $V$. coralliilyticus bacterial challenge, washed, and placed in pathogen-free seawater after the third day of pathogen exposure, anemones would recover and show 100\% survivorship comparable to unexposed (control) anemones (Figure 3-4). Based on these results, a sub-lethal challenge of a three-day pathogen exposure at $1 \times 10^{8} \mathrm{CFU} \mathrm{ml}^{-1}$ was used for the immune priming experiments. The bacterial challenges were conducted at $30^{\circ} \mathrm{C}$ as it has been shown the virulence in these pathogens increases at temperatures above $28^{\circ} \mathrm{C}[30,36,37]$. We demonstrated that this experimental temperature was not a factor of mortality during the bacterial exposure trials (Figure 3-2B). The same experiment was conducted with a two day challenge using $S$. marcescens with the same results and that temperature was not a factor in these experiments (Figure 3-3B).

\subsubsection{Priming trial with $V$. coralliilyticus}

Following the above trials, three experiments were performed to evaluate the existence of a priming response. Anemones were first subjected to a sub-lethal exposure of $V$. coralliilyticus followed by resting periods (pathogen-free recovering time from the sublethal challenge) of either two, four, or six weeks before exposing the sea anemones again to a lethal exposure (ten day pathogen challenge). It is important to note that none of the anemones died during the resting period or prior to the lethal challenge. The response and survivorship of these anemones (primed group) were compared to anemones that were 
exposed to a lethal challenge but without prior sub-lethal exposure (non-primed group), and also to a control group in which anemones were never exposed to sub-lethal or lethal bacterial challenges. The results showed that anemones that had previously encountered the pathogen (primed) had a higher survivorship than those anemones that encountered the pathogen for the first time (Figure 3-5; Kaplan Meier; Mantel - Cox Post hoc test, $\mathrm{p}=$ 0.0001). The survivorship rate appeared to vary as a function of the lapsed time between the two consecutive pathogen exposures. Anemones exposed to the lethal challenge two and four weeks after the sub-lethal exposure presented seven - and five - fold increases in survival, respectively, compared to the non-primed anemones (Figure 3-5A-B; KaplanMeier; Mantel - Cox Post hoc test; Two weeks, $\mathrm{p}=0.031$; Four weeks, $\mathrm{p}=0.039$ ). However, the experimental group of anemones challenged six weeks after the sub-lethal exposure showed a 1.4 fold increase in survivorship that was not statistically significant (Figure 3-5C; Kaplan-Meier; Mantel - Cox Post hoc test, $\mathrm{p}>0.05$ ). The improved response of the anemones to repeated encounters of the pathogen suggests the existence of transient defense priming that lasts for up to four weeks.

To determine whether the improved response in the primed anemones was not due to a chronic infection that continued over the experimental period, the pathogen load on the subjected anemones after the sub-lethal exposure was quantified using quantitative PCR (qPCR). Results from the assay indicated that by day four of the recovery period, $V$. coralliilyticus was no longer detectable in E. pallida (Figure 3-6A; ANOVA, p>0.05), suggesting that the improved response to pathogen upon repetitive encounters was due to a priming phenomenon and not to chronic infection. The same qPCR assay was used to confirm that $V$. coralliilyticus was present in E. pallida hosts throughout the lethal 
experiment, which showed considerable presence of pathogen load throughout the lethal exposure (Figure 3-6B).

\subsubsection{Priming trials with $S$. marcescens}

A similar experiment to the priming experiment in $V$. coralliilyticus was performed using S. marcescens. In these experiments anemones were first subjected to a sub-lethal exposure of S. marcescens followed by a pathogen - free recovery period of either two or four weeks before a final lethal exposure to the pathogen. As in the V. coralliilyticus experiments, none of the anemones died during the sub-lethal or recovery periods. The survivorship of the primed anemones was compared to non-primed and controls during the lethal exposure. The results showed that anemones that had previously encountered the pathogen survived for a greater length of time (but not number of surviving individuals at the end of the experiment) than non-primed anemones during the lethal exposure after a two week recovery period (Figure 3-7A; Kaplan-Meier p=0.000). However after a four week recovery period, primed anemones showed higher survivorship than non-primed individuals (Figure 3-7B; Kaplan-Meier; Mantel - Cox Post hoc test $\mathrm{p}=0.000$ ). The improved response of anemones after four weeks of exposure with S. marcescens verifies the existence of the transient form of the priming defense encountered with $V$. coralliilyticus.

\subsubsection{Priming specificity}

In order to test the specificity of immune priming in E. pallida, survival was measured under two treatments using both $V$. coralliilyticus and S. marcescens with a two and four week recovery period. Experiments were conducted in three phases as described above. 
In one experimental set up, S. marcescens was the bacterium used in the sub-lethal exposure for two days at a final concentration of $10^{8} \mathrm{CFU} \mathrm{ml}^{-1}$. After a pathogen-free recovery period of two or four weeks, half of the $S$. marcescens primed anemones were challenged a second time with $10^{8} \mathrm{CFU} \mathrm{ml}^{-1}$ S. marcescens while the remaining half were challenged with $10^{8} \mathrm{CFU} \mathrm{ml}^{-1} \mathrm{~V}$. corallillyticus during the ten-day lethal exposure.

Additionally there were anemones in the lethal exposure that had previously not been challenged with any bacterium and were challenged for the first time with either $S$. marcescens or $V$. coralliilyticus. The second set of priming specificity experiments used an identical set up described above except that $10^{8} \mathrm{CFU} \mathrm{ml^{-1 }}$ V. coralliilyticus was used as the challenge bacterium during the sub-lethal exposure.

In either of the experimental set-ups, none of the anemones died during the sub-lethal or recovery periods. When $V$. coralliilyticus was used as the bacterium during the sub-lethal exposure, there was a significant increase in survival of E. pallida exposed to the same bacterium during lethal exposure for both the two (Figure 3-8A Kaplan-Meier; Mantel Cox Post hoc test $\mathrm{p}=0.004$ ) and four (Figure 3-8B Kaplan-Meier; Mantel - Cox Post hoc test $\mathrm{p}=0.023$ ) week recovery periods when compared to those challenged with $S$. marcescens during the lethal exposure. This increased survival of anemones exposed to the same pathogen twice as opposed to different pathogens during the sub-lethal and lethal exposures indicates that $V$. coralliilyticus priming may be pathogen specific.

When S. marcescens was used as the priming bacteria during the sub-lethal exposure, there was significantly higher survival of anemones that were challenged during the lethal phase of the experiment with $V$. coralliilyticus after a two week recovery period (Figure 3-9A Kaplan-Meier; Mantel - Cox Post hoc test $\mathrm{p}=0.004$ ) but not after four weeks (Figure 
3-9B Kaplan-Meier; Mantel - Cox Post hoc test $\mathrm{p}=0.091$ ) in comparison to those challenged in both phases with S. marcescens. Interestingly, there was no significant difference in survival between both $V$. coralliilyticus treatments (primed versus nonprimed) during the lethal exposure after a two (Kaplan-Meier; Mantel - Cox Post hoc test $\mathrm{p}=0.378$ ) and four (Kaplan-Meier; Mantel - Cox Post hoc test $\mathrm{p}=0.320$ ) week recovery period. Additionally there was no difference between primed and non-primed anemones for the S. marcescens treatment during the lethal exposure after a two (Kaplan-Meier; Mantel - Cox Post hoc test $\mathrm{p}=0.165$ ) and four (Kaplan-Meier; Mantel - Cox Post hoc test $\mathrm{p}=0.902$ ) week recovery period. Increased survival of $V$. coralliilyticus challenged anemones to $S$. marcescens challenged anemones during the lethal exposure phase of these experiments indicates that a $S$. marcescens priming response may not be pathogen specific.

\subsubsection{Proteomic analysis to dissect the molecular changes associated with the immune $V$. coralliilyticus associated priming response}

Further exploration of the immunological priming phenomenon took place at the protein level by analyzing samples collected four weeks following the post-priming phase with V. coralliilyticus and immediately before the lethal exposure. V. coralliilyticus was chosen for these experiments due to its efficacy as a pathogen as well as the ability to characterize pathogen clearance using the qPCR assay.

A two-dimensional fluorescence gel electrophoresis combined with mass spectrometry was used for the analysis. Based on the replicated 2D fluorescent in-gel analysis, a total of 1400 spots were detected. From this proteome, 39 spots (2.79\%) with at least 1.3 -fold 
change were identified as being differentially expressed between primed and non-primed anemones four weeks after the sub-lethal exposure to the primed anemones (Biological Variation Analysis, BVA, $\mathrm{p}<0.05)$. Among these proteins, 16 were up-regulated, and 23 proteins were down-regulated in the primed anemones (Figure 3-10). Of the 39 identified spots, the protein identities of 32 spots were determined using MALDI-TOF mass spectrometry and proteomic database comparisons with high confidence (Confidence Interval $>95 \%$; Table 3-1). The protein profiles showed surprising complexity as some of these spots represented multiple isoforms of proteins varying in molecular mass and/or charge (Figure 3-11). The differentially expressed proteins identified through this method were involved in 27 different biological processes. The most represented biological processes were metabolic process ( $\mathrm{n}=14, \mathrm{GO}$ : 0008152), cellular process $(\mathrm{n}=13$, GO: 0009987), response to stimulus ( $\mathrm{n}=8$, GO: 0050896), and single organism process ( $\mathrm{n}=12$, GO: 0044699) (Figure 3-12, Table 3-2). The representation of biological processes was similar between up-regulated and down-regulated proteins except the categories of developmental processes and cellular component organization and biogenesis, which were only represented by up-regulated proteins.

Of the proteins identified in this study, heat shock protein 70 was the most highly upregulated protein in primed E. pallida with a 2.02-fold-higher expression in primed as opposed to control anemones (Table 3-1). Interestingly, a second protein also identified as heat shock protein 70, based on amino acid sequence of the generated mass-spec polypeptides was the most highly down-regulated protein with a 9.73 fold decrease in expression in primed anemones when compared to controls. However the size of this 
protein on the gels does not correspond to a 70 kda protein (Figure 3-11) indicating that this protein might be a smaller Heat Shock Protein.

\subsection{Discussion}

The sea anemone, E. pallida, showed susceptibility to bacterial challenge with $V$. coralliilyticus and $S$. marcescens similar to coral species affected by the same bacterial pathogen at seawater temperatures 3 to $5^{\circ} \mathrm{C}$ warmer than ambient temperatures $[30,37]$. However, the survivorship of the challenged anemones depended on previous pathogen exposure. Anemones that encountered the pathogen in sub-lethal conditions prior to lethal exposures showed higher survivorship than naïve anemones encountering the pathogen for the first time. Such findings suggest the potential presence of a protective priming defense mechanism in some members of the phylum Cnidaria. The degree to which priming was successful was pathogen specific. Challenge experiments conducted with $V$. coralliilyticus showed greater survivorship during the lethal portion of the experiments than S. marcescens. Additionally, mortality occurred more quickly in S. marcescens than in $V$. coralliilyticus. This difference in survival and mortality rate may be due to virulence of the bacteria. $V$. coralliilyticus appears to stimulate an effective priming response while S. marcescens could be required to be administered as a non-toxic vaccine such as a heat killed bacterial vaccine. The inability to use a live bacterial strain for vaccine purposes has also been a problem facing human vaccine developers; most are too toxic or virulent to effectively attenuate and are therefore ineffective vaccines [40]. One example of such a vaccine given to humans is the tetanus vaccine which is administered as a non-toxic vaccine that does not contain bacteria but still elicits an immune response [41]. It is therefore possible that in the sea anemone, different vaccine forms are needed depending 
on the pathogen as is also depicted in humans. However, further research is warranted in elucidating if a different form of bacterial preparation is needed to cause more effective priming of E. pallida to $S$. marcescens. The priming response was also shown to be shortlived, lasting up to one month. The improved response of primed compared to nonprimed anemones was not the result of a sustained immune response due to a chronic infection from the sub-lethal exposure, as the pathogen $V$. corallilyticus was cleared by the sea anemones four days after the termination of the sub-lethal exposure and several weeks before the second pathogen exposure but are still needed for S. marcescens. This is critical as a chronic infection in which a low level response of the immune system continues actively combating an infection [42] and cause a more rapid secondary response in a subsequent pathogen challenge due to an already engaged immune system of the attacked host [9]. It is important to note that it is possible that even though $V$. corallilyticus presence decreases beyond detection, the presence of large concentrations of Vibrio at the onset of the experiment may have impacted the other microbial species associated with the anemone that may function as beneficial symbionts. Further studies are required to explore this possibility. Our findings demonstrate that the cnidarian defense system is functionally capable of unexpectedly durable induced protection. This suggests that selective pressures that triggered the evolution of immunological priming have a signature from early diverging animals.

Immunological priming has been documented in other invertebrates including crustaceans and insects $[5-7,9,10]$. In these cases, the improved response to the pathogens upon multiple encounters was also shown to be short-lived. For instance, the social bumble bee, Bombus terrestris, gain increased protection against pathogens upon a 
secondary exposure that lasted up to 27 days [9]. In this case, priming of this duration would compare with an average life span of around 4 weeks for adult $B$. terrestris workers in the field. It highlights the clear ecological, and thus evolutionary, benefits of immunological priming in these organisms. In the case of cnidarians, such as anthozoans that can live for hundreds of years, immunological priming that confers a lasting protection of a month might appear to have a low ecological and evolutionary value. Interestingly, a similar timeframe of priming has also been described within the context of allorecognition in cnidarians. For example, specific memory of tissue transplantation immunity has been demonstrated to last four weeks in the coral Montopora verrucosa [16], and eight weeks in the gorgonian, Swiftia exerta [18]. Yet some corals, such as the hydrocoral Millepora dichotoma appear not to possess a memory component to allorecognition [43]. The three above examples show a varying memory response to previously encountered allografts. In the cases that do show allomemory, it appears also to be relatively short-lived. While the mechanisms used in alloimmunity by cnidarians are unknown, it is possible that common ground might exist between the mechanisms modulating the processes of allografting and pathogen recognition. Regardless of the similarity between the mechanisms, the question remains as to what would be the advantage for a long-lived organism to have such a short-lived priming of their defense system. We speculate that short-lasting priming of the defense response could be ecologically relevant if pathogen encounters are concentrated and restricted to particular seasons (short period of time) characterized by high stress. In such seasons when pathogens are more active and virulent, cnidarians could be ecologically and evolutionary benefited if they have the capability to remember pathogenic encounters during the 
duration of the high stress season. This would allow maximizing the allocation of energy towards immunological priming when it is most needed since it has been shown to be energetically taxing on other organismal processes [44]. In recent years we have learned that sustained high temperatures above the average seasonal maximum are often related to an increase of disease outbreaks [24,26,30,45-47]. For example, Bruno and collaborators (2007) showed a highly significant relationship between the frequencies of warm temperature anomalies and the occurrence of white syndrome in Pacific reefbuilding corals. High temperatures during the summer months have also been associated with the activation of virulence among bacterial pathogens that are common residents in the coral reef environment $[30,48,49]$. Moreover, the high virulence and disease prevalence is seasonal in the majority of cases and ceases as the water temperature declines at the end of the summer [20,24]. Therefore, it is conceivable that the short duration of immunological priming described for E. pallida mirrors the short time window when pathogens are seasonally active and during which they could be encountered repetitively by the sea anemone. This strategy would allow the sea anemone to reallocate energy use to other vital physiological needs during times where pathogens are less infectious. Additionally, the duration of priming might also be pathogen specific. For example, in mice different pathogens elicit different lengths of time of priming and memory [50]. Pathogens that are encountered more often by a given organism could cause longer priming/memory. Further investigations are needed to understand whether different pathogens trigger longer immunological memory.

This study also indicates that some bacteria may cause a bacterial specific immune priming response while others do not. V. coralliilyticus conferred a bacterially specific 
priming response while $S$. marcescens did not. The nonspecific priming with $S$.

marcescens could be due to the fact that it may not be as common of a pathogen in the water column as $V$. coralliilyticus. Thus the anemone's immune system may not be as prepared to defend against it as potentially for a more commonly found bacterium such as V. coralliilyticus [51]. Furthermore, specificity of immune priming could occur at the species level and thus improved priming could be conferred using any Vibrio sp. Further research would be needed to indicate whether E. pallida has the potential to differentiate specific Vibrio strains or if any Vibrio sp. could initiate the specific priming phenomenon. Pathogen specific immune priming has been found in several invertebrates: fruit fly Drosophilla melanogaster [11], the woodlice Porcellio scaber [12] and mosquito Anopheles gambiae [13] but not in the meal worm, Tenebrio molitor [51].

\subsubsection{Proteomic analysis of immune priming in E. pallida}

The phenomenological data presented above indicate that there are responses in cnidarians that might be trained by past experience and increase upon a second exposure. This adds to the growing notion that invertebrates have extremely plastic immune effectors that can generate novel and functional immune response changes in relation to past experience. In the past the logical fallacy that because an organism lacks B and $\mathrm{T}$ cells, the organism will also lack an adaptive immune response has hindered our appreciation of the capability of basal metazoans to possess immunological priming and memory [52]. These organisms could generate a trained immune response in another way as has been documented for insects $[53,54]$. In our study we attempted to characterize molecular changes correlated with the priming phenomenon using a comparative 
proteomic approach to start dissecting the mechanism underlying an inducible enhanced immunity in cnidarians.

Statistically significant differences in proteomic profiles between naïve sea anemones and those primed after pathogen exposure suggests a clear molecular signature associated with immunological priming in cnidarians. The group of differentially expressed genes was diverse, suggesting that the molecular regulation of the priming defense is governed by changes in multiple cellular processes. None of these proteins were identified as antimicrobial peptides, which are the molecules normally produced during the actual fighting and clearing of pathogen infections in cnidarians [55-57]. In other invertebrates such as bumblebees, antimicrobial peptides are produced immediately after the bacterial challenge and then subside thereafter when the pathogen load decreases [9]. Therefore, the lack of differentially expressed antimicrobial peptides was expected as the proteomic analysis was conducted in primed anemones at least three weeks after the pathogen from the sub-lethal exposure was cleared. Consequently the changes in protein alteration detected in the primed anemones four weeks after the first pathogen exposure seem to be related the phenomenon of immunological priming rather than to pathogen clearance.

Gene ontology analysis indicated that many of the differentially produced proteins linked to immune defense priming were grouped into metabolic processes pathways, a pattern that has also been detected from transcriptomic analyses in corals affected with disease signs $[58,59]$. An example of a metabolic protein is the Fructose-Bisphosphate Aldolase protein that is an enzyme involved in glycolysis, a metabolic process that assures the production of energy required for a large number of other metabolic processes. We detected a higher amount of this protein in primed anemones suggesting an enhanced 
metabolic function in primed animals. Previous studies have also shown a correlation between increased expression of metabolic enzymes in the response to secondary exposure of pathogens [60]. Recently, it was proposed that a shift of central glucose metabolism from oxidative phosphorylation to aerobic glycolysis (the "Warburg effect") is the metabolic basis for trained immunity (i.e. the memory characteristics of the innate immune system recently described in vertebrates; [61]), providing the energy and metabolic substrates for the increased activation of trained immune cells [62]. Further experimental and physiological studies are needed to investigate whether an increase of glycolysis is indeed a fundamental process in primed "trained" immunity in a basal group within metazoans, such as cnidarians. Findings from these future research avenues will provide an appreciation of the evolutionary origin for the key role of metabolism in innate host defense.

Many of the identified proteins in this study show homology to immune genes functionally characterized in other organisms. Although we need to be cautious when borrowing functionality of these proteins based on homology to other organisms [63], their expression in this study bolsters the idea that they may be involved in the immune response of E. pallida. In the context of cnidarian immunology, we discuss key changes in protein production involved in following functional groups: stress response, ion transport and proteolysis.

Several proteins involved in stress response were detected in association with defense priming: two heat shock protein 70s (HSP70) and one heat shock protein 60 (HSP60) were up-regulated whereas three small heat shock proteins ( $20 \mathrm{kDa})$ were downregulated. It is well known that the up-regulation of HSP synthesis provides resistance to 
toxic stresses such as heat shock $[64,65]$, however, their involvement has also been shown in response to many other environmental and biological insults, such as pathogenic infections [66]. Recently, we also documented transcriptional up-regulation of a HSP 70 gene in the scleractinian coral, Acropora millepora, within hours of exposure to bacterial pathogens [38]. There is still no clear understanding of the molecular mechanisms involving HSP in response to pathogenic infection and whether its action in the immune defense is at the intracellular and/or at the extracellular level. However, it has been suggested that many HSPs have the property of damage associated molecular patterns (DAMPs) as they can bind to exposed hydrophobic residues of a wide spectrum of polypeptides [67]. HSPs could play a critical role in mediating innate immunity by activating Toll-like receptor (TLR) signaling due to their status as DAMPs and thus induce cytokine- mediated inflammatory responses. For instance, some evidence indicates that extracellular HSP70 can interact with TLR4 under a number of pathological situations $[68,69]$. Furthermore, HSP70 has been implicated in immunity stimulation either by antibody-independent activation of the complement immune system [70] or by enhancing the expression of the prophenoloxidase system [71]. Under the hypothesis of DAMP-acting HSPs, it is possible that a higher synthesis of HSPs in primed organism, such as in the case of the sea anemone from this study, could allow for a faster response at the detection of infection-associated danger through interaction of TLR-HSP-DAMP, and thus induce a quicker inflammatory response upon a new exposure to pathogens (see model at Figure 3-13). This model is supported by studies conducted on the brine shrimp Artemia showing that heat-induced accumulation of HSP70 appears to protect crustacean from pathogenic infection by $V$. campbellii [72]. Current findings have shown that direct 
delivery of HSP vaccines to crustaceans improve their defense response and success to fight infections of pathogens [71-73]. For example, feeding with E. coli YS2 overproducing DnaK, the prokaryotic equivalent of Hsp70, enhances gnotobiotic Artemia larvae survival approximately two- to three-fold upon challenge with pathogenic $V$. campbellii [73].

Other proteins detected in this study were putatively characterized as being involved in ion transport. One of particular attention was the inotropic glutamate receptor (iGluR)like protein found to be up-regulated in the primed anemones. iGluRs are ligand-gated ion channels best known for their role in fast excitatory neurotransmission in vertebrate and invertebrate nervous systems. However, new findings have shown that many homologs of these receptors are implicated in other biological process. A novel family of iGluR-related genes from insects (referred to as Ionotropic Receptors, IR) have been characterized as chemosensory receptors and are involved in olfaction and gustation processes [74,75]. The findings that these receptors are present across diverse groups of organisms from bacteria, plants and animals also suggests that this receptor family represents an evolutionarily ancient mechanism for sensing both internal and external chemical cues [74]. Of great interest are the findings showing that plant iGluRs are implicated in sensing a broad range of amino acids as part of the defense mechanism against infectious agents [76]. Recent studies examining the wound response and disease susceptibility in Arabidopsis thaliana Glutamate-Like Receptors (GLR) knockout mutants have provided evidence that some members of the GLR gene family encode important components of the plant's defense response [77]. These discoveries are in line with our finding of higher production of iGluR-like proteins in primed Exaiptasia 
anemones. If involved in recognizing/sensing danger associated molecular components, a primed anemone with higher levels of expression of iGluRs would be better prepared to respond faster to infectious agents upon secondary exposures (Figure 3-13).

Finally, we detected a higher production of immune related proteolytic proteins including aminopeptidases and cathepsin, suggesting a potential enhancing key role of proteolysis in immune priming. For instance, capthepsins are key lytic enzymes and members of the proteases machinery packed in host lysosomes. These enzymes are not only involved in lysosome-contained pathogen degradation but also have been implicated in activating endosomal Toll-Like Receptors (TLR), which induce downstream cytokine-mediated pro-inflammatory responses $[78,79]$. Cathepsins generate a proteolytic cleavage, a prerequisite for TLR7 and TLR9 signaling [80,81]. Greater amounts of this protein in primed anemones implies that up-take of pathogens via phagocytosis will be digested and cleared faster through the phagosome-lysosome pathway. Additionally, their recognition by TLRs could be enhanced by a higher rate of proteolytic cleavage.

\subsection{Conclusions}

In summary, while immune priming has been found in several invertebrates [6,9], this study discovered for the first time a similar phenomenon in an early diverging animal. Our findings support the notion that immunological priming may have evolved much earlier in the tree of life than previously thought. Priming effectivity may be driven by the natural abundance of bacterial species as well as their ability to elicit a bacterially specific response. Additionally, the considerable amount of proteins that appear to be involved in the immune response of primed E. pallida suggests immunological priming 
in cnidarians is a more complex phenomenon than so far has been recognized.

Furthermore, finding immunological priming in a sea anemone implicates the potential presence of the same mechanisms in other cnidarians such as corals. Future research addressing these mechanisms might be of crucial influence on developing restoration strategies for threatened and endangered coral reef species. As a potential outcome, "immunization" could become a tool to improve tolerance and survivorship of long-lived wild and re-introduced corals and thus, mitigate the deterioration of coral reef ecosystems. 


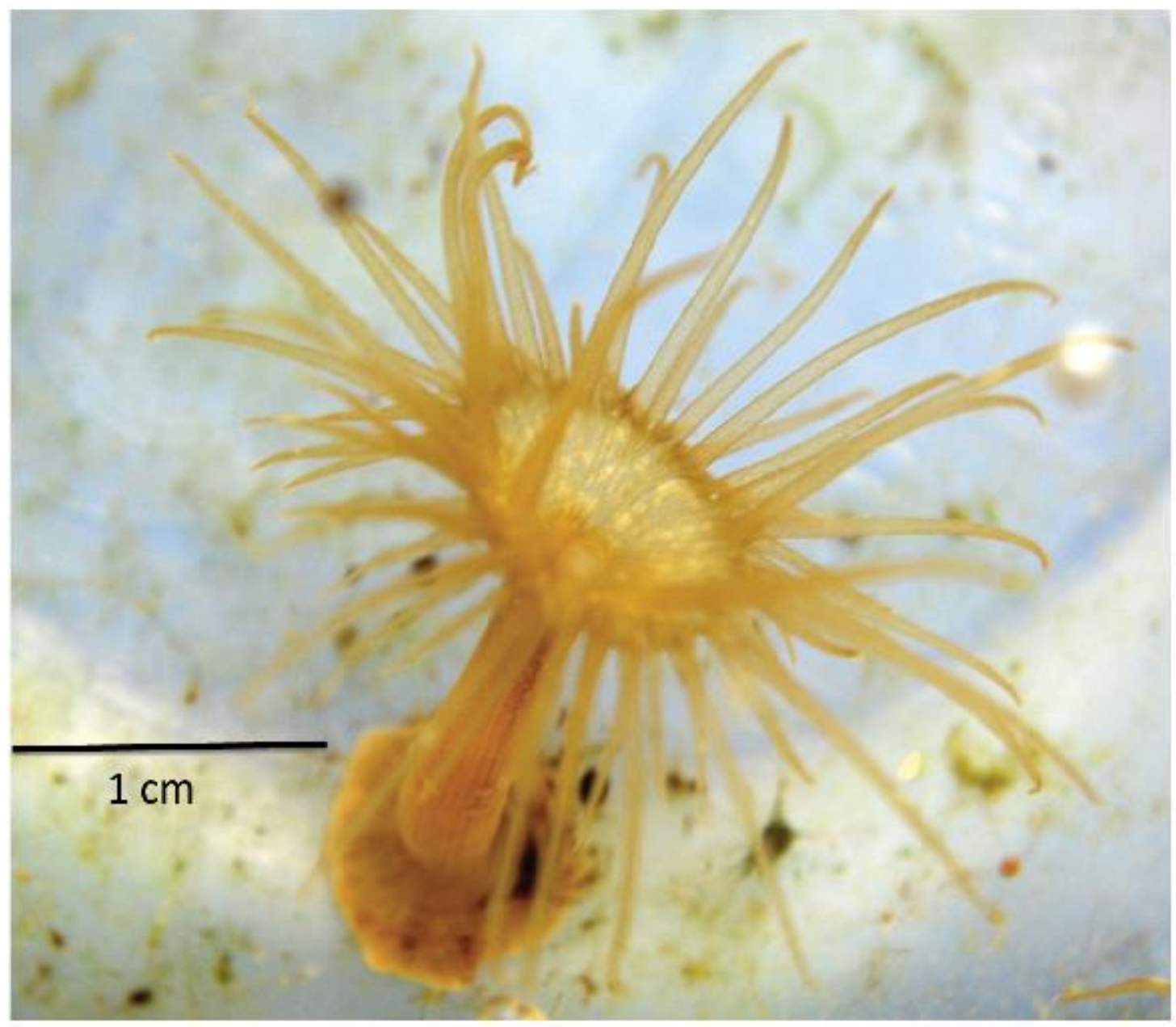

Figure 3-1. The sea anemone, Exaiptasia pallida, utilized in the immunological studies as a Cnidarian model system. 
A

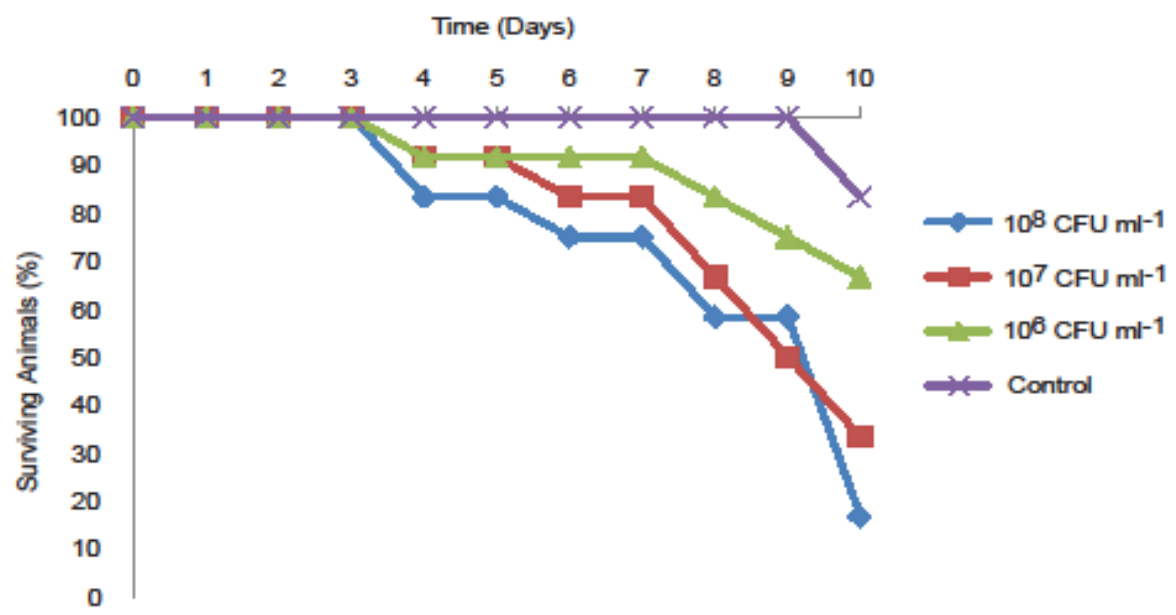

B

Time (Days)

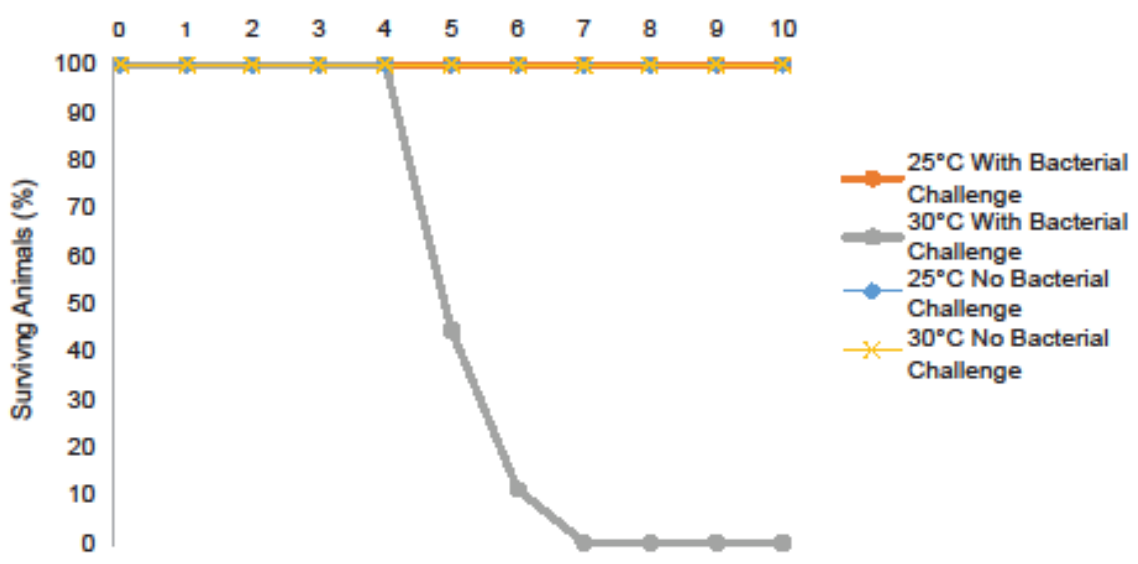

Figure 3-2. Percent survival of Exaiptasia pallida to the exposure of the bacterial pathogen Vibrio coralliilyticus over ten days. A) Percent survival of $E$. pallida anemones under three different concentrations of $V$. coralliilyticus inoculum: $10^{6}$, $10^{7}$, and $10^{8} \mathrm{CFU} \mathrm{ml}^{-1}$ at $30^{\circ} \mathrm{C}$. The inoculum concentration of $10^{8} \mathrm{CFU} \mathrm{ml}^{-1}$ was chosen for the priming experiment since it showed the most consistent mortality results than using other inoculum concentration. B) Percent survival of $E$. pallida to the exposure of Vibrio coralliilyticus inoculum at different temperatures over ten days. Challenges were conducted at a concentration inoculum of $10^{8} \mathrm{CFU} \mathrm{ml}^{-1}$ at both 25 and $30^{\circ} \mathrm{C}$. One hundred percent mortality was recorded at the bacterial challenge conducted at $30^{\circ} \mathrm{C}$ by day seven of the experiment. Importantly, an increased temperature alone with no bacterial challenge did not cause mortality. Additionally, a bacterial challenge at $25^{\circ} \mathrm{C}$ did not result in mortality over the ten-day experiment. These results indicated that bacterial infections of Vibrio coralliilyticus require to be performed at $30^{\circ} \mathrm{C}$, and that this experimental temperature has no negative effect on survivorship of Exaiptasia pallida anemones. 

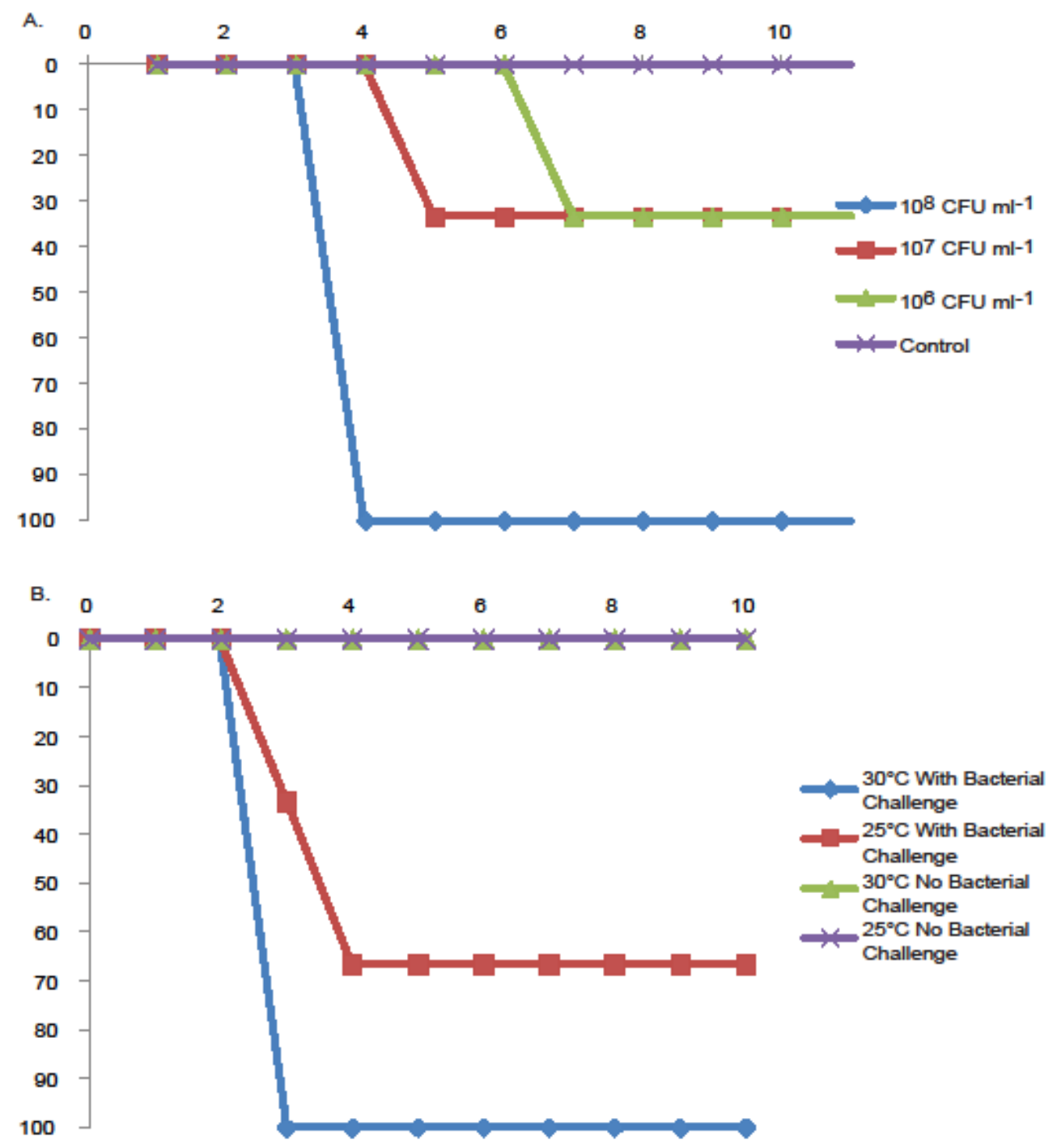

Figure 3-3. Percent survival of Exaiptasia pallida to the exposure of the bacterial pathogen Serratia marcescens over ten days. A) Percent survival of $E$. pallida anemones under three different concentrations of $S$. marcescens inoculum: $10^{6}$, $10^{7}$, and $10^{8} \mathrm{CFU} \mathrm{ml}^{-1}$ at $30^{\circ} \mathrm{C}$. The inoculum concentration of $10^{8} \mathrm{CFU} \mathrm{ml}^{-1}$ was chosen for the priming experiment since it showed the most consistent mortality results than using other inoculum concentration. B) Percent survival of $E$. pallida to the exposure of $S$. marcescens inoculum at different temperatures over ten days. Challenges were conducted at a concentration inoculum of $10^{8} \mathrm{CFU} \mathrm{ml}^{-1}$ at both 25 and $30^{\circ} \mathrm{C}$. One hundred percent mortality was recorded at the bacterial challenge conducted at $30^{\circ} \mathrm{C}$ by day three of the experiment. Importantly, an increased temperature alone with no bacterial challenge did not cause mortality. Additionally, a bacterial challenge at $25^{\circ} \mathrm{C}$ did not result in mortality over the ten-day experiment. These results indicated that bacterial infections of Serratia marcescens require to be performed at $30^{\circ} \mathrm{C}$, and that this experimental temperature has no negative effect on survivorship of Exaiptasia pallida anemones. 


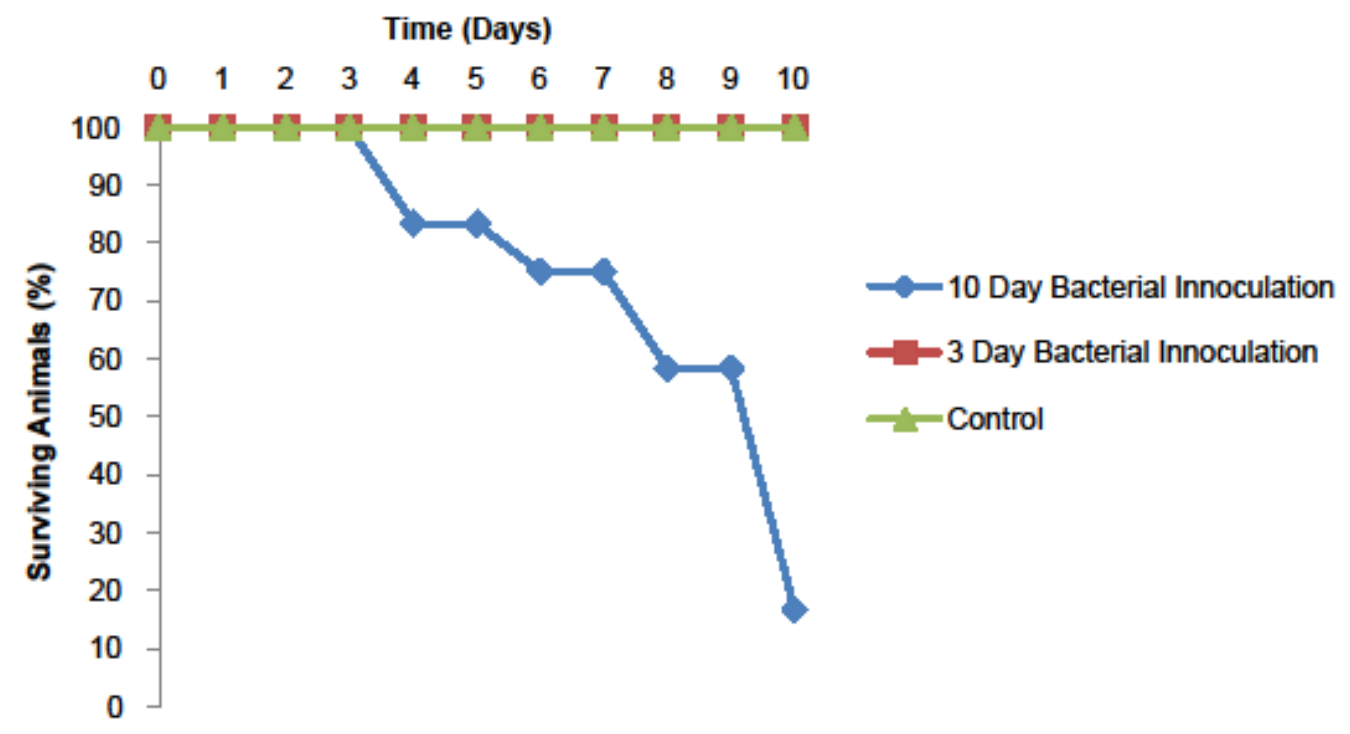

Figure 3-4. Percent survival of Exaiptasia pallida anemones varying the exposure time to $V$. coralliilyticus at a dose of $10^{8} \mathrm{CFU} \mathrm{ml}^{-1}$ : ten days, three days, and control. Results indicate that sea anemones show the same degree of survival to controls when only exposed to the bacterial pathogen, $V$. coralliilyticus for three days. The anemones that were exposed to the pathogen for ten days started dying after the fourth day of exposure. These results suggested that a 3-day exposure to the pathogen at $1 \times 10^{8} \mathrm{CFU} \mathrm{ml}^{-1}$ is considered a sub-lethal treatment and was used as the priming condition in the immunological experiments in this study. Exposure for more than four days is considered lethal. 

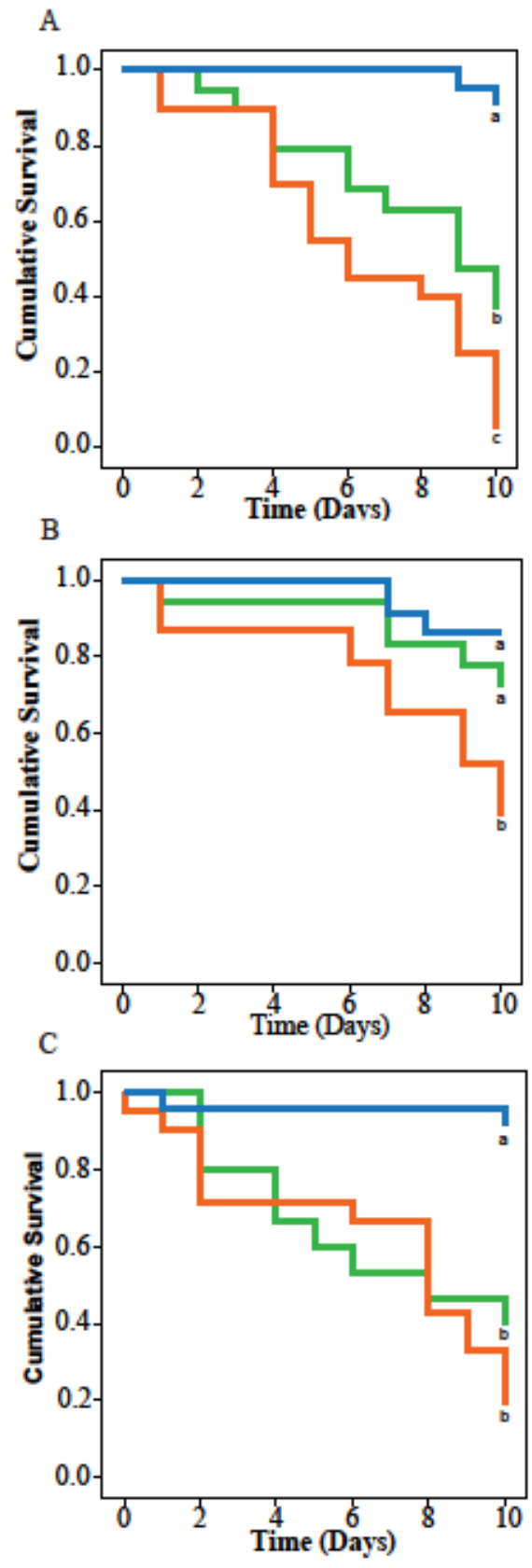

Figure 3-5: Kaplan-Meier survival plots for Exaiptasia pallida during 10-day lethal challenge to the pathogen Vibrio coralliilyticus following: A) two weeks; B) four weeks; and C) six weeks recovery period post priming with a sub-lethal exposure. Green lines indicate those anemones that were primed with a sub-lethal exposure prior to the lethal challenge; orange lines represent anemones that were exposed only to the 10-day lethal challenge with no prior priming, and blue lines indicate control anemones that were not exposed at all to the pathogen. Different letters next to the graphed lines indicate statistically significant difference among the treatment at p 0.05 (Kaplan-Meier; Mantel Cox Post hoc test) $\mathrm{N}=20$ per treatment. 

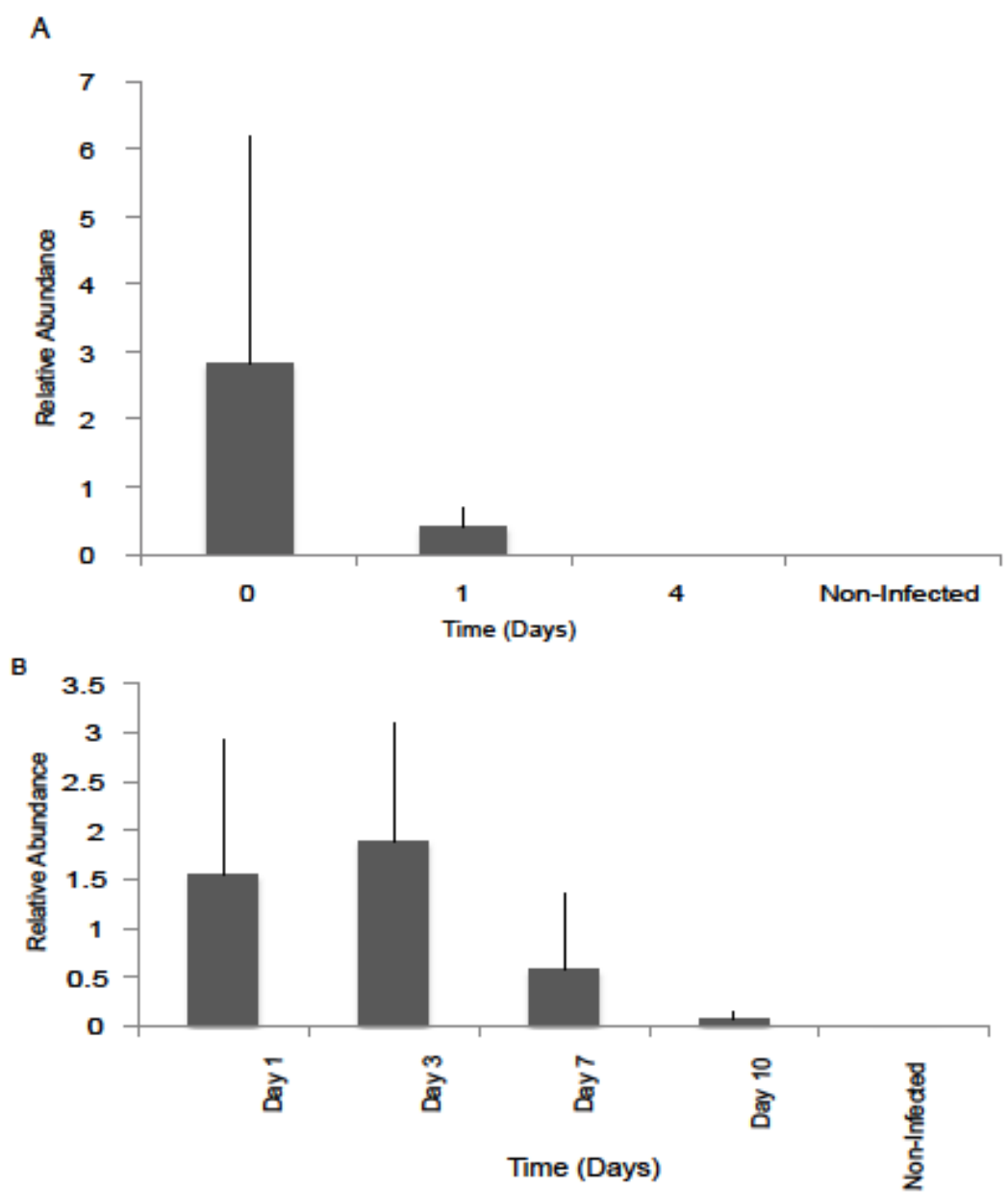

Figure 3-6: Relative Abundance of Vibrio coralliilyticus load in infected Exaiptasia pallida anemones estimated through specific quantitative PCR amplification of the pathogen $16 \mathrm{~S}$ rDNA. A) Relative abundance of $V$. coralliilyticus load in infected anemones during the first four days after the completion of the sub-lethal exposure. The relative abundance of the pathogen is defined as the amount of bacterial load on the anemone in comparison to a bacterial concentration of $1 x$ $10^{8} \mathrm{CFU} \mathrm{ml}^{-1}$. Day 0 represents anemones sampled immediately after being transferred to a new well for recovery at the completion of the sub-lethal exposure, Day 1 and Day 4 represent anemones sampled after one and four days following the completion of the sub-lethal exposure, respectively. Results indicate that $V$. coralliilyticus is cleared by E.pallida anemones by day four following the completion of the sub-lethal exposure. Error bars indicate standard deviation. B) Relative abundance of $V$. coralliilyticus load anemones during the ten-day lethal exposure. Day 1,3,7, and 10 represent days when anemones were sampled during the ten-day lethal exposure. Enror bars indicate standard deviation. Results indicate that a considerable amount of $V$. coralliilyticus load is present in the tissue of $E$. pallida throughout the ten-day lethal exposure. The highest pathogen load was detected during the first three days of the challenge and then it declined at day 7 suggesting some level of clearance by the few anemones that had survived at this time. However, statistical analysis found no significant difference in pathogen load on the anemones among all the sampling times (One-way ANOVA; $\mathrm{p}>0.1$ ). 
A

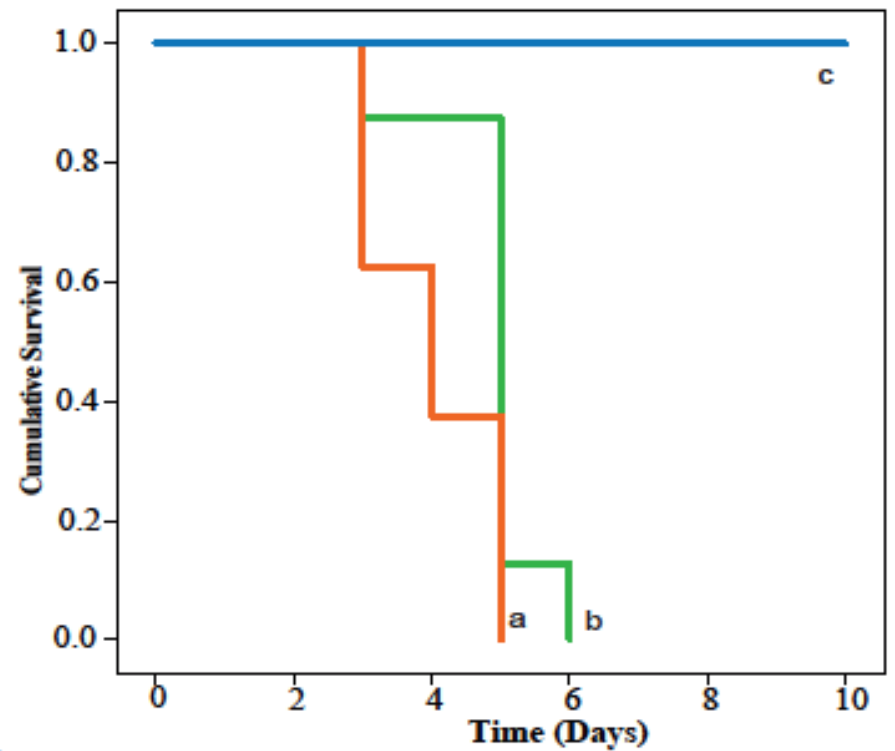

B

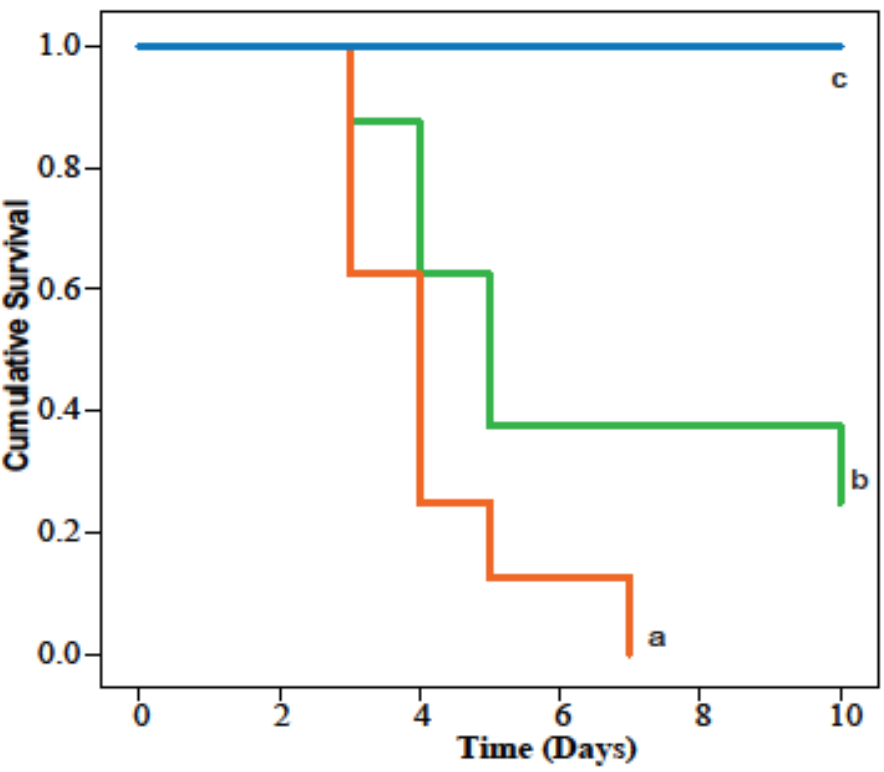

Figure 3-7. Kaplan-Meier survival plots for Exaiptasia pallida during 10-day lethal challenge to the pathogen Serratia marcescens following: A) two weeks and B) four weeks recovery period post priming with a sub-lethal exposure. Green lines indicate those anemones that were primed with a sub-lethal exposure prior to the lethal challenge; orange lines represent anemones that were exposed only to the 10-day lethal challenge with no prior priming, and blue lines indicate control anemones that were not exposed at all to the pathogen. Different letters next to the graphed lines indicate statistically significant difference among the treatment at $\mathrm{p}=0.05$ (Kaplan-Meier; Mantel - Cox Post hoc test) $\mathrm{N}=20 \mathrm{per}$ treatment. 


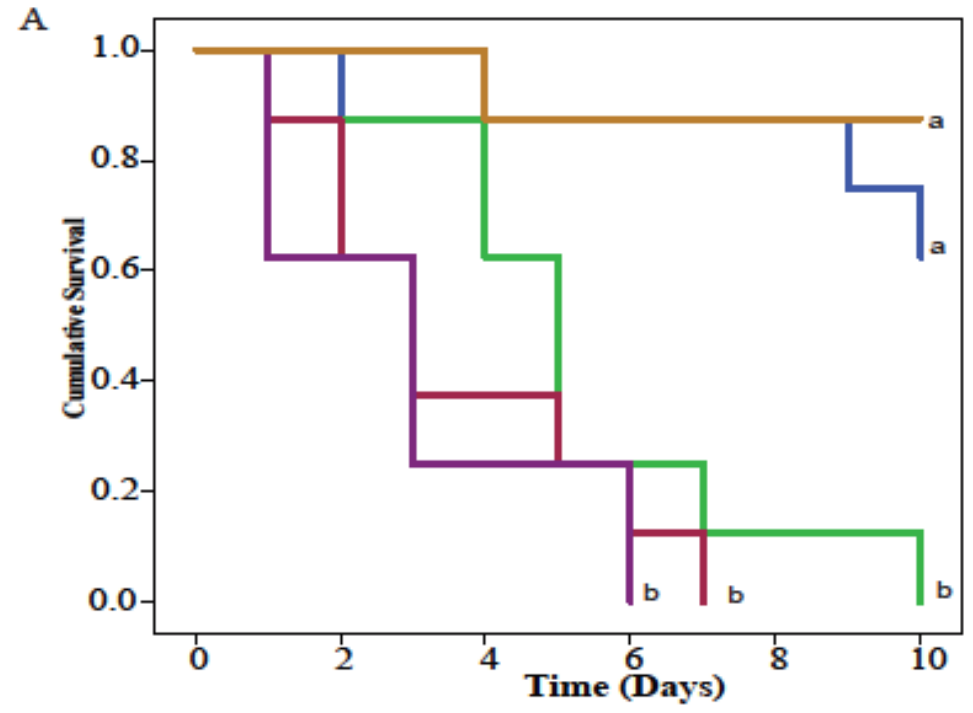

B

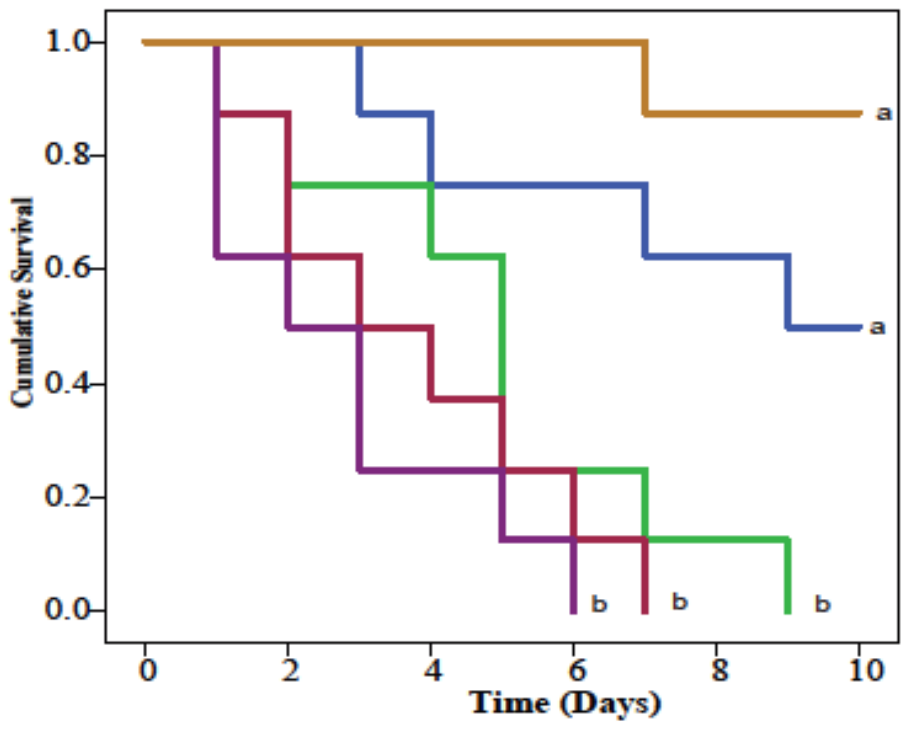

Figure 3-8. Kaplan-Meier bacterial specificity survival plots for Exaiptasia pallida during 10-day lethal challenge after a sub -lethal exposure to the pathogen Vibrio coralliilyticus following: A) two weeks and B) four weeks recovery period. Blue lines indicate those primed anemones that were challenged during the lethal exposure with $V$. coralliilyticus; green lines represent primed anemones that were exposed to $S$. marcescens during the lethal exposure; pink lines represent anemones that were exposed only to the 10 -day lethal challenge with no prior priming with $V$. coralliilyticus; purple lines indicate anemones that were exposed only to the 10-day lethal challenge with $\mathrm{S}$. marcescens with no prior priming; and orange lines indicate control anemones that were not exposed at all to the pathogen. Different letters next to the graphed lines indicate statistically significant difference among the treatment at $\mathrm{p}<0.05$ (Kaplan-Meier; Mantel - Cox Post hoc test) $N=20$ per treatment. 
A
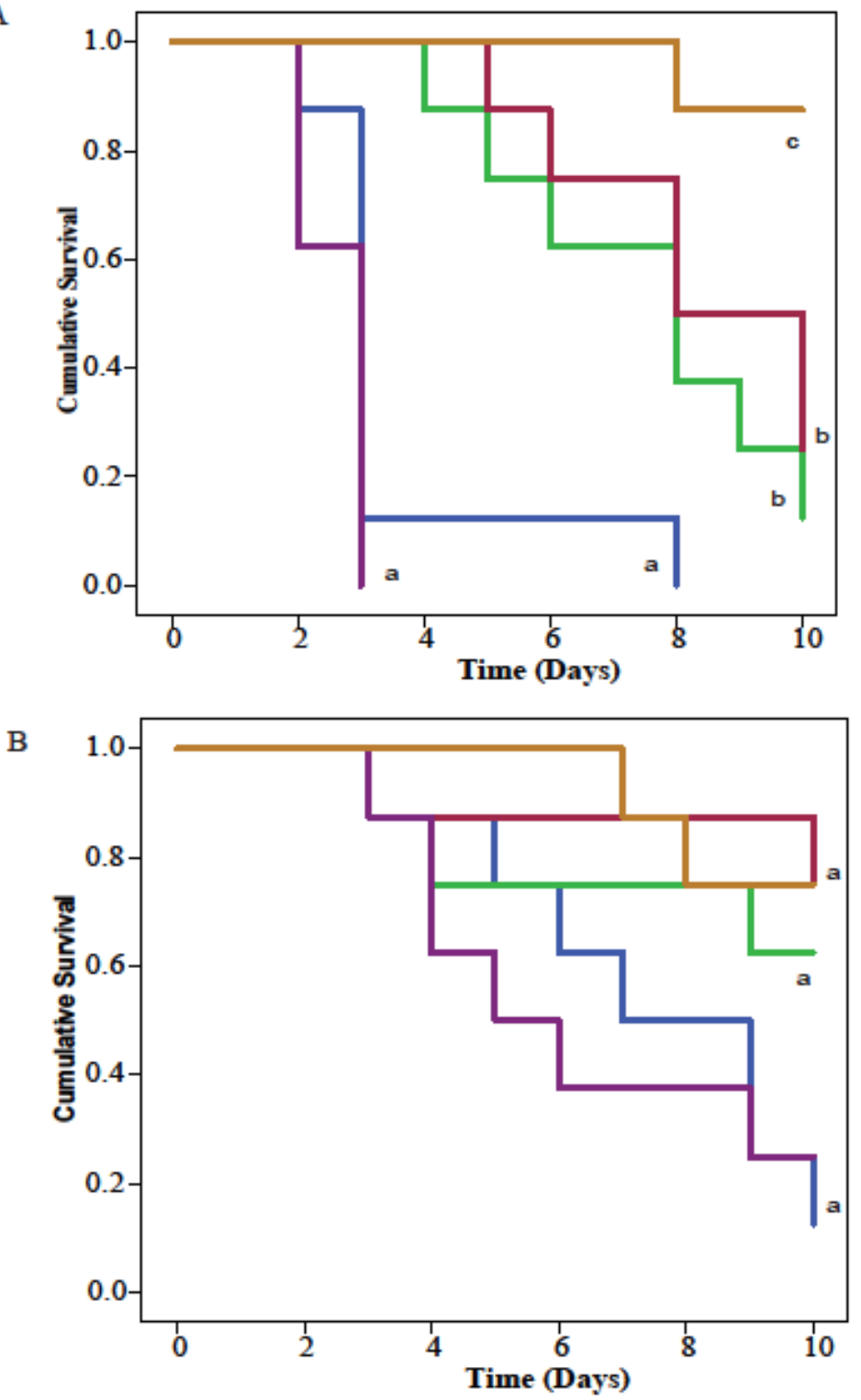

Figure 3-9. Kaplan-Meier bacterial specificity survival plots for Exaiptasia pallida during 10-day lethal challenge after a sub -lethal exposure to the pathogen Serratia marcescens following: A) two weeks and B) four weeks recovery period. Blue lines indicate those primed anemones that were challenged during the lethal exposure with $S$. marcescens; green lines represent primed anemones that were exposed to $V$. coralliilyticus during the lethal exposure; pink lines represent anemones that were exposed only to the 10-day lethal challenge with no prior priming with $V$. coralliilyticus; purple lines indicate anemones that were exposed only to the 10-day lethal cahallenge with $S$. marcescens with no prior priming; and orange lines indicate control anemones that were not exposed at all to the pathogen. Different letters next to the graphed lines indicate statistically significant difference among the treatment at $\mathrm{p}<0.05$ (Kaplan-Meier; Mantel - Cox Post hoc test) $\mathrm{N}=20$ per treatment. 


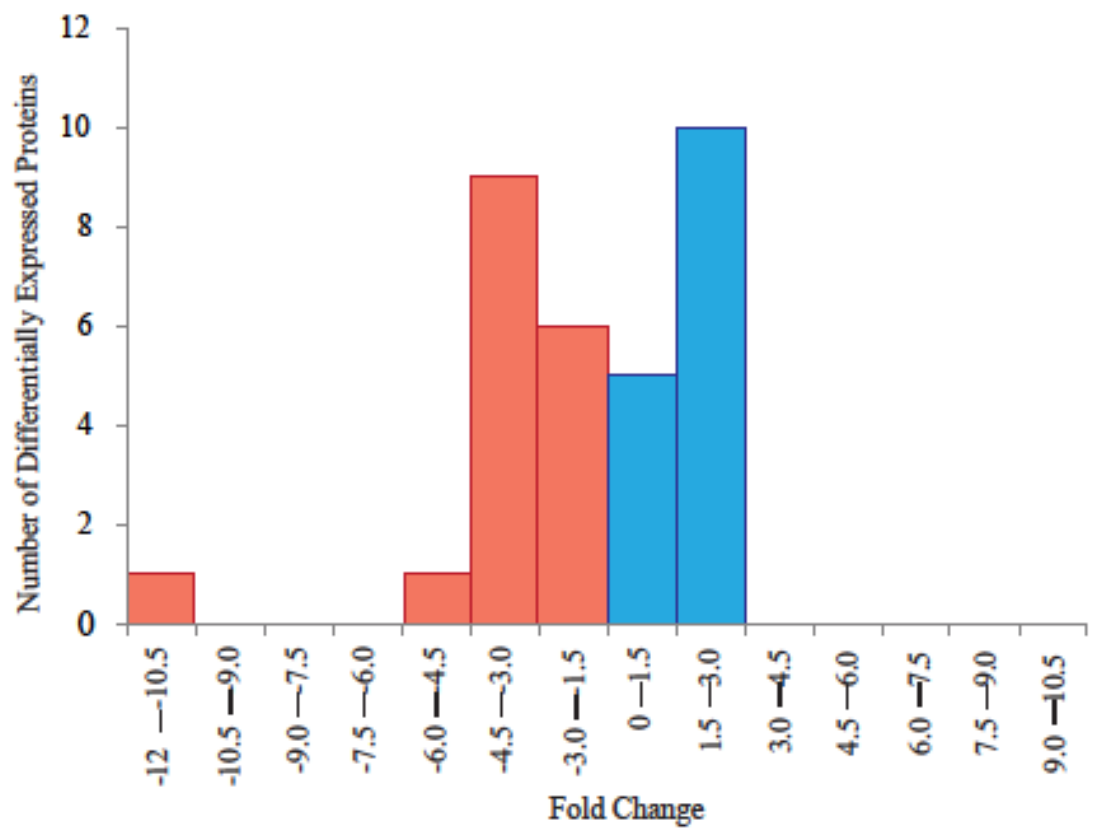

Figure 3-10: Histogram of the differentially expressed proteins as a function of fold change from Exaiptasia pallida anemones four weeks post priming in comparison to naïve anemones never exposed to the pathogen. Blue bars indicate proteins that were differentially up-regulated in the anemones previously primed with a sub-lethal exposure to the pathogen; and red bars indicates down-regulated proteins in the same treatment. 


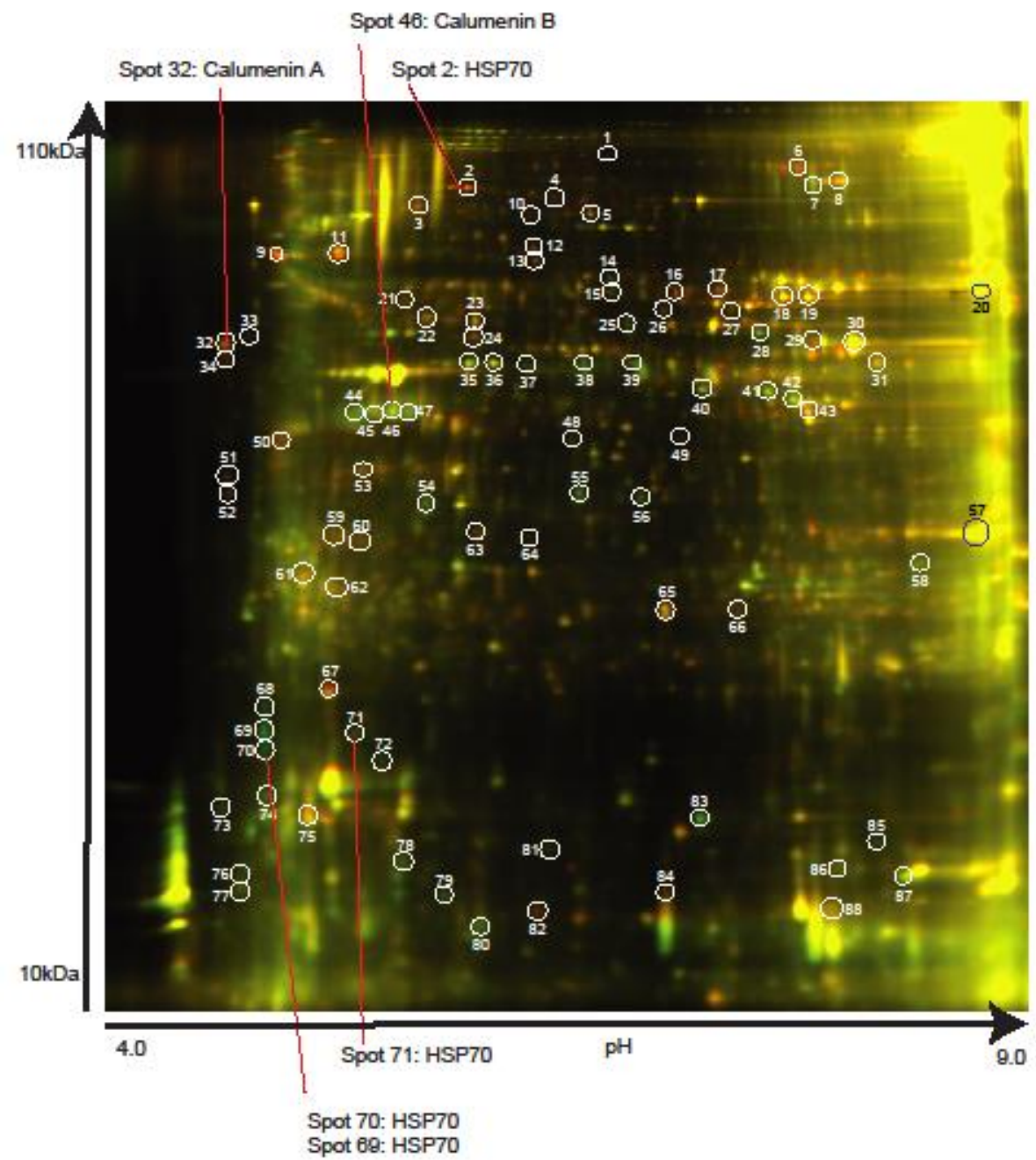

Figure 3-11. CyDye switch, two dimensional fluorescence difference gel electrophoresis (2D-DIGE) analysis of proteomes from naīve $(\mathrm{N}=3)$ and pathogen-primed $(\mathrm{N}=3)$ Exaiptasia pallida sea anemones. Naīve anemone samples were labeled with $\mathrm{Cy} 3$ (green) and primed anemone samples with $\mathrm{Cy} 5$ (red). Samples were then mixed and separated on analytical 2-D DIGE. The resulting gel was scanned and the merged image is shown where red proteins represent proteins whose expression is higher in the primed anemone tissue and green proteins represent proteins whose expression is higher in the naïve anemone tissue. The depicted gel is one example of the three replicated gels produced in this proteomic analysis. Circled and numbered spots represent proteins, which were most differentially expressed of which only those indicated by yellow circles were able to be analyzed using Mass-Spec and reported in Table 1. Red lines indicate protein numbers $2,32,46,69,70$, and 71 pointing out the different isoforms detected of HSP70 and calumenin. 

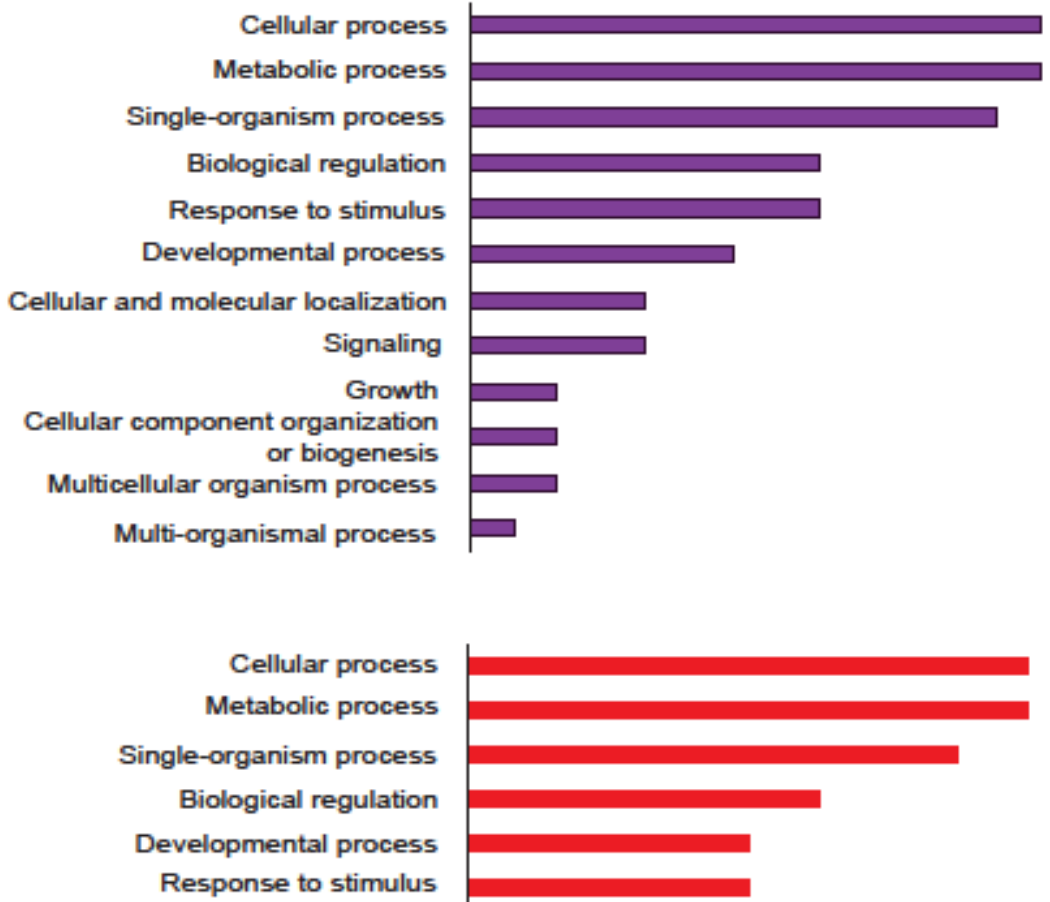

Multi-organism process

Multicellular organismal process

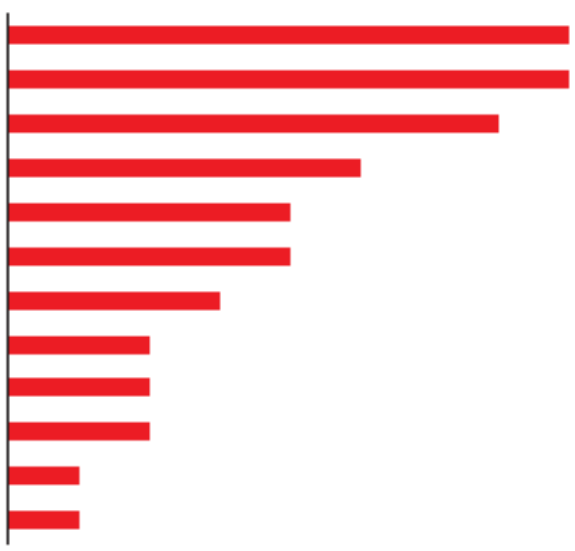

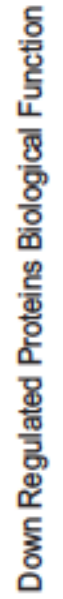

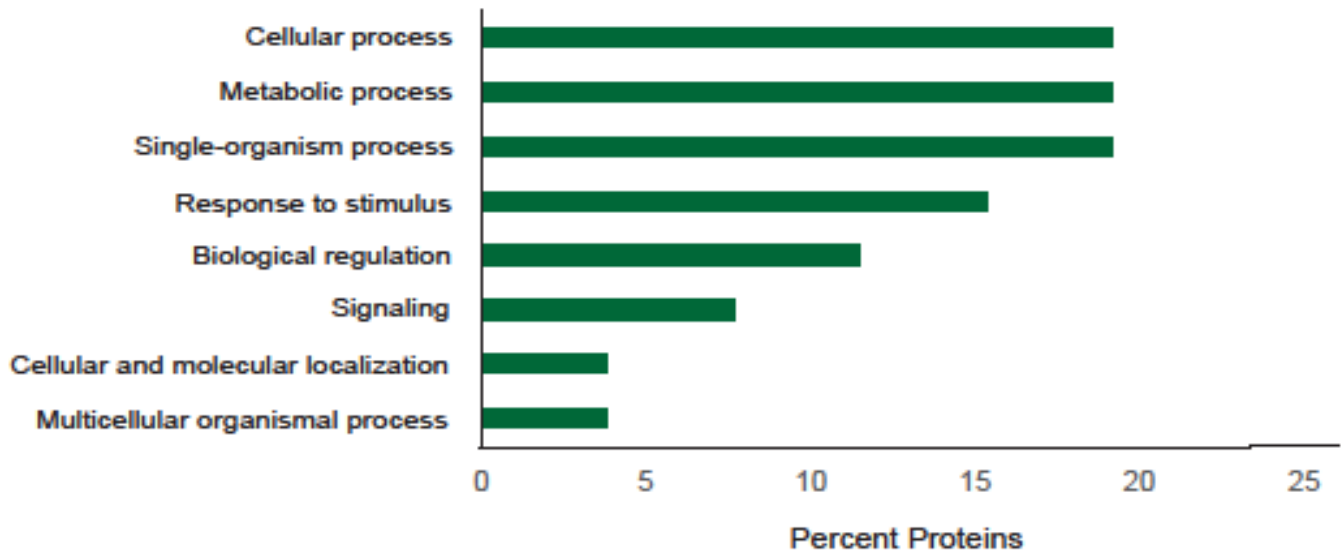

Figure 3-12. Representation of biological processes Gene Ontology (GO) terms for the 32 Exaiptasia pallida characterized proteins. The results are summarized in three subgroups: all GO terms, GO terms from up-regulated and down-regulated proteins. 


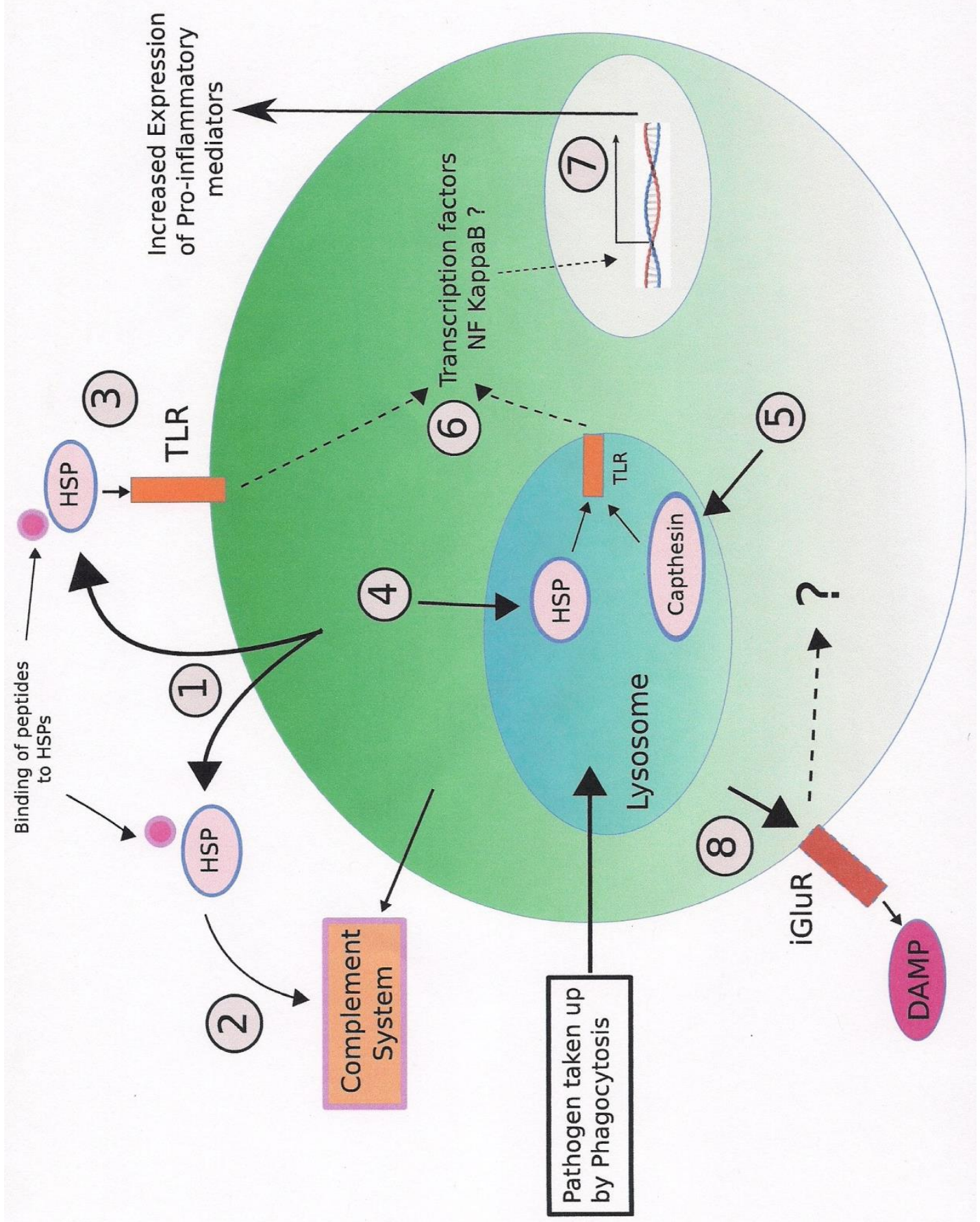

Figure 3-13. Proposed model of Heat Shock Proteins (HSP), Capthesin and Glutamate Receptor (iGluR) roles in cnidarian molecular defense priming: (1) HSP are up regulated and some are extracellularly secreted where bind to peptides and act as DAMPs; (2) as DAMPs, HSP help with a faster activation of the innate complement system, and /or (3) 
interact and cause a quicker activation of outer host cell membrane TLRs; (4)

intracellularly, up-regulated HSP proteins can be delivered into lysosomes in which they can also interact and activate endosomal cell membrane TLRs; (5) higher production of Capthesin are delivered into lysosomes in which they can also interact and activate endosomal cell membrane TLRs; (6) activated TLRs either from the outer membrane or endosomal membranes will trigger cell signaling pathways that will converge in the activation of transcription factors (likely NF-kappa B) that will ultimately induce the expression of immune-related genes (7) resulting in the production of potential proinflammatory molecules; (8) Higher expression of iGluR expressed on the outer membrane will also facilitate a faster sensing of potential DAMPs upon secondary exposure of pathogens. 


\begin{tabular}{|c|c|c|c|c|c|c|}
\hline 2D Gel & Protein & Exaiptasia & Protein & Protei & Fold & $\mathbf{P}$ \\
\hline Spot & Identification & 1 & MW & n PI & Change & value \\
\hline Number & & Genome & (Da) & & 2 & T test \\
\hline
\end{tabular}

\begin{tabular}{|c|c|c|c|c|c|c|}
\hline 2 & $\begin{array}{l}\text { Heat Shock Protein } \\
(70 \mathrm{KDa})\end{array}$ & AIPGENE12496 & 74,685 & 5.6 & 2.02 & 0.091 \\
\hline 6 & $\begin{array}{l}\text { Signal Recognition } \\
\text { Particle }\end{array}$ & AIPGENE24594 & 72,108 & 6.4 & 1.88 & 0.120 \\
\hline 84 & MRP Protein & AIPGENE1468 & 95,674 & 9.3 & 1.72 & 0.029 \\
\hline 32 & Calumenin - A & AIPGENE25880 & 35,247 & 4.5 & 1.69 & 0.015 \\
\hline 34 & Glutamate Receptor & AIPGENE24462 & 101,286 & 9.2 & 1.63 & 0.008 \\
\hline 50 & Myosin Heavy Chain & AIPGENE8264 & 220,878 & 5.4 & 1.63 & 0.022 \\
\hline 27 & Aminopeptidase & AIPGENE26826 & 53,551 & 6.4 & 1.59 & 0.005 \\
\hline 3 & Zona Pellucida & AIPGENE843 & 47,035 & 5.0 & 1.57 & 0.044 \\
\hline 11 & $\begin{array}{l}\text { Heat Shock Protein } \\
(60 \mathrm{KDa})\end{array}$ & AIPGENE15267 & 62,708 & 5.3 & 1.57 & 0.051 \\
\hline 13 & Moesin/ezrin/radixin & AIPGENE9804 & 66,884 & 5.8 & 1.56 & 0.064 \\
\hline 43 & $\begin{array}{l}\text { Fructose- } \\
\text { Bisphosphate } \\
\text { Aldolase }\end{array}$ & AIPGENE2871 & 38,732 & 7.6 & 1.50 & 0.055 \\
\hline 61 & $\begin{array}{l}\text { Heat Shock Protein } \\
(70 \mathrm{KDa})\end{array}$ & AIPGENE12775 & 41,848 & 5.4 & 1.47 & 0.067 \\
\hline
\end{tabular}




\begin{tabular}{|c|c|c|c|c|c|c|}
\hline \multirow[t]{3}{*}{57} & Voltage Dependent & AIPGENE3808 & 35,188 & 9.1 & 1.45 & 0.027 \\
\hline & Anion Selective & & & & & \\
\hline & Channel & & & & & \\
\hline \multirow[t]{2}{*}{82} & Rho GDP- & AIPGENE26434 & 22,251 & 4.8 & 1.32 & 0.120 \\
\hline & Dissociation Inhibitor & & & & & \\
\hline 65 & Cathepsin & AIPGENE26157 & 36,124 & 6.7 & 1.25 & 0.041 \\
\hline \multirow[t]{2}{*}{42} & Aspartate & AIPGENE19338 & 45,969 & 6.8 & -1.47 & 0.004 \\
\hline & Aminotransferase & & & & & \\
\hline 87 & Zinc Finger Protein & AIPGENE28354 & 68,856 & 8.8 & -1.48 & 0.015 \\
\hline 35 & Cysteine Desulfurase & AIPGENE22361 & 54,104 & 6.2 & -1.48 & 0.091 \\
\hline 39 & Fumarylacetoacetase & AIPGENE8362 & 46,370 & 6.2 & -1.49 & 0.013 \\
\hline \multirow[t]{2}{*}{15} & Selenium Binding & AIPGENE13749 & 53,877 & 5.9 & -1.50 & 0.003 \\
\hline & Protein & & & & & \\
\hline 28 & Cysteine Desulfurase & AIPGENE22361 & 54,104 & 6.2 & -1.50 & 0.005 \\
\hline 14 & Bleomycin Hydrolase & AIPGENE9335 & 55,335 & 5.8 & -1.53 & 0.015 \\
\hline \multirow[t]{2}{*}{41} & Pancreatic & AIPGENE19570 & 38,517 & 8.7 & -1.55 & 0.025 \\
\hline & Triacylglycerol Lipase & & & & & \\
\hline 71 & $\begin{array}{l}\text { Heat Shock Protein } \\
(70 \mathrm{KDa})\end{array}$ & AIPGENE8252 & 41,986 & 5.3 & -1.58 & 0.055 \\
\hline 46 & Calumenin B & AIPGENE9938 & 38,837 & 5.5 & -1.59 & 0.004 \\
\hline 38 & Cysteine Desulfurase & AIPGENE22361 & 54,104 & 6.2 & -1.69 & 0.002 \\
\hline 56 & Hemicentin & AIPGENE28714 & 49,371 & 6.6 & -1.70 & 0.011 \\
\hline 55 & Thyroglobulin & AIPGENE20635 & 314,272 & 8.6 & -1.85 & 0.004 \\
\hline 74 & Nuclear Receptor & AIPGENE629 & 49,435 & 5.4 & -1.91 & 0.046 \\
\hline
\end{tabular}




\begin{tabular}{|c|c|c|c|c|c|c|}
\hline 70 & $\begin{array}{l}\text { Heat Shock Protein } \\
(70 \mathrm{KDa})\end{array}$ & AIPGENE8252 & 41,986 & 5.3 & -2.67 & 0.002 \\
\hline 68 & $\begin{array}{l}\text { Cyclic AMP and } \\
\text { cGMP }\end{array}$ & AIPGENE4644 & 51,903 & 5.8 & -4.05 & 0.017 \\
\hline & Phosphodiesterase & & & & & \\
\hline 69 & $\begin{array}{l}\text { Heat Shock Protein } \\
(70 \mathrm{KDa})\end{array}$ & AIPGENE8252 & 41,986 & 5.3 & -9.73 & 0.004 \\
\hline
\end{tabular}

Table 3-1. Identification of 32 proteins subjected to Mass Spectrometry analysis. 2D Gel Spot Number: Number as indicated on the 2D-DIGE gel on figure X; Protein Identification: Identity assigned by BLAST data base searches; Exaiptasia Genome Gene ID: Gene ID is based on the mapping identification for the Exaiptasia genome drafted by Voolstra, Pringle, Baumgarten [82]; Protein MW: Molecular weight of the protein; Protein PI: Isoelectric point of the protein; Fold Change: The fold change is based on protein expression of primed anemones versus non-primed (naïve) anemones; P Value T test: The significance probability value based on statistical $\mathrm{T}$ test. 


\begin{tabular}{|c|c|c|c|c|c|c|c|}
\hline $\begin{array}{c}\text { Spot } \\
\text { Number }\end{array}$ & $\begin{array}{c}\text { Protein } \\
\text { ID }\end{array}$ & $\begin{array}{l}\text { Aiptasia } \\
\text { Gene ID }\end{array}$ & $\begin{array}{c}\text { Protein } \\
\text { MW }\end{array}$ & $\begin{array}{c}\text { Protein } \\
\text { PI }\end{array}$ & $\begin{array}{c}\text { Fold } \\
\text { Change }\end{array}$ & $\begin{array}{c}\text { Biological process } \\
\text { (GO Term) }\end{array}$ & Level 3 GO Terms \\
\hline 2 & $\begin{array}{l}\text { Heat } \\
\text { Shock } \\
\text { Protein } \\
\text { (70 KDa) }\end{array}$ & $\begin{array}{l}\text { AIPGENE } \\
12496\end{array}$ & 74,685 & 5.6 & 2.02 & $\begin{array}{l}\text { Response to yeast, } \\
\text { ER overload } \\
\text { response, activation } \\
\text { of signaling protein } \\
\text { activity involved in } \\
\text { unfolding protein } \\
\text { response, cerebellum } \\
\text { structural } \\
\text { organization, } \\
\text { cerebellar Purinje cell } \\
\text { layer development, } \\
\text { negative regulation of } \\
\text { transforming growth } \\
\text { factor beta receptor } \\
\text { signaling pathway, } \\
\text { positive regulation of } \\
\text { protein ubiquination, } \\
\text { cellular response to } \\
\text { glucose starvation, } \\
\text { negative regulation of }\end{array}$ & $\begin{array}{l}\text { Response to stress, } \\
\text { cellular response to } \\
\text { stimulus, single- } \\
\text { organism cellular } \\
\text { process, anatomical } \\
\text { structure development, } \\
\text { single multicellular } \\
\text { organism process, } \\
\text { single organism } \\
\text { developmental process, } \\
\text { regulation of biological } \\
\text { process, response to } \\
\text { endogenous stimulus, } \\
\text { response to chemical, } \\
\text { catabolic process, } \\
\text { organic substance } \\
\text { metabolic substance } \\
\text { cellular response to } \\
\text { stimulus }\end{array}$ \\
\hline
\end{tabular}




\begin{tabular}{|c|c|c|c|c|c|c|c|}
\hline & & & & & & $\begin{array}{l}\text { apoptotic process, } \\
\text { proteolysis involved } \\
\text { in cellular protein } \\
\text { catabolic process, } \\
\text { cellular response to } \\
\text { interleukin -4 }\end{array}$ & \\
\hline 6 & $\begin{array}{l}\text { Signal } \\
\text { Recogniti } \\
\text { on Particle }\end{array}$ & $\begin{array}{l}\text { AIPGENE } \\
24594\end{array}$ & 72,108 & 6.44 & 1.88 & $\begin{array}{l}\text { GTP catabolic } \\
\text { process, SRP- } \\
\text { dependent } \\
\text { cotranslational } \\
\text { protein targeting to } \\
\text { membrane }\end{array}$ & $\begin{array}{l}\text { Single organism } \\
\text { cellular process }\end{array}$ \\
\hline 84 & $\begin{array}{l}\text { MRP } \\
\text { Protein }\end{array}$ & $\begin{array}{l}\text { AIPGENE } \\
1468\end{array}$ & 95,674 & 9.3 & 1.72 & Metabolic process & $\begin{array}{l}\text { Single-organism } \\
\text { metabolic process, } \\
\text { nitrogen compound } \\
\text { metabolic process, } \\
\text { cellular metabolic } \\
\text { process, organic } \\
\text { substance metabolic } \\
\text { process }\end{array}$ \\
\hline 32 & $\begin{array}{l}\text { Calumeni } \\
\mathrm{n}-\mathrm{A}\end{array}$ & $\begin{array}{l}\text { AIPGENE } \\
25880\end{array}$ & 35,247 & 4.5 & 1.69 & proteolysis & $\begin{array}{l}\text { Primary metabolic } \\
\text { process, organic }\end{array}$ \\
\hline
\end{tabular}




\begin{tabular}{|c|c|c|c|c|c|c|c|}
\hline & & & & & & & $\begin{array}{l}\text { substance metabolic } \\
\text { process }\end{array}$ \\
\hline 34 & $\begin{array}{l}\text { Glutamate } \\
\text { Receptor }\end{array}$ & $\begin{array}{l}\text { AIPGENE } \\
24462\end{array}$ & 101,286 & 9.2 & 1.63 & $\begin{array}{l}\text { Ion transmembrane } \\
\text { transport, ionotropic } \\
\text { glutamate receptor } \\
\text { signaling pathway }\end{array}$ & $\begin{array}{l}\text { Single organism } \\
\text { cellular process, single } \\
\text { organism localization, } \\
\text { single organism } \\
\text { signaling, cellular } \\
\text { response to stimulus, } \\
\text { regulation of biological } \\
\text { process }\end{array}$ \\
\hline 50 & $\begin{array}{l}\text { Myosin } \\
\text { Heavy } \\
\text { Chain }\end{array}$ & $\begin{array}{l}\text { AIPGENE } \\
8264\end{array}$ & 220,878 & 5.4 & 1.63 & NA & \\
\hline 27 & $\begin{array}{l}\text { Aminopep } \\
\text { tidase }\end{array}$ & $\begin{array}{l}\text { AIPGENE } \\
26826\end{array}$ & 53,551 & 6.4 & 1.59 & $\begin{array}{l}\text { Proteolysis, } \\
\text { regulation of catalytic } \\
\text { activity, protein } \\
\text { metabolic process }\end{array}$ & $\begin{array}{l}\text { Primary metabolic } \\
\text { process, organic } \\
\text { substance metabolic } \\
\text { process, regulation of } \\
\text { molecular function }\end{array}$ \\
\hline 3 & $\begin{array}{l}\text { Zona } \\
\text { Pellucida }\end{array}$ & $\begin{array}{l}\text { AIPGENE } \\
843\end{array}$ & 47,035 & 5.0 & 1.57 & $\begin{array}{l}\text { Receptor mediated } \\
\text { endocytosis, cell } \\
\text { adhesion, calcium ion } \\
\text { binding, negative }\end{array}$ & $\begin{array}{l}\text { Establishment of } \\
\text { localization, organic } \\
\text { substance metabolic } \\
\text { process, regulation of }\end{array}$ \\
\hline
\end{tabular}




\begin{tabular}{|c|c|c|c|c|c|c|c|}
\hline & & & & & & $\begin{array}{l}\text { regulation of } \\
\text { peptidase activity }\end{array}$ & molecular function \\
\hline 11 & $\begin{array}{l}\text { Heat } \\
\text { Shock } \\
\text { Protein } \\
(60 \mathrm{KDa})\end{array}$ & $\begin{array}{l}\text { AIPGENE } \\
15267\end{array}$ & 62,708 & 5.3 & 1.57 & $\begin{array}{l}\text { Fin regeneration, } \\
\text { protein refolding, } \\
\text { oxaloacetate } \\
\text { metabolic process, } \\
\text { glycerol biosynthetic } \\
\text { process, aspartate } \\
\text { biosynthetic process, } \\
\text { aspartate catabolic } \\
\text { process, response to } \\
\text { hormone, glutamate } \\
\text { catabolic process to } \\
\text { aspartate, glutamate } \\
\text { catabolic process t 2- } \\
\text { oxoglutarate, fatty } \\
\text { acid homeostasis }\end{array}$ & $\begin{array}{l}\text { Single organism } \\
\text { metabolic process, } \\
\text { organic substance } \\
\text { metabolic process, } \\
\text { cellular metabolic } \\
\text { process, primary } \\
\text { metabolic process, } \\
\text { nitrogen compound } \\
\text { metabolic process, } \\
\text { response to chemical, } \\
\text { single organism } \\
\text { cellular process, } \\
\text { regulation of biological } \\
\text { quality }\end{array}$ \\
\hline 13 & $\begin{array}{l}\text { Moesin/Ez } \\
\text { rin/Radixi } \\
\mathrm{n}\end{array}$ & $\begin{array}{l}\text { AIPGENE } \\
9804\end{array}$ & 66,884 & 5.8 & 1.56 & $\begin{array}{l}\text { Positive regulation of } \\
\text { gene expression, } \\
\text { cellular component } \\
\text { organization, } \\
\text { establishment of }\end{array}$ & $\begin{array}{l}\text { Organic substance } \\
\text { metabolic process, } \\
\text { regulation of biological } \\
\text { process, cellular } \\
\text { component }\end{array}$ \\
\hline
\end{tabular}




\begin{tabular}{|c|c|c|c|c|c|c|c|}
\hline & & & & & & endothelial barrier & $\begin{array}{l}\text { organization, single } \\
\text { organism } \\
\text { developmental process, } \\
\text { single organism } \\
\text { cellular process, } \\
\text { anatomical structure } \\
\text { development }\end{array}$ \\
\hline 43 & $\begin{array}{l}\text { Fructose- } \\
\text { Bisphosph } \\
\text { ate } \\
\text { Aldolase }\end{array}$ & $\begin{array}{l}\text { AIPGENE } \\
2871\end{array}$ & 38,732 & 7.6 & 1.5 & Glycolytic process & $\begin{array}{l}\text { Cellular metabolic } \\
\text { process, nitrogen } \\
\text { compound metabolic } \\
\text { process, organic } \\
\text { substance metabolic } \\
\text { process, primary } \\
\text { metabolic process, } \\
\text { single-organism } \\
\text { metabolic process, } \\
\text { catabolic process }\end{array}$ \\
\hline 61 & $\begin{array}{l}\text { Heat } \\
\text { Shock } \\
\text { Protein } \\
(70 \mathrm{KDa})\end{array}$ & $\begin{array}{l}\text { AIPGENE } \\
12775\end{array}$ & 41,848 & 5.4 & 1.47 & NA & \\
\hline 57 & Voltage & AIPGENE & 35,188 & 9.1 & 1.45 & Anion transport, fin & Single organism \\
\hline
\end{tabular}




\begin{tabular}{|c|c|c|c|c|c|c|c|}
\hline & $\begin{array}{l}\text { Dependent } \\
\text { Anion } \\
\text { Selective } \\
\text { Channel }\end{array}$ & 3808 & & & & $\begin{array}{l}\text { regeneration, } \\
\text { regulation of anion } \\
\text { transport, } \\
\text { transmembrane } \\
\text { transport }\end{array}$ & $\begin{array}{l}\text { localization, } \\
\text { establishment of } \\
\text { localization, response } \\
\text { to stress, single } \\
\text { organism } \\
\text { developmental process, } \\
\text { anatomical structure } \\
\text { development, } \\
\text { establishment of } \\
\text { localization, regulation } \\
\text { of biological process }\end{array}$ \\
\hline 82 & $\begin{array}{l}\text { Rho GDP- } \\
\text { Dissociati } \\
\text { on } \\
\text { Inhibitor }\end{array}$ & $\begin{array}{l}\text { AIPGENE } \\
26434\end{array}$ & 22,251 & 4.8 & 1.32 & $\begin{array}{l}\text { Proteolysis, } \\
\text { regulation of catalytic } \\
\text { activity, protein } \\
\text { metabolic process }\end{array}$ & $\begin{array}{l}\text { Organic substance } \\
\text { metabolic process, } \\
\text { primary metabolic } \\
\text { process, regulation of } \\
\text { molecular function }\end{array}$ \\
\hline 65 & Cathepsin & $\begin{array}{l}\text { AIPGENE } \\
26157\end{array}$ & 36,124 & 6.7 & 1.25 & $\begin{array}{l}\text { Proteolysis, } \\
\text { regulation of catalytic } \\
\text { activity, protein } \\
\text { metabolic process }\end{array}$ & $\begin{array}{l}\text { Organic substance } \\
\text { metabolic process, } \\
\text { primary metabolic } \\
\text { process, regulation of } \\
\text { molecular function }\end{array}$ \\
\hline 42 & Aspartate & AIPGENE & 45,969 & 6.8 & -1.47 & Oxaloacetate & Single organism \\
\hline
\end{tabular}




\begin{tabular}{|c|c|c|c|c|c|c|c|}
\hline & $\begin{array}{l}\text { Aminotran } \\
\text { sferase }\end{array}$ & 19338 & & & & $\begin{array}{l}\text { metabolic process, } \\
\text { glycerol biosynthetic } \\
\text { process, aspartate } \\
\text { biosynthetic process, } \\
\text { aspartate catabolic } \\
\text { process, response to } \\
\text { hormone, glutamate } \\
\text { catabolic process to } \\
\text { aspartate, glutamate } \\
\text { catabolic process to } \\
\text { 2-oxoglutarate, fatty } \\
\text { acid homeostasis }\end{array}$ & $\begin{array}{l}\text { metabolic process, } \\
\text { organic substance } \\
\text { metabolic process, } \\
\text { cellular metabolic } \\
\text { process, single } \\
\text { organism cellular } \\
\text { process, biosynthetic } \\
\text { process, primary } \\
\text { metabolic process, } \\
\text { nitrogen compound } \\
\text { metabolic process, } \\
\text { response to chemical, } \\
\text { regulation of biological } \\
\text { quality }\end{array}$ \\
\hline 87 & $\begin{array}{l}\text { Zinc } \\
\text { Finger } \\
\text { Protein }\end{array}$ & $\begin{array}{l}\text { AIPGENE } \\
28354\end{array}$ & 68,856 & 8.78 & -1.48 & $\begin{array}{l}\text { Regulation of } \\
\text { transcription, DNA } \\
\text { template, chitin } \\
\text { metabolic process }\end{array}$ & $\begin{array}{l}\text { Organic substance } \\
\text { metabolic process, } \\
\text { nitrogen compound } \\
\text { metabolic process, } \\
\text { cellular metabolic } \\
\text { process, biosynthetic } \\
\text { process }\end{array}$ \\
\hline 35 & Cysteine & AIPGENE & 54,104 & 6.2 & -1.48 & Metabolic process & Nitrogen compound \\
\hline
\end{tabular}




\begin{tabular}{|c|c|c|c|c|c|c|c|}
\hline & $\begin{array}{l}\text { Desulfuras } \\
\text { e }\end{array}$ & 22361 & & & & & $\begin{array}{l}\text { metabolic process, } \\
\text { primary metabolic } \\
\text { process, cellular } \\
\text { metabolic process, } \\
\text { organic substance } \\
\text { metabolic process }\end{array}$ \\
\hline 39 & $\begin{array}{l}\text { Fumarylac } \\
\text { etoacetase }\end{array}$ & $\begin{array}{l}\text { AIPGENE } \\
8362\end{array}$ & $46,370.7$ & 6.2 & -1.49 & $\begin{array}{l}\text { Arginine catabolic } \\
\text { process, aromatic } \\
\text { amino acid family } \\
\text { metabolic process }\end{array}$ & $\begin{array}{l}\text { Nitrogen compound } \\
\text { metabolic process, } \\
\text { organic substance } \\
\text { metabolic process, } \\
\text { cellular metabolic } \\
\text { process, single } \\
\text { organism cellular } \\
\text { process, single } \\
\text { organism metabolic } \\
\text { process }\end{array}$ \\
\hline 15 & $\begin{array}{l}\text { Selenium } \\
\text { Binding } \\
\text { Protein }\end{array}$ & $\begin{array}{l}\text { AIPGENE } \\
13749\end{array}$ & 53,877 & 5.9 & -1.5 & $\begin{array}{l}\text { Protein transport, } \\
\text { brown fat } \\
\text { differentiation }\end{array}$ & $\begin{array}{l}\text { Single organism } \\
\text { developmental process, } \\
\text { single organism } \\
\text { cellular process }\end{array}$ \\
\hline 28 & $\begin{array}{l}\text { Cysteine } \\
\text { Desulfuras }\end{array}$ & $\begin{array}{l}\text { AIPGENE } \\
22361\end{array}$ & 54,104 & 6.2 & -1.5 & Metabolic process & $\begin{array}{l}\text { Nitrogen compound } \\
\text { metabolic process, }\end{array}$ \\
\hline
\end{tabular}




\begin{tabular}{|c|c|c|c|c|c|c|c|}
\hline & $\mathrm{e}$ & & & & & & $\begin{array}{l}\text { primary metabolic } \\
\text { process, cellular } \\
\text { metabolic process, } \\
\text { organic substance } \\
\text { metabolic process }\end{array}$ \\
\hline 14 & $\begin{array}{l}\text { Bleomyci } \\
\mathrm{n} \\
\text { Hydrolase }\end{array}$ & $\begin{array}{l}\text { AIPGENE } \\
9335\end{array}$ & 55,335 & 5.8 & -1.53 & $\begin{array}{l}\text { Proteolysis, response } \\
\text { to drug }\end{array}$ & $\begin{array}{l}\text { Organic substance } \\
\text { metabolic process, } \\
\text { primary metabolic } \\
\text { process, response to } \\
\text { chemical }\end{array}$ \\
\hline 41 & $\begin{array}{l}\text { Pancreatic } \\
\text { Triacylgly } \\
\text { cerol } \\
\text { Lipase }\end{array}$ & $\begin{array}{l}\text { AIPGENE } \\
19570\end{array}$ & 38,517 & 8.7 & -1.55 & $\begin{array}{l}\text { Lipid metabolic } \\
\text { process }\end{array}$ & $\begin{array}{l}\text { Organic substance } \\
\text { metabolic process, } \\
\text { primary metabolic } \\
\text { process, single } \\
\text { organism metabolic } \\
\text { process }\end{array}$ \\
\hline 71 & $\begin{array}{l}\text { Heat } \\
\text { Shock } \\
\text { Protein } \\
(70 \mathrm{KDa})\end{array}$ & $\begin{array}{l}\text { AIPGENE } \\
8252\end{array}$ & 41,986 & 5.3 & -1.58 & NA & \\
\hline 46 & $\begin{array}{l}\text { Calumeni } \\
\text { n B }\end{array}$ & $\begin{array}{l}\text { AIPGENE } \\
9938\end{array}$ & 38,837 & 5.5 & -1.59 & NA & \\
\hline
\end{tabular}




\begin{tabular}{|c|c|c|c|c|c|c|c|}
\hline 38 & $\begin{array}{l}\text { Cysteine } \\
\text { Desulfuras } \\
\text { e }\end{array}$ & $\begin{array}{l}\text { AIPGENE } \\
22361\end{array}$ & 54,104 & 6.2 & -1.69 & Metabolic process & $\begin{array}{l}\text { Nitrogen compound } \\
\text { metabolic process, } \\
\text { primary metabolic } \\
\text { process, cellular } \\
\text { metabolic process, } \\
\text { organic substance } \\
\text { metabolic process }\end{array}$ \\
\hline 56 & $\begin{array}{l}\text { Hemicenti } \\
\mathrm{n}\end{array}$ & $\begin{array}{l}\text { AIPGENE } \\
28714\end{array}$ & 49,371 & 6.6 & -1.7 & $\begin{array}{l}\text { Chitin metabolic } \\
\text { process }\end{array}$ & $\begin{array}{l}\text { Organic substance } \\
\text { metabolic process, } \\
\text { nitrogen compound } \\
\text { metabolic process }\end{array}$ \\
\hline 55 & $\begin{array}{l}\text { Thyroglob } \\
\text { ulin }\end{array}$ & $\begin{array}{l}\text { AIPGENE } \\
20635\end{array}$ & $\begin{array}{l}314,272 . \\
6\end{array}$ & 8.56 & -1.85 & $\begin{array}{l}\text { Cell matrix adhesion, } \\
\text { negative regulation of } \\
\text { endopeptidase } \\
\text { activity, negative } \\
\text { regulation of } \\
\text { peptidase activity }\end{array}$ & $\begin{array}{l}\text { Organic substance } \\
\text { metabolic process, } \\
\text { regulation of biological } \\
\text { process, regulation of } \\
\text { molecular function }\end{array}$ \\
\hline 74 & $\begin{array}{l}\text { Nuclear } \\
\text { Receptor }\end{array}$ & $\begin{array}{l}\text { AIPGENE } \\
629\end{array}$ & $49,435.8$ & 5.39 & -1.91 & $\begin{array}{l}\text { Regulation of } \\
\text { transcription, } \\
\text { intracellular receptor } \\
\text { signaling pathway, } \\
\text { response to lipid, }\end{array}$ & $\begin{array}{l}\text { Single organism } \\
\text { signaling, cellular } \\
\text { response to stimulus, } \\
\text { single organism } \\
\text { cellular process, }\end{array}$ \\
\hline
\end{tabular}




\begin{tabular}{|c|c|c|c|c|c|c|c|}
\hline & & & & & & organ development & $\begin{array}{l}\text { regulation of biological } \\
\text { process, response to } \\
\text { chemical, single } \\
\text { multicellular organism } \\
\text { process, single } \\
\text { organism } \\
\text { developmental process }\end{array}$ \\
\hline 70 & $\begin{array}{l}\text { Heat } \\
\text { Shock } \\
\text { Protein } \\
(70 \mathrm{KDa})\end{array}$ & $\begin{array}{l}\text { AIPGENE } \\
8252\end{array}$ & 41,986 & 5.3 & -2.67 & NA & \\
\hline 68 & $\begin{array}{l}\text { Cyclic } \\
\text { AMP and } \\
\text { cGMP } \\
\text { Phosphodi } \\
\text { esterase }\end{array}$ & $\begin{array}{l}\text { AIPGENE } \\
4644\end{array}$ & 51,903 & 5.8 & -4.05 & NA & \\
\hline 69 & $\begin{array}{l}\text { Heat } \\
\text { Shock } \\
\text { Protein } \\
(70 \mathrm{KDa})\end{array}$ & $\begin{array}{l}\text { AIPGENE } \\
8252\end{array}$ & 41,986 & 5.3 & -9.73 & NA & \\
\hline
\end{tabular}

Table 3-2: Blast2GO gene ontology terms provided for the 30 proteins analyzed by Mass Spectrometry. 


\subsection{References}

1. Janeway C, Travers P, Walport M, Capra J (1999) Immunobiology: the immune system in health and disease. New York, New York: Elsevier Science Ltd./Garland Publishing.

2. Beck G, Habicht GS (1996) Immunity and the invertebrates - The fabulously complex immune systems of humans and other mammals evolved over hundreds of millions of years-in sometimes surprising ways. Scientific American 275: 60-+.

3. Loker ES, Adema CM, Zhang SM, Kepler TB (2004) Invertebrate immune systems not homogeneous, not simple, not well understood. Immunological Reviews 198: $10-24$.

4. Little TJ, Hultmark D, Read AF (2005) Invertebrate immunity and the limits of mechanistic immunology. Nature Immunology 6: 651-654.

5. Kurtz J (2004) Memory in the innate and adaptive immune systems. Microbes and Infection 6: 1410-1417.

6. Kurtz J, Franz K (2003) Evidence for memory in invertebrate immunity. Nature 425: 37-38.

7. Little TJ, O'Connor B, Colegrave N, Watt K, Read AF (2003) Maternal transfer of strain-specific immunity in an invertebrate. Current Biology 13: 489-492.

8. Roth O, Sadd BM, Schmid-Hempel P, Kurtz J (2009) Strain-specific priming of resistance in the red flour beetle, Tribolium castaneum. Proceedings of the Royal Society B-Biological Sciences 276: 145-151.

9. Sadd BM, Schmid-Hempel P (2006) Insect immunity shows specificity in protection upon secondary pathogen exposure. Current Biology 16: 1206-1210. 
10. Johnson KN, van Hulten MCW, Barnes AC (2008) "Vaccination" of shrimp against viral pathogens: phenomenology and underlying mechanisms. Vaccine 26: 48854892.

11. Pham LN, Dionne MS, Shirasu-Hiza M, Schneider DS (2007) A specific primed immune response in Drosophila is dependent on phagocytes. PLoS Pathog 3: e26.

12. Roth O, Kurtz J (2009) Phagocytosis mediates specificity in the immune defence of an invertebrate, the woodlouse Porcellio scaber (Crustacea: Isopoda). Developmental \& Comparative Immunology 33: 1151-1155.

13. Rodrigues J, Brayner FA, Alves LC, Dixit R, Barillas-Mury C (2010) Hemocyte differentiation mediates innate immune memory in Anopheles gambiae mosquitoes. Science 329: 1353-1355.

14. Hildemann WH, Bigger CH, Jokiel PL (1979) Characteristics of immune memory in invertebrates. American Zoologist 19: 911-911.

15. Hildemann WH, Jokiel PL, Bigger CH, Johnston IS (1980) Allogeneic polymorphism and alloimmune memory in the coral, Montipora verrucosa. Transplantation 30: 297-301.

16. Hildemann WH, Raison RL, Cheung G, Hull CJ, Akaka L, et al. (1977) Immunological specificity and memory in a scleractinian coral. Nature 270: 219223.

17. Bigger $\mathrm{CH}$ (1980) Interspecific and intraspecific acrorhagial aggressive-behavior among sea anemones - a recognition of self and not-self. Biological Bulletin 159: $117-134$.

18. Saltercid L, Bigger CH (1991) Alloimmunity in the gorgonian coral Swiftia exerta. Biological Bulletin 181: 127-134. 
19. Bourne DG, Garren M, Work TM, Rosenberg E, Smith GW, et al. (2009) Microbial disease and the coral holobiont. Trends in Microbiology 17: 554-562.

20. Richardson LL (1998) Coral diseases: what is really known? Trends in Ecology \& Evolution 13: 438-443.

21. Rosenberg E, Koren O, Reshef L, Efrony R, Zilber-Rosenberg I (2007) The role of microorganisms in coral health, disease and evolution. Nature Reviews Microbiology 5: 355-362.

22. Sheridan C, Kramarsky-Winter E, Sweet M, Kushmaro A, Leal MC (2013) Diseases in coral aquaculture: causes, implications and preventions. Aquaculture 396: 124135.

23. Harvell CD, Mitchell CE, Ward JR, Altizer S, Dobson AP, et al. (2002) Ecology climate warming and disease risks for terrestrial and marine biota. Science 296: 2158-2162.

24. Harvell D, Jordan-Dahlgren E, Merkel S, Rosenberg E, Raymundo L, et al. (2007) Coral disease, environmental drivers, and the balance between coral and microbial associates. Oceanography 20: 172-195.

25. Hoegh-Guldberg O, Mumby PJ, Hooten AJ, Steneck RS, Greenfield P, et al. (2007) Coral reefs under rapid climate change and ocean acidification. Science 318: 1737-1742.

26. Burge CA, Eakin CM, Friedman CS, Froelich B, Hershberger PK, et al. (2014) Climate change influences on marine infectious diseases: implications for management and society. Annual Review of Marine Science, Vol 6 6: 249-277.

27. Weis VM, Davy SK, Hoegh-Guldberg O, Rodriguez-Lanetty M, Pringe JR (2008) Cell biology in model systems as the key to understanding corals. Trends in Ecology \& Evolution 23: 369-376. 
28. Otero C, Brown T, Rodriguez-Lanetty M. Genomic analysis shows bacterial community shifts in Aiptasia pallida between environments.; 2014; Jacksonville, FL.

29. Santos SR, Gutierrez-Rodriguez C, Coffroth MA (2003) Phylogenetic identification of symbiotic dinoflagellates via length heteroplasmy in domain $\mathrm{V}$ of chloroplast large subunit (cp23S)-ribosomal DNA sequences. Marine Biotechnology 5: 130140.

30. Ben-Haim Y, Thompson FL, Thompson CC, Cnockaert MC, Hoste B, et al. (2003) Vibrio coralliilyticus sp nov., a temperature-dependent pathogen of the coral Pocillopora damicornis. International Journal of Systematic and Evolutionary Microbiology 53: 309-315.

31. Sussman M, Willis BL, Victor S, Bourne DG (2008) Coral pathogens identified for White Syndrome (WS) epizootics in the Indo-Pacific. Plos One 3.

32. Zaragoza WJ, Krediet CJ, Meyer JL, Canas G, Ritchie KB, et al. (2014) Outcomes of infections of sea anemone Aiptasia pallida with Vibrio spp. pathogenic to corals. Microbial Ecology 68: 388-396.

33. Brown T, Rodriguez-Lanetty M (2015) Molecular mechanisms underpinning immunological memory in a basal metazoan (Cnidaria). Integrative and Comparative Biology 55: E21-E21.

34. Patterson KL, Porter JW, Ritchie KE, Polson SW, Mueller E, et al. (2002) The etiology of white pox, a lethal disease of the Caribbean elkhorn coral, Acropora palmata. Proceedings of the National Academy of Sciences of the United States of America 99: 8725-8730.

35. Krediet CJ, Meyer JL, Gimbrone N, Yanong R, Berzins I, et al. (2014) Interactions between the tropical sea anemone Aiptasia pallida and Serratia marcescens, an opportunistic pathogen of corals. Environmental Microbiology Reports 6: 287292. 
36. Alagely A, Krediet CJ, Ritchie KB, Teplitski M (2011) Signaling-mediated cross-talk modulates swarming and biofilm formation in a coral pathogen Serratia marcescens. The ISME journal 5: 1609-1620.

37. Ben-Haim Y, Zicherman-Keren M, Rosenberg E (2003) Temperature-regulated bleaching and lysis of the coral Pocillopora damicornis by the novel pathogen Vibrio coralliilyticus. Applied and Environmental Microbiology 69: 4236-4242.

38. Brown T, Bourne D, Rodriguez-Lanetty M (2013) Transcriptional activation of $c 3$ and $h s p 70$ as part of the immune response of Acropora millepora to bacterial challenges. Plos One 8.

39. Polson SW, Higgins JL, Woodley CM. PCR-based assay for detection of four coral pathogens; 2008; Ft. Lauderdale, Florida.

40. Link K (2005) The vaccine controversy: The history, use, and safety of vaccinations: Greenwood Publishing Group.

41. Gergen PJ, McQuillan GM, Kiely M, Ezzati-Rice TM, Sutter RW, et al. (1995) A population-based serologic survey of immunity to tetanus in the United States. New England Journal of Medicine 332: 761-767.

42. Young D, Hussell T, Dougan G (2002) Chronic bacterial infections: living with unwanted guests. Nature Immunology 3: 1026-1032.

43. Rinkevich B (2004) Allorecognition and xenorecognition in reef corals: a decade of interactions. Hydrobiologia 530: 443-450.

44. Contreras-Garduno J, Rodriguez MC, Rodriguez MH, Alvarado-Delgado A, LanzMendoza H (2014) Cost of immune priming within generations: trade-off between infection and reproduction. Microbes and Infection 16: 261-267. 
45. Bruno JF, Selig ER, Casey KS, Page CA, Willis BL, et al. (2007) Thermal stress and coral cover as drivers of coral disease outbreaks. Plos Biology 5: 1220-1227.

46. Cervino JM, Hayes RL, Polson SW, Polson SC, Goreau TJ, et al. (2004) Relationship of Vibrio species infection and elevated temperatures to yellow blotch/band disease in Caribbean corals. Applied and Environmental Microbiology 70: 68556864.

47. Ruiz-Moreno D, Vargas IS, Olson KE, Harrington LC (2012) Modeling dynamic introduction of Chikungunya Virus in the United States. Plos Neglected Tropical Diseases 6.

48. Ward JR, Kim K, Harvell CD (2007) Temperature affects coral disease resistance and pathogen growth. Marine Ecology-Progress Series 329: 115-121.

49. Miller AW, Richardson LL (2012) Fine structure analysis of black band disease (BBD) infected coral and coral exposed to the BBD toxins microcystin and sulfide. Journal of Invertebrate Pathology 109: 27-33.

50. Abdul-Careem MF, Lee AJ, Pek EA, Gill N, Gillgrass AE, et al. (2012) Genital HSV2 infection induces short-term NK cell memory. Plos One 7.

51. Dhinaut J, Chogne M, Moret Y (2017) Immune priming specificity within and across generations reveals the range of pathogens affecting evolution of immunity in an insect. Journal of Animal Ecology.

52. Ziauddin J, Schneider DS (2012) Where does innate immunity stop and adaptive immunity begin? Cell Host \& Microbe 12: 394-395.

53. Dong YM, Taylor HE, Dimopoulos G (2006) AgDscam, a hypervariable immunoglobulin domain-containing receptor of the Anopheles gambiae innate immune system. Plos Biology 4: 1137-1146. 
54. Watson FL, Puttmann-Holgado R, Thomas F, Lamar DL, Hughes M, et al. (2005) Extensive diversity of Ig-superfamily proteins in the immune system of insects. Science 309: 1874-1878.

55. Hemmrich G, Miller DJ, Bosch TCG (2007) The evolution of immunity: a low-life perspective. Trends in Immunology 28: 449-454.

56. Jesus Otero-Gonzalez A, Magalhaes BS, Garcia-Villarino M, Lopez-Abarrategui C, Sousa DA, et al. (2010) Antimicrobial peptides from marine invertebrates as a new frontier for microbial infection control. FASEB Journal 24: 1320-1334.

57. Mydlarz LD, Jones LE, Harvell CD (2006) Innate immunity environmental drivers and disease ecology of marine and freshwater invertebrates. Annual Review of Ecology Evolution and Systematics. pp. 251-288.

58. Libro S, Kaluziak ST, Vollmer SV (2013) RNA-seq profiles of immune related genes in the staghorn coral Acropora cervicornis infected with white band disease. Plos One 8.

59. Pinzon JHC, Beach-Letendre J, Weil E, Mydlarz LD (2014) Relationship between phylogeny and immunity suggests older Caribbean coral lineages are more resistant to disease. Plos One 9.

60. Bolte S, Roth O, Philipp EER, Saphoerster J, Rosenstiel P, et al. (2013) Specific immune priming in the invasive ctenophore Mnemiopsis leidyi. Biology Letters 9.

61. Netea MG, Quintin J, van der Meer JWM (2011) Trained immunity: a memory for innate host defense. Cell Host \& Microbe 9: 355-361.

62. Cheng SC, Quintin J, Cramer RA, Shepardson KM, Saeed S, et al. (2014) mTORand HIF-1 alpha-mediated aerobic glycolysis as metabolic basis for trained immunity. Science 345: 1579-+. 
63. Rinkevich B (2011) The 'immunology trap' of anthozoans. Visions and Perspectives.

64. Li GC, Werb Z (1982) Correlation between synthesis of heat-shock proteins and development of thermotolerance in Chinese hamster fibroblasts. Proceedings of the National Academy of Sciences of the United States of America-Biological Sciences 79: 3218-3222.

65. Lindquist S, Craig EA (1988) The heat-shock proteins. Annual Review of Genetics 22: 631-677.

66. Zugel U, Kaufmann SHE (1999) Immune response against heat shock proteins in infectious diseases. Immunobiology 201: 22-35.

67. Kono H, Rock KL (2008) How dying cells alert the immune system to danger. Nature Reviews Immunology 8: 279-289.

68. Sanchez-Perez L, Kottke T, Daniels GA, Diaz RM, Thompson J, et al. (2006) Killing of normal melanocytes, combined with heat shock protein 70 and CD40L expression, cures large established melanomas. Journal of Immunology 177: 4168-4177.

69. Zhang K, Zhou B, Wang YY, Rao L, Zhang L (2013) The TLR4 gene polymorphisms and susceptibility to cancer: a systematic review and meta-analysis. European Journal of Cancer 49: 946-954.

70. Prohaszka Z, Singh M, Nagy K, Kiss E, Lakos G, et al. (2002) Heat shock protein 70 is a potent activator of the human complement system. Cell Stress \& Chaperones 7: $17-22$.

71. Baruah K, Ranjan J, Sorgeloos P, MacRae TH, Bossier P (2011) Priming the prophenoloxidase system of Artemia franciscana by heat shock proteins protects against Vibrio campbellii challenge. Fish \& Shellfish Immunology 31: 134-141. 
72. Sung YY, Pineda C, MacRae TH, Sorgeloos P, Bossier P (2008) Exposure of gnotobiotic Artemia franciscana larvae to abiotic stress promotes heat shock protein 70 synthesis and enhances resistance to pathogenic Vibrio campbellii. Cell Stress \& Chaperones 13: 59-66.

73. Sung YY, Dhaene T, Defoirdt T, Boon N, MacRae TH, et al. (2009) Ingestion of bacteria overproducing DnaK attenuates Vibrio infection of Artemia franciscana larvae. Cell Stress \& Chaperones 14: 603-609.

74. Benton R, Vannice KS, Gomez-Diaz C, Vosshall LB (2009) Variant ionotropic glutamate receptors as chemosensory receptors in Drosophila. Cell 136: 149-162.

75. Croset V, Rytz R, Cummins SF, Budd A, Brawand D, et al. (2010) Ancient protostome origin of chemosensory ionotropic glutamate receptors and the evolution of insect taste and olfaction. Plos Genetics 6.

76. Forde BG, Roberts MR (2014) Glutamate receptor-like channels in plants: a role as amino acid sensors in plant defence? F1000Prime Reports 6.

77. Mousavi SAR, Chauvin A, Pascaud F, Kellenberger S, Farmer EE (2013) Glutamate receptor-like genes mediate leaf-to-leaf wound signalling. Nature 500: 422-+.

78. Conus S, Simon H-U (2010) Cathepsins and their involvement in immune responses. Swiss Medical Weekly 140: 4-11.

79. Matsumoto F, Saitoh SI, Fukui R, Kobayashi T, Tammura N, et al. (2008) Cathepsins are required for toll-like receptor 9 responses. Biochemical and Biophysical Research Communications 367: 693-699.

80. Ewald SE, Lee BL, Lau L, Wickliffe KE, Shi GP, et al. (2008) The ectodomain of Toll-like receptor 9 is cleaved to generate a functional receptor. Nature 456: 658U688. 
81. Park B, Brinkmann MM, Spooner E, Lee CC, Kim YM, et al. (2008) Proteolytic cleavage in an endolysosomal compartment is required for activation of Toll-like receptor 9. Nature Immunology 9: 1407-1414.

82. Baumgarten S, Simakov O, Esherick LY, Liew YJ, Lehnert EM, et al. (2015) The genome of Aiptasia, a sea anemone model for coral symbiosis. Proceedings of the National Academy of Sciences of the United States of America 112: 1189311898. 


\section{Chapter 4: Transcriptomics of immune priming in the sea anemone Exaiptasia pallida}

\subsection{Abstract}

Immunological priming allows for organisms to respond more rapidly to a previously encountered bacterial pathogen and has traditionally been viewed as a trait of the adaptive immune system. Cnidarians possess only an innate immune system and therefore should not possess this trait. However, previous work has shown that the model cnidarians Exaiptasia pallida possess a form of immune priming. However, little is known about the molecular mechanisms that are underpinning this phenomenon. In this study, a whole transcriptome analysis was used to compare gene expression profiles of primed, naïve challenged, and unchallenged E. pallida prior to and during the lethal exposure. Our findings indicate that priming in E. pallida is a multigene process which involves transcripts found in three major steps: signaling, prevention, and protection and that many of these genes are unique to priming response. Many of these gene has previously been located in the transcriptome of this cnidarian, this is the first time these genes have been implicated in immune priming.

\subsection{Introduction}

Immunological memory allows an organism to respond more rapidly to subsequent encounters with a pathogen but has long been viewed as a trait of the adaptive immune system [1]. Since invertebrate organisms only possess an innate immune system, it is generally held that they are incapable of immunological memory. Additionally, these 
organisms lack critical components of the adaptive immune system central to immunological memory: lymphocytes and antibodies are absent in invertebrates [1-4].

Despite the lack of classical adaptive immunity components, more recent work has documented immunological priming in multiple invertebrates [5-10] including the sea anemone Exaiptasia pallida [11]. The bubble bee, Bombus terrestris, gains increased immunological protection upon secondary exposure that persists for up to 27 days [10]; this duration of pathogen protection is relevant as $B$. terrestris has a lifespan of just four weeks [10]. In our previous study, E. pallida showed an enhanced response to secondary pathogen exposure up to one month after the primary exposure using the known coral pathogen Vibrio coralliilyticus. While the duration of immune priming may appear brief, we speculate that this priming may occur seasonally. Additionally, priming may be energetically costly to the organism; the temporary activation of priming during periods of high pathogen risk may represent a beneficial energetic compromise [11]. Elucidating mechanisms underpinning immunological priming in invertebrates is necessary to aid phenomenological studies [12]. Phenomenological studies are critical for uncovering and documenting the incident while molecular studies are crucial to identify the mechanisms behind invertebrate immune priming. Transcriptomic studies on immune priming will allow for the identification of many genes traditionally not viewed as being involved in immunity and are imperative in ending studies that borrow functionality from vertebrate immunity to invertebrate immunity [13]. Previous invertebrate immunological priming studies have largely been phenomenological and offer little in terms of mechanism (e.g. $[7,10])$. From the studies that have been conducted, molecular mechanisms appear to vary between organisms. Multiple organisms employ phagocytosis as a part of their innate 
immune response [14-16]. In the woodlouse Porcellio scaber, enhanced phagocytosis activity was demonstrated after the first encounter with Bacillus thuringiensis or Escherichia coli [9]. Furthermore, in shrimp, bacterial pre-exposure was shown to enhance cellular immunity during secondary challenge by increasing the number of phagocytic cells [17].

In Drosophila, a pathogen response in the form of antimicrobial peptides (AMPs) is induced by either Toll or Imd pathways, depending upon the type of pathogen encountered [18]. Furthermore, the expressed AMP is specifically triggered by type of pathogen encountered; fungal pathogens induce the production of antifungal AMPs while gram negative bacteria elicit the production of AMPs appropriate for the destruction of these pathogens [18]. Additionally, it has been suggested that in Drosophila, highly diverse isoforms of Dscam formed by alternative splicing may be the driver of immune priming [19]. Pattern recognition receptors have more widely been proposed as a potential mechanism for immune priming in invertebrates [15]. Recently, a minimal proteomic analysis indicated that immune priming in E. pallida is a multi-gene process that likely involves heat shock proteins, glutamate receptors, cathepsin, and toll-like receptors [11]. Studying disease as it pertains to cnidarians such as corals and sea anemones is of critical importance as the world's coral reefs are in peril, in part due to the impacts of widespread coral disease. Disease affects more than 130 coral species worldwide [20-22]. The number of known coral-associated diseases has also increased from two in 1965 to 25 in 2013 [21,23]. Immune priming is therefore of interest in longlived Anthozoans such as corals and sea anemones as these organisms can have lifespans of hundreds and even thousands of years [24]. During their lifespan, they will likely 
encounter and respond to the same pathogen many times. Potential support for the existence of immune priming originates from two coral species that displayed susceptibility to a bacterial pathogen only to later become resistant to the bacterium in subsequent years. The first report of apparent acquired pathogen resistance was observed in the coral Oculina patagonica, in which the bacterium Vibrio shiloi was shown to be the causative agent of bacteria-induced bleaching [25]. While the original study conducted between this coral and pathogen showed reproducible signs of disease [25], later studies showed that this strain no longer caused disease in O. patagonica [26]. A second example is seen in the bacterium Serratia marcescens PDL 100 which no longer causes white pox in the Caribbean coral Acropora palmata [27]. While the transient immunological priming found in E. pallida suggests that actively maintaining a primed status over periods exceeding multiple months may be too costly for the organism [11], priming may still aid in defense against repeated encounters with pathogens during the summer months when ocean temperatures are warm and bacterial loads are elevated. Short-term memory has also been demonstrated in corals in the context of tissue transplantation immunity which lasts for four weeks in the coral Montipora verrucosa [28] and eight weeks in the gorgonian Swiftia exerta [29].

Corals are notoriously challenging to keep in aquaria for experiments. In order to circumvent this problem, the sea anemone E. pallida has been selected as a tractable model system to study anthozoans due to its similarity to corals and amenability to study in the laboratory [30].

This study aimed to elucidate the molecular mechanisms underpinning immunological priming more extensively in the sea anemone E. pallida using a transcriptomic approach. 
Understanding the molecular mechanisms that drive immunological memory in cnidarians could shed light on how these organisms are able to sufficiently defend themselves from pathogens over their extensive life spans. This work addresses multiple questions in cnidarian immune priming. First, we ask which gene expression changes are associated with immune priming prior in E. pallida, both prior to and following pathogen challenge. Second, we seek to identify the transcriptome of infection. This knowledge will also allow for a better understanding of the evolution of immune priming.

\subsection{Materials and Methods}

\subsubsection{Exaiptasia husbandry}

E. pallida anemones used in this experiment originate from the $\mathrm{CC} 7$ clonal population (John Pringle Lab, Stanford University) and were maintained in artificial seawater at $25^{\circ} \mathrm{C}$ prior to experimental manipulations. The populations were maintained on a day: night cycle of 12 hours light:12 hours darkness and exposed to 30 to $60 \mu$ mole photons $\mathrm{m}^{-2} \mathrm{~s}^{-1}$ of light. Anemones were fed freshly hatched Artemia nauplii two times per week. E. pallida used in this study ranged from $3 \mathrm{~mm}$ to $10 \mathrm{~mm}$ in height.

\subsubsection{Experimental design and sample collection}

E. pallida priming experiments were conducted as previously described by Brown and Rodriguez-Lanetty [11]. Briefly, this experiment compares the transcriptomic states of $E$. pallida with the coral pathogen $V$. coralliilyticus. A total of 45 anemones were placed in individual wells of 12-well culture plates containing $4.5 \mathrm{ml}$ of artificial seawater and

allowed to recover from handling for 24 hours at $30^{\circ} \mathrm{C}$ under 30 to $60 \mu$ mole photons $\mathrm{m}^{-2}$ $\mathrm{s}^{-1}$ of light. After 24 hours, a randomly selected group of 18 anemones were exposed to 
$10^{8} \mathrm{CFU} \mathrm{ml}{ }^{-1}$ of $V$. coralliilyticus, constituting the primed treatment group. The remaining anemones were subjected to sham inoculation and randomly assigned to either naive (18 individuals) or unchallenged (9 individuals) groups.

After four days, water changes were performed on all anemones. Anemones were held under the aforementioned conditions for four weeks and fed Artemia twice weekly, with water changes following feeding. After four weeks, three pools of three anemones (nine animals pooled into three biological replicates) were snap frozen from both the primed group and naive group, comprising $0 \mathrm{~h}$ primed and $0 \mathrm{~h}$ naive samples. Concurrently, the remaining nine primed and nine naive animals were exposed to $10^{8} \mathrm{CFU} \mathrm{ml}{ }^{-1}$ of the pathogen, with the remaining nine unchallenged anemones subjected to sham inoculation; these three treatment groups represent $4 \mathrm{~h}$ primed, $4 \mathrm{~h}$ naive, and $4 \mathrm{~h}$ unchallenged groups, respectively. Four hours following pathogen challenge, all remaining anemones were snap frozen.

\subsubsection{Pathogen culture methods}

Vibrio coralliilyticus strain BAA-450 (ATCC) was recovered from glycerol stocks by streaking on a marine agar plate (Difco, USA) and incubating overnight at $30^{\circ} \mathrm{C}$. The following day a single colony was picked with a sterile inoculation loop and grown to logarithmic phase at $30^{\circ} \mathrm{C}$ in marine broth (Difco, USA) while shaking at $100 \mathrm{rpm}$. The cultures were pelleted by centrifugation at $3900 \mathrm{~g}$ for five minutes and then resuspended in an equal volume of sterile seawater. Bacterial cells were prepared to a final concentration of $10^{9} \mathrm{CFU} \mathrm{ml} l^{-1}$ according to a growth curve established for $V$. coralliilyticus based upon optical density at $600 \mathrm{~nm}$. CFU counts were performed on 
aliquots of culture to confirm the intended concentration for both priming and infection applications.

\subsubsection{Library preparation and sequencing}

Total RNA was extracted from frozen anemone tissue using a hybrid method combining an initial homogenization in one $\mathrm{ml}$ of Trizol Reagent (Invitrogen, Carlsbad, CA), following manufacturer's instructions through the chloroform extraction step. At this point, the aqueous phase was recovered, mixed with an equal volume of ethanol, and applied to a Qiagen RNeasy Mini Plant Kit (Hilden, Germany) column for DNase treatment and cleanup.

Library preparation and sequencing were performed from two micrograms of total RNA by Molecular Research LP (Shallowater, TX, USA). Libraries were prepared using Illumina (San Francisco, CA, USA) TruSeq v2 chemistry following ribosomal RNA depletion with Ribo-Zero Gold. The 15 libraries were pooled and sequenced in one Illumina HiSeq 150 base pair paired-end lane, yielding a minimum of 10 million read pairs per library.

Sequencing data were initially used for a genome-guided assembly, but this proved problematic as more than $90 \%$ of the reads did not originate from the host mRNA. Instead, paired-end reads were mapped to Exaiptasia gene models [31]. This method is not ideal as it does not allow for novel transcript discovery, but given the paucity of host reads, this was identified as the most reasonable approach. Paired-end reads from each sample were mapped using Bowtie [32] implemented through RSEM [33], resulting in a range of 192,377 to $1,251,453$ mapped read pairs per sample (mean 607,123 pairs, SD 
293,513). All data was quality trimmed to Q30 using Trimmomatic [34]. Using raw read counts from RSEM, gene expression analysis was performed using the R package edge $\mathrm{R}$ [35]. Here data was normalized via TMM, fit to a general linearized model, and assessed with a full factorial ANODEV. Tests were only performed on gene models to which a minimum of 10 reads mapped. All reported genes have a FDR-corrected p-value less than 0.05. All transcripts were annotated with Blast2GO [36]. Fischer's exact tests were performed to identify overrepresented gene ontology terms, with a FDR-corrected pvalue cutoff of 0.05 .

\subsection{Results and Discussion}

\subsubsection{Overall trends in gene expression in primed hosts}

Differentially expressed genes were detected in all comparisons, both prior to and four hours following challenge (Figure 4-1a). Our analyses detected more differentially expressed genes (DEGs) between primed and naïve hosts just prior to pathogen challenge (131 DEGs; see Figure 4-2) than four hours following challenge via exposure to $V$. coralliilyticus (28 DEGs).

Four hours after the pathogen challenge, a greater number of genes were differentially expressed in primed vs. unchallenged anemones (151 DEGs) than naïve vs. unchallenged anemones (78 DEGs; see Figure 4-4). The greater number of differentially expressed genes in primed anemones suggests that these anemones have a greater transcriptional response earlier during pathogen challenge, acting more rapidly than naïve anemones. Furthermore, of these 151 differentially expressed genes, 117 were upregulated while 32 were downregulated. These differences in overall gene expression modulation may 
indicate that primed anemones can mount a more rapid response to the pathogen than naïve E. pallida.

\subsubsection{Overrepresented gene ontology terms amongst differentially expressed genes}

Four weeks following the cessation of priming and just prior to pathogen challenge $(0 \mathrm{~h})$, we detected a total of 131 differentially expressed genes between the $0 \mathrm{~h}$ primed and $0 \mathrm{~h}$ naïve treatments. Of these, 38 were upregulated in the primed treatment. This set of genes was enriched for three specific gene ontologies: positive regulation of GTPase activity, Rho guanyl-nucleotide exchange factor activity, and phosphoric diester hydrolase activity (FDR < 0.05). 4h naive vs. $4 \mathrm{~h}$ unchallenged and $4 \mathrm{~h}$ naive vs. $4 \mathrm{~h}$ primed comparisons were not significantly enriched for any gene ontology terms.

\subsubsection{Enrichment of phosphoric diester hydrolase activity}

The significance of this phosphodiesterase activity in primed anemones is currently unknown, but in mammalian systems phosphodiesterases are active in macrophages where they counter inflammation inhibition through cyclic nucleotide signaling [37-40]. A potential role is supported by the fact that two of the phosphodiesterases upregulated in Oh Primed anemones are cAMP-specific (Table 4-2).

\subsubsection{Enrichment of GTPase and Rho guanyl-nucleotide exchange factor activity}

GTPase and Rho guanyl-nucleotide exchange factor activity have numerous activities in cell signaling, but are of particular interest in the context of innate immunity. The basic activities of innate immunity - recognition of the pathogen, phagocytosis, and subsequent clearing via degradation or apoptosis - must be highly controlled to avoid unnecessary 
collateral damage to the organism. Rho GTPase is a key regulator of these basic activities. One curious observation from the set of genes enriched for the GO terms GTPase and Rho guanyl-nucleotide exchange factor activity is the presence of multiple genes involved in the activation of ADP ribosylation factor 6 (ARF6), including an arfGAP ortholog and multiple GTPase-activating proteins that act on ARF6 (AIPGENE28379, AIPGENE5416, AIPGENE28597, AIPGENE5417, AIPGENE28598; Table 4-1). ARF6 is a small GTP-binding protein involved in membrane trafficking during receptor-mediated endocytosis [41] which has been directly implicated in innate immunity by its role in the uptake of $\mathrm{CpG}$ oligodeoxynucleotide into endosomes, a ratelimiting step in TLR9 signaling [42]. Modulation of this critical part of a signaling cascade could be a characteristic of immune priming.

\subsubsection{Molecular mechanisms of immune priming}

\subsubsection{Signaling}

Our proposed model of immune priming in E. pallida is a multigene phenomenon (Figure 4-3). We propose that recognition of $V$. coralliilyticus is accomplished via a leucine rich repeat (LRR), upregulated in primed anemones (anemones that had previously been challenged with the pathogen). Two different LRR-containing transcripts, both annotated as lrr-containing 16A isoform X2, were identified; one LRR transcript is upregulated in primed anemones in comparison to naïve anemones just prior to pathogen challenge (AIPGENE19656; Table 4-3) and another is upregulated following pathogen challenged (AIPGENE19649; Table 4-4). LRRs are evolutionarily-conserved domains that are associated with innate immunity in both vertebrates and invertebrates. They act as pattern 
recognition receptors (PRRs) by sensing pathogen associated molecular patterns (PAMP) [43]. Leucine-rich repeat domains have previously been implicated in cnidarian immune responses, in particular as a component of the Hydra toll-like receptor; Hydra toll-like receptors lack extracellular leucine-rich repeats, but possess separate leucine-rich transmembrane proteins which work in tandem with intracellular toll-receptor related proteins for the recognition of microbes [44]. Differential expression of LRRs in response to PAMPs has been demonstrated in corals, with an LRR transcript downregulated in the coral Orbicella faveolata in response to lipopolysaccharide (LPS) challenge [45].

In our proposed model (Figure 4-3), an E3 ubiquitin ligase lies downstream of a LRR binding with a PAMP. LRRs interact with an E3 ubiquitin ligase [43] which is significantly upregulated prior to pathogen challenge and downregulated four hours postexposure (Table 4-2). In plants, E3 ubiquitin ligase targets LRR proteins, acting to attenuate the immune response and avoid autoimmunity by preventing the buildup of resistance proteins [46].

\subsubsection{Prevention}

Four hours after pathogen exposure, a tight junction-associated protein, ZO-1, is upregulated in primed E. pallida when compared to naive challenged anemones (AIPGENE11422; Table 4-4). Tight junctions are important barriers that prevent the entry of pathogens [47]. A congener of $V$. coralliilyticus, the human pathogen $V$. cholera, produces a toxin, zot, which attacks tight junctions [48]. The role of tight junction toxins in $V$. coralliilyticus is not currently know, but the upregulation of tight junctions at four hours could indicate that primed anemones are erecting cell surface barriers to prevent 
the further entry of pathogens earlier in the immune response than naïve individuals. This may represent part of a more effective immune response, reducing the extent of infection and reducing lethality in primed anemones.

\subsubsection{Protection}

Inflammatory response has been previously identified as a major component of coral immune response to disease $[45,49-52]$. Inflammation appears to be a major protecting factor in immunological priming in E. pallida with several components implicated in inflammation differentially expressed. Both nuclear factor of activated $\mathrm{T}$ cell transcription factor 5 (NFAT5) and TRAF2 are upregulated in primed anemones when compared to naïve challenged anemones. Integrin-linked kinase (ILK) is a another transcript that is implicated in the inflammation and was differentially expressed in all three comparisons: downregulated in primed anemones at zero hours in comparison to naive hosts, but later upregulated in primed anemones following pathogen challenge, and finally downregulated in naive hosts in comparison to unchallenged animals four hours after pathogen challenge. In mammalian macrophages, NFAT5 expression is activated by the interaction of a TLR with LPS or heat-inactivated Escherichia coli, with downstream pro-inflammatory cytokine production leading to macrophage activation [53]. Further, NFAT5 is ubiquitously upregulated in response to LPS in the amphioxus species Branchiostoma belcheri. [54]. The upregulation of an NFAT5 ortholog (AIPGENE1103;

Table 4-3) is at zero hours in primed anemones suggests that persistent inflammation may be playing a role in immune priming in E. pallida. Further, the aforementioned enriched phosphodiesterase activity presumably promotes and maintains this inflammation cycle. 
TRAF2 is another gene involved in inflammation (AIPGENE19990). It promotes TLRstimulated proinflammatory cytokine expression in macrophages [55]. The most common cascade of events after TRAF2 activation leads to NF- $\mathrm{kB}$ activation [56,57]. While this study did not detect differential expression of NF- $\mathrm{kB}$, this is not particularly surprising as $\mathrm{NF}-\mathrm{kB}$ is post-transcriptionally regulated (reviewed by [58]). The activation of NF- $\mathrm{kB}$ can lead to apoptosis, mediated by Rho guanine nucleotide exchange factor signalling [59]. It is important to note that NF- $\mathrm{\kappa B}$ is a dimeric transcription factor that can influence genes that are involved in a wide range of processes which include immunity, inflammation, stress responses [60]. There is also support for an alternate mechanism of NF- $\kappa \mathrm{B}$ activation in immune priming. Integrin-linked kinase (ILK) is involved in an alternative activation of NF- $\mathrm{KB}$ signaling by modulating the phosphorylation of $\mathrm{p} 65$ at Ser536 [61].

Calcium influx also appears to be an important protective component of immunological priming in E. pallida. We observed notable calcium-binding EF-hand family protein activity, with one transcript upregulated in primed individuals when compared to naive $E$. pallida at zero hours (AIPGENE 27831), and another calcium-binding EF-hand family protein transcript (AIPGENE 26984) upregulated at four hours. Calcium influx in response to the stress associated with pathogen encounters is one of the early responses of plants to pathogen encounters [62]. Calcium ions act as a signatures associated with a pathogen, with sensing accomplished by the EF-hand family proteins calmodulin and calcineurin B-like proteins [63]. The constitutive expression of the EF-hand family protein calmodulin can alone elicit a pathogen response, resulting in resistance to pathogens [64]. This suggests that calmodulins are rate-limiting factors in the pathogenic 
response of plants [64]. Though it is currently unknown whether mechanisms of calciummediated pathogen signaling present in plants are conserved in Exaiptasia, the increased expression of calcium binding transcripts in primed anemones both prior to and following pathogen challenge presents this possibility as a hypothesis.

\subsubsection{A potential role of epigenetics in priming}

Among the genes differentially expressed across time points, the transcript for histonelysine $\mathrm{N}$-methyltransferase $2 \mathrm{C}$ (KMT2C) is downregulated in primed anemones in comparison to naive anemones at both zero and four hours. This may indicate active chromatin remodeling associated with immune priming, as KMT2C is a critical component of the histone H3 lysine 4 methyltransferase complex and modulates various biological processes via heterochromatin modification $[65,66]$. Trimethylation of H3K4 is recognized as one of the strongest indicators of transcriptionally-active genes [67].

The epigenetic marks upon histone H3 caused by a decreased expression of KMT2C could potentially be involved in the persistence of immunological priming over the course of thirty days. In mammalian systems, there is a well-described role of epigenetic control of the inflammatory response (reviewed by [68]. In human dendritic cells, a decrease in $\mathrm{H} 3 \mathrm{~K} 4$ trimethylation leads to an increase in proinflammatory cytokines [69]. Whereas this was the result of the increased expression of a H3K4 demethylase [69], the decreased expression of a $\mathrm{H} 3 \mathrm{~K} 4$ methylase could potentially have a similar outcome over time. Histone involvement in immune memory has previously been demonstrated in distant taxa, with evidence of $\mathrm{H} 3 \mathrm{~K} 4$ modifications established during a priming event in Arabidopsis thaliana [70]. It remains unclear how a potential H3K4 methylation mark in 
Exaiptasia is potentially removed, but the decreased expression of KMT2C may suggest a lack of maintenance in these marks, potentially promoting an inflammatory response.

\subsubsection{Differentially expressed transcript with ortholog involved in adaptive immunity}

Forkhead box (FOX) proteins represent a diverse family of proteins, with several types involved in the adaptive immune response [71,72]. This family of proteins is characterized by the presence of a conserved 110 amino acid binding domain which is known as the forkhead domain or winged helix domain [72]. Forkhead box P3 (FOXP3) encodes transcription factors which are necessary for the generation and function of regulatory T cells. FOXP3 regulates the expression of TLR10 on T regulatory cells [71]. They play an essential role in controlling the immune response by controlling immune response, maintaining tolerance, and preventing autoimmunity [73]. FOXO is another transcription factor that is a member of this family. It is critical in regulating proliferation, apoptosis, and oxidative stress [72]. FOXO1 is found to be more highly expressed in T and B cells while FOXO3 shows greater expression in granulocytes, macrophages, and dendritic cells [74].

Two transcripts annotated as FOXP1 are differentially expressed between 4h Naive and 4h Primed treatments, with one upregulated in primed anemones (AIPGENE8666; Table 4) and the other downregulated (AIPGENE8667). The coding sequences of these apparent isoforms differ by a single amino acid. The established role of FOXP is as a transcription factor that is involved in the formation of lymphoid cells, where it is expressed in resting and activated B-cells [75]. While lymphoid and B-cells are important 
components of immune memory in the adaptive immune system, the function of a putative FOXP1 in cnidarian innate immunity remains unknown. Further, it is possible that the function of these FOXP1 homologs have diverged widely since the cnidarian/bilaterian split; the precise role of these transcripts in cnidarian immune priming will require further investigation.

\subsubsection{Incongruence and congruence with proteomic evidence of immune priming}

Previous work conducted on E. pallida immune priming from our research group found 39 differentially expressed proteins between primed and naïve anemones at zero hours, and the identity of 32 of these proteins was determined [11]. When comparing the two studies, only one of the proteins was also identified in both the proteomic work as well as in this transcriptomic study (AIPGENE28714). This is not entirely surprising since proteomics and transcriptomics interrogate different timescales of gene expression. Numerous explanations may be involved in the differences observed; for example, protein levels may be lagging behind transcription, while some genes may exhibit posttranscriptional and/or post-translational regulation as shown by Ghazalpour et al. (2011). It is also possible that many of the transcripts differentially expressed in primed anemones were not detected in the previous proteomic study due to the detection limit of the proteomic analysis. Proteomic analysis implementing differential in-gel electrophoresis (DIGE) depends upon the separation of proteins based upon mass and isolectric point, followed by sequencing of differentially features. Some of the transcripts detected could have very similar isoelectric points and therefore separate poorly on the gel, preventing identification by DIGE. 
The only differentially expressed gene in both studies was a rhamnospondin-2 ortholog (AIPGENE28714), which was downregulated in primed anemones in comparison to naive hosts at zero hours in both studies [11]. Rhamnospondin is a rhamnos-binding lectin (RBL) which recognize rhamnos, a mannose derived methylpentos sugar. In fish, RBLs are involved in immune response [77], with expression of the protein in cells associated with immunity such as lymphocytes, neutrophils, gill mucus cells, intestine goblet cells, spleen cells, and thrombocytes [78,79]. RBLs found in chum salmon and steelhead trout agglutinate $E$. coli and B. subtilis by recognition of the LPS and lipoteichoic acid of the bacterium. Additionally, it is hypothesized that rhamnospondin may possess dual pathogen recognition properties. The RBL domain of the molecule may act as a pattern recognition receptor (PRR) while the thrombospondin may act as the extracellular domain [80]. In cnidarians, rhamnospondin localized to the mouth of Hydractinia may aid in preventing pathogens from entering the organism [80].

While RBLs are upregulated in oysters in response to virulent Vibrio spp. [81] this study instead identifies downregulation prior to challenge. It is relevant that the RBL downregulated in primed E. pallida is involved in a priming response, rather than an acute infection. There are several cases whereby lectins are beneficially downregulated in response to pathogen challenge such as in macrophages [82,83] and in the shrimp Litopenaeus vannamei [84].

\subsubsection{Transcriptome of infection in naive host to first encounter of the pathogen}

The transcriptome of infection in naive hosts in comparison to unchallenged anemones (4h naive vs $4 \mathrm{~h}$ unchallenged) is associated with a dramatic upregulation of transcripts, 
with 63 differentially expressed gene upregulated in comparison to 15 downregulated (Figure 4-1). This pattern of upregulation of genes during an immune challenge has also been detected in corals [85] and could be indicative of the host allocating many of its resources to immune response.

One common response to a pathogen challenge is inflammation, and was observed in this study through the upregulation of numerous inflammation-related transcripts. A proteoglycan transcript is upregulated in naïve anemones (AIPGENE10560; Table 4-5); proteoglycans regulate immunity and can activate intracellular inflammasomes [86-88] by activating caspase 1 and inducing inflammation in response to microbial infection [89]. JUNB is a transcription factor that regulates macrophage activation in response to LPS [90]. Macrophages are critical components of the immune system since they engulf bacteria and can trigger inflammation [90]. The upregulation of these genes indicates an inflammatory response of E. pallida to challenge with $V$. coralliilyticus, and possibly the activity of a yet-to-be-characterized cnidarian counterpart to the vertebrate macrophage.

Another common theme among differentially expressed transcripts in naïve-infected

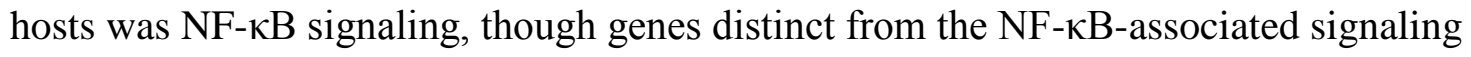
were observed in primed anemones. One upstream effector of NF- $\kappa \mathrm{B}$ signaling, an ortholog of caspase recruitment domain-containing protein 9, or Card9 (AIPGENE 5354), was upregulated in naïve anemones. In mammalian cells, Card9 binds to Bcl10 and

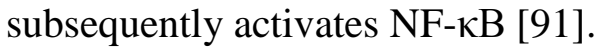

A transcript for an interferon regulatory factor 8 (IRF8) ortholog is upregulated in naïve hosts in comparison to unchallenged animals. IRF8 has numerous roles in vertebrate 
systems and is required for the formation of macrophages, monocytes, dendritic cells, basophils, and eosinophils [92]. Additionally, immune stimulation allows for IRF8 to associate with transcription factors that induce an immune response [92]. In Hydra, IRF genes and NF- $\mathrm{kB}$ regulate the production of cytokines and antimicrobial peptides [93]. A second transcript found differentially expressed in this study that relates to NF- $\mathrm{\kappa B}$ is sprouty homolog 4. In Drosophila, it is upregulated after IFR1receptors are triggered [94]; here, we find the upregulation of a putative sprouty homolog 4 activity instead accompanying the aforementioned IRF activity.

Another gene differentially expressed in the naïve challenged host when compared to the controls is tumor necrosis factor alpha induced protein (TNFAIP3) which is a gene that is induced by tumor necrosis factor (TNF) [95]. TNF is a cytokine that induces cell death [96]. TNFAIP3 is a primary mediator of both chronic and acute inflammation [97,98]. Additionally, TNFAIP3 has been shown to inhibit NF-kB activation and TNF-mediated apoptosis. It is also required for termination of NF-kB signaling in response to bacterial lipopolysaccharide (LPS) [95] with increases in expression of TNFAIP3 occurring after stimulation with LPS [98]. Therefore, upregulation of this transcript strongly indicates that primed E. pallida are undergoing an inflammatory response as well as recognition of bacterial LPS.

The involvement of heat shock proteins (HSPs) has been demonstrated in innate immunity in many invertebrates including corals [99]. DNAJ, a chaperone component of HSP40 and HSP70 [100], is upregulated in naive E. pallida when compared to controls animals. Further, HSPs in plants are mediated by PRRs which recognize PAMPs to 
activate the immune system [101]. More specifically, HSP40 and HSP70 have been implicated as chaperones during microbial pathogenesis in plants [102].

Nematogalectin is a lectin that is involved in the formation of nematocysts, the stinging cells of cnidarians, in Hydra [103]. Orthologs of nematogalectin are downregulated in diseased coral tissue, suggesting a weakened immune system [52]. The upregulation in naive E. pallida in this study in comparison to controls could indicate an active defense against invading pathogen.

Hemin receptors are downregulated in naive challenged anemones. Hemin is involved in iron acquisition in bacteria which is critical for their survival [104]. Downregulation of this gene could indicate that the immune response in E. pallida targets iron acquisition in V. coralliilyticus, therefore causing its death.

\subsection{Conclusions}

This study details for the first time the transcriptomic response associated with immune priming in an anthozoan, both prior to and following pathogen challenge. The transcriptomic signature of priming involved numerous pathways, indicating the involvement of potential pathogen recognition receptors, an inflammatory response, and activators of NF-kB. While many of these transcripts have previously been identified in

E.pallida as important components of its immune response, this is the first time they have been described as being involved in immune priming. 
A

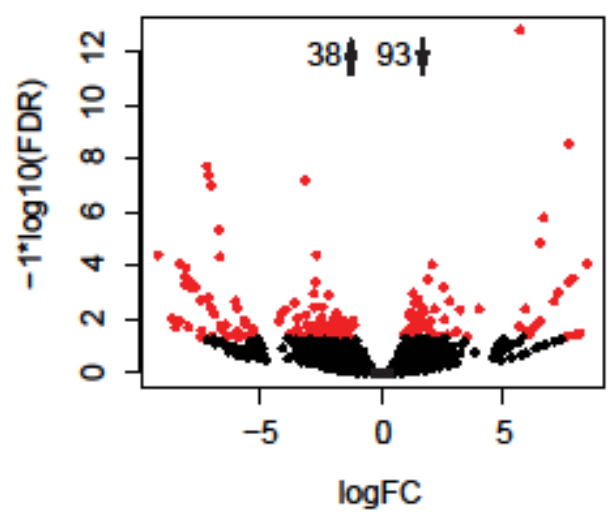

B
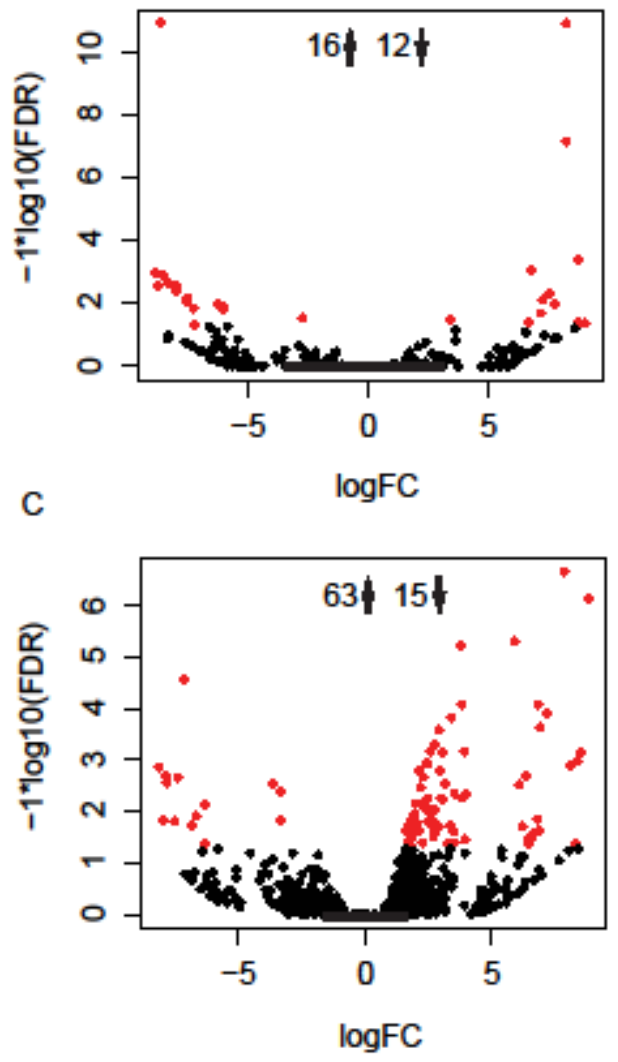

Figure 4-1. Volcano plots indicating differentially expressed transcripts for: A) zero hour naïve vs zero hour primed, B) four hour naïve challenged vs four hour primed, C) four hour unchallenged vs four hour naïve challenged. Negative values on the $\mathrm{x}$ axis indicate downregulation of genes on the right side of the comparisons while positive values indicate upregulation. Red points indicates FDR-corrected p-values of $<0.05$. " $\uparrow "$ 
indicates number of genes significantly upregulated in the comparison. " $\downarrow$ " indicates number of genes significantly downregulated in the comparison. 


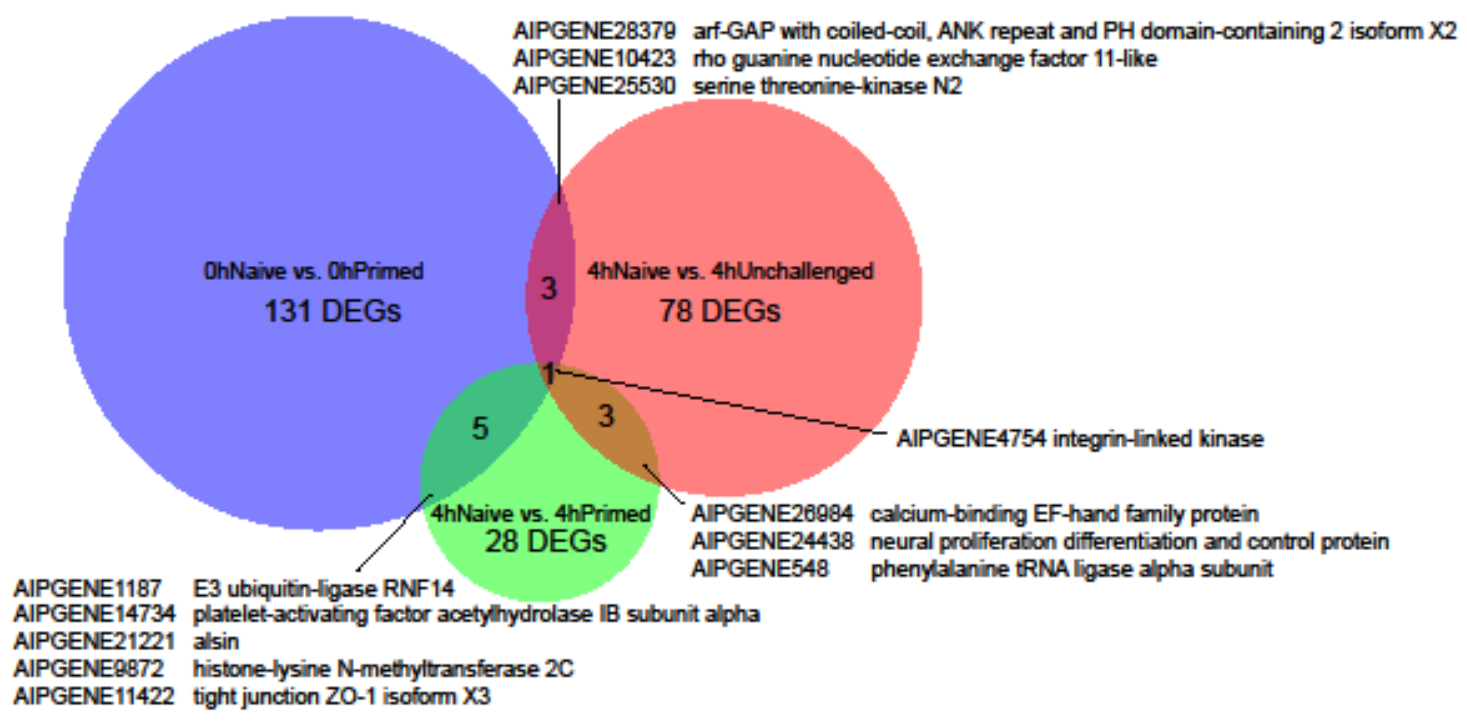

Figure 4-2. Venn diagram indicating transcripts that are shared by the treatments which are identified by transcript number from the genome (AIPGENE number) and annotation from Blast2GO. Total number of differentially expressed genes (DEGs) are also indicated. 


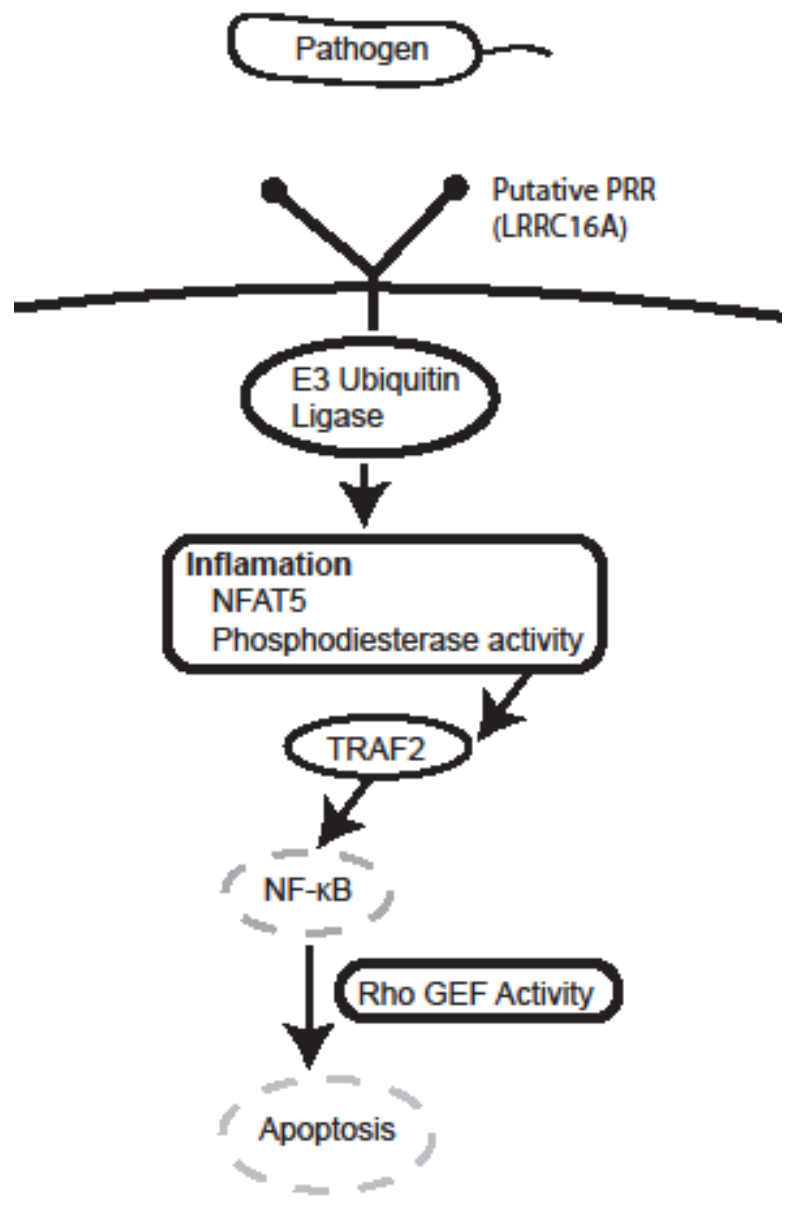

Figure 4-3. Working model of immune priming in E. pallida. Closed lines around gene names indicate transcripts differentially expressed in this study. Dashed lines indicate transcripts not differentially expressed in this study. 


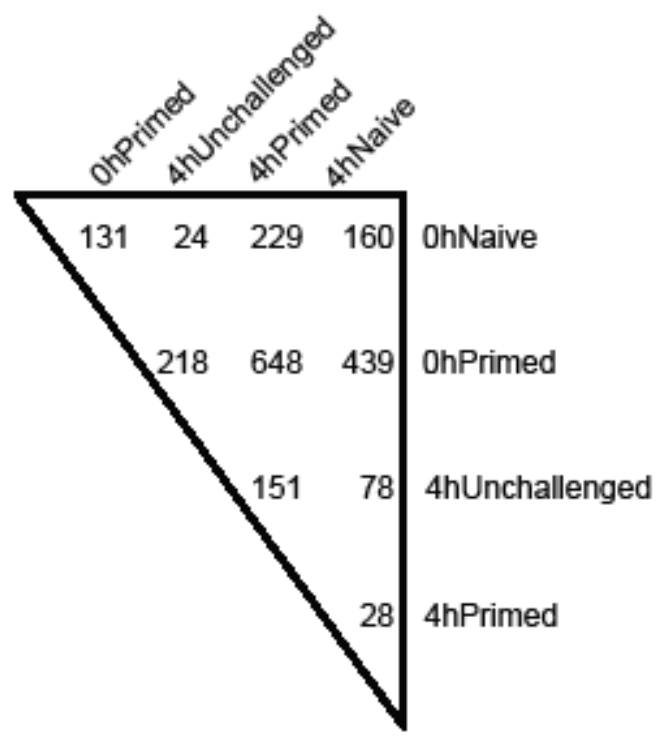

Figure 4-4. Counts of differentially expressed genes between pairwise comparisons of all treatments (FDR-corrected p-value $<0.05 ; 2$-fold minimum fold change). 
Phosphoric diester hydrolase activity

$\begin{array}{lllr}\text { Gene ID } & \text { Annotation } & \text { FDR } & \text { IogFC } \\ \text { AIPGENE702 } & \text { 1-phosphatidylinositol 4,5-bisphosphate phosphodiesterase gamma-1-like } & 1.01 \mathrm{E}-03 & 7.3 \\ \text { AIPGENE12904 } & \text { high affinity cAMP-specific and IBMX-insensitive 3 5-cyclic phosphodiesterase 8A isoform X1 } & 1.67 \mathrm{E}-06 & 6.7 \\ \text { AIPGENE12906 } & \text { high affinity cAMP-specific and IBMX-insensitive 3,5-cyclic phosphodiesterase 8B isoform X1 } & 1.98 \mathrm{E}-02 & 6.2 \\ \text { AIPGENE26754 } & \text { 1-phosphatidylinositol 4,5-bisphosphate phosphodiesterase beta-1 } & 3.47 \mathrm{E}-03 & -2.4 \\ \text { AIPGENE9087 } & \text { glycerophosphodiester phosphodiesterase domain-containing 1 } & 4.71 \mathrm{E}-02 & -5.9\end{array}$

Rho guanyl-nucleotide exchange factor activity and positive regulation of GTPase activity

$\begin{array}{ll}\text { Gene ID } & \text { Annotation } \\ \text { AIPGENE15346 } & \text { triple functional domain }\end{array}$

FDR $\log \mathrm{FC}$

AIPGENE28379 arf-GAP with coiled-coil, ANK repeat and PH domain-containing 2 isoform X2

AIPGENE10448

AIPGENE2764

rho guanine nucleotide exchange factor 11-like

rho GTPase-activating 6-like isoform X

3.26E-02

$3.08 \mathrm{E}-04$

$1.07 \mathrm{E}-02$

$3.88 \mathrm{E}-02$

AIPGENE10423

rho guanine nucleotide exchange factor 11 -like

$3.88 \mathrm{E}-02$

AIPGENE1534

triple functional domain

$4.71 \mathrm{E}-02$
$1.71 \mathrm{E}-02$

$1.71 \mathrm{E}-02$

$1.49 \mathrm{E}-03$

AIPGENE5416

(-like, partia

stromal membrane-associated 1-like, partia

stromal membrane-associated 1-like, partial

rho guanine nucleotide exchange factor 11-like

$1.49 \mathrm{E}-03$

AIPGENE5410

..53E-03

AIPGENE15339

triple functional domain

$1.17 \mathrm{E}-02$
$8.88 \mathrm{E}-05$

AIPGENE15336

Table 4-1. Transcripts associated with enriched GO terms found in this study. 


\begin{tabular}{|l|l|c|c|}
\hline Gene ID & Annotation & 0h logFC & 4h logFC \\
\hline AIPGENE11422 & tight junction ZO-1 isoform X3 & 7.7 & 8.3 \\
\hline AIPGENE1187 & E3 ubiquitin-ligase RNF14 & 2.8 & -6.9 \\
\hline AIPGENE14734 & platelet-activating factor acetylhydrolase IB subunit alpha & -7.8 & -7.8 \\
\hline AIPGENE21221 & alsin & -7.9 & -8.3 \\
\hline AIPGENE9872 & histone-lysine N-methyltransferase 2C & -8.6 & -8.8 \\
\hline
\end{tabular}

Table 4-2. Genes differentially expressed in primed E. pallida prior to and after the secondary challenge. Green indicates genes that are upregulated in primed organisms while red indicates downregulation. Log fold change ( $\operatorname{LogFC})$ is indicated in the table. 


\begin{tabular}{|c|c|c|c|}
\hline Gene ID & Annotation & $\log F C$ & FDR \\
\hline AIPGENE11903 & predicted protein & 8.5 & $8.88 \mathrm{E}-05$ \\
\hline AIPGENE15346 & triple functional domain & 8.1 & $3.26 \mathrm{E}-02$ \\
\hline AIPGENE19656 & $\begin{array}{l}\text { leucine-rich repeat-containing } 16 \mathrm{~A} \text { isoform } \\
\mathrm{X} 2\end{array}$ & 8.0 & 3.69E-02 \\
\hline AIPGENE28379 & $\begin{array}{l}\text { arf-GAP with coiled-coil, ANK repeat and PH } \\
\text { domain-containing } 2 \text { isoform } \mathrm{X} 2\end{array}$ & 7.9 & $3.08 \mathrm{E}-04$ \\
\hline AIPGENE26078 & glutamate synthase [NADPH] isoform X1 & 7.9 & $3.08 \mathrm{E}-04$ \\
\hline AIPGENE1103 & $\begin{array}{l}\text { nuclear factor of activated T-cells } 5 \text { isoform } \\
\mathrm{X} 5\end{array}$ & 7.7 & 4.40E-04 \\
\hline AIPGENE21078 & tolloid 2 isoform $\mathrm{X} 9$ & 7.7 & $2.78 \mathrm{E}-09$ \\
\hline AIPGENE11422 & tight junction ZO-1 isoform $\mathrm{X} 3$ & 7.7 & $4.13 \mathrm{E}-02$ \\
\hline AIPGENE702 & $\begin{array}{l}\text { 1-phosphatidylinositol 4,5-bisphosphate } \\
\text { phosphodiesterase gamma-1-like }\end{array}$ & 7.3 & $1.01 \mathrm{E}-03$ \\
\hline AIPGENE10448 & $\begin{array}{l}\text { rho guanine nucleotide exchange factor 11- } \\
\text { like }\end{array}$ & 7.1 & $2.12 \mathrm{E}-03$ \\
\hline AIPGENE12904 & $\begin{array}{l}\text { high affinity cAMP-specific and IBMX- } \\
\text { insensitive } 3,5 \text {-cyclic phosphodiesterase } 8 \mathrm{~A} \\
\text { isoform X1 }\end{array}$ & 6.7 & $1.67 \mathrm{E}-06$ \\
\hline AIPGENE27641 & rho GTPase-activating 6-like isoform X2 & 6.5 & $1.07 \mathrm{E}-02$ \\
\hline AIPGENE26457 & $\begin{array}{l}\text { biogenesis of lysosome-related organelles } \\
\text { complex } 1 \text { subunit } 6\end{array}$ & 6.5 & $1.38 \mathrm{E}-05$ \\
\hline
\end{tabular}




\begin{tabular}{|c|c|c|c|}
\hline AIPGENE2200 & spliceosome RNA helicase DDX39B & 6.5 & $1.14 \mathrm{E}-02$ \\
\hline AIPGENE12906 & $\begin{array}{l}\text { high affinity cAMP-specific and IBMX- } \\
\text { insensitive } 3,5 \text {-cyclic phosphodiesterase } 8 \mathrm{~B} \\
\text { isoform } \mathrm{X} 1\end{array}$ & 6.2 & $1.98 \mathrm{E}-02$ \\
\hline AIPGENE11103 & $\begin{array}{l}\text { adenosine monophosphate- transferase FICD } \\
\text { homolog }\end{array}$ & 6.2 & $1.93 \mathrm{E}-02$ \\
\hline AIPGENE16214 & $60 \mathrm{~S}$ ribosomal L3 & 6.1 & $3.51 \mathrm{E}-02$ \\
\hline AIPGENE27705 & predicted protein & 6.0 & $2.71 \mathrm{E}-02$ \\
\hline AIPGENE6006 & tensin-1-like isoform $\mathrm{X} 8$ & 5.9 & $4.25 \mathrm{E}-03$ \\
\hline AIPGENE23550 & ATP-binding cassette sub-family A member 1 & 5.8 & $4.55 \mathrm{E}-02$ \\
\hline AIPGENE27625 & $\begin{array}{l}\text { serine threonine- kinase DCLK1-like isoform } \\
\mathrm{X} 1\end{array}$ & 5.7 & $1.88 \mathrm{E}-02$ \\
\hline AIPGENE26142 & $\begin{array}{l}\text { hydroxyacylglutathione hydrolase, } \\
\text { mitochondrial-like }\end{array}$ & 5.7 & $1.59 \mathrm{E}-13$ \\
\hline AIPGENE8370 & coiled-coil domain-containing 13-like & 4.0 & $4.30 \mathrm{E}-03$ \\
\hline AIPGENE9615 & guanylate cyclase soluble subunit beta- 1 & 3.5 & $4.63 \mathrm{E}-02$ \\
\hline AIPGENE11604 & $\begin{array}{l}\text { phosphatase } 1 \text { regulatory subunit } 12 \mathrm{~A} \text { isoform } \\
\mathrm{X} 6\end{array}$ & 3.2 & $4.38 \mathrm{E}-03$ \\
\hline AIPGENE6691 & hypothetical protein RirG_067820 & 3.1 & $3.09 \mathrm{E}-02$ \\
\hline AIPGENE1187 & E3 ubiquitin- ligase RNF14 & 2.8 & $2.07 \mathrm{E}-03$ \\
\hline AIPGENE4548 & $\begin{array}{l}\text { mitochondrial genome maintenance } \\
\text { exonuclease } 1\end{array}$ & 2.7 & $3.88 \mathrm{E}-02$ \\
\hline AIPGENE26093 & transmembrane 11 , mitochondrial isoform $\mathrm{X} 2$ & 2.7 & $3.84 \mathrm{E}-02$ \\
\hline
\end{tabular}




\begin{tabular}{|c|c|c|c|}
\hline AIPGENE22130 & |--NA--- & 2.6 & $1.01 \mathrm{E}-02$ \\
\hline AIPGENE27831 & $\begin{array}{l}\text { EF-hand calcium-binding domain-containing } \\
6\end{array}$ & 2.6 & $4.00 \mathrm{E}-02$ \\
\hline AIPGENE16903 & ---NA--- & 2.5 & $6.62 \mathrm{E}-04$ \\
\hline AIPGENE20226 & ---NA--- & 2.4 & $4.41 \mathrm{E}-02$ \\
\hline AIPGENE10554 & ---NA--- & 2.3 & $4.31 \mathrm{E}-02$ \\
\hline AIPGENE10416 & thiamine transporter SLC35F3 & 2.2 & $4.18 \mathrm{E}-03$ \\
\hline AIPGENE16130 & chitin deacetylase-like 5 , isoform $\mathrm{H}$ & 2.2 & $4.04 \mathrm{E}-02$ \\
\hline AIPGENE2697 & equinatoxin II short & 2.1 & $8.88 \mathrm{E}-05$ \\
\hline AIPGENE16938 & ---NA--- & 2.0 & $1.14 \mathrm{E}-02$ \\
\hline AIPGENE25212 & eukaryotic translation initiation factor $1 \mathrm{~b}$ & -2.0 & $1.02 \mathrm{E}-02$ \\
\hline AIPGENE26133 & arginine serine-rich PNISR isoform X1 & -2.1 & $1.34 \mathrm{E}-02$ \\
\hline AIPGENE26246 & tolloid 1 & -2.1 & $4.76 \mathrm{E}-02$ \\
\hline AIPGENE19068 & glycine cleavage system $\mathrm{H}$, mitochondrial & -2.1 & $1.93 \mathrm{E}-02$ \\
\hline AIPGENE18686 & ---NA--- & -2.2 & $4.13 \mathrm{E}-02$ \\
\hline AIPGENE10233 & alanyl-tRNA editing Aarsd1 & -2.2 & $1.28 \mathrm{E}-03$ \\
\hline AIPGENE26878 & $\begin{array}{l}\text { gamma-aminobutyric acid receptor-associated } \\
\text {-like } 2\end{array}$ & -2.2 & 3.57E-02 \\
\hline AIPGENE29157 & glutathione S-transferase Mu 3-like & -2.3 & $1.66 \mathrm{E}-02$ \\
\hline AIPGENE1209 & transmembrane 116 & -2.4 & $3.25 \mathrm{E}-02$ \\
\hline AIPGENE26754 & 1-phosphatidylinositol 4,5-bisphosphate & -2.4 & $3.47 \mathrm{E}-03$ \\
\hline
\end{tabular}




\begin{tabular}{|c|c|c|c|}
\hline & phosphodiesterase beta-1 & & \\
\hline AIPGENE28714 & rhamnospondin-2, partial & -2.5 & $8.16 \mathrm{E}-03$ \\
\hline AIPGENE12493 & prostaglandin E synthase 2-like & -2.5 & $3.57 \mathrm{E}-02$ \\
\hline AIPGENE10280 & $\begin{array}{l}\text { lutropin-choriogonadotropic hormone } \\
\text { receptor isoform X1 }\end{array}$ & -2.6 & $3.46 \mathrm{E}-02$ \\
\hline AIPGENE25290 & coiled-coil domain-containing 37 & -2.6 & $1.49 \mathrm{E}-02$ \\
\hline AIPGENE18984 & $\begin{array}{l}\text { mediator of RNA polymerase II transcription } \\
\text { subunit } 10\end{array}$ & -2.6 & $1.24 \mathrm{E}-02$ \\
\hline AIPGENE17468 & luc7 3 & -2.7 & $4.04 \mathrm{E}-05$ \\
\hline AIPGENE26715 & PRELI domain-containing 1, mitochondrial & -2.7 & $3.77 \mathrm{E}-04$ \\
\hline AIPGENE27430 & \begin{tabular}{|l}
---NA--- \\
\end{tabular} & -2.7 & $3.64 \mathrm{E}-02$ \\
\hline AIPGENE25810 & zinc finger Dzip1-like & -2.8 & $1.10 \mathrm{E}-03$ \\
\hline AIPGENE19995 & P2X purinoceptor 7-like & -2.8 & $3.47 \mathrm{E}-03$ \\
\hline AIPGENE21872 & ---NA--- & -2.8 & $1.92 \mathrm{E}-02$ \\
\hline AIPGENE10296 & ATP-dependent DNA helicase PIF5-like & -2.9 & $4.89 \mathrm{E}-02$ \\
\hline AIPGENE601 & Glutamate--cysteine ligase regulatory subunit & -3.0 & $1.93 \mathrm{E}-02$ \\
\hline AIPGENE17685 & Regulator of G- signaling 12 & -3.0 & $3.57 \mathrm{E}-02$ \\
\hline AIPGENE7602 & palmitoyl- thioesterase 1 & -3.1 & $1.69 \mathrm{E}-02$ \\
\hline AIPGENE5657 & $\begin{array}{l}\text { phospholipid hydroperoxide glutathione } \\
\text { peroxidase, mitochondrial-like }\end{array}$ & -3.1 & 4.69E-02 \\
\hline AIPGENE13422 & $\begin{array}{l}\text { polyribonucleotide nucleotidyltransferase } 1, \\
\text { mitochondrial isoform X2 }\end{array}$ & -3.1 & $7.52 \mathrm{E}-03$ \\
\hline
\end{tabular}




\begin{tabular}{|c|c|c|c|}
\hline AIPGENE17083 & glutathione S-transferase U20-like & -3.1 & $1.69 \mathrm{E}-02$ \\
\hline AIPGENE13655 & caskin-1 & -3.1 & $6.77 \mathrm{E}-08$ \\
\hline AIPGENE18014 & ---NA--- & -3.3 & $4.60 \mathrm{E}-02$ \\
\hline AIPGENE13240 & $\begin{array}{l}\text { beta-1,4-N-acetylgalactosaminyltransferase 3- } \\
\text { like }\end{array}$ & -3.5 & $1.02 \mathrm{E}-02$ \\
\hline AIPGENE10764 & nap homolog 1 & -3.5 & $2.84 \mathrm{E}-02$ \\
\hline AIPGENE3926 & chromatin assembly factor 1 subunit $\mathrm{A}$ & -3.5 & $2.36 \mathrm{E}-02$ \\
\hline AIPGENE26075 & monocarboxylate transporter 10 & -3.5 & $2.10 \mathrm{E}-02$ \\
\hline AIPGENE25687 & chitinase 3-like & -3.6 & $2.58 \mathrm{E}-03$ \\
\hline AIPGENE18705 & NLRC5, partial & -3.8 & $3.57 \mathrm{E}-02$ \\
\hline AIPGENE1959 & serine threonine- kinase WNK4-like & -3.9 & $4.69 \mathrm{E}-02$ \\
\hline AIPGENE18163 & $\begin{array}{l}\text { zinc finger SWIM domain-containing } 8 \\
\text { isoform X1 }\end{array}$ & -3.9 & $4.38 \mathrm{E}-03$ \\
\hline AIPGENE22282 & allograft inflammatory factor 1 & -4.2 & $6.07 \mathrm{E}-03$ \\
\hline AIPGENE7509 & metallophosphoesterase domain-containing 1 & -4.2 & $1.14 \mathrm{E}-02$ \\
\hline AIPGENE9708 & endothelin-converting enzyme 1 isoform X2 & -5.2 & $4.83 \mathrm{E}-02$ \\
\hline AIPGENE20964 & WD repeat-containing 26 & -5.3 & $3.32 \mathrm{E}-02$ \\
\hline AIPGENE2174 & UPF0364 C6orf211, partial & -5.3 & $2.24 \mathrm{E}-02$ \\
\hline AIPGENE2756 & alkylhydroperoxidase & -5.4 & $3.43 \mathrm{E}-02$ \\
\hline AIPGENE2805 & $\begin{array}{l}\text { EF-hand calcium-binding domain-containing } \\
6\end{array}$ & -5.5 & $1.24 \mathrm{E}-02$ \\
\hline
\end{tabular}




\begin{tabular}{|c|c|c|c|}
\hline AIPGENE27176 & E3 ubiquitin- ligase HECTD1 & -5.6 & 4.13E-02 \\
\hline AIPGENE19076 & nuclear receptor coactivator 5 & -5.6 & $1.49 \mathrm{E}-02$ \\
\hline AIPGENE24226 & predicted protein & -5.7 & $1.34 \mathrm{E}-02$ \\
\hline AIPGENE27631 & serine threonine- kinase DCLK2 isoform X1 & -5.7 & $1.14 \mathrm{E}-02$ \\
\hline AIPGENE9087 & $\begin{array}{l}\text { glycerophosphodiester phosphodiesterase } \\
\text { domain-containing } 1\end{array}$ & -5.9 & $4.71 \mathrm{E}-02$ \\
\hline AIPGENE20477 & stomatin 1 & -5.9 & 3.82E-03 \\
\hline AIPGENE24069 & thioredoxin 1 & -5.9 & $2.96 \mathrm{E}-02$ \\
\hline AIPGENE3682 & discoidin domain-containing receptor 2-like & -6.0 & $4.81 \mathrm{E}-02$ \\
\hline AIPGENE26456 & $\begin{array}{l}\text { biogenesis of lysosome-related organelles } \\
\text { complex } 1 \text { subunit } 6\end{array}$ & -6.0 & $2.02 \mathrm{E}-03$ \\
\hline AIPGENE10423 & $\begin{array}{l}\text { rho guanine nucleotide exchange factor 11- } \\
\text { like }\end{array}$ & -6.1 & $3.88 \mathrm{E}-02$ \\
\hline AIPGENE27094 & serine threonine- kinase & -6.1 & $2.98 \mathrm{E}-02$ \\
\hline AIPGENE15345 & triple functional domain & -6.4 & $4.71 \mathrm{E}-02$ \\
\hline AIPGENE9789 & SON isoform X1 & -6.4 & $1.65 \mathrm{E}-02$ \\
\hline AIPGENE7168 & ---NA--- & -6.6 & $2.22 \mathrm{E}-02$ \\
\hline AIPGENE28598 & stromal membrane-associated 1-like, partial & -6.6 & $1.50 \mathrm{E}-02$ \\
\hline AIPGENE5417 & stromal membrane-associated 1-like, partial & -6.6 & $1.71 \mathrm{E}-02$ \\
\hline AIPGENE9780 & $\begin{array}{l}\text { S-adenosylmethionine decarboxylase } \\
\text { proenzyme }\end{array}$ & -6.7 & 4.72E-05 \\
\hline AIPGENE15730 & zinc finger Ran-binding domain-containing 2 & -6.7 & $4.76 \mathrm{E}-06$ \\
\hline
\end{tabular}




\begin{tabular}{|c|c|c|c|}
\hline AIPGENE16926 & $\begin{array}{l}\text { heterogeneous nuclear ribonucleo A B } \\
\text { isoform X2 }\end{array}$ & -6.9 & $6.50 \mathrm{E}-03$ \\
\hline AIPGENE17334 & charged multivesicular body 6-like & -7.0 & $4.35 \mathrm{E}-03$ \\
\hline AIPGENE8368 & NGFI-A-binding 1-like & -7.0 & $4.13 \mathrm{E}-02$ \\
\hline AIPGENE10555 & ---NA--- & -7.0 & $1.05 \mathrm{E}-07$ \\
\hline AIPGENE4542 & poly [ADP-ribose] polymerase 4-like & -7.0 & $3.88 \mathrm{E}-02$ \\
\hline AIPGENE23841 & Aryl hydrocarbon receptor & -7.0 & $3.47 \mathrm{E}-03$ \\
\hline AIPGENE2268 & RNA RNP complex-1-interacting phosphatase & -7.1 & $1.53 \mathrm{E}-03$ \\
\hline AIPGENE20810 & TNF receptor-associated factor 3 isoform $\mathrm{X} 1$ & -7.1 & $4.26 \mathrm{E}-08$ \\
\hline AIPGENE28597 & stromal membrane-associated 1-like, partial & -7.2 & $1.53 \mathrm{E}-03$ \\
\hline AIPGENE5416 & stromal membrane-associated 1-like, partial & -7.2 & $1.49 \mathrm{E}-03$ \\
\hline AIPGENE3347 & glycerol kinase-like isoform X2 & -7.2 & $2.04 \mathrm{E}-08$ \\
\hline AIPGENE25530 & serine threonine- kinase $\mathrm{N} 2$ & -7.4 & $2.71 \mathrm{E}-02$ \\
\hline AIPGENE10451 & $\begin{array}{l}\text { rho guanine nucleotide exchange factor 11- } \\
\text { like }\end{array}$ & -7.4 & $2.05 \mathrm{E}-03$ \\
\hline AIPGENE21371 & NLRC3-like & -7.5 & $4.54 \mathrm{E}-02$ \\
\hline AIPGENE6064 & nuclear factor $1 \mathrm{X}$-type isoform $\mathrm{X} 3$ & -7.5 & $2.47 \mathrm{E}-02$ \\
\hline AIPGENE18841 & $\begin{array}{l}\text { AChain A, Crystal Structure Of Menin } \\
\text { Reveals The Binding Site For Mixed Lineage } \\
\text { Leukemia (Mll) }\end{array}$ & -7.7 & 6.37E-04 \\
\hline AIPGENE14734 & $\begin{array}{l}\text { platelet-activating factor acetylhydrolase IB } \\
\text { subunit alpha }\end{array}$ & -7.8 & 4.54E-04 \\
\hline
\end{tabular}




\begin{tabular}{|c|c|c|c|}
\hline AIPGENE21076 & tolloid 2 isoform $\mathrm{X} 9$ & -7.9 & $6.76 \mathrm{E}-04$ \\
\hline AIPGENE4152 & $\begin{array}{l}\text { phosphatase } 1 \text { regulatory subunit } 12 \mathrm{~B} \text { isoform } \\
\mathrm{X} 3\end{array}$ & -7.9 & $2.03 \mathrm{E}-02$ \\
\hline AIPGENE21221 & alsin & -7.9 & $1.27 \mathrm{E}-04$ \\
\hline AIPGENE3885 & $\begin{array}{l}\text { C3 and PZP-like alpha-2-macroglobulin } \\
\text { domain-containing } 8\end{array}$ & -8.0 & $1.61 \mathrm{E}-02$ \\
\hline AIPGENE4754 & integrin-linked kinase & -8.0 & $4.54 \mathrm{E}-04$ \\
\hline AIPGENE4439 & dystrophin-like isoform X1 & -8.1 & $5.21 \mathrm{E}-04$ \\
\hline AIPGENE20657 & Glycogenin-1, partial & -8.1 & $2.60 \mathrm{E}-04$ \\
\hline AIPGENE15336 & triple functional domain & -8.3 & $8.88 \mathrm{E}-05$ \\
\hline AIPGENE15339 & triple functional domain isoform $\mathrm{X} 1$ & -8.3 & $1.17 \mathrm{E}-02$ \\
\hline AIPGENE17495 & fibroblast growth receptor 4 & -8.3 & $9.62 \mathrm{E}-03$ \\
\hline AIPGENE23829 & $\begin{array}{l}\text { reversion-inducing cysteine-rich with Kazal } \\
\text { motifs }\end{array}$ & -8.5 & $2.02 \mathrm{E}-02$ \\
\hline AIPGENE9872 & histone-lysine $\mathrm{N}$-methyltransferase $2 \mathrm{C}$ & -8.6 & $1.02 \mathrm{E}-02$ \\
\hline AIPGENE4157 & $\begin{array}{l}\text { phosphatase } 1 \text { regulatory subunit } 12 \mathrm{~B} \text { isoform } \\
\mathrm{X} 3\end{array}$ & -9.2 & 4.04E-05 \\
\hline
\end{tabular}

Table 4-3. Differentially expressed transcripts from a comparison of zero hour naïve vs. zero hour primed treatments. 


\begin{tabular}{|c|c|c|c|}
\hline Gene ID & Annotation & $\log \mathrm{FC}$ & FDR \\
\hline AIPGENE2148 & GTP-binding 2, partial & 9.1 & $\begin{array}{r}4.44 \mathrm{E}- \\
02\end{array}$ \\
\hline AIPGENE9872 & histone-lysine $\mathrm{N}$-methyltransferase $2 \mathrm{C}$ & 8.8 & $\begin{array}{r}4.14 \mathrm{E}- \\
04\end{array}$ \\
\hline AIPGENE15342 & triple functional domain & 8.8 & $\begin{array}{r}4.27 \mathrm{E}- \\
02\end{array}$ \\
\hline AIPGENE8667 & forkhead box P & 8.3 & $\begin{array}{r}1.23 \mathrm{E}- \\
11\end{array}$ \\
\hline AIPGENE21221 & alsin & 8.3 & $\begin{array}{r}7.17 \mathrm{E}- \\
08\end{array}$ \\
\hline AIPGENE14734 & $\begin{array}{l}\text { platelet-activating factor acetylhydrolase IB } \\
\text { subunit alpha }\end{array}$ & 7.8 & $\begin{array}{r}1.06 \mathrm{E}- \\
02\end{array}$ \\
\hline AIPGENE21271 & focal adhesion kinase 1 isoform $\mathrm{X} 8$ & 7.6 & $\begin{array}{r}4.99 \mathrm{E}- \\
03\end{array}$ \\
\hline AIPGENE25512 & $\begin{array}{l}\text { cadherin EGF LAG seven-pass G-type receptor } \\
1\end{array}$ & 7.3 & $\begin{array}{r}7.92 \mathrm{E}- \\
03\end{array}$ \\
\hline AIPGENE21426 & asparagine--tRNA ligase, cytoplasmic & 7.3 & $\begin{array}{r}2.08 \mathrm{E}- \\
02\end{array}$ \\
\hline AIPGENE1187 & E3 ubiquitin- ligase RNF14 & 6.9 & $\begin{array}{r}8.38 \mathrm{E}- \\
04\end{array}$ \\
\hline AIPGENE23257 & sequestosome-1 isoform X2 & 6.7 & $\begin{array}{r}4.10 \mathrm{E}- \\
02\end{array}$ \\
\hline
\end{tabular}




\begin{tabular}{|c|c|c|c|}
\hline AIPGENE3871 & ankyrin repeat & 3.4 & $\begin{array}{r}3.19 \mathrm{E}- \\
02\end{array}$ \\
\hline AIPGENE7376 & heterogeneous nuclear ribonucleor A1 & -2.7 & $\begin{array}{r}3.04 \mathrm{E}- \\
02\end{array}$ \\
\hline AIPGENE17905 & patched domain-containing 3-like isoform X1 & -6.0 & $\begin{array}{r}1.70 \mathrm{E}- \\
02\end{array}$ \\
\hline AIPGENE695 & gamma soluble NSF attachment & -6.0 & $\begin{array}{r}1.24 \mathrm{E}- \\
02\end{array}$ \\
\hline AIPGENE15047 & cubilin & -6.2 & $\begin{array}{r}1.14 \mathrm{E}- \\
02\end{array}$ \\
\hline AIPGENE20792 & $\begin{array}{l}\text { rho guanine nucleotide exchange factor } 7 \\
\text { isoform } \mathrm{X} 1\end{array}$ & -7.2 & $\begin{array}{r}1.46 \mathrm{E}- \\
02\end{array}$ \\
\hline AIPGENE23711 & $\begin{array}{l}\text { single-stranded DNA-binding 3-like isoform } \\
\mathrm{X} 3\end{array}$ & -7.2 & $\begin{array}{r}4.95 \mathrm{E}- \\
02\end{array}$ \\
\hline AIPGENE548 & phenylalanine tRNA ligase alpha subunit & -7.5 & $\begin{array}{r}6.81 \mathrm{E}- \\
03\end{array}$ \\
\hline AIPGENE19990 & TNF receptor associated factor 2 like & -7.5 & $\begin{array}{r}9.34 \mathrm{E}- \\
03\end{array}$ \\
\hline AIPGENE4754 & predicted protein & -8.0 & $\begin{array}{r}3.87 \mathrm{E}- \\
03\end{array}$ \\
\hline AIPGENE15338 & triple function domain & -8.0 & $\begin{array}{r}2.79 \mathrm{E}- \\
03\end{array}$ \\
\hline AIPGENE8207 & $\begin{array}{l}\text { hepatocyte growth factor-regulated tyrosine } \\
\text { kinase substrate }\end{array}$ & -8.1 & $\begin{array}{r}4.02 \mathrm{E}- \\
03\end{array}$ \\
\hline
\end{tabular}




\begin{tabular}{|l|l|r|r|} 
& & $2.31 \mathrm{E}-$ \\
AIPGENE11422 & tight junction ZO - 1 isoform X3 & -8.3 & 03 \\
\hline & & -8.5 & $1.21 \mathrm{E}-$ \\
AIPGENE26984 & calcium ion binding & & \\
\hline & & -8.6 & $1.23 \mathrm{E}-$ \\
AIPGENE8666 & forkhead box P & & 11 \\
\hline & leucine-rich repeat-conatinaing 16A isoform & & $2.79 \mathrm{E}-$ \\
AIPGENE19649 & X2 & -8.7 & 03 \\
\hline & & & $1.03 \mathrm{E}-$ \\
AIPGENE24438 & 1-like & -8.9 & 03 \\
\hline
\end{tabular}

Table 4-4. Differentially expressed transcripts from a comparison of four hour naïve vs. four hour primed treatments. 


\begin{tabular}{|c|c|c|c|}
\hline Gene ID & Annotation & $\log \mathrm{FC}$ & FDR \\
\hline AIPGENE21646 & $\begin{array}{l}\text { cAMP-responsive element modulator isoform } \\
\mathrm{X} 3\end{array}$ & 8.9 & $\begin{array}{r}7.35 \mathrm{E}- \\
07\end{array}$ \\
\hline AIPGENE28379 & $\begin{array}{l}\text { arf-GAP with coiled-coil, ANK repeat and PH } \\
\text { domain-containing } 2 \text { isoform } \mathrm{X} 2\end{array}$ & 8.6 & $\begin{array}{r}7.23 \mathrm{E}- \\
04\end{array}$ \\
\hline AIPGENE11190 & nematogalectin-related isoform $\mathrm{X} 1$ & 8.4 & $\begin{array}{r}1.04 \mathrm{E}- \\
03\end{array}$ \\
\hline AIPGENE25193 & type 1 collgen alpha1 chain & 8.4 & $\begin{array}{r}4.16 \mathrm{E}- \\
02\end{array}$ \\
\hline AIPGENE4149 & $\begin{array}{l}\text { phosphatase } 1 \text { regulatory subunit } 12 \mathrm{~B} \text { isoform } \\
\mathrm{X} 3\end{array}$ & 8.1 & $\begin{array}{r}1.22 \mathrm{E}- \\
03\end{array}$ \\
\hline AIPGENE7190 & actin-binding LIM 1 isoform X14 & 7.9 & $\begin{array}{r}2.17 \mathrm{E}- \\
07\end{array}$ \\
\hline AIPGENE2642 & beta-1,3-galactosyltransferase 5 & 7.3 & $\begin{array}{r}1.19 \mathrm{E}- \\
04\end{array}$ \\
\hline AIPGENE13182 & $\begin{array}{l}\text { sushi, von Willebrand factor type A, EGF and } \\
\text { pentraxin domain-containing 1-like }\end{array}$ & 6.9 & $\begin{array}{r}2.32 \mathrm{E}- \\
04\end{array}$ \\
\hline AIPGENE13389 & AP-4 complex subunit sigma-1 & 6.9 & $\begin{array}{r}8.32 \mathrm{E}- \\
05\end{array}$ \\
\hline AIPGENE10423 & rho guanine nucleotide exchange factor 11-like & 6.9 & $\begin{array}{r}2.35 \mathrm{E}- \\
02\end{array}$ \\
\hline AIPGENE17751 & sodium myo-inositol cotransporter 2 & 6.8 & $\begin{array}{r}1.39 \mathrm{E}- \\
02\end{array}$ \\
\hline
\end{tabular}




\begin{tabular}{|c|c|c|c|}
\hline AIPGENE15489 & $\begin{array}{l}\text { histidine--tRNA ligase, cytoplasmic isoform } \\
\text { X1 }\end{array}$ & 6.7 & $\begin{array}{r}2.57 \mathrm{E}- \\
02\end{array}$ \\
\hline AIPGENE14669 & low-density lipo receptor-related 4 -like & 6.6 & $\begin{array}{r}3.13 \mathrm{E}- \\
02\end{array}$ \\
\hline AIPGENE3224 & $\begin{array}{l}\text { Arf-GAP with coiled-coil, ANK repeat and PH } \\
\text { domain-containing 2, partial }\end{array}$ & 6.5 & $\begin{array}{r}3.22 \mathrm{E}- \\
02\end{array}$ \\
\hline AIPGENE16874 & TNFAIP3 interacting 1 & 6.5 & $\begin{array}{r}4.05 \mathrm{E}- \\
02\end{array}$ \\
\hline AIPGENE11683 & ---NA--- & 6.4 & $\begin{array}{r}2.03 \mathrm{E}- \\
03\end{array}$ \\
\hline AIPGENE23348 & transmembrane 9 superfamily member 3 & 6.3 & $\begin{array}{r}1.96 \mathrm{E}- \\
02\end{array}$ \\
\hline AIPGENE3414 & dnaJ homolog subfamily $\mathrm{C}$ member 21 & 6.1 & $\begin{array}{r}2.95 \mathrm{E}- \\
03\end{array}$ \\
\hline AIPGENE24619 & neuropeptide FF receptor 2 & 6.0 & $\begin{array}{r}4.90 \mathrm{E}- \\
06\end{array}$ \\
\hline AIPGENE27789 & actin-fragmin kinase-like isoform $\mathrm{X} 1$ & 4.0 & $\begin{array}{r}4.71 \mathrm{E}- \\
03\end{array}$ \\
\hline AIPGENE26215 & solute carrier family 25 member 36 & 4.0 & $\begin{array}{r}3.44 \mathrm{E}- \\
02\end{array}$ \\
\hline AIPGENE23083 & calcium calmodulin-dependent kinase I & 3.9 & $\begin{array}{r}6.77 \mathrm{E}- \\
04\end{array}$ \\
\hline AIPGENE1126 & ---NA--- & 3.9 & $\begin{array}{r}5.40 \mathrm{E}- \\
03\end{array}$ \\
\hline
\end{tabular}




\begin{tabular}{|c|c|c|c|}
\hline AIPGENE2788 & hypothetical protein DAPPUDRAFT_225707 & 3.9 & $\begin{array}{r}8.56 \mathrm{E}- \\
05\end{array}$ \\
\hline AIPGENE11806 & matrix metalloproteinase-24-like & 3.8 & $\begin{array}{r}5.98 \mathrm{E}- \\
06\end{array}$ \\
\hline AIPGENE16131 & ---NA--- & 3.6 & $\begin{array}{r}4.05 \mathrm{E}- \\
02\end{array}$ \\
\hline AIPGENE10892 & $\begin{array}{l}\text { PREDICTED: uncharacterized protein } \\
\text { LOC106177382 }\end{array}$ & 3.6 & $\begin{array}{r}4.33 \mathrm{E}- \\
03\end{array}$ \\
\hline AIPGENE21311 & sprouty homolog 4 & 3.5 & $\begin{array}{r}2.43 \mathrm{E}- \\
02\end{array}$ \\
\hline AIPGENE1568 & interferon regulatory factor 8 & 3.4 & $\begin{array}{r}1.53 \mathrm{E}- \\
04\end{array}$ \\
\hline AIPGENE22125 & hypothetical protein AC249 & 3.4 & $\begin{array}{r}1.82 \mathrm{E}- \\
02\end{array}$ \\
\hline AIPGENE16549 & ---NA--- & 3.3 & $\begin{array}{r}4.05 \mathrm{E}- \\
02\end{array}$ \\
\hline AIPGENE12575 & predicted protein & 3.2 & $\begin{array}{r}2.95 \mathrm{E}- \\
03\end{array}$ \\
\hline AIPGENE17762 & predicted protein & 3.1 & $\begin{array}{r}5.67 \mathrm{E}- \\
03\end{array}$ \\
\hline AIPGENE5210 & ---NA--- & 3.1 & $\begin{array}{r}6.77 \mathrm{E}- \\
04\end{array}$ \\
\hline AIPGENE14815 & chymotrypsin-like protease CTRL-1 & 3.0 & $\begin{array}{r}5.50 \mathrm{E}- \\
03\end{array}$ \\
\hline
\end{tabular}




\begin{tabular}{|c|c|c|c|}
\hline AIPGENE10221 & reverse transcriptase, partial & 3.0 & $\begin{array}{r}1.96 \mathrm{E}- \\
02\end{array}$ \\
\hline & hypothetical protein & & $1.58 \mathrm{E}-$ \\
\hline AIPGENE26260 & NEMVEDRAFT_v1g248367 & 3.0 & 03 \\
\hline AIPGENE14579 & hypothetical protein AC249 & 2.9 & $\begin{array}{r}2.50 \mathrm{E}- \\
04\end{array}$ \\
\hline AIPGENE24297 & ras-related Rab-24 isoform $\mathrm{X} 1$ & 2.8 & $\begin{array}{r}1.83 \mathrm{E}- \\
02\end{array}$ \\
\hline AIPGENE22808 & zinc finger 501 & 2.8 & $\begin{array}{r}9.13 \mathrm{E}- \\
03\end{array}$ \\
\hline AIPGENE72 & ---NA--- & 2.8 & $\begin{array}{r}2.52 \mathrm{E}- \\
02\end{array}$ \\
\hline AIPGENE22726 & ---NA--- & 2.8 & $\begin{array}{r}5.08 \mathrm{E}- \\
04\end{array}$ \\
\hline AIPGENE10516 & predicted protein & 2.7 & $\begin{array}{r}3.13 \mathrm{E}- \\
02\end{array}$ \\
\hline AIPGENE6165 & integrin alpha-8 & 2.7 & $\begin{array}{r}1.46 \mathrm{E}- \\
02\end{array}$ \\
\hline AIPGENE19884 & hypothetical protein BRAFLDRAFT_98085 & 2.7 & $\begin{array}{r}1.83 \mathrm{E}- \\
02\end{array}$ \\
\hline AIPGENE15501 & ---NA--- & 2.6 & $\begin{array}{r}9.13 \mathrm{E}- \\
03\end{array}$ \\
\hline AIPGENE3420 & vascular endothelial growth factor C-like & 2.6 & $\begin{array}{r}6.77 \mathrm{E}- \\
04\end{array}$ \\
\hline
\end{tabular}




\begin{tabular}{|c|c|c|c|}
\hline AIPGENE10853 & ---NA--- & 2.5 & $\begin{array}{r}1.17 \mathrm{E}- \\
03\end{array}$ \\
\hline AIPGENE23561 & predicted protein & 2.5 & $\begin{array}{r}5.50 \mathrm{E}- \\
03\end{array}$ \\
\hline AIPGENE8869 & predicted protein & 2.5 & $\begin{array}{r}1.54 \mathrm{E}- \\
02\end{array}$ \\
\hline AIPGENE7998 & actin, cytoplasmic & 2.5 & $\begin{array}{r}9.69 \mathrm{E}- \\
03\end{array}$ \\
\hline AIPGENE14095 & ---NA--- & 2.4 & $\begin{array}{r}1.17 \mathrm{E}- \\
03\end{array}$ \\
\hline AIPGENE9737 & pyroglutamylated RFamide peptide receptor & 2.4 & $\begin{array}{r}4.01 \mathrm{E}- \\
02\end{array}$ \\
\hline AIPGENE15929 & vascular endothelial growth factor C-like & 2.4 & $\begin{array}{r}2.13 \mathrm{E}- \\
03\end{array}$ \\
\hline AIPGENE27791 & actin-fragmin kinase-like isoform X1 & 2.3 & $\begin{array}{r}7.08 \mathrm{E}- \\
03\end{array}$ \\
\hline AIPGENE22518 & transcription factor ETV6 [Exaiptasia pallida] & 2.3 & $\begin{array}{r}4.05 \mathrm{E}- \\
02\end{array}$ \\
\hline AIPGENE5354 & $\begin{array}{l}\text { caspase recruitment domain-containing protein } \\
9\end{array}$ & 2.2 & $\begin{array}{r}3.33 \mathrm{E}- \\
03\end{array}$ \\
\hline AIPGENE2207 & endonuclease-reverse transcriptase & 2.2 & $\begin{array}{r}2.29 \mathrm{E}- \\
02\end{array}$ \\
\hline AIPGENE10560 & chondroitin proteoglycan 2-like & 2.1 & $\begin{array}{r}2.31 \mathrm{E}- \\
02\end{array}$ \\
\hline
\end{tabular}




\begin{tabular}{|c|c|c|c|}
\hline AIPGENE2530 & $\begin{array}{l}\text { SAM pointed domain-containing Ets } \\
\text { transcription factor isoform } \mathrm{X} 2\end{array}$ & 2.1 & $\begin{array}{r}1.58 \mathrm{E}- \\
03\end{array}$ \\
\hline AIPGENE181 & ---NA--- & 2.1 & $\begin{array}{r}2.29 \mathrm{E}- \\
02\end{array}$ \\
\hline AIPGENE22969 & |--NA--- & 2.0 & $\begin{array}{r}1.61 \mathrm{E}- \\
02\end{array}$ \\
\hline AIPGENE20436 & transcription factor jun-B-like & 2.0 & $\begin{array}{r}7.01 \mathrm{E}- \\
03\end{array}$ \\
\hline AIPGENE22891 & Forkhead box C2 & -3.3 & $\begin{array}{r}1.48 \mathrm{E}- \\
02\end{array}$ \\
\hline AIPGENE4010 & histone-lysine N-methyltransferase PRDM6 & -3.3 & $\begin{array}{r}4.18 \mathrm{E}- \\
03\end{array}$ \\
\hline AIPGENE1175 & hemin receptor & -3.6 & $\begin{array}{r}2.95 \mathrm{E}- \\
03\end{array}$ \\
\hline AIPGENE13390 & AP-4 complex subunit sigma-1 & -6.3 & $\begin{array}{r}7.08 \mathrm{E}- \\
03\end{array}$ \\
\hline AIPGENE28575 & ubiquitin-associated domain-containing 1 & -6.3 & $\begin{array}{r}4.18 \mathrm{E}- \\
02\end{array}$ \\
\hline AIPGENE1276 & $\begin{array}{l}\text { unconventional myosin-XVIIIa-like isoform } \\
\mathrm{X} 2\end{array}$ & -6.7 & $\begin{array}{r}1.19 \mathrm{E}- \\
02\end{array}$ \\
\hline AIPGENE548 & phenylalanine--tRNA ligase alpha subunit & -6.9 & $\begin{array}{r}1.91 \mathrm{E}- \\
02\end{array}$ \\
\hline AIPGENE12907 & $\begin{array}{l}\text { high affinity cAMP-specific and IBMX- } \\
\text { insensitive } 3,5 \text {-cyclic phosphodiesterase 8B } \\
\text { isoform X1 }\end{array}$ & -7.2 & $\begin{array}{r}2.83 \mathrm{E}- \\
05\end{array}$ \\
\hline
\end{tabular}




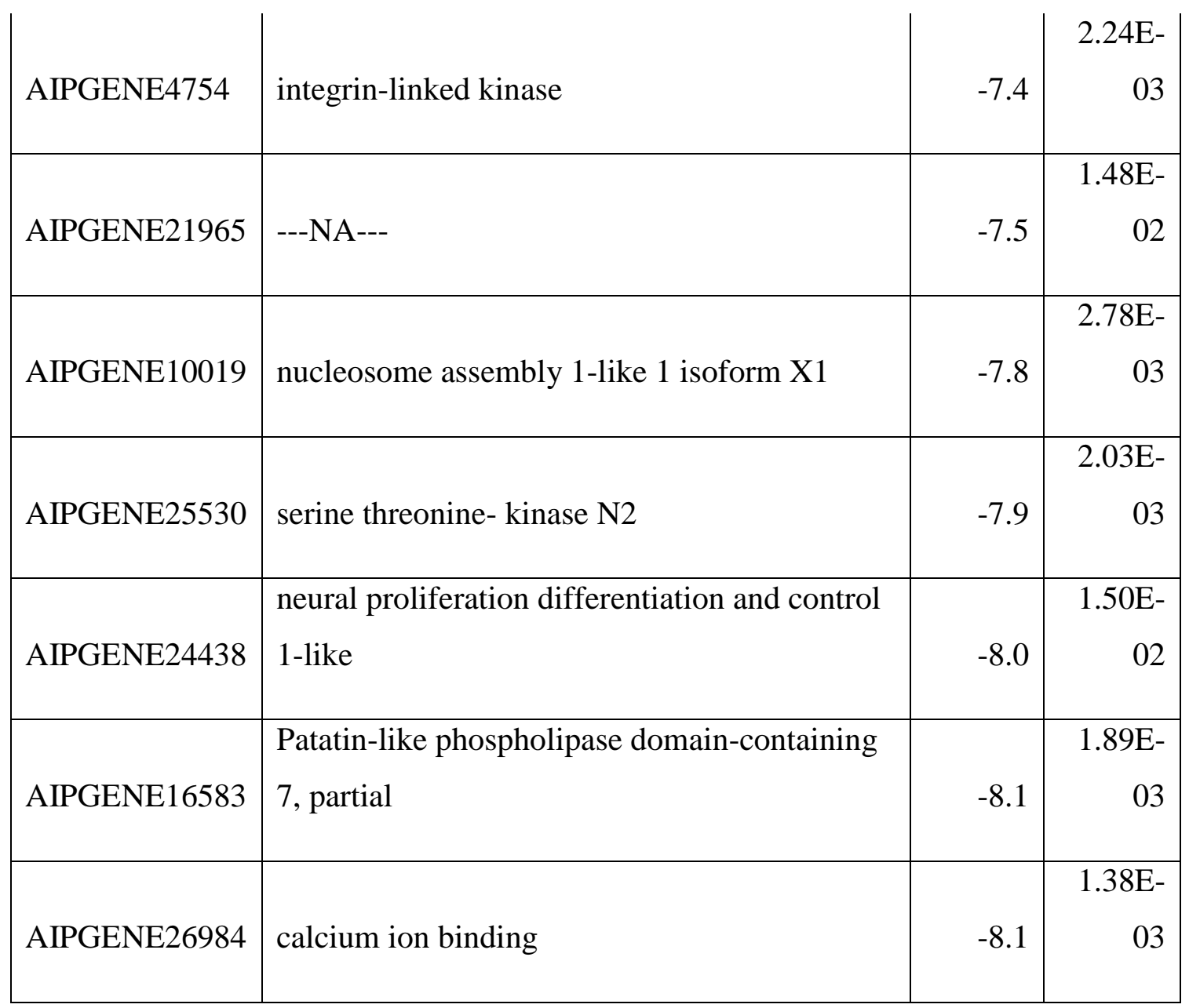

Table 4-5. Differentially expressed transcripts from a comparison of four hour naive vs. four hour unchallenged treatments. 


\subsection{References}

1. Janeway C, Travers P, Walport M, Capra J (1999) Immunobiology: the immune system in health and disease. New York, New York: Elsevier Science Ltd./Garland Publishing.

2. Beck G, Habicht GS (1996) Immunity and the invertebrates - The fabulously complex immune systems of humans and other mammals evolved over hundreds of millions of years-in sometimes surprising ways. Scientific American 275: 60-+.

3. Little TJ, Hultmark D, Read AF (2005) Invertebrate immunity and the limits of mechanistic immunology. Nature Immunology 6: 651-654.

4. Loker ES, Adema CM, Zhang SM, Kepler TB (2004) Invertebrate immune systems not homogeneous, not simple, not well understood. Immunological Reviews 198: $10-24$.

5. Johnson KN, van Hulten MCW, Barnes AC (2008) "Vaccination" of shrimp against viral pathogens: phenomenology and underlying mechanisms. Vaccine 26: 48854892.

6. Kurtz J (2004) Memory in the innate and adaptive immune systems. Microbes and Infection 6: 1410-1417.

7. Kurtz J, Franz K (2003) Evidence for memory in invertebrate immunity. Nature 425: 37-38.

8. Little TJ, O'Connor B, Colegrave N, Watt K, Read AF (2003) Maternal transfer of strain-specific immunity in an invertebrate. Current Biology 13: 489-492.

9. Roth O, Sadd BM, Schmid-Hempel P, Kurtz J (2009) Strain-specific priming of resistance in the red flour beetle, Tribolium castaneum. Proceedings of the Royal Society B-Biological Sciences 276: 145-151. 
10. Sadd BM, Schmid-Hempel P (2006) Insect immunity shows specificity in protection upon secondary pathogen exposure. Current Biology 16: 1206-1210.

11. Brown T, Rodriguez-Lanetty M (2015) Defending against pathogens - immunological priming and its molecular basis in a sea anemone, cnidarian. Scientific Reports 5.

12. Pinaud S, Portela J, Duval D, Nowacki FC, Olive MA, et al. (2016) A shift from cellular to humoral responses contributes to innate immune memory in the vector snail Biomphalaria glabrata. Plos Pathogens 12.

13. Rinkevich B (2011) The 'immunology trap' of anthozoans. Visions and Perspectives.

14. Netea MG, Quintin J, van der Meer JWM (2011) Trained immunity: a memory for innate host defense. Cell Host \& Microbe 9: 355-361.

15. Rowley AF, Powell A (2007) Invertebrate immune systems-specific, quasi-specific, or nonspecific? Journal of Immunology 179: 7209-7214.

16. Wang JJ, Wang LL, Yang CY, Jiang QF, Zhang H, et al. (2013) The response of mRNA expression upon secondary challenge with Vibrio anguillarum suggests the involvement of C-lectins in the immune priming of scallop Chlamys farreri. Developmental and Comparative Immunology 40: 142-147.

17. Pope EC, Powell A, Roberts EC, Shields RJ, Wardle R, et al. (2011) Enhanced cellular immunity in shrimp (Litopenaeus vannamei) after 'vaccination'. Plos One 6.

18. Lemaitre B, Reichhart JM, Hoffmann JA (1997) Drosophila host defense: differential induction of antimicrobial peptide genes after infection by various classes of microorganisms. Proc Natl Acad Sci U S A 94: 14614-14619. 
19. Watson FL, Puttmann-Holgado R, Thomas F, Lamar DL, Hughes M, et al. (2005) Extensive diversity of Ig-superfamily proteins in the immune system of insects. Science 309: 1874-1878.

20. Harvell D, Jordan-Dahlgren E, Merkel S, Rosenberg E, Raymundo L, et al. (2007) Coral disease, environmental drivers, and the balance between coral and microbial associates. Oceanography 20: 172-195.

21. Sutherland KP, Porter JW, Torres C (2004) Disease and immunity in Caribbean and Indo-Pacific zooxanthellate corals. Marine Ecology Progress Series 266: 273-302.

22. Willis BL, Page CA, Dinsdale EA (2004) Coral disease on the Great Barrier Reef; Rosenberg ELY, editor. 69-104 p.

23. Woodley CM, Downs CA, Bruckner AW, Porter JW, Galloway SB, editors (2016) Diseases of coral. Hoboken, New Jersey: John Wiley \& Sons.

24. Roark EB, Guilderson TP, Dunbar RB, Fallon SJ, Mucciarone DA (2009) Extreme longevity in proteinaceous deep-sea corals. Proceedings of the National Academy of Sciences of the United States of America 106: 5204-5208.

25. Israely T, Banin E, Rosenberg E (2001) Growth, differentiation and death of Vibrio shiloi in coral tissue as a function of seawater temperature. Aquatic Microbial Ecology 24: 1-8.

26. Ainsworth T, Fine M, Roff G, Hoegh-Guldberg O (2008) Bacteria are not the primary cause of bleaching in the Mediterranean coral Oculina patagonica. ISME Journal 2: 67-73.

27. Sutherland KP, Porter JW, Turner JW, Thomas BJ, Looney EE, et al. (2010) Human sewage identified as likely source of White Pox disease of the threatened Caribbean elkhorn coral, Acropora palmata. Environmental Microbiology 12: 1122-1131. 
28. Hildemann WH, Raison RL, Cheung G, Hull CJ, Akaka L, et al. (1977)

Immunological specificity and memory in a scleractinian coral. Nature 270: 219223.

29. Saltercid L, Bigger CH (1991) Alloimmunity in the gorgonian coral Swiftia exerta. Biological Bulletin 181: 127-134.

30. Weis VM, Davy SK, Hoegh-Guldberg O, Rodriguez-Lanetty M, Pringe JR (2008) Cell biology in model systems as the key to understanding corals. Trends in Ecology \& Evolution 23: 369-376.

31. Baumgarten S, Simakov O, Esherick LY, Liew YJ, Lehnert EM, et al. (2015) The genome of Aiptasia, a sea anemone model for coral symbiosis. Proceedings of the National Academy of Sciences of the United States of America 112: 1189311898.

32. Langmead B, Trapnell C, Pop M, Salzberg SL (2009) Ultrafast and memory-efficient alignment of short DNA sequences to the human genome. Genome Biology 10.

33. Li B, Dewey CN (2011) RSEM: accurate transcript quantification from RNA-Seq data with or without a reference genome. BMC Bioinformatics 12.

34. Bolger AM, Lohse M, Usadel B (2014) Trimmomatic: a flexible trimmer for Illumina sequence data. Bioinformatics 30: 2114-2120.

35. Robinson MD, McCarthy DJ, Smyth GK (2010) edgeR: a bioconductor package for differential expression analysis of digital gene expression data. Bioinformatics 26: 139-140.

36. Conesa A, Gotz S, Garcia-Gomez JM, Terol J, Talon M, et al. (2005) Blast2GO: a universal tool for annotation, visualization and analysis in functional genomics research. Bioinformatics 21: 3674-3676. 
37. Erdely A, Kepka-Lenhart D, Clark M, Zeidler-Erdely P, Poljakovic M, et al. (2006) Inhibition of phosphodiesterase 4 amplifies cytokine-dependent induction of arginase in macrophages. American Journal of Physiology-Lung Cellular and Molecular Physiology 290: L534-L539.

38. Jin SLC, Conti M (2002) Induction of the cyclic nucleotide phosphodiesterase PDE4B is essential for LPS-activated TNF-alpha responses. Proceedings of the National Academy of Sciences of the United States of America 99: 7628-7633.

39. Jin SLC, Lan L, Zoudilova M, Conti M (2005) Specific role of phosphodiesterase 4B in lipopolysaccharide-induced signaling in mouse macrophages. Journal of Immunology 175: 1523-1531.

40. Tchatalbachev S, Ghai R, Hossain H, Chakraborty T (2010) Gram-positive pathogenic bacteria induce a common early response in human monocytes. BMC Microbiology 10.

41. D'Souza-Schorey C, Li GP, Colombo MI, Stahl PD (1995) A regulatory role ARF6 in recptormediated endocytosis. Science 267: 1175-1178.

42. Wu JY, Kuo CC (2012) Pivotal role of ADP-ribosylation factor 6 in toll-like receptor 9-mediated immune signaling. Journal of Biological Chemistry 287: 4323-4334.

43. Ng A, Xavier RJ (2011) Leucine-rich repeat (LRR) proteins integrators of pattern recognition and signaling in immunity. Autophagy 7: 1082-1084.

44. Bosch TCG, Augustin R, Anton-Erxleben F, Fraune S, Hemmrich G, et al. (2009) Uncovering the evolutionary history of innate immunity: The simple metazoan Hydra uses epithelial cells for host defence. Developmental and Comparative Immunology 33: 559-569.

45. Fuess LE, Pinzon CJH, Weil E, Mydlarz LD (2016) Associations between transcriptional changes and protein phenotypes provide insights into immune regulation in corals. Developmental and Comparative Immunology 62: 17-28. 
46. Duplan V, Rivas S (2014) E3 ubiquitin-ligases and their target proteins during the regulation of plant innate immunity. Frontiers in Plant Science 5.

47. Brandner J, Zorn-Kruppa M, Yoshida T, Moll I (2015) Epidermal tight junctions in health and disease. Tissue.

48. Fasano A, Baudry B, Pumplin DW, Wasserman SS, Tall BD, et al. (1991) Vibrio cholerae produces a second enterotoxin, which affects intestinal tight junctions. Proceedings of the National Academy of Sciences 88: 5242-5246.

49. Libro S, Vollmer SV (2016) Genetic signature of resistance to White Band Disease in the Caribbean staghorn coral Acropora cervicornis. Plos One 11.

50. Quinn RA, Vermeij MJ, Hartmann AC, d'Auriac IG, Benler S, et al. Metabolomics of reef benthic interactions reveals a bioactive lipid involved in coral defence; 2016. The Royal Society. pp. 20160469.

51. Vidal-Dupiol J, Ladriere O, Destoumieux-Garzon D, Sautiere PE, Meistertzheim AL, et al. (2011) Innate immune responses of a scleractinian coral to vibriosis. Journal of Biological Chemistry.

52. Wright RM, Aglyamova GV, Meyer E, Matz MV (2015) Gene expression associated with white syndromes in a reef building coral, Acropora hyacinthus. BMC Genomics 16.

53. Kim NH, Choi S, Han EJ, Hong BK, Choi SY, et al. (2014) The xanthine oxidaseNFAT5 pathway regulates macrophage activation and TLR-induced inflammatory arthritis. European Journal of Immunology 44: 2721-2736.

54. Song XJ, Hu J, Jin P, Chen LM, Ma F (2013) Identification and evolution of an NFAT gene involving Branchiostoma belcheri innate immunity. Genomics 102: 355-362. 
55. Jin J, Xiao YC, Hu HB, Zou Q, Li YC, et al. (2015) Proinflammatory TLR signalling is regulated by a TRAF2-dependent proteolysis mechanism in macrophages. Nature Communications 6.

56. Friedman R, Hughes AL (2002) Molecular evolution of the NF- $\kappa B$ signaling system. Immunogenetics 53: 964-974.

57. Sun L, Chen ZJ (2004) The novel functions of ubiquitination in signaling. Current opinion in cell biology 16: 119-126.

58. Yamamoto Y, Gaynor RB (2004) I $\kappa$ B kinases: key regulators of the NF- $\kappa$ B pathway. Trends in biochemical sciences 29: 72-79.

59. Aznar S, Lacal JC (2001) Rho signals to cell growth and apoptosis. Cancer Letters 165: $1-10$.

60. Leeman JR, Gilmore TD (2008) Alternative splicing in the NF-kappa B signaling pathway. Gene 423: 97-107.

61. Ahmed AU, Sarvestani ST, Gantier MP, Williams BRG, Hannigan GE (2014) Integrin-linked kinase modulates lipopolysaccharide- and Helicobacter pyloriinduced nuclear factor kappa B-activated tumor necrosis factor-alpha production via regulation of p65 serine 536 phosphorylation. Journal of Biological Chemistry 289: 27776-27793.

62. Gao X, Cox Jr KL, He P (2014) Functions of calcium-dependent protein kinases in plant innate immunity. Plants 3: 160-176.

63. Luan S, Kudla J, Rodriguez-Concepcion M, Yalovsky S, Gruissem W (2002) Calmodulins and calcineurin B-like proteins calcium sensors for specific signal response coupling in plants. The Plant Cell 14: S389-S400. 
64. Do Heo W, Lee SH, Kim MC, Kim JC, Chung WS, et al. (1999) Involvement of specific calmodulin isoforms in salicylic acid-independent activation of plant disease resistance responses. Proceedings of the National Academy of Sciences 96: 766-771.

65. Koch CM, Andrews RM, Flicek P, Dillon SC, Karaoz U, et al. (2007) The landscape of histone modifications across $1 \%$ of the human genome in five human cell lines. Genome Research 17: 691-707.

66. Pekowska A, Benoukraf T, Zacarias-Cabeza J, Belhocine M, Koch F, et al. (2011) $\mathrm{H} 3 \mathrm{~K} 4$ tri-methylation provides an epigenetic signature of active enhancers. EMBO Journal 30: 4198-4210.

67. Ruthenburg AJ, Allis CD, Wysocka J (2007) Methylation of lysine 4 on histone H3: intricacy of writing and reading a single epigenetic mark. Molecular Cell 25: 1530 .

68. Medzhitov R, Horng T (2009) Transcriptional control of the inflammatory response. Nature Reviews Immunology 9: 692-703.

69. Ptaschinski C, Mukherjee S, Moore ML, Albert M, Helin K, et al. (2015) RSVinduced H3K4 demethylase KDM5B leads to regulation of dendritic cell-derived innate cytokines and exacerbates pathogenesis in vivo. Plos Pathogens 11.

70. Jaskiewicz M, Conrath U, Peterhansel C (2011) Chromatin modification acts as a memory for systemic acquired resistance in the plant stress response. EMBO Reports 12: 50-55.

71. Bell MP, Svingen PA, Rahman MK, Xiong Y, Faubion WA (2007) FOXP3 regulates TLR10 expression in human T regulatory cells. Journal of Immunology 179: 1893-1900.

72. Birkenkamp KU, Coffer PJ (2003) FOXO transcription factors as regulators of immune homeostasis: molecules to die for? Journal of Immunology 171: 16231629. 
73. Zhan H, Sinclair J, Adams S, Cale CM, Murch S, et al. (2008) Immune reconstitution and recovery of FOXP3 (forkhead box P3)-expressing T cells after transplantation for IPEX (immune dysregulation, polyendocrinopathy, enteropathy, X-linked) syndrome. Pediatrics 121: E998-E1002.

74. Dejean AS, Hedrick SM, Kerdiles YM (2011) Highly specialized role of Forkhead Box O transcription factors in the immune system. Antioxidants \& Redox Signaling 14: 663-674.

75. Shaffer A, Rosenwald A, Staudt LM (2002) Lymphoid malignancies: the dark side of B-cell differentiation. Nature Reviews Immunology 2: 920-933.

76. Ghazalpour A, Bennett B, Petyuk VA, Orozco L, Hagopian R, et al. (2011) Comparative analysis of proteome and transcriptome variation in mouse. PLoS Genet 7: 9.

77. Tateno H, Yamaguchi T, Ogawa T, Muramoto K, Watanabe T, et al. (2002) Immunohistochemical localization of rhamnose-binding lectins in the steelhead trout (Oncorhynchus mykiss). Developmental and Comparative Immunology 26: 543-550.

78. Hosono M, Ishikawa K, Mineki R, Murayama K, Numata C, et al. (1999) Tandem repeat structure of rhamnose-binding lectin from catfish (Silurus asotus) eggs. Biochimica et Biophysica Acta (BBA)-General Subjects 1472: 668-675.

79. Okamoto M, Tsutsui S, Tasumi S, Suetake H, Kikuchi K, et al. (2005) Tandem repeat L-rhamnose-binding lectin from the skin mucus of ponyfish, Leiognathus nuchalis. Biochemical and Biophysical Research Communications 333: 463-469.

80. Schwarz RS, Hodes-Villamar L, Fitzpatrick KA, Fain MG, Hughes AL, et al. (2007) A gene family of putative immune recognition molecules in the hydroid Hydractinia. Immunogenetics 59: 233-246. 
81. de Lorgeril J, Zenagui R, Rosa RD, Piquemal D, Bachere E (2011) Whole transcriptome profiling of successful immune response to Vibrio infections in the oyster Crassostrea gigas by digital gene expression analysis. Plos One 6.

82. Ezekowitz RAB, Austyn J, Stahl PD, Gordon S (1981) Surface-properties of Bacillus calmette - guerin - activated mouse macrophages - reduced expression of mannose - specific endocytosis, fc-receptors, and antigen F4-80 accompanies induction of IA. Journal of Experimental Medicine 154: 60-76.

83. Marodi L, Schreiber S, Anderson DC, Macdermott RP, Korchak HM, et al. (1993) Enhancement of macrophage candidacidal activity by interferon - gamma increased phagocytosis, killing, and calcium signal mediated by decreased number of mannose receptors. Journal of Clinical Investigation 91: 2596-2601.

84. Ma THT, Tiu SHK, He J-G, Chan S-M (2007) Molecular cloning of a C-type lectin (LvLT) from the shrimp Litopenaeus vannamei: early gene down-regulation after WSSV infection. Fish \& Shellfish Immunology 23: 430-437.

85. Libro S, Kaluziak ST, Vollmer SV (2013) RNA-seq profiles of immune related genes in the staghorn coral Acropora cervicornis infected with white band disease. Plos One 8.

86. Gross O, Thomas CJ, Guarda G, Tschopp J (2011) The inflammasome: an integrated view. Immunological Reviews 243: 136-151.

87. Newton K, Dixit VM (2012) Signaling in innate immunity and inflammation. Cold Spring Harbor perspectives in biology 4: a006049.

88. Frey H, Schroeder N, Manon-Jensen T, Iozzo RV, Schaefer L (2013) Biological interplay between proteoglycans and their innate immune receptors in inflammation. FEBS Journal 280: 2165-2179.

89. Martinon F, Burns K, Tschopp J (2002) The inflammasome: a molecular platform triggering activation of inflammatory caspases and processing of proIL- $\beta$. Molecular Cell 10: 417-426. 
90. Fontana MF, Baccarella A, Pancholi N, Pufall MA, Herbert DR, et al. (2015) JUNB is a key transcriptional modulator of macrophage activation. Journal of Immunology 194: 177-186.

91. Liang P, Wang X, Wang R, Wan Z, Han W, et al. (2015) CARD9 deficiencies linked to impaired neutrophil functions against Phialophora verrucosa. Mycopathologia 179: 347-357.

92. Kurotaki D, Tamura T (2016) Transcriptional and epigenetic regulation of innate immune cell development by the transcription factor, interferon regulatory factor8. Journal of Interferon and Cytokine Research 36: 433-441.

93. Wenger Y, Buzgariu W, Reiter S, Galliot B (2014) Injury-induced immune responses in Hydra. Seminars in Immunology 26: 277-294.

94. Sharma B, Joshi S, Sassano A, Majchrzak B, Kaur S, et al. (2012) Sprouty proteins are negative regulators of interferon (IFN) signaling and IFN-inducible biological responses. Journal of Biological Chemistry 287: 42352-42360.

95. Vereecke L, Beyaert R, van Loo G (2009) The ubiquitin-editing enzyme A20 (TNFAIP3) is a central regulator of immunopathology. Trends in Immunology 30: 383-391.

96. Tartaglia LA, Ayres TM, Wong GH, Goeddel DV (1993) A novel domain within the $55 \mathrm{kd}$ TNF receptor signals cell death. Cell 74: 845-853.

97. Beutler B, Kruys V (1995) Lipopolysaccharide signal transduction, regulation of tumor necrosis factor biosynthesis, and signaling by tumor necrosis factor itself. Journal of Cardiovascular Pharmacology 25: S1-S8.

98. Carballo E, Lai WS, Blackshear PJ (1998) Feedback inhibition of macrophage tumor necrosis factor-alpha production by tristetraprolin. Science 281: 1001-1005. 
99. Brown T, Bourne D, Rodriguez-Lanetty M (2013) Transcriptional activation of c3 and hsp70 as part of the immune response of Acropora millepora to bacterial challenges. Plos One 8.

100. Qiu XB, Shao YM, Miao S, Wang L (2006) The diversity of the DnaJ/Hsp40 family, the crucial partners for Hsp70 chaperones. Cellular and Molecular Life Sciences 63: $2560-2570$.

101. Chisholm ST, Coaker G, Day B, Staskawicz BJ (2006) Host-microbe interactions: shaping the evolution of the plant immune response. Cell 124: 803-814.

102. Park CJ, Seo YS (2015) Heat shock proteins: a review of the molecular chaperones for plant immunity. Plant Pathology Journal 31: 323-333.

103. Hwang JS, Takaku Y, Momose T, Adamczyk P, Ozbek S, et al. (2010) Nematogalectin, a nematocyst protein with GlyXY and galectin domains, demonstrates nematocyte-specific alternative splicing in Hydra. Proceedings of the National Academy of Sciences of the United States of America 107: 1853918544.

104. Nagy G, Dobrindt U, Kupfer M, Emody L, Karch H, et al. (2001) Expression of hemin receptor molecule $\mathrm{ChuA}$ is influenced by $\mathrm{RfaH}$ in uropathogenic Escherichia coli strain 536. Infection and Immunity 69: 1924-1928. 


\section{Chapter 5: Final conclusions and synthesis}

\subsection{Conclusions}

The purpose of this dissertation was to identify mechanisms used by cnidarians to defend themselves against biotic stressors. First I explored whether homologs of genes involved in the complement immune pathway as well as heat stress were involved in the immune response of a basal metazoan to biotic stressors. Secondly I tested the evolutionary roots of immunological priming to examine if this phenomenon occurs in basal metazoans. Finally, the transcriptional profile of immune priming in cnidarians was analyzed.

In my first data chapter, I tested whether three gene homologs that are involved in the complement system and heat stress are also involved in the immune response of the coral Acropora millepora to biotic stressors. The gene c3-like was chosen since C3 is a central component of the complement pathway whereby all three known initiation mechanisms (alternative, lectin, and classical) converge on it [1]. C3's function is to bind to the surface of the microbial invader and act as an opsonin and thereby tagging it for destruction [1]. Additionally, homologs of this gene have been identified in corals [2] but its function in cnidarian immunity was never described. Results from this study indicated that $c 3$-like is involved in the immune response of $A$. millepora since it showed increased gene expression that coincided with the immergence of disease. The c-type lectin gene was also chosen as a gene of interest for this study since it is a pathogen recognition receptor which binds to carbohydrates on microorganisms [1,3-6]. Homologs of c-type lectins have also been identified in cnidarians $[3,5]$ with one being identified in coral immunity against pathogenic challenge [3]. There are many variants of c-type lectins and 
this study did not find differential expression of this variant of the gene and therefore we cannot conclude that it functions in the early response of corals to pathogenic challenge. It is important to note though that another variant may respond to pathogenic challenge and it is important to study many c-type lectin variants. Finally we chose heat shock protein $70(h s p 70)$ as a gene of interest since it is a gene that is known to be involved in heat stress responses of many organisms [7-9] as well as immunity [10,11]. However, hsp70 had not been tested in coral immunity before. This study found that $h s p 70$ was upregulated in response to visible signs of disease as well as stress with no visible sign of disease. This study was important in that it was the first experimental evidence that supported the activation of $c 3$-like and $h s p 70$ in the coral immune response over a 24 hour period. These finding open many new questions for future investigations. Rather than focusing on a gene targeted study over time, a transcriptomics approach should be taken. It is important to note that there have been resent studies researching transcriptomic changes associated with disease [12-16] but these studies only look into changes that occur at a snapshot in time. Instead studies should look into transcriptome changes that occur at several time points during the challenge experiment. Such studies would identify many genes and pathways involved in the immune response of corals and track them through time. Additionally these studies would identify genes that were not previously considered candidate immune genes and therefore identify new coral associated immune genes.

Chapters three and four investigated the evolutionary roots of immune priming by studying whether this phenomenon occurs in a basal metazoan, the cnidarian, Exaiptasia pallida and its molecular signature. This phenomenon is usually only associated with the 
adaptive immune system whereby an organism responds more rapidly to subsequent encounters with the same pathogen. It is also the basis for the construction of vaccines against many very destructive diseases in many organisms. Despite being traditionally viewed as only a component of the adaptive immune system, immune priming has been found in invertebrates that only possess an innate immune system [17-23]. The reason for investigating this phenomenon in cnidarians is that they are long lived organisms with corals able to live for hundreds of years. During this long life, they presumably encounter the same bacterium multiple times. Therefore the question was asked if these early diverging organisms also possess a form of immunological priming. Results indicated that a transient form of immune priming occurred in E. pallida that was present up to one month after the first encounter with the pathogen. This short term duration of priming was also observed in corals during allorecognition experiments [24-27]. Our study was the first to show immune priming to a pathogen in such a basal metazoan and therefore it evolved earlier in the tree of life than previously thought. Additionally the study showed that immune priming may be pathogen specific depending on the pathogen used since the response appeared to be specific for one pathogen but not the other. Pathogen specificity is a hallmark trait of adaptive immune memory but has shown mixed results in terms on invertebrate priming. It has been shown to be specific in some organisms [28-30] but not in others [31]. The discovery of immune priming in E. pallida opens up the question of whether immune priming is also present in corals which would greatly benefit from possessing a form it. The presence of this would allow for the possibility of creating vaccines for disease susceptible corals. The possibility of natural vaccines would be of 
great benefit to coral reef management strategies and coral restoration since treating diseased corals with antibiotics is unrealistic.

The proteomic and transcriptomic studies conducted for this dissertation indicated that immune priming in cnidarians is a multigene process. The proteomic analysis identified several heat shock proteins, cathepsin, and a glutamate receptor as constituents of the immune priming phenomenon in E. pallida. Heat shock proteins are of interest in immune priming as increases in expression have previously been shown to confer resistance to ammonia stress in the carp, Cyprinus carpio [32] and immune priming in the shrimp Artemia franciscana to Vibrio infections [33]. Increases in expression of cathepsin may suggest a role of proteolysis in immune priming. Proteolytic cleavage is required for the cleavage of two known immune genes TLR7 and TLR9 [34,35]. Additionally, greater concentrations of this protein in primed anemones could indicate that there is an uptake of the pathogen by phagocytosis that will be digested and cleared faster than naïve animals. Glutamate receptors are of interest with respect to immune priming in that in plants, they have been shown to be capable of sensing a broad range of amino acids as part of their immune defense [36]. While these genes have been implicated in immunity in other organisms, this is the first study to show that they are involved in the innate immune response of cnidarians. The transcriptomic study conducted in chapter four, showed that immune priming utilized several pathways which included pathogen recognition receptors, inflammation response, and activators of NF$\kappa \mathrm{B}$. Pathogen recognition receptors are important in that they recognize foreign objects and initiate the immune response. The leucine rich repeat (LRR) receptor discovered in this study is of particular interest since they are known to recognize pathogen associated 
molecular patterns (PAMPS) [37] and have been implicated in the immune response of other cnidarians such as hydra [38] and corals [39]. An inflammation response associated with immune priming is intriguing as it has also been found to be a major constituent of the coral immune system $[13,15,39-41]$ but has never been associated with priming. The different activators of NF- $\mathrm{KB}$ is of particular interest since it is a major constituent of the immune response which can lead to apoptosis but can also be involved in immune processes such as inflammation and stress response [42]. Its association with immune priming has never not been shown. Furthermore, one of the differentially expressed proteins from chapter three was also found in the transcriptomic study, a rhamnospondin2 orthalog which is a rhamnos binding lectin (RBL). This RBL was downregulated in primed anemones when compared to naïve at zero hours in both comparisons. While conventional wisdom would suggest that RBLs should be upregulated in response to pathogens other studies have also found them to be beneficially downregulated with pathogen challenge in macrophages $[43,44]$. This is the first study to implicate it in cnidarians priming. These molecular based studies have illuminated many genes that involved in the priming response E. pallida. Future studies can now specifically target these genes at more time points. The present study identified these genes during the lethal phase of the experiment; it would also be interesting to study the differential response of these genes during the sub-lethal and recovery periods. Additionally it would be of interest to study the transcriptomic profiles of other cnidarians that are shown to possess immunological priming. It is of interest to learn if priming in all cnidarians functions similarly at the molecular level. This knowledge could be used in conservation to develop management plans. For example, if a particular gene is associated with immune priming 
in all cnidarans it could be used as a biomarker to establish which organisms are primed and more likely to survive a disease outbreak.

Overall, my dissertation work has shown that the innate immune system of cnidarians is more complex than previously envisioned, involving multiple pathways. The work has shown that several putative immune genes with homologs in vertebrates and other invertebrates, function in the immune response of corals to bacterial challenge. Furthermore, we show that immune priming evolved earlier in evolutionary history than previously thought and the molecular signature of it in the model cnidarian E. pallida. While the work from this dissertation has aided in answering some questions in cnidarian immunity, there are still many more waiting to be answered!

\subsection{References}

1. Janeway C, Travers P, Walport M, Capra J (1999) Immunobiology: the immune system in health and disease. New York, New York: Elsevier Science Ltd./Garland Publishing.

2. Miller DJ, Hemmrich G, Ball EE, Hayward DC, Khalturin K, et al. (2007) The innate immune repertoire in Cnidaria - ancestral complexity and stochastic gene loss. Genome Biology 8.

3. Kvennefors ECE, Leggat W, Hoegh-Guldberg O, Degnan BM, Barnes AC (2008) An ancient and variable mannose-binding lectin from the coral Acropora millepora binds both pathogens and symbionts. Developmental and Comparative Immunology 32: 1582-1592.

4. Leulier F, Parquet C, Pili-Floury S, Ryu JH, Caroff M, et al. (2003) The Drosophila immune system detects bacteria through specific peptidoglycan recognition. Nature Immunology 4: 478-484.

5. Wood-Charlson EM, Weis VM (2009) The diversity of C-type lectins in the genorne of a basal metazoan, Nematostella vectensis. Developmental and Comparative Immunology 33: 881-889. 
6. Fujita T (2002) Evolution of the lectin-complement pathway and its role in innate immunity. Nature Reviews Immunology 2: 346-353.

7. Black NA, Voellmy R, Szmant AM (1995) Heat-shock protein induction in Montastraea faveolata and Aiptasia pallida exposed to elevated-temperatures. Biological Bulletin 188: 234-240.

8. Sharp VA, Brown BE, Miller D (1997) Heat shock protein (hsp 70) expression in the tropical reef coral Goniopora djiboutiensis. Journal of Thermal Biology 22: 1119.

9. Vidal-Dupiol J, Dheilly NM, Rondon R, Grunau C, Cosseau C, et al. (2014) Thermal stress triggers broad Pocillopora damicornis transcriptomic remodeling, while Vibrio coralliilyticus infection induces a more targeted immuno-suppression response. Plos One 9.

10. Theriault JR, Mambula SS, Sawamura T, Stevenson MA, Calderwood SK (2005) Extracellular HSP70 binding to surface receptors present on antigen presenting cells and endothelial/epithelial cells. FEBS Letters 579: 1951-1960.

11. Vabulas RM, Ahmad-Nejad P, Ghose S, Kirschning CJ, Issels RD, et al. (2002) HSP70 as endogenous stimulus of the toll/interleukin-1 receptor signal pathway. Journal of Biological Chemistry 277: 15107-15112.

12. Libro S, Kaluziak ST, Vollmer SV (2013) RNA-seq profiles of immune related genes in the staghorn coral Acropora cervicornis infected with white band disease. Plos One 8.

13. Libro S, Vollmer SV (2016) Genetic signature of resistance to White Band Disease in the Caribbean staghorn coral Acropora cervicornis. Plos One 11.

14. Shinzato C, Shoguchi E, Kawashima T, Hamada M, Hisata K, et al. (2011) Using the Acropora digitifera genome to understand coral responses to environmental change. Nature 476: 320-U382.

15. Wright RM, Aglyamova GV, Meyer E, Matz MV (2015) Gene expression associated with white syndromes in a reef building coral, Acropora hyacinthus. BMC Genomics 16.

16. Burge CA, Mouchka ME, Harvell CD, Roberts S (2013) Immune response of the Caribbean sea fan, Gorgonia ventalina, exposed to an Aplanochytrium parasite as revealed by transcriptorne sequencing. Frontiers in Physiology 4.

17. Kurtz J (2005) Specific memory within innate immune systems. Trends in Immunology 26: 186-192. 
18. Kurtz J, Franz K (2003) Evidence for memory in invertebrate immunity. Nature 425: 37-38.

19. Little TJ, Hultmark D, Read AF (2005) Invertebrate immunity and the limits of mechanistic immunology. Nature Immunology 6: 651-654.

20. Little TJ, O'Connor B, Colegrave N, Watt K, Read AF (2003) Maternal transfer of strain-specific immunity in an invertebrate. Current Biology 13: 489-492.

21. Loker ES, Adema CM, Zhang SM, Kepler TB (2004) Invertebrate immune systems not homogeneous, not simple, not well understood. Immunological Reviews 198: $10-24$.

22. Netea MG, Quintin J, van der Meer JWM (2011) Trained immunity: a memory for innate host defense. Cell Host \& Microbe 9: 355-361.

23. Pope EC, Powell A, Roberts EC, Shields RJ, Wardle R, et al. (2011) Enhanced cellular immunity in shrimp (Litopenaeus vannamei) after 'vaccination'. Plos One 6.

24. Bigger CH, Jokiel PL, Hildemann WH, Johnston IS (1982) Characterization of alloimmune memory in a sponge. Journal of Immunology 129: 1570-1572.

25. Hildemann WH, Bigger CH, Jokiel PL (1979) Characteristics of immune memory in invertebrates. American Zoologist 19: 911-911.

26. Hildemann WH, Jokiel PL, Bigger CH, Johnston IS (1980) Allogeneic polymorphism and alloimmune memory in the coral, Montipora verrucosa. Transplantation 30: 297-301.

27. Hildemann WH, Raison RL, Cheung G, Hull CJ, Akaka L, et al. (1977) Immunological specificity and memory in a scleractinian coral. Nature 270: 219223.

28. Pham LN, Dionne MS, Shirasu-Hiza M, Schneider DS (2007) A specific primed immune response in Drosophila is dependent on phagocytes. PLoS Pathog 3: e26.

29. Roth O, Kurtz J (2009) Phagocytosis mediates specificity in the immune defence of an invertebrate, the woodlouse Porcellio scaber (Crustacea: Isopoda). Developmental \& Comparative Immunology 33: 1151-1155.

30. Rodrigues J, Brayner FA, Alves LC, Dixit R, Barillas-Mury C (2010) Hemocyte differentiation mediates innate immune memory in Anopheles gambiae mosquitoes. Science 329: 1353-1355. 
31. Dhinaut J, Chogne M, Moret Y (2017) Immune priming specificity within and across generations reveals the range of pathogens affecting evolution of immunity in an insect. Journal of Animal Ecology.

32. Sung YY, Liew HJ, Bolong AMA, Wahid MEA, MacRae TH (2014) The induction of Hsp70 synthesis by non-lethal heat shock confers thermotolerance and resistance to lethal ammonia stress in the common carp, Cyprinus carpio (Linn). Aquaculture Research 45: 1706-1712.

33. Sung YY, Dhaene T, Defoirdt T, Boon N, MacRae TH, et al. (2009) Ingestion of bacteria overproducing DnaK attenuates Vibrio infection of Artemia franciscana larvae. Cell Stress \& Chaperones 14: 603-609.

34. Ewald SE, Lee BL, Lau L, Wickliffe KE, Shi GP, et al. (2008) The ectodomain of Toll-like receptor 9 is cleaved to generate a functional receptor. Nature 456: 658U688.

35. Park B, Brinkmann MM, Spooner E, Lee CC, Kim YM, et al. (2008) Proteolytic cleavage in an endolysosomal compartment is required for activation of Toll-like receptor 9. Nature Immunology 9: 1407-1414.

36. Forde BG, Roberts MR (2014) Glutamate receptor-like channels in plants: a role as amino acid sensors in plant defence? F1000Prime Reports 6.

37. Ng A, Xavier RJ (2011) Leucine-rich repeat (LRR) proteins Integrators of pattern recognition and signaling in immunity. Autophagy 7: 1082-1084.

38. Bosch TCG, Augustin R, Anton-Erxleben F, Fraune S, Hemmrich G, et al. (2009) Uncovering the evolutionary history of innate immunity: The simple metazoan Hydra uses epithelial cells for host defence. Developmental and Comparative Immunology 33: 559-569.

39. Fuess LE, Pinzon CJH, Weil E, Mydlarz LD (2016) Associations between transcriptional changes and protein phenotypes provide insights into immune regulation in corals. Developmental and Comparative Immunology 62: 17-28.

40. Quinn RA, Vermeij MJ, Hartmann AC, d'Auriac IG, Benler S, et al. Metabolomics of reef benthic interactions reveals a bioactive lipid involved in coral defence; 2016. The Royal Society.

41. Vidal-Dupiol J, Ladriere O, Destoumieux-Garzon D, Sautiere PE, Meistertzheim AL, et al. (2011) Innate immune responses of a scleractinian coral to vibriosis. Journal of Biological Chemistry.

42. Leeman JR, Gilmore TD (2008) Alternative splicing in the NF-kappa B signaling pathway. Gene 423: 97-107. 
43. Ezekowitz RAB, Austyn J, Stahl PD, Gordon S (1981) Surface-properties of Bacillus calmette - guerin - activated mouse macrophages - reduced expression of mannose - specific endocytosis, fc-receptors, and antigen F4-80 accompanies induction of IA. Journal of Experimental Medicine 154: 60-76.

44. Marodi L, Schreiber S, Anderson DC, Macdermott RP, Korchak HM, et al. (1993) Enhancement of macrophage candidacidal activity by interferon - gamma increased phagocytosis, killing, and calcium signal mediated by decreased number of mannose receptors. Journal of Clinical Investigation 91: 2596-2601. 


\section{TANYA BROWN}

September 10, 1980

2003

2007

$2007-2010$

2011-2012

2012-2017
Born, Buffalo, New York

B.S. Marine Science Rider University Lawrenceville, NJ

M.S. Biotechnology Advisor: Dr. Daniel Brazeau University at Buffalo, The State University of New York Buffalo, NY

Research Associate Supervisor: Brian Tsuji PharmD University at Buffalo, The State University of New York Buffalo, NY

Doctoral Candidate University of Louisiana Lafayette Lafayette, LA

Graduate Fellow University of Louisiana Lafayette Lafayette, LA

Doctoral Candidate Florida International University Miami, FL

Teaching Assistant Florida International University Miami, FL

Dissertation Year Fellow Florida International University Miami, FL 


\section{PAPERS AND PUBLICATIONS}

Brown, T., D. Bourne, and M. Rodriguez-Lanetty. 2013. Transcriptional Activation of c3 and hsp70 as Part of the Immune Response of Acropora millepora to Bacterial Challenges. Plos One 8.

Brown, T. and M. Rodriguez-Lanetty. 2015. Defending against pathogens immunological priming and its molecular basis in a sea anemone, cnidarian. Scientific Reports 5.

Brown, T. C. Otero, A. Grajales, E. Rodriguez, M. Rodriguez-Lanetty. (2017) Worldwide exploration of the microbiome harbored by the cnidarian model, Exaiptasia pallida (Agassiz in Verrill, 1864) indicates a lack of bacterial association specificity at a lower taxonomic rank. PeerJ.

Brown T, Bourne D, Rodriguez-Lanetty M. Differential immune response in the reef building coral, Acropora millepora, to two ecologically relevant bacteria. 112th Annual American Society of Microbiology Meeting. San Francisco, CA, June 2012.

Brown T, Rodriguez-Lanetty M. Do Cnidarians remember previous foe attacks? 113th Annual American Society of Microbiology Meeting. Denver, CO, May 2013.

Brown T, Rodriguez-Lanetty M. Immune priming occurs in the sea anemone, Aiptasia pallida. 43rd Benthic Ecology Meeting. Jacksonville, FL, March 2014.

Brown T, Rodriguez-Lanetty M. Molecular mechanisms underpinning immunological memory in a basal metazoan (Cnidaria). Society of Integrative and Comparative Biology Meeting. West Palm Beach, FL, January 2015.

Brown T, Rodriguez-Lanetty M. Analysis of proteins involved in immunological memory in a basal metazoan, Exaiptasia pallida. Association of Marine Laboratories of the Caribbean, Biannual Conference, Willemstad, Curacao, May 2015.

Brown T, Rodriguez-Lanetty M. How do they do it? An exploration of the molecular underpinnings of immune priming in the sea anemone, Exaiptasia pallida. 13th International Coral Reef Symposium. Honolulu, HI, June 2016.

Brown T, Waikel P, Bhedi C, Lewis C, Richardson L, Rodriguez-Lanetty M. Finding the needle in the hay stack. Use of the cnidarian model system Exaiptasia pallida to screen potential disease causing pathogens in corals. 19th Annual Biomedical and Comparative Immunology Symposium. Miami, FL, March 2017. 